\title{
Rational Design, Optimization, and Biological Evaluation of Novel MEK4 Inhibitors against Pancreatic Adenocarcinoma
}

\author{
Ada J. Kwong, ${ }^{\S}$ Thao Pham, ${ }^{\ddagger}$ Hannah Oelschlager,${ }^{\S}$ Hidayatullah G. Munshi, ${ }^{*}{ }^{\ddagger}$ Karl A. Scheidt*,§ \\ ${ }^{\S}$ Department of Chemistry, Center for Molecular Innovation and Drug Discovery, Northwestern University, 2145 Sheridan Road, \\ Evanston, IL 60208, USA \\ * Department of Medicine, Feinberg School of Medicine, Northwestern University, 303 E. Superior Street, Chicago, Illinois 60611 , \\ USA
}

\section{Supporting Information \\ Table of Contents}

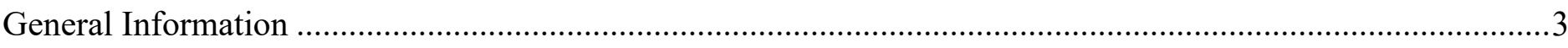

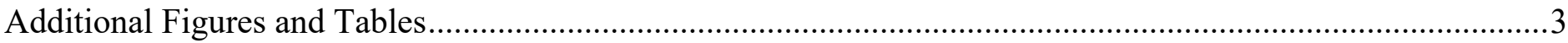

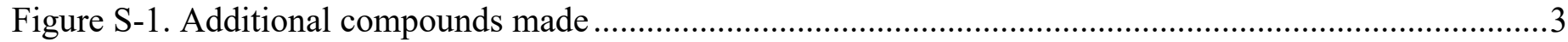

Figure S-2. Eurofins DiscoverX ScanEDGE Kinase Panel for 150 .............................................................

Figure S-3. Eurofins DiscoverX ScanELECT Kinase Panel with MEK3, 5, and 6 ..........................................

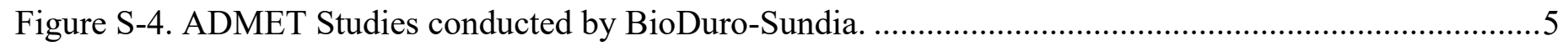

A) $\log D$, B) Liver Microsome Stability, C) PAMPA, D) Caco-2, E) CYP inhibition........................................

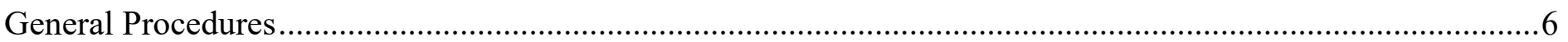

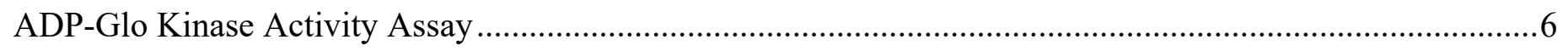

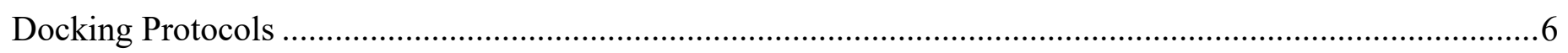

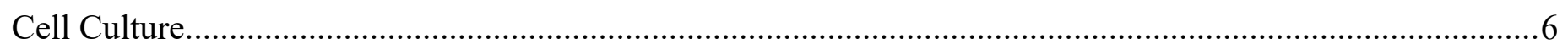

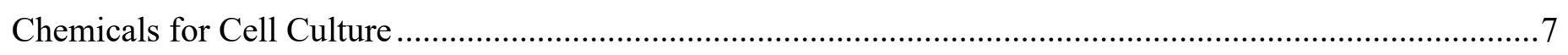

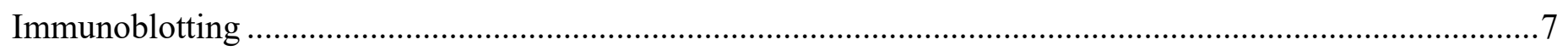

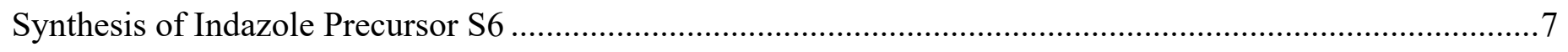

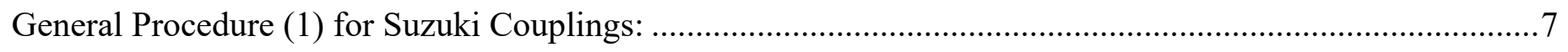

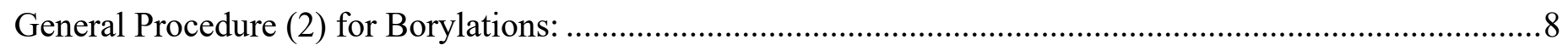

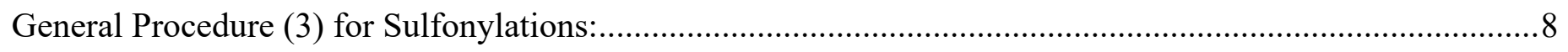

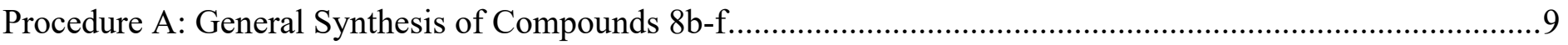

Tabulated Data of Compounds 8a-f....................................................................................................

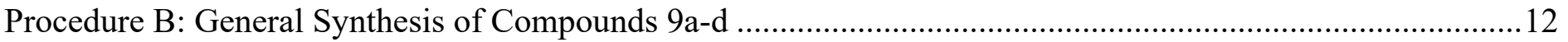

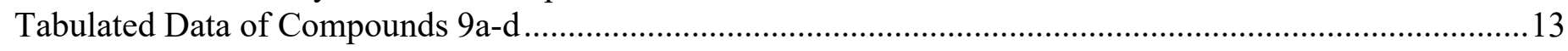

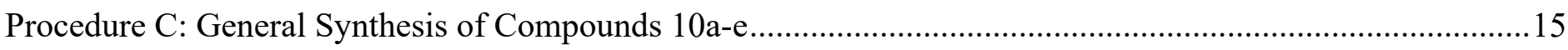




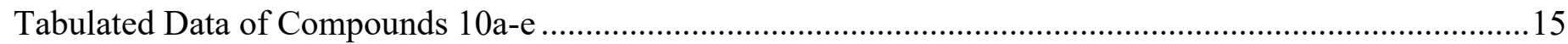

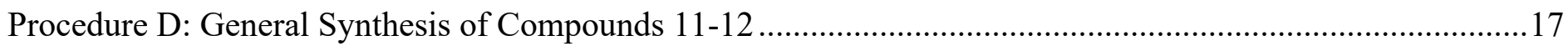

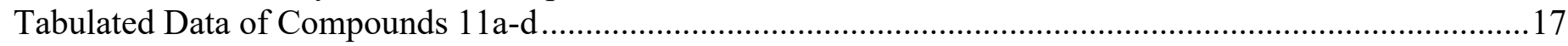

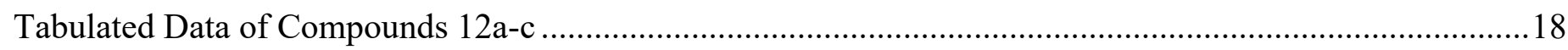

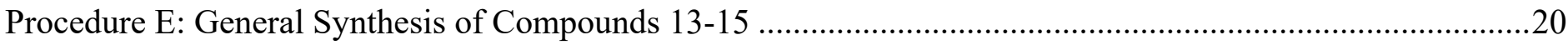

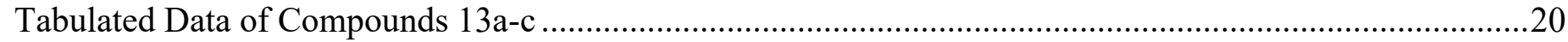

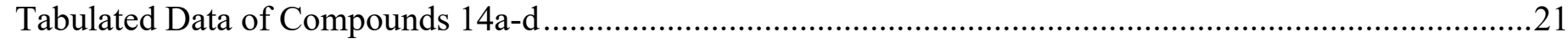

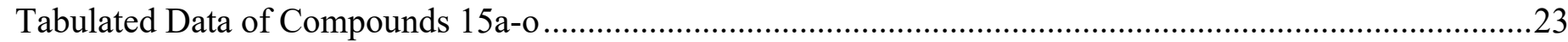

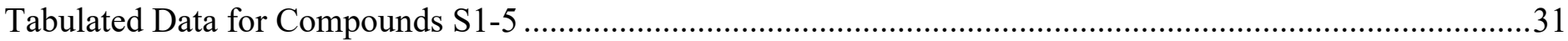

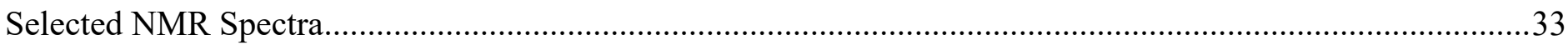

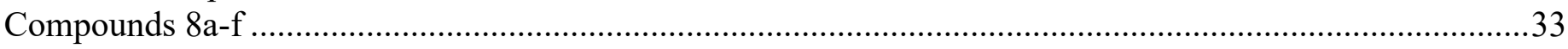

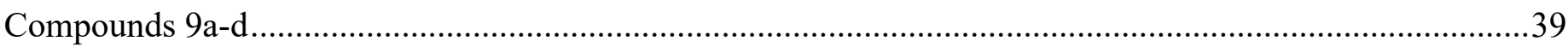

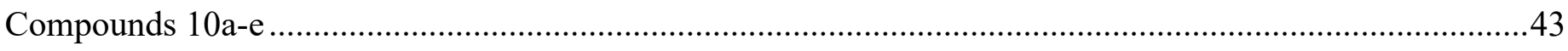

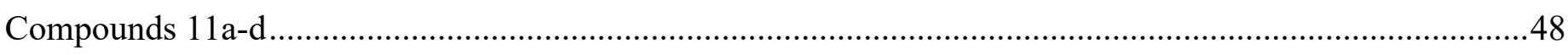

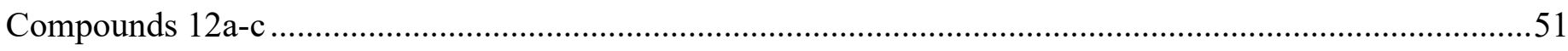

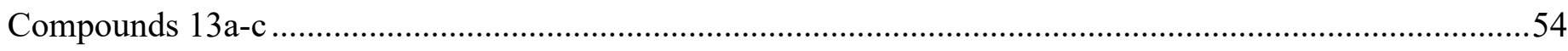

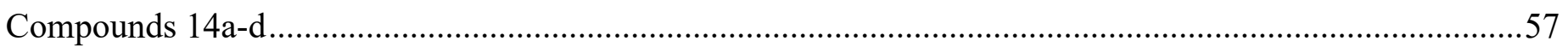

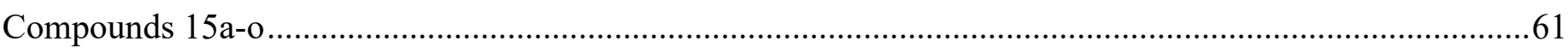

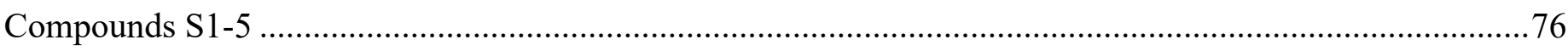

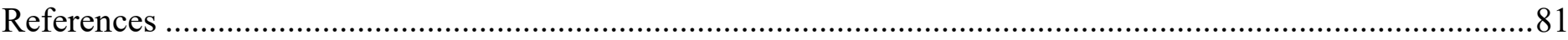




\section{General Information}

All reactions were carried out in glassware with magnetic stirring. Purification of reaction products were carried out by flash chromatography on Biotage Isolera 4 systems with Ultra-grade silica cartridges. Analytical thin layer chromatography was performed on EM Reagent $0.25 \mathrm{~mm}$ silica gel $60-\mathrm{F}$ plates. Visualization was accomplished with UV light. Monitoring of reactions via UPLC was done on a WATERS Acquity-H UPLC-MS with a single quad detector (SQD, ESI). ${ }^{1} \mathrm{H}$ NMR spectra were recorded on AVANCE III $500 \mathrm{MHz}$ w/ direct cryoprobe $(500 \mathrm{MHz})$ spectrometer and are reported in ppm using solvent as an internal standard (DMSO- $d_{6}$ at $2.50 \mathrm{ppm}, \mathrm{MeOD}$ at $3.31 \mathrm{ppm})$. Data are reported as $(\mathrm{s}=$ singlet, $\mathrm{d}=$ doublet, $\mathrm{t}=$ triplet, $\mathrm{q}=$ quartet, hept $=$ heptet, $\mathrm{m}=$ multiplet, $\mathrm{b}=$ broad; coupling constant(s) in $\mathrm{Hz}$; integration.) Proton-decoupled ${ }^{13} \mathrm{C}$ NMR spectra were recorded on an AVANCE III $500 \mathrm{MHz}$ w/ direct cryoprobe (126 MHz) spectrometer and are reported in ppm using solvent as an internal standard (DMSO- $d_{6}$ at $39.5 \mathrm{ppm}, \mathrm{MeOD}$ at $49.0 \mathrm{ppm}$ ). Compounds were found to be $>90 \%$ pure, assessed by ${ }^{1} \mathrm{H}$ NMR (AVANCE III $500 \mathrm{MHz}$ w/ direct cryoprobe (500 MHz) spectrometer) and UPLC-MS (WATERS Acquity-H UPLC-MS with a SQD). High-resolution mass spectrometry (HRMS) was obtained using an Agilent 6201 LCMS-TOF (ESI), Agilent LCMS 6545 QTOF (ESI), or Bruker IMPACT II (ESI). All microwave-assisted reactions were carried out in a Biotage initiator.

\section{Additional Figures and Tables}

Figure S-1. Additional compounds made

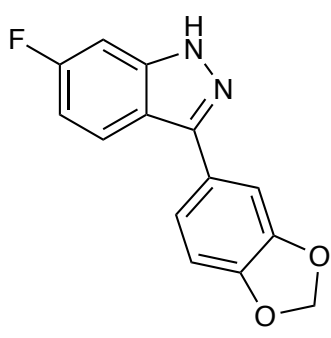

S1

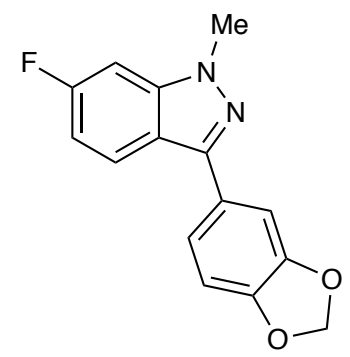

S2

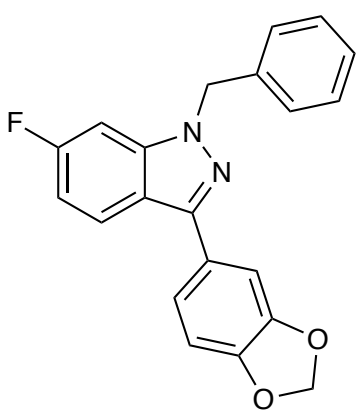

S3

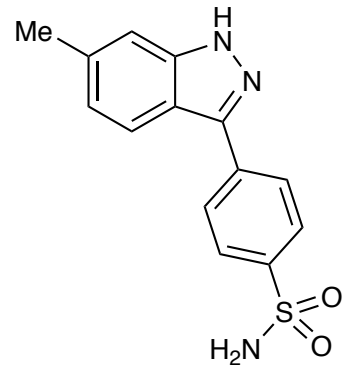

S4<smiles>NS(=O)(=O)c1ccc(-c2n[nH]c3cc(C(F)(F)F)ccc23)cc1</smiles>

S5 
Figure S-2. Eurofins DiscoverX ScanEDGE Kinase Panel for $\mathbf{1 5 0}$

\begin{tabular}{|c|c|c|c|}
\hline Target & NUCC-226297 & Target & NUCC-226297 \\
\hline Gene Symbol & \%Ctrl@10000nM & Gene Symbol & \%Ctrl @10000nM \\
\hline ABL1(E255K)-phosphorylated & 19 & KIT(D816V) & 8.9 \\
\hline ABL1(T315I)-phosphorylated & 3.9 & KIT(V559D,T670I) & 1.2 \\
\hline ABL1-nonphosphorylated & 57 & LKB1 & 76 \\
\hline ABL1-phosphorylated & 45 & MAP3K4 & 84 \\
\hline ACVR1B & 89 & MAPKAPK2 & 100 \\
\hline ADCK3 & 87 & MARK3 & 41 \\
\hline AKT1 & 98 & MEK1 & 0.7 \\
\hline AKT2 & 100 & MEK2 & 1.4 \\
\hline ALK & 31 & MET & 100 \\
\hline AURKA & 38 & MKNK1 & 85 \\
\hline AURKB & 47 & MKNK2 & 85 \\
\hline AXL & 6.9 & MLK1 & 57 \\
\hline BMPR2 & 0.2 & p38-alpha & 92 \\
\hline BRAF & 93 & p38-beta & 84 \\
\hline BRAF(V600E) & 93 & PAK1 & 46 \\
\hline BTK & 78 & PAK2 & 41 \\
\hline CDK11 & 100 & PAK4 & 76 \\
\hline CDK2 & 47 & PCTK1 & 36 \\
\hline CDK3 & 35 & PDGFRA & 16 \\
\hline CDK7 & 2.6 & PDGFRB & 19 \\
\hline CDK9 & 59 & PDPK1 & 38 \\
\hline CHEK1 & 100 & PIK3C2B & 73 \\
\hline CSF1R & 18 & PIK3CA & 76 \\
\hline CSNK1D & 36 & PIK3CG & 5.3 \\
\hline CSNK1G2 & $\begin{array}{l}30 \\
1.1\end{array}$ & PIM1 & 32 \\
\hline DCAMKL1 & 75 & PIM2 & 5.6 \\
\hline DYRK1B & 15 & PIM3 & 25 \\
\hline EGFR & $\begin{array}{l}15 \\
72\end{array}$ & PKAC-alpha & 86 \\
\hline EGFR(L858R) & $\begin{array}{l}72 \\
100\end{array}$ & PLK1 & 76 \\
\hline EPHA2 & $\begin{array}{l}100 \\
92\end{array}$ & PLK3 & 71 \\
\hline ERBB2 & $\begin{array}{l}92 \\
100\end{array}$ & PLK4 & 4.9 \\
\hline ERBB4 & 100 & PRKCE & 90 \\
\hline ERDD4 & 99 & RAF1 & 97 \\
\hline ERK1 & 89 & RET & 55 \\
\hline FAK & 100 & RIOK2 & 48 \\
\hline FGFR2 & 32 & ROCK2 & 77 \\
\hline FGFR3 & 23 & RSK2(Kin.Dom.1-N-terminal) & 0.7 \\
\hline FLT3 & 2.6 & SNARK & 28 \\
\hline GSK3B & 85 & SRC & 71 \\
\hline IGF1R & 100 & SRPK3 & 88 \\
\hline IKK-alpha & 83 & TGFBR1 & 71 \\
\hline IKK-beta & 91 & TIE2 & 59 \\
\hline INSR & 52 & TRKA & 6.7 \\
\hline JAK2(JH1domain-catalytic) & 14 & TSSK1B & 79 \\
\hline JAK3(JH1domain-catalytic) & 6.9 & TYK2(JH1domain-catalytic) & 5.2 \\
\hline JNK1 & 0.15 & ULK2 & 53 \\
\hline JNK2 & 0.25 & VEGFR2 & 5.7 \\
\hline JNK3 & 0.1 & YANK3 & 100 \\
\hline $\mathrm{KIT}$ & 3.7 & ZAP70 & 98 \\
\hline
\end{tabular}


Figure S-3. Eurofins DiscoverX ScanELECT Kinase Panel with MEK3, 5, and 6

10e 150

\begin{tabular}{|l|lll|lll|}
\hline Target & \multicolumn{3}{c|}{ NUCC-202952 } & \multicolumn{3}{c|}{ NUCC-226297 } \\
\hline Gene & \%Ctrl @ & \%Ctrl @ & $\%$ Ctrl @ & \%Ctrl @ & $\%$ Ctrl @ & $\%$ Ctrl @ \\
Symbol & $100 \mathrm{nM}$ & $1000 \mathrm{nM}$ & $10000 \mathrm{nM}$ & $100 \mathrm{nM}$ & $1000 \mathrm{nM}$ & $10000 \mathrm{nM}$ \\
\hline MEK3 & 100 & 60 & 9.5 & 65 & 14 & 0.05 \\
\hline MEK5 & 100 & 78 & 24 & 73 & 13 & 0.4 \\
\hline MEK6 & 100 & 88 & 50 & 90 & 40 & 3 \\
\hline
\end{tabular}

Figure S-4. ADMET Studies conducted by BioDuro-Sundia.

A) $\log$, B) Liver Microsome Stability, C) PAMPA, D) Caco-2, E) CYP inhibition A) $\log D$

\begin{tabular}{|l|l|}
\hline Compound & $\log \mathrm{D}_{7.4}$ \\
\hline 150 & 3.22 \\
\hline $\mathbf{1 0 e}$ & 2.80 \\
\hline Testosterone & 3.43 \\
\hline
\end{tabular}

B) Liver Microsome Stability

\begin{tabular}{|c|c|c|c|}
\hline \multirow[b]{2}{*}{ Compound } & \multicolumn{3}{|l|}{ Human } \\
\hline & $\mathrm{T}_{1 / 2}(\min )$ & $\begin{array}{l}\text { In vitro } \quad \mathrm{CL}_{\text {int }} \\
(\mu \mathrm{L} / \mathrm{min} / \mathrm{mg} \text { protein })\end{array}$ & $\mathrm{CL}_{\text {hep }}(\mathrm{mL} / \mathrm{min} / \mathrm{kg})$ \\
\hline 150 & $>186.4$ & $<7.4$ & $<6.1$ \\
\hline $10 e$ & 114.5 & 12.1 & 8.4 \\
\hline Dextromethorphan & 34.0 & 40.8 & 14.4 \\
\hline
\end{tabular}

C) PAMPA

\begin{tabular}{|l|l|l|}
\hline Compound & $\mathrm{Pe}_{\mathrm{e}}\left(10^{-6} \mathrm{~cm} / \mathrm{s}\right)$ & Recovery $(\%)$ \\
\hline $\mathbf{1 5 0}$ & 0.003 & 43.8 \\
\hline $\mathbf{1 0 e}$ & 0.117 & 61.7 \\
\hline Warfarin & 3.34 & 101 \\
\hline
\end{tabular}

D) $\mathrm{Caco}-2$

\begin{tabular}{|l|l|l|l|l|l|}
\hline \multirow{2}{*}{ Compound } & $\mathbf{P}_{\text {app }}\left(\mathbf{1 0 ^ { - 6 }} \mathbf{c m} / \mathbf{s}\right)$ & \multirow{2}{*}{ Efflux ratio } & Recovery (\%) \\
\cline { 2 - 3 } & $\mathbf{A} \rightarrow \mathbf{B}$ & $\mathbf{B} \rightarrow \mathbf{A}$ & & $\mathbf{A} \rightarrow \mathbf{B}$ & $\mathbf{B} \rightarrow \mathbf{A}$ \\
\hline $\mathbf{1 5 0}$ & 7.9 & 32.6 & 4.1 & 136.5 & 98.8 \\
\hline $\mathbf{1 0 e}$ & 30.5 & 46.5 & 1.5 & 103.8 & 107.6 \\
\hline Nadolol & 0.9 & 0.9 & 1.1 & 98.6 & 109.8 \\
\hline Propranolol & 36.8 & 24.6 & 0.7 & 93.0 & 106.2 \\
\hline
\end{tabular}




\begin{tabular}{|l|l|l|l|l|l|} 
Taxol & 0.1 & 2.5 & 20.2 & 98.0 & 88.9 \\
\hline
\end{tabular}

E) CYP Inhibition

\begin{tabular}{|c|c|c|c|c|c|}
\hline \multirow{2}{*}{ Compound } & \multicolumn{5}{|c|}{$\mathrm{IC}_{50}(\mu \mathrm{M})$} \\
\hline & $1 \mathrm{~A} 2$ & $2 \mathrm{Cg}$ & $2 C 19$ & 2D6 & $3 A 4 / 5$ \\
\hline 150 & 26.2 & 1.19 & 3.72 & 20.6 & $>50$ \\
\hline $10 e$ & 14.6 & $>50$ & 47.2 & $>50$ & $>50$ \\
\hline Positive control & 0.0902 & 0.526 & 8.61 & 0.0505 & 0.0205 \\
\hline
\end{tabular}

\section{General Procedures}

\section{ADP-Glo Kinase Activity Assay}

Procedure for a $5 \mu \mathrm{L}$ Kinase reaction using the ADP-Glo Kinase Assay Kit from Promega. Staurosporine was used as the positive control, and DMSO as the negative control. Activity of recombinant active full-length human MEK4 (Carna Biosciences) was measured using the ADP-Glo assay with recombinant full-length human p38a (MAPK14). Kinase reactions with MEK7 (Carna Biosciences) were done at the same concentration and amounts with recombinant full-length human JNK1 (MAPK8).

Using a Mantis, a mixture of MEK and p38 $\alpha$ was dispensed into a 384 low volume white Proxiplate. For each well, $4 \mathrm{ng}$ of MEK4 and $600 \mathrm{ng}$ of p38 $\alpha$ in Kinase buffer (CST) were used, and $1 \mu \mathrm{L}$ of this mixture was dispensed per well.

Inhibitor was prepared in a DMSO solution. A dose response dilution was done in a 384-well Echo transfer plate. Using an Echo Access, $10 \mathrm{~nL}$ of each solution was dispensed into the same 384 low volume white Proxiplate as above. This mixture was allowed to incubate for 30 minutes at room temperature.

Using a Mantis, $1 \mathrm{uL}$ of an $8 \mu \mathrm{M}$ ATP solution was added to each well, and the plate was allowed to incubate for another 1 hour at room temperature. Using the Mantis again, $4 \mu \mathrm{L}$ of ADP Glo Reagent was dispensed into each well, and the plate was allowed to incubate for $45 \mathrm{~min}$ at room temperature. Finally, $9 \mu \mathrm{L}$ of Kinase Detection Reagent was added manually to each well, and the plate was allowed to incubate for 45 minutes at room temperature. Luminescence was read on a Synergy Neo2 Plate Reader with filter cubes 3 and 114. Integration time was 0.20 seconds, gain set to 160, read height set at $6 \mathrm{~mm}$. All experiments were done in triplicate on the plate, and at least in one separate technical duplicate. Each experiment's $\mathrm{IC}_{50}$ values are reported as $\left(\mathrm{IC}_{50} \pm \mathrm{SEM}\right)$ and can be found under each compound's characterization data in the tabulated data section.

\section{Docking Protocols}

The refined MEK4 PDB was used for docking. ${ }^{1}$ After preparing the protein and the ligand set, all smallmolecule structures were docked into the active site of MEK4 using Schrodinger Maestro software. We generated a $10 \AA \times 10 \AA \times 10 \AA$ cube in the ATP binding site of the MEK4 structure and used all the default parameters for docking.

\section{Cell Culture}

Human pancreatic cancer cell lines (CD18/HPAF-II and MiaPaCa2) and HEK293T cells were obtained from American Type Culture Collection. All cell lines were cultured according to the manufacturer's protocol. All 
media contained 10\% Fetal Bovine Serum (FBS) and antibiotics (100 U/mL Penicillin and $100 \mu \mathrm{g} / \mathrm{mL}$ Streptomycin).

\section{Chemicals for Cell Culture}

Anisomycin was purchased from MedChemExpress and the MEK1/2 inhibitor U0126 was purchased from Cell Signaling. Both compounds were dissolved in DMSO as instructed by the manufacturer.

\section{Immunoblotting}

Whole cell extracts of cultured cells were prepared in radioimmunoprecipitation (RIPA) lysis buffer supplemented with phosphatase and protease inhibitors (Calbiochem). Protein concentration was determined by the bicinchoninic acid assay (BCA) (ThermoFisher) and separated by the SDS-PAGE technique. The following antibodies were obtained from Cell Signaling and used at the dilution recommended by the manufacturer: phospho-JNK (\#4668), total JNK (\#9252), MEK7 (\#4172), phospho-ERK1/2 (phospho-p42/44 MAPK, \#9101), phospho-p38 MAPK (\#9211), and total p38 MAPK (\#9212). Total ERK1/2 (p42/44 MAPK, sc-514302) and HSP90 (sc-7940) were obtained from Santa Cruz Biotechnology and used at the dilution recommended by the manufacturer. Secondary anti-mouse IgG (A4416) and anti-rabbit IgG (A6667) antibodies were purchased from Sigma-Aldrich and used a 1:4000 dilution. Images of blots were acquired on HyBlot ES Autoradiography Film (Thomas Scientific, Swedesboro, NJ, USA) following incubation with SuperSignal West Pico PLUS (ThermoFisher).

\section{Synthesis of Indazole Precursor S6}

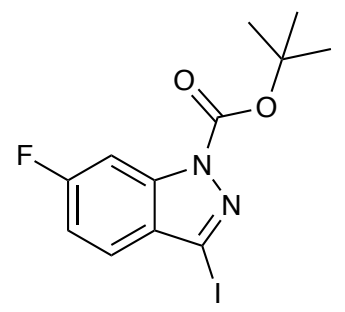

tert-butyl 6-fluoro-3-iodo-1H-indazole-1-carboxylate. (S6) To a solution of 6-fluoro-1H-indazole (10.00 g, $73.5 \mathrm{mmol})$ in DMF $(147 \mathrm{~mL})$ was added $\mathrm{KOH}(9.07 \mathrm{~g}, 162 \mathrm{mmol})$, followed by $\mathrm{I}_{2}(24.2 \mathrm{~g}, 95.5 \mathrm{mmol})$. The reaction was monitored by TLC or UPLC and allowed to run to completion. To this solution, di-tert-butyl dicarbonate (19.2 g, $88.2 \mathrm{mmol}$ ) was added, and the reaction was again monitored by TLC/UPLC and allowed to run to completion. Reaction was poured in an ice bath with saturated aqueous $\mathrm{Na}_{2} \mathrm{~S}_{2} \mathrm{O}_{3}$, adding more saturated aqueous $\mathrm{Na}_{2} \mathrm{~S}_{2} \mathrm{O}_{3}$ until all iodine color disappeared. The mixture was then transferred to a fritted funnel and washed with water and hexanes to afford S6 (22.2 g, 84\%) as a pale-yellow solid. Analytical data for S6: ${ }^{1} \mathrm{H}$ NMR $\left(500 \mathrm{MHz}, \mathrm{DMSO}-d_{6}\right) \delta 7.75(\mathrm{dd}, J=9.6,2.3 \mathrm{~Hz}, 1 \mathrm{H}), 7.59(\mathrm{dd}, J=8.8,5.1 \mathrm{~Hz}, 1 \mathrm{H}), 7.33(\mathrm{td}$, $J=9.0,2.3 \mathrm{~Hz}, 1 \mathrm{H}), 1.64(\mathrm{~s}, 9 \mathrm{H}) .{ }^{13} \mathrm{C} \mathrm{NMR}\left(126 \mathrm{MHz}, \mathrm{DMSO}-d_{6}\right) \delta 163.4\left(\mathrm{~d}, J_{C-F}=246.7 \mathrm{~Hz}\right), 147.4,139.3$ $\left(\mathrm{d}, J_{C-F}=13.7 \mathrm{~Hz}\right), 126.6,124.0\left(\mathrm{~d}, J_{C-F}=11.3 \mathrm{~Hz}\right), 113.6\left(\mathrm{~d}, J_{C-F}=25.8 \mathrm{~Hz}\right), 100.6\left(\mathrm{~d}, J_{C-F}=28.9 \mathrm{~Hz}\right), 85.5$, 27.6. HRMS (electrospray): Exact mass calculated for $\mathrm{C}_{12} \mathrm{H}_{12} \mathrm{FIN}_{2} \mathrm{O}_{2} \mathrm{Na}^{+}[\mathrm{M}+\mathrm{Na}]$, 384.9825. Found 384.9812.

\section{General Procedure (1) for Suzuki Couplings:}



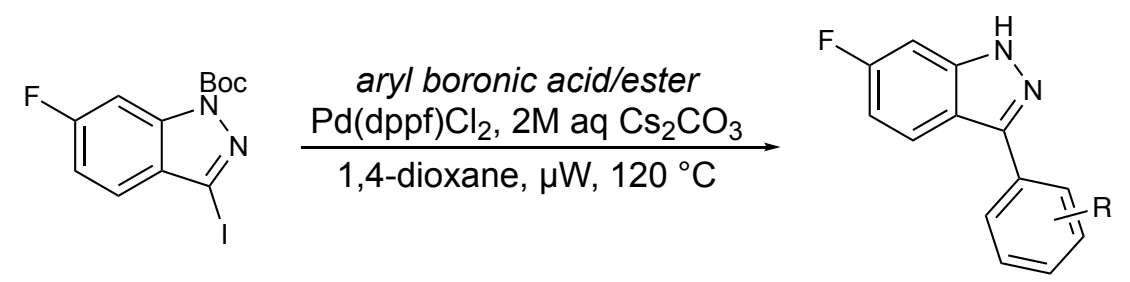

To a flame-dried microwave vial, $\mathbf{S 6}$ (1.2 equiv.), $\mathrm{PdCl}_{2}$ (dppf) (0.05 equiv.), and aryl boronic acid/ester (1 equiv.) was added. The vial was crimped and purged with nitrogen. To this vial was added degassed 1,4dioxane $(0.40 \mathrm{M})$ and $2 \mathrm{M}$ aqueous $\mathrm{Na}_{2} \mathrm{CO}_{3}(0.40 \mathrm{M})$. This mixture was microwaved at $120^{\circ} \mathrm{C}$ for 1 hour. The solution was diluted with water and extracted with EtOAc $(3 \times 10 \mathrm{~mL})$. The organic layer was separated, dried over $\mathrm{Na}_{2} \mathrm{SO}_{4}$, and then concentrated in vacuo. The residue was purified by flash column chromatography ( 0 $80 \% \mathrm{EtOAc/Hex} \mathrm{over} 20$ column volumes) to afford the Suzuki coupling product.

\section{General Procedure (2) for Borylations:}
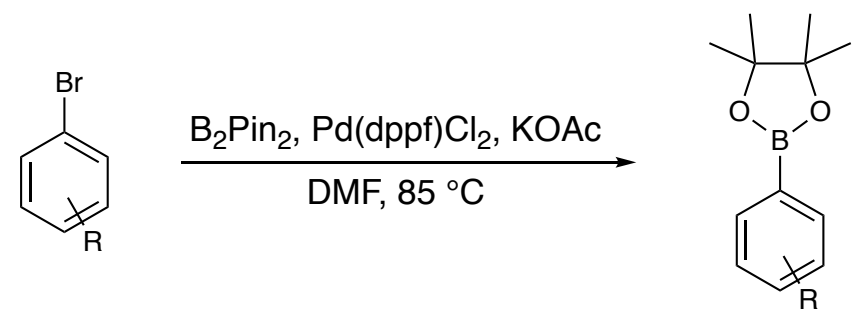

To a flame-dried round bottom was added the aryl bromide (1 equiv.), 4,4,4',4',5,5,5',5'-octamethyl-2,2'bi(1,3,2-dioxaborolane) (1.2 equiv.), $\mathrm{Pd}(\mathrm{dppf}) \mathrm{Cl}_{2}$ (applicable for both para- and meta- substituted compounds) or $\mathrm{Pd}\left(\mathrm{PPh}_{3}\right) \mathrm{Cl}_{2}$ (better yielding for para- substituted) (0.05 equiv.), and KOAc (2.0 equiv). Degassed, anhydrous DMF $(0.2 \mathrm{M})$ was added. The reaction was heated at $85^{\circ} \mathrm{C}$ and monitored by UPLC. After running overnight, the reaction was diluted in water and extracted with EtOAc $(3 \times 30 \mathrm{~mL})$. The organic layer was heavily washed with brine, dried over $\mathrm{Na}_{2} \mathrm{SO}_{4}$ and concentrated in vacuo. The residue was purified by flash column chromatography $\left(\mathrm{SiO}_{2}, \mathrm{EtOAc} / \mathrm{Hex}\right)$ to afford product.

\section{General Procedure (3) for Sulfonylations:}
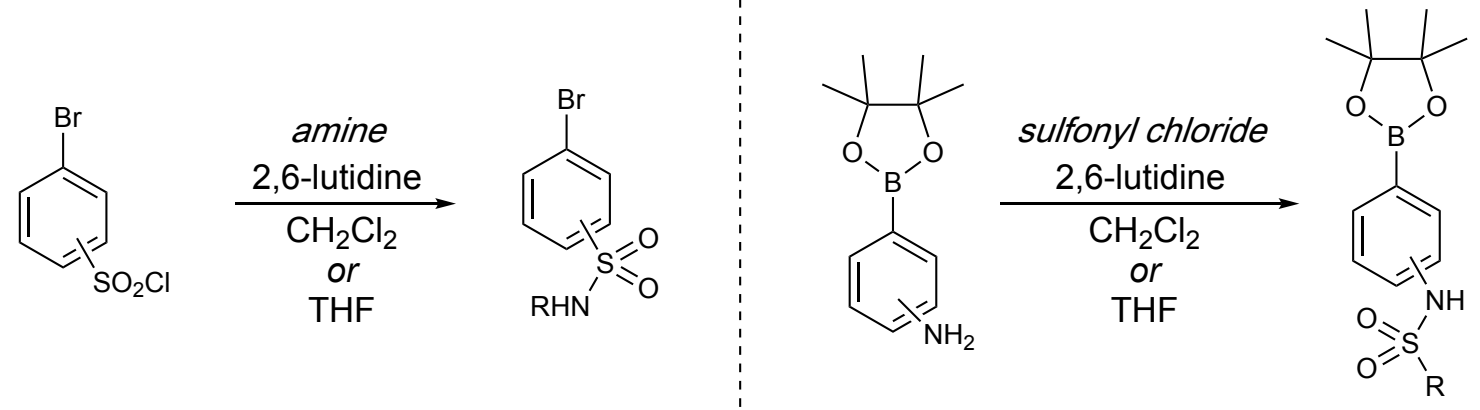

To a flame-dried round bottom was added the amine (1 equiv.), anhydrous $\mathrm{CH}_{2} \mathrm{Cl}_{2}$ or THF (0.25 M), and 2,6lutidine (2.0 equiv.). Lutidine prevented formation of side products, compared to triethylamine and pyridine. Some products were successfully isolated or carried forward after employing pyridine or triethylamine in THF at the same equivalence. Reactions were dropped to $0{ }^{\circ} \mathrm{C}$ and sulfonyl chloride (1.1 equiv.) added dropwise (dissolved in a small amount of $\mathrm{CH}_{2} \mathrm{Cl}_{2}$ if solid). The reaction was monitored by UPLC. After running overnight, the reaction was diluted in water and extracted with $\mathrm{CH}_{2} \mathrm{Cl}_{2}$ (EtOAc if reaction was in THF). The organic layer was dried over $\mathrm{Na}_{2} \mathrm{SO}_{4}$ or dried via Biotage phase separator and concentrated in vacuo. The 
residue was purified by flash column chromatography $\left(\mathrm{SiO}_{2}, \mathrm{EtOAc} / \mathrm{Hex}\right)$ to afford product. Reactions yielded product in $50-85 \%$ yield.

\section{Procedure A: General Synthesis of Compounds 8b-f}

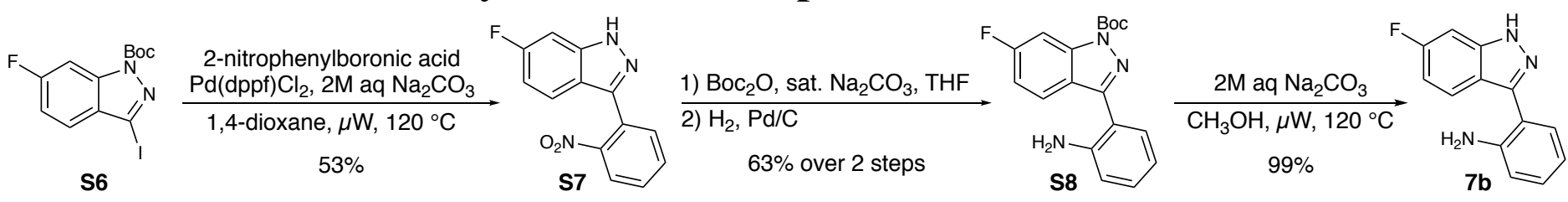

Synthesis of S7. Prepared according to General Procedure 1.

Analytical data: ${ }^{1} \mathrm{H}$ NMR $\left(500 \mathrm{MHz}\right.$, Methanol- $\left.d_{4}\right) \delta 8.03(\mathrm{~d}, J=8.1 \mathrm{~Hz}, 1 \mathrm{H}), 7.82(\mathrm{dd}, J=7.3,1.6 \mathrm{~Hz}, 2 \mathrm{H})$, $7.70(\mathrm{ddd}, J=8.5,6.6,2.3 \mathrm{~Hz}, 1 \mathrm{H}), 7.59(\mathrm{dd}, J=8.9,5.0 \mathrm{~Hz}, 1 \mathrm{H}), 7.28(\mathrm{dd}, J=9.3,2.1 \mathrm{~Hz}, 1 \mathrm{H}), 7.02(\mathrm{td}, J=$ 9.1, $2.2 \mathrm{~Hz}, 1 \mathrm{H})$.

Synthesis of tert-butyl 3-(2-aminophenyl)-6-fluoro-1H-indazole-1-carboxylate S8. To a solution of 6-fluoro-3(2-nitrophenyl)-1H-indazole S7 (1.68 g, $6.53 \mathrm{mmol})$ in THF $(32.7 \mathrm{~mL})$, di-tert-butyl decarbonate (2.85 g, 13.1 mmol) and saturated aqueous $\mathrm{Na}_{2} \mathrm{CO}_{3}(32.7 \mathrm{~mL})$ were added. The reaction was stirred vigorously overnight. The solution was diluted with brine and extracted with EtOAc $(3 \times 25 \mathrm{~mL})$. The organic layer was separated, dried over $\mathrm{Na}_{2} \mathrm{SO}_{4}$, then concentrated in vacuo. Tert-butyl 6-fluoro-3-(2-nitrophenyl)-1H-indazole-1carboxylate residue was taken directly to the next step. Boc protection was done to make purification of the following product easier.

Analytical data of intermediate: ${ }^{1} \mathrm{H}$ NMR $\left(500 \mathrm{MHz}\right.$, Methanol- $\left.d_{4}\right) \delta 8.04(\mathrm{dd}, J=8.9,5.1 \mathrm{~Hz}, 1 \mathrm{H}), 7.92(\mathrm{dd}$, $J=9.6,2.3 \mathrm{~Hz}, 1 \mathrm{H}), 7.72(\mathrm{dd}, J=7.8,1.6 \mathrm{~Hz}, 1 \mathrm{H}), 7.28-7.20(\mathrm{~m}, 2 \mathrm{H}), 6.95(\mathrm{dd}, J=8.2,1.1 \mathrm{~Hz}, 1 \mathrm{H}), 6.85$ (td, $J=7.5,1.2 \mathrm{~Hz}, 1 \mathrm{H}), 1.76(\mathrm{~s}, 9 \mathrm{H})$.

To a solution of tert-butyl 6-fluoro-3-(2-nitrophenyl)-1H-indazole-1-carboxylate residue in degassed methanol (9.4 mL), $\mathrm{H}_{2} / \mathrm{C}(3.79 \mathrm{mg}, 1.88 \mathrm{mmol})$ was added, and the solution purged with argon. The solution was then purged with $\mathrm{H}_{2}$. An additional input of $\mathrm{H}_{2}$ was left in the headspace for a constant 1 atm pressure of $\mathrm{H}_{2}$. The reaction was stirred overnight (product should start crashing out soon after hydrogenation starts). The solution was filtered through celite, rinsing with EtOAc (Product is not very soluble in methanol). This was concentrated in vacuo. The residual solid was purified by flash column chromatography $\left(\mathrm{SiO}_{2}, 0-20 \%\right.$ EtOAc/Hex) to afford tert-butyl 3-(2-aminophenyl)-6-fluoro- $1 H$-indazole-1-carboxylate (1.35g, 63\% over 2 steps) as a white solid.

Analytical data of S8: ${ }^{1} \mathrm{H}$ NMR $\left(500 \mathrm{MHz}, \mathrm{DMSO}-d_{6}\right) \delta 8.09(\mathrm{dd}, J=8.9,5.2 \mathrm{~Hz}, 1 \mathrm{H}), 7.85(\mathrm{dd}, J=9.8,2.4$ $\mathrm{Hz}, 1 \mathrm{H}), 7.69$ (dd, $J=7.8,1.6 \mathrm{~Hz}, 1 \mathrm{H}), 7.33$ (td, $J=9.0,2.4 \mathrm{~Hz}, 1 \mathrm{H}), 7.20$ (ddd, $J=8.5,7.1,1.6 \mathrm{~Hz}, 1 \mathrm{H}), 6.88$ $(\mathrm{dd}, J=8.2,1.2 \mathrm{~Hz}, 1 \mathrm{H}), 6.73(\mathrm{td}, J=7.4,1.2 \mathrm{~Hz}, 1 \mathrm{H}), 6.17(\mathrm{~s}, 2 \mathrm{H}), 1.67(\mathrm{~s}, 9 \mathrm{H}) .{ }^{13} \mathrm{C}$ NMR $(126 \mathrm{MHz}$, DMSO$\left.d_{6}\right) \delta 162.6\left(\mathrm{~d}, J_{C-F}=245.8 \mathrm{~Hz}\right), 148.5,148.2,147.0,140.2\left(\mathrm{~d}, J_{C-F}=13.4 \mathrm{~Hz}\right), 130.2,129.6,124.3\left(\mathrm{~d}, J_{C-F}=\right.$ $11.0 \mathrm{~Hz}), 121.2,115.9\left(\mathrm{~d}, J_{C-F}=20.0 \mathrm{~Hz}\right), 113.1,112.9,112.8,100.7\left(\mathrm{~d}, J_{C-F}=28.3 \mathrm{~Hz}\right), 85.0,27.6$.

$\underline{\text { Synthesis of } \mathbf{7 b}}$. To a flame-dried microwave vial, tert-butyl 3-(2-aminophenyl)-6-fluoro-1H-indazole-1carboxylate $(200 \mathrm{mg}, 0.61 \mathrm{mmol})$, methanol $(6.1 \mathrm{~mL})$ and $2 \mathrm{M}$ aqueous $\mathrm{Na}_{2} \mathrm{CO}_{3}(2.0 \mathrm{~mL})$ were added. The vial was crimped, and this mixture was microwaved at $120{ }^{\circ} \mathrm{C}$ for 15 minutes. The solution was extracted with EtOAc $(3 \times 10 \mathrm{~mL})$. The organic layer was separated, dried over $\mathrm{Na}_{2} \mathrm{SO}_{4}$, then concentrated in vacuo to afford $7 \mathbf{b}(138 \mathrm{mg}, 99 \%)$ as a white solid. 


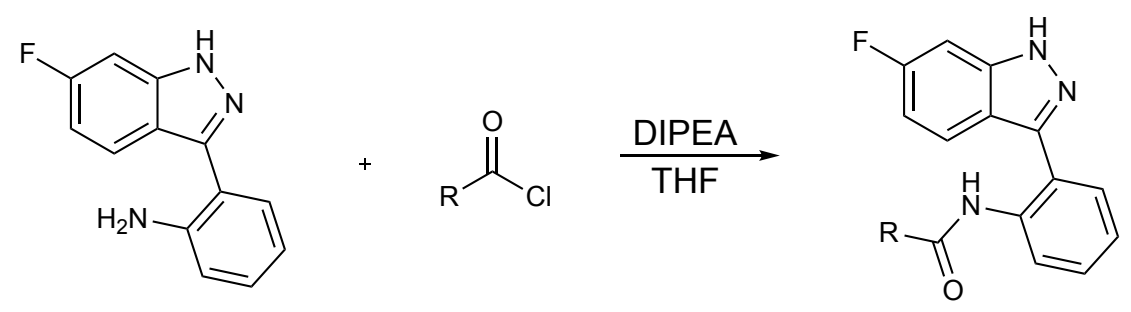

In a flame-dried vial, a solution of $7 \mathbf{b}$ (1 equiv.) in THF $(0.20 \mathrm{M})$ was cooled to $0{ }^{\circ} \mathrm{C}$. DIPEA (1.2 equiv) was added dropwise. After stirring for a few minutes, acyl chloride (1.1 equiv.) was added dropwise. The reaction was allowed to reach room temperature and monitored by TLC (if reaction is run for too long, dialkylated product will be isolated). The reaction was concentrated in vacuo, and the residue was purified by flash column chromatography. Reaction did not work with protected indazole.

\section{Tabulated Data of Compounds 8a-f}

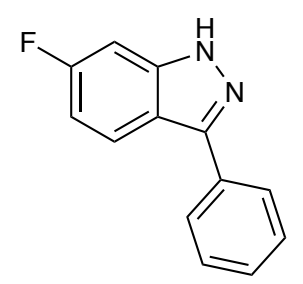

6-fluoro-3-phenyl-1 $\boldsymbol{H}$-indazole (8a). Prepared according to General Procedure 1 from indazole $\mathbf{S 6}$ (300 mg, $0.828 \mathrm{mmol})$, residue purified by flash column chromatography $\left(\mathrm{SiO}_{2}, 0-10 \% \mathrm{EtOAc} / \mathrm{Hex}\right)$ to afford 6-fluoro-3phenyl-1H-indazole (134 mg, 76\%) as an off-white solid. Analytical data: ${ }^{1} \mathrm{H}$ NMR (500 MHz, DMSO-d 6 ) $\delta$ 13.29 (s, 1H), $8.08(\mathrm{dd}, \mathrm{J}=8.9,5.1 \mathrm{~Hz}, 1 \mathrm{H}), 7.99-7.94(\mathrm{~m}, 2 \mathrm{H}), 7.52(\mathrm{dd}, \mathrm{J}=8.4,6.9 \mathrm{~Hz}, 2 \mathrm{H}), 7.44-7.39(\mathrm{~m}$, 1H), 7.37 (dd, J = 9.5, $2.3 \mathrm{~Hz}, 1 \mathrm{H}), 7.08$ (td, J = 9.2, $2.3 \mathrm{~Hz}, 1 \mathrm{H}) .{ }^{13} \mathrm{C}$ NMR $(126 \mathrm{MHz}$, DMSO-d 6 ) $\delta 161.2(\mathrm{~d}$, $\left.\mathrm{J}_{\mathrm{C}-\mathrm{F}}=241.9 \mathrm{~Hz}\right), 143.5,141.7\left(\mathrm{~d}, \mathrm{~J}_{\mathrm{C}-\mathrm{F}}=12.6 \mathrm{~Hz}\right), 133.2,128.9,127.9,126.8,122.6\left(\mathrm{~d}, \mathrm{~J}_{\mathrm{C}-\mathrm{F}}=10.9 \mathrm{~Hz}\right), 117.3$, $110.6\left(\mathrm{~d}, \mathrm{~J}_{\mathrm{C}-\mathrm{F}}=25.8 \mathrm{~Hz}\right), 95.9\left(\mathrm{~d}, \mathrm{~J}_{\mathrm{C}-\mathrm{F}}=25.8 \mathrm{~Hz}\right)$. HRMS (ESI): Exact mass calculated for $\mathrm{C}_{13} \mathrm{H}_{10} \mathrm{FN}_{2}{ }^{+}[\mathrm{M}+\mathrm{H}]$, 213.0828. Found 213.0826. $\mathrm{IC}_{50}: 0.31 \mu \mathrm{M}[0.22 \pm 0.11, \mathrm{n}=3 ; 0.40 \pm 0.18, \mathrm{n}=3]$

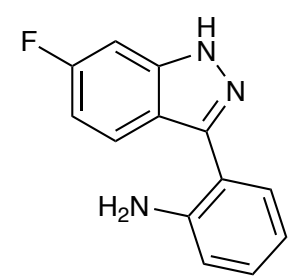

2-(6-fluoro-1H-indazol-3-yl)aniline (8b). Prepared according to General Procedure A. See details above. Analytical data: ${ }^{1} \mathrm{H}$ NMR $\left(500 \mathrm{MHz}, \mathrm{DMSO}-d_{6}\right) \delta 13.24(\mathrm{~s}, 1 \mathrm{H}), 7.99(\mathrm{dd}, J=9.0,5.2 \mathrm{~Hz}, 1 \mathrm{H}), 7.66(\mathrm{dd}, J=$ $7.7,1.6 \mathrm{~Hz}, 1 \mathrm{H}), 7.37$ (dd, $J=9.5,2.3 \mathrm{~Hz}, 1 \mathrm{H}), 7.11$ (ddd, $J=8.5,7.2,1.6 \mathrm{~Hz}, 1 \mathrm{H}), 7.06$ (td, $J=9.1,2.3 \mathrm{~Hz}$, $1 \mathrm{H}), 6.85(\mathrm{dd}, J=8.1,1.2 \mathrm{~Hz}, 1 \mathrm{H}), 6.71(\mathrm{td}, J=7.4,1.2 \mathrm{~Hz}, 1 \mathrm{H}), 6.05(\mathrm{~s}, 2 \mathrm{H}) .{ }^{13} \mathrm{C}$ NMR $\left(126 \mathrm{MHz}\right.$, DMSO- $\left.d_{6}\right)$ $\delta 161.3\left(\mathrm{~d}, J_{\mathrm{C}-\mathrm{F}}=242.0 \mathrm{~Hz}\right), 146.2,143.8,141.0\left(\mathrm{~d}, J_{\mathrm{C}-\mathrm{F}}=12.9 \mathrm{~Hz}\right), 128.9,128.5,123.2\left(\mathrm{~d}, J_{\mathrm{C}-\mathrm{F}}=11.1 \mathrm{~Hz}\right)$, 118.0, $115.7\left(\mathrm{~d}, J_{\mathrm{C}-\mathrm{F}}=19.5 \mathrm{~Hz}\right), 115.4,110.3,110.1,95.7\left(\mathrm{~d}, J_{\mathrm{C}-\mathrm{F}}=25.8 \mathrm{~Hz}\right)$. HRMS (ESI): Exact mass calculated for $\mathrm{C}_{13} \mathrm{H}_{10} \mathrm{FN}_{3}{ }^{+}[\mathrm{M}+\mathrm{H}], 228.0937$. Found 228.0931. IC $\mathrm{I}_{50}:>80 \mu \mathrm{M}$ 


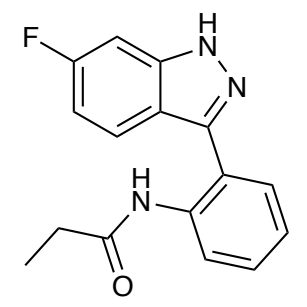

N-(2-(6-fluoro-1H-indazol-3-yl)phenyl)propionamide (8c). Prepared according to General Procedure A from $\mathbf{8 b}$ to afford product (50 mg, 80\%) as a white solid. Analytical data: ${ }^{1} \mathrm{H}$ NMR (500 MHz, DMSO-d6) $\delta 13.54$ $(\mathrm{s}, 1 \mathrm{H}), 10.34(\mathrm{~s}, 1 \mathrm{H}), 8.24(\mathrm{~d}, J=8.2 \mathrm{~Hz}, 1 \mathrm{H}), 7.86(\mathrm{dd}, J=9.0,5.1 \mathrm{~Hz}, 1 \mathrm{H}), 7.80(\mathrm{dd}, J=7.7,1.6 \mathrm{~Hz}, 1 \mathrm{H})$, $7.45-7.38$ (m, 2H), 7.27 (td, $J=7.5,1.3 \mathrm{~Hz}, 1 \mathrm{H}), 7.09$ (td, $J=9.2,2.3 \mathrm{~Hz}, 1 \mathrm{H}), 2.28(\mathrm{q}, J=7.5 \mathrm{~Hz}, 2 \mathrm{H}), 1.06$ $(\mathrm{t}, J=7.6 \mathrm{~Hz}, 3 \mathrm{H}) .{ }^{13} \mathrm{C}$ NMR $\left(126 \mathrm{MHz}, \mathrm{DMSO}-d_{6}\right) \delta 171.75,161.48\left(\mathrm{~d}, J_{C-F}=242.5 \mathrm{~Hz}\right), 142.59,141.20(\mathrm{~d}$, $\left.J_{C-F}=13.0 \mathrm{~Hz}\right), 136.04,129.48,128.42,123.85,122.79\left(\mathrm{~d}, J_{C-F}=11.1 \mathrm{~Hz}\right), 122.45,122.39,118.03,110.76(\mathrm{~d}$, $\left.J_{C-F}=26.1 \mathrm{~Hz}\right), 95.97\left(\mathrm{~d}, J_{C-F}=25.9 \mathrm{~Hz}\right), 30.05$, 9.49. HRMS (electrospray): Exact mass calculated for $\mathrm{C}_{16} \mathrm{H}_{15} \mathrm{FN}_{3} \mathrm{O}^{+}[\mathrm{M}+\mathrm{H}], 284.1199$. Found 284.1194. $\mathrm{IC}_{50}:>80 \mu \mathrm{M}$

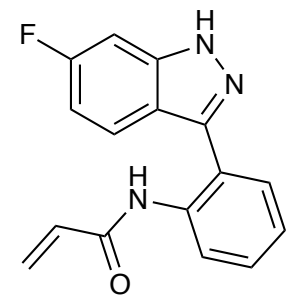

N-(2-(6-fluoro-1H-indazol-3-yl)phenyl)acrylamide (8d). Prepared according to General Procedure A with the corresponding acid chloride from $\mathbf{8 b}$ to afford $\mathbf{8 d}(50 \mathrm{mg}, 58 \%)$ as a white solid. Analytical data: ${ }^{1} \mathrm{H} \mathrm{NMR}$ $\left(500 \mathrm{MHz}, \mathrm{DMSO}-d_{6}\right) \delta 13.54(\mathrm{bs}, 1 \mathrm{H}), 10.52(\mathrm{~s}, 1 \mathrm{H}), 8.27(\mathrm{~d}, J=8.2 \mathrm{~Hz}, 1 \mathrm{H}), 7.88-7.79(\mathrm{~m}, 2 \mathrm{H}), 7.48-$ $7.40(\mathrm{~m}, 2 \mathrm{H}), 7.32(\mathrm{td}, J=7.5,1.3 \mathrm{~Hz}, 1 \mathrm{H}), 7.08(\mathrm{td}, J=9.2,2.3 \mathrm{~Hz}, 1 \mathrm{H}), 6.32(\mathrm{dd}, J=17.1,10.1 \mathrm{~Hz}, 1 \mathrm{H}), 6.23$ $(\mathrm{dd}, J=17.0,1.9 \mathrm{~Hz}, 1 \mathrm{H}), 5.75(\mathrm{dd}, J=10.0,1.8 \mathrm{~Hz}, 1 \mathrm{H}) .{ }^{13} \mathrm{C}$ NMR $\left(126 \mathrm{MHz}, \mathrm{DMSO}-d_{6}\right) \delta 163.3,161.5(\mathrm{~d}$, $\left.J_{C-F}=242.7 \mathrm{~Hz}\right), 142.4,141.2\left(\mathrm{~d}, J_{C-F}=13.0 \mathrm{~Hz}\right), 135.7,132.3,129.7,128.5,126.7,124.4,123.1,122.8,122.7$ $\left(\mathrm{d}, J_{C-F}=11.1 \mathrm{~Hz}\right), 118.1,110.8\left(\mathrm{~d}, J_{C-F}=26.2 \mathrm{~Hz}\right), 96.0\left(\mathrm{~d}, J_{C-F}=25.9 \mathrm{~Hz}\right)$. HRMS (ESI): Exact mass calculated for $\mathrm{C}_{16} \mathrm{H}_{13} \mathrm{FN}_{3} \mathrm{O}^{+}[\mathrm{M}+\mathrm{H}], 282.1042$. Found 282.1037. $\mathrm{IC}_{50}:>80 \mu \mathrm{M}$

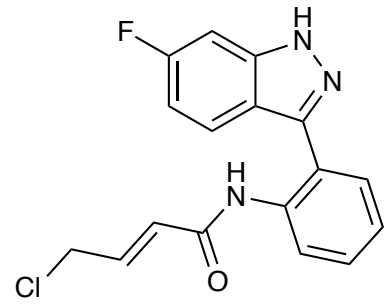

N-(2-(6-fluoro-1H-indazol-3-yl)phenyl)propionamide (8e). Prepared according to General Procedure A with the corresponding acid chloride from $\mathbf{8 b}$ to afford product $(86 \mathrm{mg}, 46 \%$ ) as a pale yellow solid. Acid chloride was made as follows: A flame dried round-bottom flask containing phenyl hypochloroselenoite (445 mg, 2.323 mmol) was charged with acetonitrile $(134 \mathrm{~mL})$. The reaction mixture was stirred for 5 minutes at room temperature to give a homogenous red solution. But-3-enoic acid (2.00 g, $134 \mathrm{~mL}, 23.2 \mathrm{mmol})$ was added by pipette (solution turned pale yellow at this point). N-chlorosuccinimide (NCS, 3.41 g, $25.6 \mathrm{mmol}$ ) in acetonitrile $(134 \mathrm{~mL})$ was then added by addition funnel. Reaction was then concentrated in vacuo, and the resulting residue was resuspended in diethyl ether. The ether layer was washed with water $(2 \times 150 \mathrm{~mL})$ and brine, dried over 
sodium sulfate, filtered, and concentrated. The acid was obtained (2.4 g, 86\%). (E)-4-chlorobut-2-enoic acid (50 $\mathrm{mg}, 0.41 \mathrm{mmol}$ ) was azeotropically washed in toluene $(3 \mathrm{x})$. This was dissolved in THF, put under nitrogen, and cooled to $0{ }^{\circ} \mathrm{C}$. Oxalyl chloride $(44 \mathrm{uL}, 0.50 \mathrm{mmol})$ was carefully added, followed by DMF $(75 \mathrm{uL}, 0.96 \mathrm{mmol})$. The solution was stirred under nitrogen and the ice bath was pulled down. The reaction was run for about 30 minutes. This was concentrated in vacuo and put under high vacuum. The residue was used the same day without further purification or isolation. Analytical data: ${ }^{1} \mathrm{H}$ NMR $\left(500 \mathrm{MHz}, \mathrm{DMSO}-d_{6}\right) \delta 13.51(\mathrm{~s}, 1 \mathrm{H})$, $10.41(\mathrm{~s}, 1 \mathrm{H}), 8.21(\mathrm{~d}, J=8.2 \mathrm{~Hz}, 1 \mathrm{H}), 7.85-7.74(\mathrm{~m}, 2 \mathrm{H}), 7.45(\mathrm{ddd}, J=8.4,7.4,1.6 \mathrm{~Hz}, 1 \mathrm{H}), 7.41(\mathrm{dd}, J=$ 9.4, $2.3 \mathrm{~Hz}, 1 \mathrm{H}), 7.31(\mathrm{td}, J=7.5,1.3 \mathrm{~Hz}, 1 \mathrm{H}), 7.06(\mathrm{td}, J=9.2,2.3 \mathrm{~Hz}, 1 \mathrm{H}), 6.82(\mathrm{dt}, J=15.0,6.1 \mathrm{~Hz}, 1 \mathrm{H})$, $6.30(\mathrm{dt}, J=15.0,1.6 \mathrm{~Hz}, 1 \mathrm{H}), 4.40(\mathrm{dd}, J=6.1,1.5 \mathrm{~Hz}, 2 \mathrm{H}) .{ }^{13} \mathrm{C}$ NMR $\left(126 \mathrm{MHz}, \mathrm{DMSO}-d_{6}\right) \delta 162.7,161.4$ $\left(\mathrm{d}, J_{C-F}=242.4 \mathrm{~Hz}\right), 142.4,141.2\left(\mathrm{~d}, J_{C-F}=13.1 \mathrm{~Hz}\right), 138.5,135.6,129.8,128.5,127.2,124.6,123.5,123.1$, $122.6\left(\mathrm{~d}, J_{C-F}=11.0 \mathrm{~Hz}\right), 118.1,110.7\left(\mathrm{~d}, J_{C-F}=26.1 \mathrm{~Hz}\right), 96.0\left(\mathrm{~d}, J_{C-F}=25.8 \mathrm{~Hz}\right), 43.3$. HRMS (ESI): Exact mass calculated for $\mathrm{C}_{17} \mathrm{H}_{14} \mathrm{ClFN}_{3} \mathrm{O}^{+}[\mathrm{M}+\mathrm{H}], 330.0809$. Found 330.0799. $\mathrm{IC}_{50}:>80 \mu \mathrm{M}$

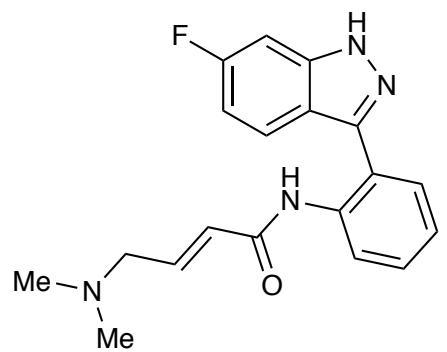

N-(2-(6-fluoro-1H-indazol-3-yl)phenyl)propionamide (8f). Prepared according to General Procedure A, using 8e as the starting material. To a flame-dried vial was added a solution of $\mathbf{8 f}$ ( $50 \mathrm{mg}, 0.15 \mathrm{mmol})$ in THF (0.51 $\mathrm{mL})$. Dimethylamine $(80 \mathrm{uL}, 1.20 \mathrm{mmol})$ was then added dropwise. The reaction was heated to $50{ }^{\circ} \mathrm{C}$ and monitored by UPLC. The reaction was concentrated in vacuo and placed under high vacuum overnight. The residue was purified by flash column chromatography $\left(\mathrm{SiO}_{2}, 0-5 \% \mathrm{MeOH} / \mathrm{DCM}\right)$ to afford 11 (35 mg, 68\%) as a white solid. Analytical data: ${ }^{1} \mathrm{H}$ NMR $\left(500 \mathrm{MHz}, \mathrm{DMSO}-d_{6}\right) \delta 13.54(\mathrm{~s}, 1 \mathrm{H}), 10.42(\mathrm{~s}, 1 \mathrm{H}), 8.28(\mathrm{~d}, J=8.2$ $\mathrm{Hz}, 1 \mathrm{H}), 7.86-7.79(\mathrm{~m}, 2 \mathrm{H}), 7.47-7.39(\mathrm{~m}, 2 \mathrm{H}), 7.30(\mathrm{td}, J=7.5,1.3 \mathrm{~Hz}, 1 \mathrm{H}), 7.07(\mathrm{td}, J=9.1,2.3 \mathrm{~Hz}, 1 \mathrm{H})$, $6.71(\mathrm{dt}, J=15.5,6.0 \mathrm{~Hz}, 1 \mathrm{H}), 6.13(\mathrm{dt}, J=15.5,1.6 \mathrm{~Hz}, 1 \mathrm{H}), 3.02(\mathrm{dd}, J=5.9,1.6 \mathrm{~Hz}, 2 \mathrm{H}), 2.15(\mathrm{~s}, 6 \mathrm{H}) .{ }^{13} \mathrm{C}$ NMR $\left(126 \mathrm{MHz}, \mathrm{DMSO}-d_{6}\right) \delta 163.2,161.5\left(\mathrm{~d}, J_{C-F}=242.6 \mathrm{~Hz}\right), 142.5,141.4,141.2\left(\mathrm{~d}, J_{C-F}=13.1 \mathrm{~Hz}\right), 135.9$, 129.6, 128.4, 126.2, 124.2, 123.0, 122.8, 122.7, $118.1,110.7$ (d, $\left.J_{C-F}=26.0 \mathrm{~Hz}\right), 96.0\left(\mathrm{~d}, J_{C-F}=25.5 \mathrm{~Hz}\right), 59.7$, 45.1. HRMS (ESI): Exact mass calculated for $\mathrm{C}_{19} \mathrm{H}_{20} \mathrm{FN}_{4} \mathrm{O}^{+}[\mathrm{M}+\mathrm{H}], 339.1621$. Found 339.1618. IC $\mathrm{C}_{50}:>80 \mu \mathrm{M}$

\section{Procedure B: General Synthesis of Compounds 9a-d}
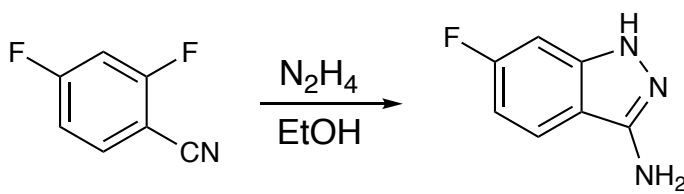

$32 \%$
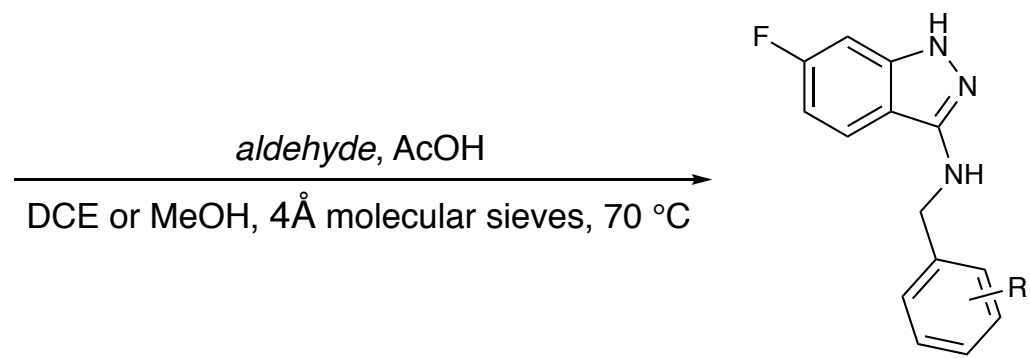

To a round bottom flask was added 2,4-fluorobenzonitrile (4.00 g, $28.8 \mathrm{mmol})$ and ethanol (140 $\mathrm{mL})$. Hydrazine monohydrate $\left(15.4 \mathrm{~mL}, 316 \mathrm{mmol}\right.$ ) was then added slowly. The reaction was heated to $75{ }^{\circ} \mathrm{C}$ (behind a blast shield) overnight. The reaction was concentrated in vacuo, taken up in water and extracted with EtOAc ( 3 x $30 \mathrm{~mL}$ ). The organic layer was washed with brine, dried over $\mathrm{Na}_{2} \mathrm{SO}_{4}$ and concentrated in vacuo to yield a 
solid crude product. The solid was purified by flash column chromatography $\left(\mathrm{SiO}_{2}, 30 \%\right.$ then $40 \%$ EtOAc/Hex stepwise) to afford 6-fluoro-1H-indazol-3-amine $(1.38 \mathrm{~g}, 32 \%)$ as an off-white solid. Spectra matches previously published data. ${ }^{2}$ Analytical data for 6-fluoro- $1 H$-indazol-3-amine: ${ }^{1} \mathrm{H}$ NMR (500 MHz, DMSO- $\left.d_{6}\right) \delta$ $11.43(\mathrm{~s}, 1 \mathrm{H}), 7.69(\mathrm{dd}, J=8.8,5.4 \mathrm{~Hz}, 1 \mathrm{H}), 6.96(\mathrm{dd}, J=10.1,2.2 \mathrm{~Hz}, 1 \mathrm{H}), 6.75(\mathrm{td}, J=9.1,2.2 \mathrm{~Hz}, 1 \mathrm{H}), 5.40$ $(\mathrm{s}, 2 \mathrm{H}) .{ }^{13} \mathrm{C}$ NMR $\left(126 \mathrm{MHz}, \mathrm{DMSO}-d_{6}\right) \delta 161.8(\mathrm{~d}, J=240.0 \mathrm{~Hz}), 149.2,141.5(\mathrm{~d}, J=13.0 \mathrm{~Hz}), 122.0(\mathrm{~d}, J=$ $11.5 \mathrm{~Hz}), 111.3,106.6(\mathrm{~d}, J=26.0 \mathrm{~Hz}), 94.7$ (d, $J=25.9 \mathrm{~Hz})$.

To a flame-dried vial was added 6-fluoro-1 $H$-indazol-3-amine (1 equiv.) and 4-fluoro-2-hydroxybenzaldehyde (1.1 equiv.) dissolved in dichloroethane (DCE) or methanol $(0.1 \mathrm{M})$ with $4 \AA$ molecular sieves. To this was added glacial acetic acid ( 3 equiv.). The reaction was heated to $70{ }^{\circ} \mathrm{C}$ and allowed to stir for an hour. Sodium triacetoxyborohydride ( 7 equiv.) was added, and the mixture was allowed to stir overnight at $50{ }^{\circ} \mathrm{C}$. Upon completion, the reaction was filtered, washed with saturated $\mathrm{NaHCO}_{3}$, the aqueous layer backextracted with EtOAc $(3 \times 10 \mathrm{~mL})$ and the organic layer concentrated in vacuo. The residue was purified by flash column chromatography to afford product.

\section{Tabulated Data of Compounds 9a-d}

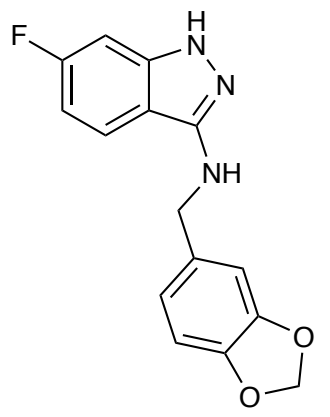

N-(benzo[d][1,3]dioxol-5-ylmethyl)-6-fluoro-1H-indazol-3-amine (9a). General Procedure B was used with the corresponding aldehyde to afford 9a (33 mg, 35\%) as a white solid. Analytical data: ${ }^{1} \mathrm{H} \mathrm{NMR}(500 \mathrm{MHz}$, DMSO-d $)_{6} \delta 11.47(\mathrm{~s}, 1 \mathrm{H}), 7.76(\mathrm{dd}, J=8.8,5.4 \mathrm{~Hz}, 1 \mathrm{H}), 6.98(\mathrm{dd}, J=10.1,2.0 \mathrm{~Hz}, 2 \mathrm{H}), 6.89-6.82(\mathrm{~m}, 2 \mathrm{H})$, $6.78-6.73(\mathrm{~m}, 1 \mathrm{H}), 6.53(\mathrm{t}, J=6.1 \mathrm{~Hz}, 1 \mathrm{H}), 5.96(\mathrm{~s}, 2 \mathrm{H}), 4.35(\mathrm{~d}, J=6.1 \mathrm{~Hz}, 2 \mathrm{H}) .{ }^{13} \mathrm{C} \mathrm{NMR}(126 \mathrm{MHz}$, DMSO-d $\left.d_{6}\right) \delta 161.9\left(\mathrm{~d}, J_{C-F}=240.2 \mathrm{~Hz}\right), 149.7,147.1,145.8,141.9\left(\mathrm{~d}, J_{C-F}=12.9 \mathrm{~Hz}\right), 134.7,121.8\left(\mathrm{~d}, J_{C-F}=\right.$ $11.5 \mathrm{~Hz}), 120.6,110.9,108.1,107.8,106.5\left(\mathrm{~d}, J_{C-F}=25.9 \mathrm{~Hz}\right), 100.7,94.7\left(\mathrm{~d}, J_{C-F}=25.9 \mathrm{~Hz}\right)$, 46.4. HRMS (ESI): Exact mass calculated for $\mathrm{C}_{15} \mathrm{H}_{13} \mathrm{FN}_{3} \mathrm{O}_{2}{ }^{+}[\mathrm{M}+\mathrm{H}], 286.0992$. Found 286.0983. IC $50: 11 \mu \mathrm{M}[9.4 \pm 1.5, \mathrm{n}=$ $3 ; 12 \pm 2.6, \mathrm{n}=3]$

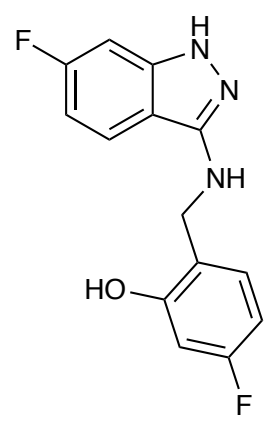

5-fluoro-2-(((6-fluoro-1H-indazol-3-yl)amino)methyl)phenol (9b). General Procedure B was used with the corresponding aldehyde to afford $9 \mathrm{~b}(22 \mathrm{mg}, 24 \%)$ as a pale yellow solid. Analytical data: ${ }^{1} \mathrm{H}$ NMR (500 MHz, DMSO- $\left.d_{6}\right) \delta 11.53(\mathrm{~s}, 1 \mathrm{H}), 10.28(\mathrm{~s}, 1 \mathrm{H}), 7.78(\mathrm{dd}, J=8.8,5.4 \mathrm{~Hz}, 1 \mathrm{H}), 7.26(\mathrm{dd}, J=8.4,7.1 \mathrm{~Hz}, 1 \mathrm{H})$, 
$6.98(\mathrm{dd}, J=10.1,2.2 \mathrm{~Hz}, 1 \mathrm{H}), 6.76(\mathrm{td}, J=9.1,2.2 \mathrm{~Hz}, 1 \mathrm{H}), 6.66-6.49(\mathrm{~m}, 3 \mathrm{H}), 4.34(\mathrm{~d}, J=5.9 \mathrm{~Hz}, 2 \mathrm{H}) .{ }^{13} \mathrm{C}$ NMR $\left(126 \mathrm{MHz}\right.$, DMSO- $\left.d_{6}\right) \delta 162.0\left(\mathrm{~d}, J_{C-F}=240.0 \mathrm{~Hz}\right), 161.6\left(\mathrm{~d}, J_{C-F}=241.8 \mathrm{~Hz}\right), 156.4,149.9,142.0\left(\mathrm{~d}, J_{C-}\right.$ $F=13.0 \mathrm{~Hz}), 130.1\left(\mathrm{~d}, J_{C-F}=10.2 \mathrm{~Hz}\right), 123.0\left(\mathrm{~d}, J_{C-F}=2.7 \mathrm{~Hz}\right), 122.0\left(\mathrm{~d}, J_{C-F}=11.5 \mathrm{~Hz}\right), 110.7,106.7\left(\mathrm{~d}, J_{C-F}\right.$ $=25.9 \mathrm{~Hz}), 105.1\left(\mathrm{~d}, J_{C-F}=20.9 \mathrm{~Hz}\right), 102.4\left(\mathrm{~d}, J_{C-F}=23.4 \mathrm{~Hz}\right), 94.8\left(\mathrm{~d}, J_{C-F}=26.0 \mathrm{~Hz}\right), 41.2$. HRMS (ESI): Exact mass calculated for $\mathrm{C}_{14} \mathrm{H}_{12} \mathrm{~F}_{2} \mathrm{~N}_{3} \mathrm{O}^{+}[\mathrm{M}+\mathrm{H}], 276.0948$. Found 276.0948. $\mathrm{IC}_{50}: 11 \mu \mathrm{M}[10 \pm 2.7, \mathrm{n}=3 ; 11$ $\pm 2.8, \mathrm{n}=3]$

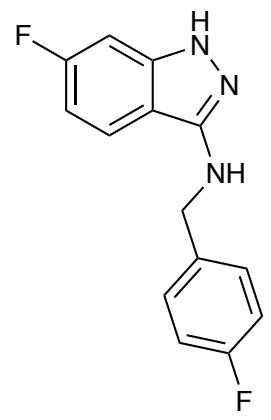

5-fluoro- $\boldsymbol{N}$-(3-fluorobenzyl)-1 $\boldsymbol{H}$-indazol-3-amine (9c). General Procedure B was used with the corresponding aldehyde to afford 9c $(30 \mathrm{mg}, 35 \%)$ as a brown solid. Analytical data: ${ }^{1} \mathrm{H}$ NMR (500 MHz, Methanol- $\left.d_{4}\right) \delta$ $7.68(\mathrm{dd}, \mathrm{J}=8.8,5.2 \mathrm{~Hz}, 1 \mathrm{H}), 7.45-7.36(\mathrm{~m}, 2 \mathrm{H}), 7.05-6.98(\mathrm{~m}, 2 \mathrm{H}), 6.92(\mathrm{dd}, \mathrm{J}=9.8,2.2 \mathrm{~Hz}, 1 \mathrm{H}), 6.73(\mathrm{td}$, $\mathrm{J}=9.1,2.2 \mathrm{~Hz}, 1 \mathrm{H}), 4.49(\mathrm{~s}, 2 \mathrm{H}) .{ }^{13} \mathrm{C} \mathrm{NMR}\left(126 \mathrm{MHz}\right.$, Methanol- $\left.d_{4}\right) \delta 164.6\left(\mathrm{~d}, \mathrm{~J}_{\mathrm{C}-\mathrm{F}}=246.8 \mathrm{~Hz}\right), 163.4\left(\mathrm{~d}, \mathrm{~J}_{\mathrm{C}-\mathrm{F}}\right.$ $=243.2 \mathrm{~Hz}), 151.8,144.1\left(\mathrm{~d}, \mathrm{~J}_{\mathrm{C}-\mathrm{F}}=13.0 \mathrm{~Hz}\right), 137.4\left(\mathrm{~d}, \mathrm{~J}_{\mathrm{C}-\mathrm{F}}=3.1 \mathrm{~Hz}\right), 130.5\left(\mathrm{~d}, \mathrm{~J}_{\mathrm{C}-\mathrm{F}}=8.0 \mathrm{~Hz}\right), 122.7\left(\mathrm{~d}, \mathrm{~J}_{\mathrm{C}-\mathrm{F}}=\right.$ $11.4 \mathrm{~Hz}), 115.9\left(\mathrm{~d}, \mathrm{~J}_{\mathrm{C}-\mathrm{F}}=21.5 \mathrm{~Hz}\right), 112.1,108.6\left(\mathrm{~d}, \mathrm{~J}_{\mathrm{C}-\mathrm{F}}=26.3 \mathrm{~Hz}\right), 95.9$ (d, J $\left.\mathrm{J}_{\mathrm{C}-\mathrm{F}}=26.5 \mathrm{~Hz}\right), 47.7$. HRMS (ESI): Exact mass calculated for $\mathrm{C}_{14} \mathrm{H}_{12} \mathrm{~F}_{2} \mathrm{~N}_{3}{ }^{+}[\mathrm{M}+\mathrm{H}], 260.0999$. found 260.1003. $\mathrm{IC}_{50}: 4.7 \mu \mathrm{M}[3.7 \pm 0.58, \mathrm{n}=3 ; 5.6 \pm$ $2.3, \mathrm{n}=3]$

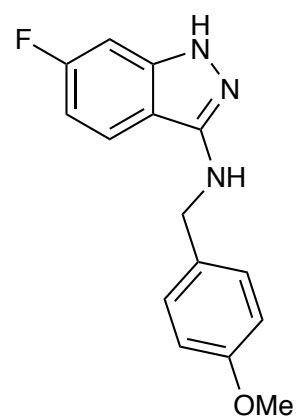

5-fluoro- $N$-(3-methoxybenzyl)-1H-indazol-3-amine (9d). General Procedure $\mathrm{B}$ was used with the corresponding aldehyde to afford 9d (61 mg, 41\%) as a pale yellow solid. Analytical data: ${ }^{1} \mathrm{H}$ NMR $(500 \mathrm{MHz}$, Methanol- $\left.d_{4}\right) \delta 7.67(\mathrm{dd}, J=8.8,5.2 \mathrm{~Hz}, 1 \mathrm{H}), 7.40-7.26(\mathrm{~m}, 2 \mathrm{H}), 6.92(\mathrm{dd}, J=9.8,2.2 \mathrm{~Hz}, 1 \mathrm{H}), 6.88-6.82$ $(\mathrm{m}, 2 \mathrm{H}), 6.72(\mathrm{td}, J=9.1,2.2 \mathrm{~Hz}, 1 \mathrm{H}), 4.44(\mathrm{~s}, 2 \mathrm{H}), 3.75(\mathrm{~s}, 3 \mathrm{H}) .{ }^{13} \mathrm{C}$ NMR $\left(126 \mathrm{MHz}, \mathrm{Methanol}-d_{4}\right) \delta 163.2(\mathrm{~d}$, $\left.\mathrm{J}_{\mathrm{C}-\mathrm{F}}=242.6 \mathrm{~Hz}\right), 162.2,158.9,150.6,142.7\left(\mathrm{~d}, \mathrm{~J}_{\mathrm{C}-\mathrm{F}}=13.0 \mathrm{~Hz}\right), 131.9,128.6,121.4\left(\mathrm{~d}, \mathrm{~J}_{\mathrm{C}-\mathrm{F}}=11.4 \mathrm{~Hz}\right), 113.4$, 110.8, 107.2 (d, $\left.\mathrm{J}_{\mathrm{C}-\mathrm{F}}=26.3 \mathrm{~Hz}\right), 94.45\left(\mathrm{~d}, \mathrm{~J}_{\mathrm{C}-\mathrm{F}}=26.5 \mathrm{~Hz}\right), 54.3,46.7$. HRMS (ESI): Exact mass calculated for $\mathrm{C}_{15} \mathrm{H}_{15} \mathrm{FN}_{3} \mathrm{O}^{+}[\mathrm{M}+\mathrm{H}], 272.1199$. Found 272.1198. $\mathrm{IC}_{50}: 8.7 \mu \mathrm{M}[7.4 \pm 1.2, \mathrm{n}=3 ; 9.9 \pm 2.8, \mathrm{n}=3]$ 


\section{Procedure C: General Synthesis of Compounds 10a-e}

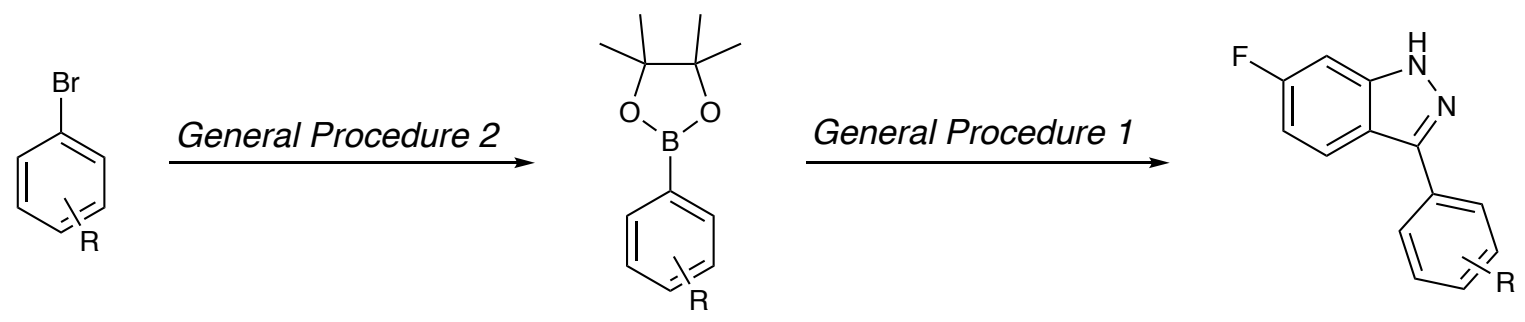

Compounds 10a-f were made through synthesis through a sequence with General Procedure 2 followed by General Procedure 1, unless otherwise noted. Some compounds can be washed with dichloromethane to remove further impurity.

\section{Tabulated Data of Compounds 10a-e}

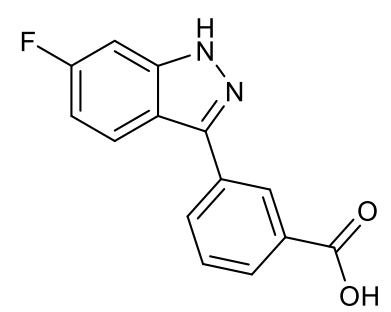

3-(6-fluoro-1H-indazol-3-yl)benzoic acid (10a). General Procedure 1 was used with S6 (1.00 g, 1 equiv.) and 3-methoxycarbonylphenylboronic acid (596 mg, 1.2 equiv.) to afford the precursor to 10a, which was dissolved in a 1:1 mixture of THF:Methanol $(0.2 \mathrm{M}$ each) and 8 equiv of $\mathrm{NaOH}(1.0 \mathrm{M})$ and stirred for 16 hours. After acidify, filtering, and washing with water, 10a was obtained in $53 \%$ yield $(377 \mathrm{mg})$ over 2 steps as an ashy white solid. Analytical data: ${ }^{1} \mathrm{H}$ NMR $\left(500 \mathrm{MHz}\right.$, DMSO- $\left.d_{6}\right) \delta 13.42(\mathrm{~s}, 1 \mathrm{H}), 13.14(\mathrm{~s}, 1 \mathrm{H}), 8.53(\mathrm{t}, J=1.8 \mathrm{~Hz}$, $1 \mathrm{H}), 8.23(\mathrm{dt}, J=7.9,1.5 \mathrm{~Hz}, 1 \mathrm{H}), 8.08(\mathrm{dd}, J=8.9,5.1 \mathrm{~Hz}, 1 \mathrm{H}), 7.98(\mathrm{dt}, J=7.7,1.5 \mathrm{~Hz}, 1 \mathrm{H}), 7.66(\mathrm{t}, J=7.7$ $\mathrm{Hz}, 1 \mathrm{H}), 7.40(\mathrm{dd}, J=9.4,2.3 \mathrm{~Hz}, 1 \mathrm{H}), 7.13(\mathrm{td}, J=9.1,2.3 \mathrm{~Hz}, 1 \mathrm{H}) .{ }^{13} \mathrm{C}$ NMR $\left(126 \mathrm{MHz}\right.$, DMSO- $\left.d_{6}\right) \delta 167.2$, $161.3\left(\mathrm{~d}, J_{\mathrm{C}-\mathrm{F}}=242.2 \mathrm{~Hz}\right), 142.6,141.9\left(\mathrm{~d}, J_{\mathrm{C}-\mathrm{F}}=12.9 \mathrm{~Hz}\right), 133.5,131.5,130.9,129.4,128.6,127.3,122.3(\mathrm{~d}$, $\left.J_{\mathrm{C}-\mathrm{F}}=11.1 \mathrm{~Hz}\right), 117.15,111.0\left(\mathrm{~d}, J_{\mathrm{C}-\mathrm{F}}=26.1 \mathrm{~Hz}\right), 96.2\left(\mathrm{~d}, J_{\mathrm{C}-\mathrm{F}}=25.8 \mathrm{~Hz}\right)$. HRMS (ESI): Exact mass calculated for $\mathrm{C}_{14} \mathrm{H}_{10} \mathrm{FN}_{2} \mathrm{O}_{2}{ }^{+}[\mathrm{M}+\mathrm{H}], 257.0726$, found 257.0726. $\mathrm{IC}_{50}: 0.096 \mu \mathrm{M},[0.082 \pm 0.026, \mathrm{n}=3 ; 0.11 \pm 0.010, \mathrm{n}$ $=3]$

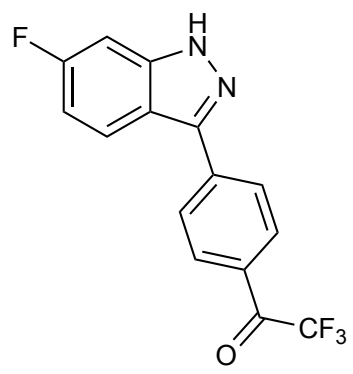

2,2,2-trifluoro-1-(4-(6-fluoro-1 $H$-indazol-3-yl)phenyl)ethan-1-one (10b). General Procedure $\mathrm{C}$ was used to afford 10b $(67 \mathrm{mg}, 39 \%)$ as a yellow solid. Analytical data: ${ }^{1} \mathrm{H}$ NMR $\left(500 \mathrm{MHz}\right.$, Methanol- $\left.d_{4}\right) \delta 8.07$ (dd, $J=$ 9.0, $5.0 \mathrm{~Hz}, 1 \mathrm{H}), 8.04-7.99(\mathrm{~m}, 2 \mathrm{H}), 7.79$ (d, $J=8.2 \mathrm{~Hz}, 2 \mathrm{H}), 7.27$ (dd, $J=9.2,2.2 \mathrm{~Hz}, 1 \mathrm{H}), 7.07$ (td, $J=9.1$, $2.2 \mathrm{~Hz}, 1 \mathrm{H}) .{ }^{13} \mathrm{C}$ NMR $\left(126 \mathrm{MHz}\right.$, Methanol- $\left.d_{4}\right) \delta 163.8\left(\mathrm{~d}, J_{\mathrm{C}-\mathrm{F}}=243.9 \mathrm{~Hz}\right), 145.7,143.6\left(\mathrm{~d}, J_{\mathrm{C}-\mathrm{F}}=12.6 \mathrm{~Hz}\right)$, 
$136.0,135.6,129.9,128.1,124.5\left(\mathrm{q}, J_{\mathrm{C}-\mathrm{F}}=287.0 \mathrm{~Hz}\right), 123.8\left(\mathrm{~d}, J_{\mathrm{C}-\mathrm{F}}=11.0 \mathrm{~Hz}\right), 118.9,112.2\left(\mathrm{~d}, J_{\mathrm{C}-\mathrm{F}}=26.4\right.$ $\mathrm{Hz}), 97.9\left(\mathrm{q}, J_{\mathrm{C}-\mathrm{F}}=31.1 \mathrm{~Hz}\right), 96.7\left(\mathrm{~d}, J_{\mathrm{C}-\mathrm{F}}=26.5 \mathrm{~Hz}\right)$. HRMS (ESI): Exact mass calculated for $\mathrm{C}_{15} \mathrm{H}_{9} \mathrm{~F}_{4} \mathrm{~N}_{2} \mathrm{O}^{+}$ $[\mathrm{M}+\mathrm{H}], 309.0651$. Found 309.0645. $\mathrm{IC}_{50}: 0.60 \mu \mathrm{M}[0.32 \pm 0.12, \mathrm{n}=3 ; 0.88 \pm 0.071, \mathrm{n}=3]$

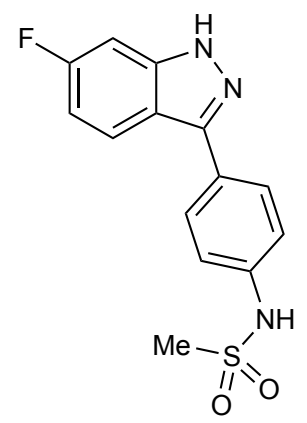

$N$-(4-(6-fluoro-1H-indazol-3-yl)phenyl)methanesulfonamide (10c). General Procedure 3 was used on the corresponding boronic acid with $\mathrm{MsCl}$, followed by General Procedure 1 with $\mathbf{S 6}$ to afford 10c (394 $\mathrm{mg}, 94 \%$ ) as an off-white solid. Analytical data: ${ }^{1} \mathrm{H}$ NMR $\left(500 \mathrm{MHz}\right.$, DMSO- $\left.d_{6}\right) \delta 13.24(\mathrm{~s}, 1 \mathrm{H}), 9.90(\mathrm{~s}, 1 \mathrm{H}), 8.08(\mathrm{dd}, J$ $=8.9,5.1 \mathrm{~Hz}, 1 \mathrm{H}), 7.96-7.92(\mathrm{~m}, 2 \mathrm{H}), 7.35(\mathrm{dd}, J=9.1,2.6 \mathrm{~Hz}, 3 \mathrm{H}), 7.07(\mathrm{td}, J=9.1,2.3 \mathrm{~Hz}, 1 \mathrm{H}), 3.05(\mathrm{~s}$, $3 \mathrm{H}) .{ }^{13} \mathrm{C}$ NMR $\left(126 \mathrm{MHz}\right.$, DMSO- $\left.d_{6}\right) \delta 161.2(\mathrm{~d}, J=241.9 \mathrm{~Hz}), 143.1,141.8(\mathrm{~d}, J=12.9 \mathrm{~Hz}), 138.2,128.7$, 127.7, 122.6 (d, $J=11.0 \mathrm{~Hz}), 119.8,117.2,110.5(\mathrm{~d}, J=25.9 \mathrm{~Hz}), 95.9$ (d, $J=25.6 \mathrm{~Hz})$. HRMS (ESI): Exact mass calculated for $\mathrm{C}_{14} \mathrm{H}_{13} \mathrm{FN}_{3} \mathrm{O}_{2} \mathrm{~S}^{+}[\mathrm{M}+\mathrm{H}], 306.0712$. Found 306.0705. $\mathrm{IC}_{50}$ : $0.48 \mu \mathrm{M}[0.33 \pm 0.26, \mathrm{n}=3 ; 0.62$ $\pm 0.25, \mathrm{n}=3]$

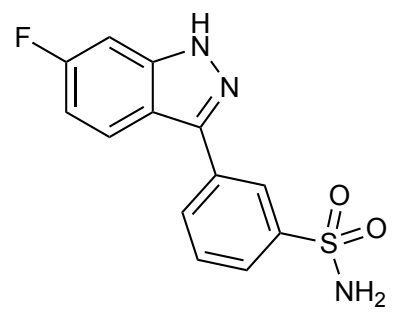

3-(6-fluoro-1H-indazol-3-yl)benzenesulfonamide (10d). General Procedure $\mathrm{C}$ was used to afford 10d (108 $\mathrm{mg}, 54 \%$ ) as an off-white solid. Analytical data: ${ }^{1} \mathrm{H}$ NMR (500 MHz, DMSO- $\left.d_{6}\right) \delta 13.50$ (bs, $\left.1 \mathrm{H}\right), 8.42$ (t, $J=$ $1.8 \mathrm{~Hz}, 1 \mathrm{H}), 8.21(\mathrm{dt}, J=7.7,1.3 \mathrm{~Hz}, 1 \mathrm{H}), 8.14(\mathrm{dd}, J=9.0,5.1 \mathrm{~Hz}, 1 \mathrm{H}), 7.85$ (ddd, $J=7.8,1.9,1.1 \mathrm{~Hz}, 1 \mathrm{H})$, $7.72(\mathrm{t}, J=7.8 \mathrm{~Hz}, 1 \mathrm{H}), 7.48(\mathrm{~s}, 2 \mathrm{H}), 7.42(\mathrm{dd}, J=9.4,2.2 \mathrm{~Hz}, 1 \mathrm{H}), 7.16(\mathrm{td}, J=9.2,2.3 \mathrm{~Hz}, 1 \mathrm{H}) .{ }^{13} \mathrm{C}$ NMR $\left(126 \mathrm{MHz}, \mathrm{DMSO}-d_{6}\right) \delta 161.3\left(\mathrm{~d}, \mathrm{~J}_{\mathrm{C}-\mathrm{F}}=242.4 \mathrm{~Hz}\right), 144.8,142.2,141.9\left(\mathrm{~d}, \mathrm{~J}_{\mathrm{C}-\mathrm{F}}=12.8 \mathrm{~Hz}\right), 133.9,129.7,124.8$, 123.6, $122.4\left(\mathrm{~d}, \mathrm{~J}_{\mathrm{C}-\mathrm{F}}=11.1 \mathrm{~Hz}\right), 117.1,111.1\left(\mathrm{~d}, \mathrm{~J}_{\mathrm{C}-\mathrm{F}}=26.1 \mathrm{~Hz}\right), 96.2\left(\mathrm{~d}, \mathrm{~J}_{\mathrm{C}-\mathrm{F}}=25.7 \mathrm{~Hz}\right)$. HRMS (ESI): Exact mass calculated for $\mathrm{C}_{13} \mathrm{H}_{9} \mathrm{FN}_{3} \mathrm{O}_{2} \mathrm{SNa}^{+}[\mathrm{M}+\mathrm{Na}], 314.0376$. Found 314.0374. $\mathrm{IC}_{50}: 3.1 \mu \mathrm{M}[2.5 \pm 0.99, \mathrm{n}=3 ; 3.6$ $\pm 0.34, \mathrm{n}=3]$

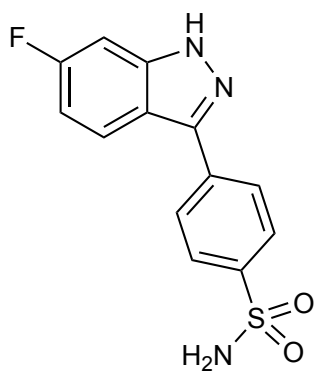

4-(6-fluoro-1H-indazol-3-yl)benzenesulfonamide (10e). General Procedure $\mathrm{C}$ listed above was used to afford $10 f(72 \mathrm{mg}, 45 \%)$ as an off-white solid. Analytical data: ${ }^{1} \mathrm{H}$ NMR (500 MHz, DMSO- $\left.d_{6}\right) \delta 13.51(\mathrm{~s}, 1 \mathrm{H}), 8.25$ 
- $8.10(\mathrm{~m}, 3 \mathrm{H}), 7.98-7.93(\mathrm{~m}, 2 \mathrm{H}), 7.42(\mathrm{~d}, \mathrm{~J}=9.2 \mathrm{~Hz}, 3 \mathrm{H}), 7.14(\mathrm{td}, \mathrm{J}=9.1,2.3 \mathrm{~Hz}, 1 \mathrm{H}) .{ }^{13} \mathrm{C} \mathrm{NMR}(126$ $\left.\mathrm{MHz}, \mathrm{DMSO}-d_{6}\right) \delta 161.3\left(\mathrm{~d}, \mathrm{~J}_{\mathrm{C}-\mathrm{F}}=242.5 \mathrm{~Hz}\right), 143.1,142.2,141.9\left(\mathrm{~d}, \mathrm{~J}_{\mathrm{C}-\mathrm{F}}=12.9 \mathrm{~Hz}\right), 136.4,127.0,126.4$, 122.6, 122.5, 117.3, $111.1\left(\mathrm{~d}, \mathrm{~J}_{\mathrm{C}-\mathrm{F}}=26.1 \mathrm{~Hz}\right), 96.2(\mathrm{~d}, \mathrm{~J}=25.9 \mathrm{~Hz})$. HRMS (ESI): Exact mass calculated for $\mathrm{C}_{13} \mathrm{H}_{11} \mathrm{FN}_{3} \mathrm{O}_{2} \mathrm{~S}^{+}[\mathrm{M}+\mathrm{H}], 292.0556$. Found 292.0555. $\mathrm{IC}_{50}: 0.061 \mu \mathrm{M}[0.057 \pm 0.011, \mathrm{n}=3 ; 0.065 \pm 0.011, \mathrm{n}=$ 3]

MEK7 IC $50: 0.54 \mu \mathrm{M}[0.52 \pm 0.67, \mathrm{n}=3 ; 0.56 \pm 0.22, \mathrm{n}=3]$

\section{Procedure D: General Synthesis of Compounds 11-12}
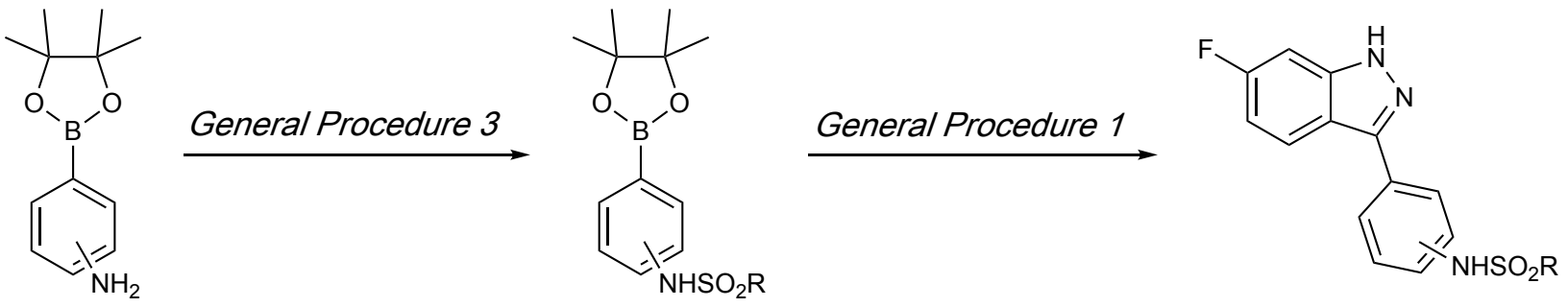

Compounds 11-12 were made through synthesis through the corresponding sulfonyl chloride and borylated aniline with General Procedure 3, followed by General Procedure 1, unless otherwise noted. Some compounds can be washed with dichloromethane to remove further impurity.

\section{Tabulated Data of Compounds 11a-d}

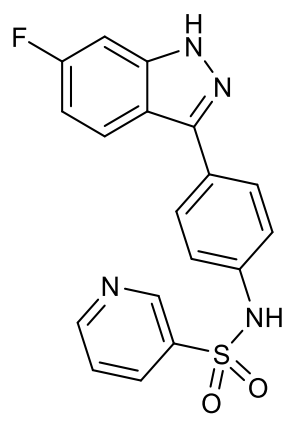

$\mathrm{N}$-(4-(6-fluoro-1H-indazol-3-yl)phenyl)pyridine-3-sulfonamide (11a). General Procedure D was used to afford 11a (128 mg, 55\%) as a white solid. Analytical data: ${ }^{1} \mathrm{H}$ NMR (500 MHz, DMSO-d $) \delta 13.24(\mathrm{~s}, 1 \mathrm{H})$, $10.66(\mathrm{~s}, 1 \mathrm{H}), 8.93(\mathrm{dd}, J=2.3,0.8 \mathrm{~Hz}, 1 \mathrm{H}), 8.79(\mathrm{dd}, J=4.8,1.6 \mathrm{~Hz}, 1 \mathrm{H}), 8.16(\mathrm{ddd}, J=8.1,2.4,1.6 \mathrm{~Hz}, 1 \mathrm{H})$, $8.03(\mathrm{dd}, J=9.0,5.1 \mathrm{~Hz}, 1 \mathrm{H}), 7.88(\mathrm{~d}, J=8.6 \mathrm{~Hz}, 2 \mathrm{H}), 7.62(\mathrm{ddd}, J=8.1,4.8,0.9 \mathrm{~Hz}, 1 \mathrm{H}), 7.33(\mathrm{dd}, J=9.5$, $2.3 \mathrm{~Hz}, 1 \mathrm{H}), 7.26(\mathrm{~d}, J=8.7 \mathrm{~Hz}, 2 \mathrm{H}), 7.04(\mathrm{td}, J=9.2,2.3 \mathrm{~Hz}, 1 \mathrm{H}) .{ }^{13} \mathrm{C}$ NMR $\left(126 \mathrm{MHz}, \mathrm{DMSO}-d_{6}\right) \delta 161.2$ $\left(\mathrm{d}, J_{\mathrm{C}-\mathrm{F}}=242.0 \mathrm{~Hz}\right), 153.6,147.1,142.8,141.8\left(\mathrm{~d}, J_{\mathrm{C}-\mathrm{F}}=12.7 \mathrm{~Hz}\right), 136.8,135.9,134.7,129.6,127.7,124.4$, $122.6\left(\mathrm{~d}, J_{\mathrm{C}-\mathrm{F}}=11.1 \mathrm{~Hz}\right), 120.8,117.1,110.5\left(\mathrm{~d}, J_{\mathrm{C}-\mathrm{F}}=25.9 \mathrm{~Hz}\right), 95.9\left(\mathrm{~d}, J_{\mathrm{C}-\mathrm{F}}=25.7 \mathrm{~Hz}\right)$. HRMS (ESI): Exact mass calculated for $\mathrm{C}_{18} \mathrm{H}_{14} \mathrm{FN}_{4} \mathrm{O}_{2} \mathrm{~S}^{+}[\mathrm{M}+\mathrm{H}], 369.0821$. Found 369.0825. $\mathrm{IC}_{50}: 0.75 \mu \mathrm{M}[0.49 \pm 0.39, \mathrm{n}=3 ; 1.0$ $\pm 0.23, \mathrm{n}=3]$

MEK7 IC $50: 2.7 \mu \mathrm{M}[1.9 \pm 0.41, \mathrm{n}=3 ; 3.5 \pm 1.5, \mathrm{n}=3 \mu \mathrm{M}]$ 


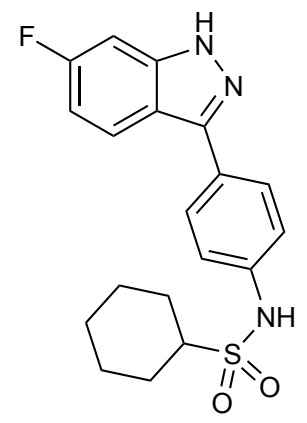

$\mathrm{N}$-(4-(6-fluoro-1H-indazol-3-yl)phenyl)cyclohexanesulfonamide (11b). General Procedure D was used to afford $11 \mathrm{~b}(172 \mathrm{mg}, 79 \%)$ as an off-white solid. Analytical data: ${ }^{1} \mathrm{H}$ NMR (500 MHz, DMSO- $\left.d_{6}\right) \delta 13.24$ (s, 1H), 9.94 (s, 1H), 8.08 (dd, $J=9.0,5.1 \mathrm{~Hz}, 1 \mathrm{H}), 7.96-7.86(\mathrm{~m}, 2 \mathrm{H}), 7.41-7.31(\mathrm{~m}, 3 \mathrm{H}), 7.06$ (td, $J=9.2,2.3$ $\mathrm{Hz}, 1 \mathrm{H}), 3.04(\mathrm{tt}, J=11.9,3.4 \mathrm{~Hz}, 1 \mathrm{H}), 2.11-2.00(\mathrm{~m}, 2 \mathrm{H}), 1.76(\mathrm{dt}, J=12.9,3.3 \mathrm{~Hz}, 2 \mathrm{H}), 1.58(\mathrm{~d}, J=12.4$ $\mathrm{Hz}, 1 \mathrm{H}), 1.44(\mathrm{qd}, J=12.5,3.6 \mathrm{~Hz}, 2 \mathrm{H}), 1.28-1.16(\mathrm{~m}, 2 \mathrm{H}), 1.11(\mathrm{qt}, J=14.4,3.8 \mathrm{~Hz}, 1 \mathrm{H}) .{ }^{13} \mathrm{C}$ NMR $(126$ MHz, DMSO- $\left.d_{6}\right) \delta 161.3\left(\mathrm{~d}, J_{\mathrm{C}-\mathrm{F}}=242.1 \mathrm{~Hz}\right), 143.1,141.8\left(\mathrm{~d}, J_{\mathrm{C}-\mathrm{F}}=12.4 \mathrm{~Hz}\right), 138.5,128.38,127.7,122.7(\mathrm{~d}$, $\left.J_{\mathrm{C}-\mathrm{F}}=11.0 \mathrm{~Hz}\right), 119.3,117.2,110.5\left(\mathrm{~d}, J_{\mathrm{C}-\mathrm{F}}=25.8 \mathrm{~Hz}\right), 95.9\left(\mathrm{~d}, J_{\mathrm{C}-\mathrm{F}}=25.8 \mathrm{~Hz}\right), 59.0,26.0,24.8,24.4$. HRMS (ESI): Mass calculated for $\mathrm{C}_{19} \mathrm{H}_{20} \mathrm{FN}_{3} \mathrm{O}_{2} \mathrm{SNa}^{+}$[M+Na], 396.1158. Found 396.1158. $\mathrm{IC}_{50}: 1.9 \mu \mathrm{M}[1.8 \pm 2.1, \mathrm{n}=$ $3 ; 1.9 \pm 0.61, \mathrm{n}=3]$

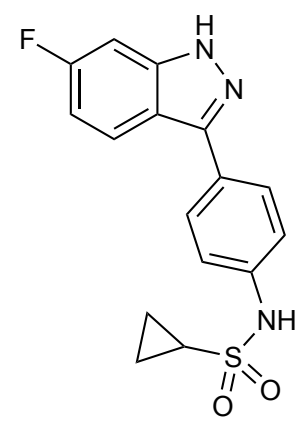

N-(4-(6-fluoro-1H-indazol-3-yl)phenyl)cyclopropanesulfonamide (11c). General Procedure D was used to afford $11 \mathrm{c}(157 \mathrm{mg}, 79 \%)$ as a pale yellow solid. Analytical data: ${ }^{1} \mathrm{H}$ NMR $\left(500 \mathrm{MHz}\right.$, DMSO- $\left.d_{6}\right) \delta 13.23$ (s, $1 \mathrm{H}), 9.88(\mathrm{~s}, 1 \mathrm{H}), 8.08(\mathrm{dd}, J=9.0,5.1 \mathrm{~Hz}, 1 \mathrm{H}), 7.96-7.91(\mathrm{~m}, 2 \mathrm{H}), 7.40-7.37(\mathrm{~m}, 2 \mathrm{H}), 7.35(\mathrm{dd}, J=9.5,2.2$ $\mathrm{Hz}, 1 \mathrm{H}), 7.07$ (td, $J=9.2,2.3 \mathrm{~Hz}, 1 \mathrm{H}), 2.68$ (tt, $J=7.4,5.2 \mathrm{~Hz}, 1 \mathrm{H}), 0.97$ (tq, $J=8.1,2.7 \mathrm{~Hz}, 4 \mathrm{H}) .{ }^{13} \mathrm{C}$ NMR $\left(126 \mathrm{MHz}, \mathrm{DMSO}-d_{6}\right) \delta 161.2\left(\mathrm{~d}, J_{\mathrm{C}-\mathrm{F}}=241.8 \mathrm{~Hz}\right), 143.1,141.8\left(\mathrm{~d}, J_{\mathrm{C}-\mathrm{F}}=12.4 \mathrm{~Hz}\right), 138.2,128.8,127.6,120.3$, $117.2,110.4\left(\mathrm{~d}, J_{\mathrm{C}-\mathrm{F}}=26.0 \mathrm{~Hz}\right), 95.9\left(\mathrm{~d}, J_{\mathrm{C}-\mathrm{F}}=25.7 \mathrm{~Hz}\right), 29.6,5.0$. HRMS (ESI): $\mathrm{C}_{16} \mathrm{H}_{15} \mathrm{FN}_{3} \mathrm{O}_{2} \mathrm{~S}^{+}[\mathrm{M}+\mathrm{H}]$, 322.0869. Found 322.0864. $\mathrm{IC}_{50}: 4.4 \mu \mathrm{M}[4.3 \pm 2.2, \mathrm{n}=3 ; 4.5 \pm 0.99, \mathrm{n}=3]$

\section{Tabulated Data of Compounds 12a-c}

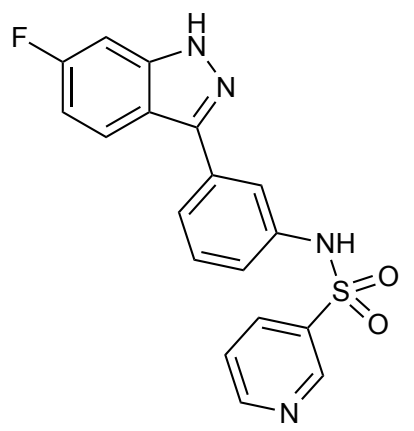


$\boldsymbol{N}$-(3-(6-fluoro-1H-indazol-3-yl)phenyl)pyridine-3-sulfonamide (12a). General Procedure D was used to afford 12a (92 mg, 45\%) as an off-white solid. Analytical data: ${ }^{1} \mathrm{H}$ NMR $\left(500 \mathrm{MHz}\right.$, DMSO- $\left.d_{6}\right) \delta 13.33(\mathrm{~s}$, $1 \mathrm{H}), 10.65(\mathrm{~s}, 1 \mathrm{H}), 8.93(\mathrm{dd}, J=2.4,0.8 \mathrm{~Hz}, 1 \mathrm{H}), 8.78(\mathrm{dd}, J=4.8,1.6 \mathrm{~Hz}, 1 \mathrm{H}), 8.16(\mathrm{ddd}, J=8.1,2.4,1.6 \mathrm{~Hz}$, $1 \mathrm{H}), 7.91(\mathrm{dd}, J=9.0,5.1 \mathrm{~Hz}, 1 \mathrm{H}), 7.73(\mathrm{t}, J=2.0 \mathrm{~Hz}, 1 \mathrm{H}), 7.68(\mathrm{dt}, J=7.8,1.3 \mathrm{~Hz}, 1 \mathrm{H}), 7.61$ (ddd, $J=8.1$, 4.8, $0.8 \mathrm{~Hz}, 1 \mathrm{H}), 7.41$ (t, $J=7.9 \mathrm{~Hz}, 1 \mathrm{H}), 7.37$ (dd, $J=9.5,2.3 \mathrm{~Hz}, 1 \mathrm{H}), 7.18$ (ddd, $J=8.1,2.3,1.0 \mathrm{~Hz}, 1 \mathrm{H})$, $7.11(\mathrm{td}, J=9.2,2.3 \mathrm{~Hz}, 1 \mathrm{H}) .{ }^{13} \mathrm{C}$ NMR $\left(126 \mathrm{MHz}, \mathrm{DMSO}-d_{6}\right) \delta 161.2\left(\mathrm{~d}, J_{\mathrm{C}-\mathrm{F}}=242.3 \mathrm{~Hz}\right), 153.6,147.1$, $142.6,141.8\left(\mathrm{~d}, J_{\mathrm{C}-\mathrm{F}}=12.9 \mathrm{~Hz}\right), 137.6,135.7,134.7,134.2,130.0,124.5,122.9,122.1\left(\mathrm{~d}, J_{\mathrm{C}-\mathrm{F}}=11.1 \mathrm{~Hz}\right)$, 119.3, 118.7, 117.1, $110.8\left(\mathrm{~d}, J_{\mathrm{C}-\mathrm{F}}=26.1 \mathrm{~Hz}\right), 96.1\left(\mathrm{~d}, J_{\mathrm{C}-\mathrm{F}}=25.8 \mathrm{~Hz}\right)$. HRMS (ESI): Exact mass calculated for $\mathrm{C}_{18} \mathrm{H}_{14} \mathrm{FN}_{4} \mathrm{O}_{2} \mathrm{~S}^{+}[\mathrm{M}+\mathrm{H}], 369.0821$. Found 369.0822. $\mathrm{IC}_{50}: 1.3 \mu \mathrm{M}[1.2 \pm 0.23, \mathrm{n}=3 ; 1.3 \pm 0.39, \mathrm{n}=3]$

MEK7 IC $50: 1.3 \mu \mathrm{M}[0.94 \pm 0.26, \mathrm{n}=3 ; 1.6 \pm 0.61, \mathrm{n}=3]$

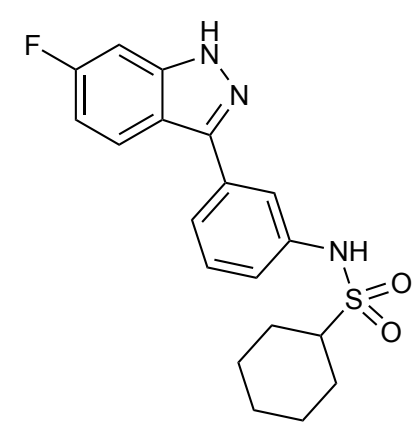

$\boldsymbol{N}$-(3-(6-fluoro-1H-indazol-3-yl)phenyl)cyclohexanesulfonamide (12b). General Procedure D was used to afford $12 b(211 \mathrm{mg}, 91 \%)$ as a yellow solid. Analytical data: ${ }^{1} \mathrm{H}$ NMR (500 MHz, DMSO- $\left.d_{6}\right) \delta 13.33(\mathrm{~s}, 1 \mathrm{H})$, $9.90(\mathrm{~s}, 1 \mathrm{H}), 8.04(\mathrm{dd}, \mathrm{J}=9.0,5.1 \mathrm{~Hz}, 1 \mathrm{H}), 7.89(\mathrm{t}, \mathrm{J}=2.0 \mathrm{~Hz}, 1 \mathrm{H}), 7.67(\mathrm{dt}, \mathrm{J}=7.8,1.2 \mathrm{~Hz}, 1 \mathrm{H}), 7.45(\mathrm{t}, \mathrm{J}=$ $7.9 \mathrm{~Hz}, 1 \mathrm{H}), 7.38(\mathrm{dd}, \mathrm{J}=9.5,2.3 \mathrm{~Hz}, 1 \mathrm{H}), 7.28(\mathrm{ddd}, \mathrm{J}=8.1,2.2,1.0 \mathrm{~Hz}, 1 \mathrm{H}), 7.12(\mathrm{td}, \mathrm{J}=9.1,2.3 \mathrm{~Hz}, 1 \mathrm{H})$, $3.03(\mathrm{tt}, \mathrm{J}=11.9,3.4 \mathrm{~Hz}, 1 \mathrm{H}), 2.11-2.00(\mathrm{~m}, 2 \mathrm{H}), 1.75(\mathrm{dt}, \mathrm{J}=13.0,3.4 \mathrm{~Hz}, 2 \mathrm{H}), 1.56(\mathrm{dt}, \mathrm{J}=12.2,3.3 \mathrm{~Hz}$, $1 \mathrm{H}), 1.44(\mathrm{qd}, \mathrm{J}=12.4,3.6 \mathrm{~Hz}, 2 \mathrm{H}), 1.20(\mathrm{qt}, \mathrm{J}=12.5,3.3 \mathrm{~Hz}, 2 \mathrm{H}), 1.11(\mathrm{tt}, \mathrm{J}=12.7,3.1 \mathrm{~Hz}, 1 \mathrm{H}) .{ }^{13} \mathrm{C} \mathrm{NMR}$ $\left(126 \mathrm{MHz}, \mathrm{DMSO}-d_{6}\right) \delta 161.3\left(\mathrm{~d}, J_{\mathrm{C}-\mathrm{F}}=242.2 \mathrm{~Hz}\right), 143.0,141.9\left(\mathrm{~d}, J_{\mathrm{C}-\mathrm{F}}=12.8 \mathrm{~Hz}\right), 139.2,134.2,130.0,122.3$ $\left(\mathrm{d}, J_{\mathrm{C}-\mathrm{F}}=11.2 \mathrm{~Hz}\right), 121.7,118.4,117.3,117.2,110.8\left(\mathrm{~d}, J_{\mathrm{C}-\mathrm{F}}=26.1 \mathrm{~Hz}\right), 96.1\left(\mathrm{~d}, J_{\mathrm{C}-\mathrm{F}}=25.8 \mathrm{~Hz}\right), 73.5,59.2$, 26.0, 25.0, 24.8, 24.3. HRMS (ESI): Exact mass calculated for $\mathrm{C}_{19} \mathrm{H}_{21} \mathrm{FN}_{3} \mathrm{O}_{2} \mathrm{~S}^{+}[\mathrm{M}+\mathrm{H}]$, 374.1338. Found 374.1329. $\mathrm{IC}_{50}: 14 \mu \mathrm{M}[13 \pm 2.7, \mathrm{n}=3 ; 15 \pm 4.4, \mathrm{n}=3]$

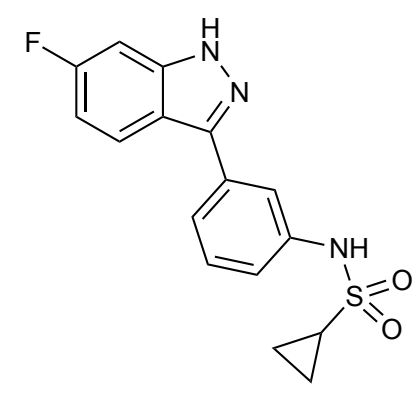

$\mathbf{N}$-(3-(6-fluoro-1H-indazol-3-yl)phenyl)cyclopropanesulfonamide (12c). General Procedure D was used to afford 12c (203 mg, 67\%) as a pale yellow solid. Analytical data: ${ }^{1} \mathrm{H}$ NMR (500 MHz, DMSO- $\left.d_{6}\right) \delta 13.33(\mathrm{~s}$, $1 \mathrm{H}), 9.86(\mathrm{~s}, 1 \mathrm{H}), 8.06(\mathrm{dd}, J=9.0,5.1 \mathrm{~Hz}, 1 \mathrm{H}), 7.90(\mathrm{t}, J=1.9 \mathrm{~Hz}, 1 \mathrm{H}), 7.71(\mathrm{dt}, J=7.8,1.3 \mathrm{~Hz}, 1 \mathrm{H}), 7.47(\mathrm{t}$, $J=7.9 \mathrm{~Hz}, 1 \mathrm{H}), 7.39(\mathrm{dd}, J=9.5,2.2 \mathrm{~Hz}, 1 \mathrm{H}), 7.30(\mathrm{ddd}, J=8.1,2.3,1.0 \mathrm{~Hz}, 1 \mathrm{H}), 7.12(\mathrm{td}, J=9.1,2.3 \mathrm{~Hz}$, $1 \mathrm{H}), 2.67(\mathrm{tt}, J=7.7,5.1 \mathrm{~Hz}, 1 \mathrm{H}), 1.03-0.88(\mathrm{~m}, 4 \mathrm{H}) .{ }^{13} \mathrm{C}$ NMR $\left(126 \mathrm{MHz}, \mathrm{DMSO}-d_{6}\right) \delta 161.7\left(\mathrm{~d}, J_{\mathrm{C}-\mathrm{F}}=\right.$ $242.1 \mathrm{~Hz}), 143.5,142.3\left(\mathrm{~d}, J_{\mathrm{C}-\mathrm{F}}=12.9 \mathrm{~Hz}\right), 139.4,134.6,130.3,122.8\left(\mathrm{~d}, J_{\mathrm{C}-\mathrm{F}}=11.1 \mathrm{~Hz}\right), 118.8,117.7,111.2$ 
$\left(\mathrm{d}, J_{\mathrm{C}-\mathrm{F}}=25.9 \mathrm{~Hz}\right), 96.6\left(\mathrm{~d}, J_{\mathrm{C}-\mathrm{F}}=25.7 \mathrm{~Hz}\right), 30.1$, 5.5. HRMS (ESI): Exact mass calculated for $\mathrm{C}_{16} \mathrm{H}_{14} \mathrm{FN}_{3} \mathrm{O}_{2} \mathrm{SNa}^{+}[\mathrm{M}+\mathrm{Na}], 354.0689$. Found 354.0685. $\mathrm{IC}_{50}: 2.5 \mu \mathrm{M}[2.1 \pm 0.51, \mathrm{n}=3 ; 2.8 \pm 0.58, \mathrm{n}=3]$

MEK7 IC $50: 6.4 \mu \mathrm{M}[5.6 \pm 2.2, \mathrm{n}=3 ; 7.1 \pm 1.6, \mathrm{n}=3]$

\section{Procedure E: General Synthesis of Compounds 13-15}
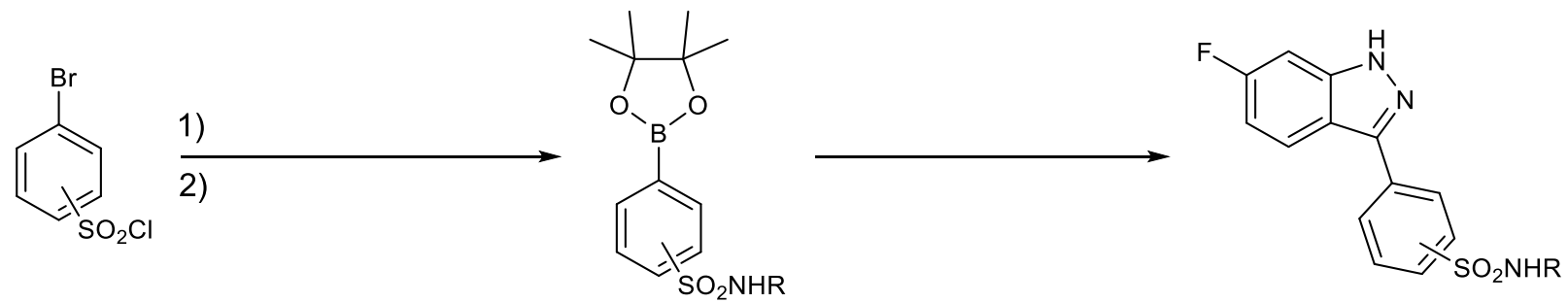

Compounds 13-15 were made through synthesis through the corresponding sulfonyl chloride and amine with General Procedure 3, followed by General Procedure 2 to produce the borylated product. The boronic ester was taken into General Procedure 1, to afford product, unless otherwise noted. Some compounds can be washed with dichloromethane to remove further impurity.

\section{Tabulated Data of Compounds 13a-c}

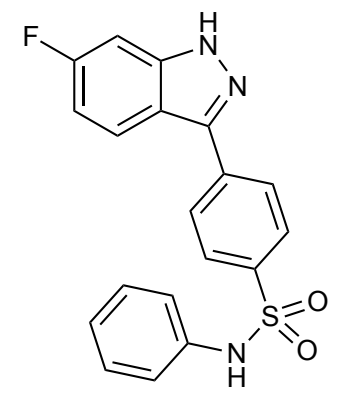

4-(6-fluoro-1 $H$-indazol-3-yl)- $N$-phenylbenzenesulfonamide (13a). General Procedure E was used to afford 13a (195 mg, 54\%) as a pale yellow solid. Analytical data: ${ }^{1} \mathrm{H}$ NMR (500 MHz, DMSO- $\left.d_{6}\right) \delta 13.54(\mathrm{~s}, 1 \mathrm{H})$, $10.35(\mathrm{~s}, 1 \mathrm{H}), 8.18-8.10(\mathrm{~m}, 3 \mathrm{H}), 7.91-7.85(\mathrm{~m}, 2 \mathrm{H}), 7.40(\mathrm{dd}, J=9.4,2.3 \mathrm{~Hz}, 1 \mathrm{H}), 7.28-7.21(\mathrm{~m}, 2 \mathrm{H})$, $7.16-7.08(\mathrm{~m}, 3 \mathrm{H}), 7.03(\mathrm{tt}, J=7.3,1.2 \mathrm{~Hz}, 1 \mathrm{H}) .{ }^{13} \mathrm{C}$ NMR $\left(126 \mathrm{MHz}, \mathrm{DMSO}-d_{6}\right) \delta 161.2\left(\mathrm{~d}, J_{\mathrm{C}-\mathrm{F}}=242.5\right.$ $\mathrm{Hz}), 142.0\left(\mathrm{~d}, J_{\mathrm{C}-\mathrm{F}}=12.7 \mathrm{~Hz}\right), 141.7,138.4,137.7,137.4,129.2,127.4,127.1,124.1,122.6\left(\mathrm{~d}, J_{\mathrm{C}-\mathrm{F}}=10.9 \mathrm{~Hz}\right)$, 120.1, 117.2, $111.2\left(\mathrm{~d}, J_{\mathrm{C}-\mathrm{F}}=26.1 \mathrm{~Hz}\right), 96.2\left(\mathrm{~d}, J_{\mathrm{C}-\mathrm{F}}=25.8 \mathrm{~Hz}\right)$. HRMS (ESI): Exact mass calculated for $\mathrm{C}_{19} \mathrm{H}_{14} \mathrm{FN}_{3} \mathrm{O}_{2} \mathrm{SNa}^{+}[\mathrm{M}+\mathrm{Na}], 390.0689$. Found 390.0688. $\mathrm{IC}_{50}: 3.5 \mu \mathrm{M}[2.4 \pm 1.0, \mathrm{n}=3 ; 4.6 \pm 4.6, \mathrm{n}=3]$

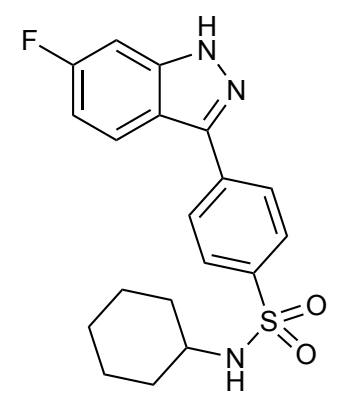

$\mathrm{N}$-cyclohexyl-4-(6-fluoro-1H-indazol-3-yl)benzenesulfonamide (13b). General Procedure E was used to afford 13b (121 mg, 81\%) as an off-white solid. Analytical data: ${ }^{1} \mathrm{H}$ NMR (500 MHz, DMSO- $\left.d_{6}\right) \delta 13.53$ (s, 
$1 \mathrm{H}), 8.23-8.11(\mathrm{~m}, 3 \mathrm{H}), 7.98-7.87(\mathrm{~m}, 2 \mathrm{H}), 7.72(\mathrm{~d}, J=7.3 \mathrm{~Hz}, 1 \mathrm{H}), 7.42(\mathrm{dd}, J=9.5,2.3 \mathrm{~Hz}, 1 \mathrm{H}), 7.14(\mathrm{t}, J$ $=9.4,8.5 \mathrm{~Hz}, 1 \mathrm{H}), 3.03-2.93(\mathrm{~m}, 1 \mathrm{H}), 1.65-1.54(\mathrm{~m}, 4 \mathrm{H}), 1.44(\mathrm{~d}, J=12.6 \mathrm{~Hz}, 1 \mathrm{H}), 1.19-1.08(\mathrm{~m}, 4 \mathrm{H})$, $1.07-1.00(\mathrm{~m}, 1 \mathrm{H}) .{ }^{13} \mathrm{C}$ NMR $\left(126 \mathrm{MHz}, \mathrm{DMSO}-d_{6}\right) \delta 161.8\left(\mathrm{~d}, J_{\mathrm{C}-\mathrm{F}}=242.5 \mathrm{~Hz}\right), 142.5,142.4\left(\mathrm{~d}, J_{\mathrm{C}-\mathrm{F}}=12.8\right.$ $\mathrm{Hz}), 141.8,137.1,127.6,127.5,123.1\left(\mathrm{~d}, J_{\mathrm{C}-\mathrm{F}}=11.0 \mathrm{~Hz}\right), 117.7,111.6\left(\mathrm{~d}, J_{\mathrm{C}-\mathrm{F}}=26.0 \mathrm{~Hz}\right), 96.7\left(\mathrm{~d}, J_{\mathrm{C}-\mathrm{F}}=25.9\right.$ $\mathrm{Hz}$ ), 52.6, 33.7, 25.3, 24.8. HRMS (ESI): Exact mass calculated for $\mathrm{C}_{19} \mathrm{H}_{20} \mathrm{FN}_{3} \mathrm{O}_{2} \mathrm{SNa}^{+}[\mathrm{M}+\mathrm{Na}], 396.1158$. Found 396.1159. $\mathrm{IC}_{50}: 10 \mu \mathrm{M}[9.1 \pm 3.5, \mathrm{n}=3 ; 11 \pm 2.8, \mathrm{n}=3]$

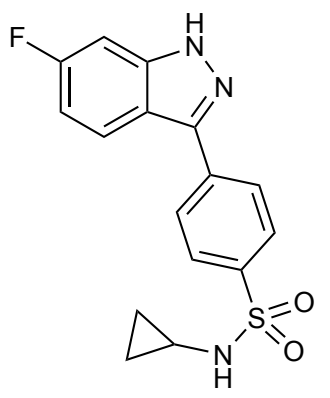

$\boldsymbol{N}$-cyclopropyl-4-(6-fluoro-1H-indazol-3-yl)benzenesulfonamide (13c). General Procedure E was used to afford 13c (73 mg, 28\%) as an off-white solid. Analytical data: ${ }^{1} \mathrm{H}$ NMR (500 MHz, DMSO- $\left.d_{6}\right) \delta 13.55$ (bs, $1 \mathrm{H}), 8.26-8.20(\mathrm{~m}, 2 \mathrm{H}), 8.19(\mathrm{dd}, J=9.0,5.1 \mathrm{~Hz}, 1 \mathrm{H}), 8.04-7.97(\mathrm{~m}, 1 \mathrm{H}), 7.96-7.91(\mathrm{~m}, 2 \mathrm{H}), 7.42(\mathrm{dd}, J=$ 9.4, $2.2 \mathrm{~Hz}, 1 \mathrm{H}), 7.14(\mathrm{td}, J=9.2,2.3 \mathrm{~Hz}, 1 \mathrm{H}), 2.16(\mathrm{tt}, J=6.9,3.6 \mathrm{~Hz}, 1 \mathrm{H}), 0.54-0.47(\mathrm{~m}, 2 \mathrm{H}), 0.46-0.40$ $(\mathrm{m}, 2 \mathrm{H}) .{ }^{13} \mathrm{C}$ NMR $\left(126 \mathrm{MHz}, \mathrm{DMSO}-d_{6}\right) \delta 161.3\left(\mathrm{~d}, J_{\mathrm{C}-\mathrm{F}}=242.5 \mathrm{~Hz}\right), 142.0,141.9\left(\mathrm{~d}, J_{\mathrm{C}-\mathrm{F}}=13.4 \mathrm{~Hz}\right), 139.2$, 137.0, 127.5, 127.1, $122.6\left(\mathrm{~d}, J_{\mathrm{C}-\mathrm{F}}=11.0 \mathrm{~Hz}\right), 117.3,111.2\left(\mathrm{~d}, J_{\mathrm{C}-\mathrm{F}}=25.9 \mathrm{~Hz}\right), 96.2\left(\mathrm{~d}, J_{\mathrm{C}-\mathrm{F}}=25.9 \mathrm{~Hz}\right), 24.1$, 5.2. HRMS (electrospray): Exact mass calculated for $\mathrm{C}_{16} \mathrm{H}_{14} \mathrm{FN}_{3} \mathrm{O}_{2} \mathrm{SNa}^{+}[\mathrm{M}+\mathrm{Na}], 354.0689$. Found 354.0679 . $\mathrm{IC}_{50}: 1.4 \mu \mathrm{M}[1.3 \pm 0.41, \mathrm{n}=3 ; 1.5 \pm 0.98, \mathrm{n}=3]$

MEK7 $\mathrm{IC}_{50}: 8.7 \mu \mathrm{M}[8.1 \pm 2.3, \mathrm{n}=3,9.3 \pm 5.3, \mathrm{n}=3 \mu \mathrm{M}]$

\section{Tabulated Data of Compounds 14a-d}

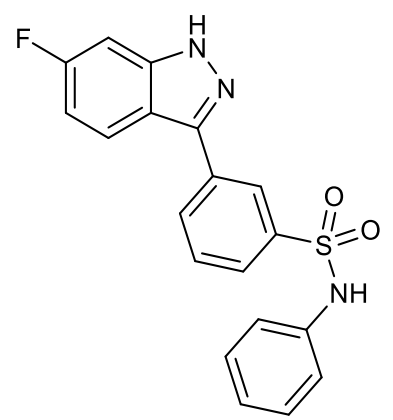

3-(6-fluoro-1H-indazol-3-yl)- $\boldsymbol{N}$-phenylbenzenesulfonamide (14a). General Procedure E was used to afford 14a (151 mg, 54\%) as a white solid. Analytical data: ${ }^{1} \mathrm{H}$ NMR (500 MHz, DMSO-d6) $\delta 13.50(\mathrm{~s}, 1 \mathrm{H}), 10.39(\mathrm{~s}$, $1 \mathrm{H}), 8.28(\mathrm{t}, J=1.8 \mathrm{~Hz}, 1 \mathrm{H}), 8.19(\mathrm{dt}, J=7.8,1.4 \mathrm{~Hz}, 1 \mathrm{H}), 7.88(\mathrm{dd}, J=9.0,5.1 \mathrm{~Hz}, 1 \mathrm{H}), 7.78(\mathrm{ddd}, J=7.9$, 1.9, $1.1 \mathrm{~Hz}, 1 \mathrm{H}), 7.69$ (t, $J=7.8 \mathrm{~Hz}, 1 \mathrm{H}), 7.41$ (dd, $J=9.4,2.2 \mathrm{~Hz}, 1 \mathrm{H}), 7.28-7.22$ (m, 2H), $7.17-7.10$ (m, $3 \mathrm{H}), 7.05(\mathrm{tt}, J=7.3,1.2 \mathrm{~Hz}, 1 \mathrm{H}) .{ }^{13} \mathrm{C} \mathrm{NMR}\left(126 \mathrm{MHz}, \mathrm{DMSO}-d_{6}\right) \delta 161.3\left(\mathrm{~d}, J_{\mathrm{C}-\mathrm{F}}=242.6 \mathrm{~Hz}\right), 141.9\left(\mathrm{~d}, J_{\mathrm{C}-\mathrm{F}}\right.$ $=12.7 \mathrm{~Hz}), 141.8,140.2,137.7,134.1,130.8,130.1,129.3,125.9,124.3,124.3,122.1\left(\mathrm{~d}, J_{\mathrm{C}-\mathrm{F}}=11.1 \mathrm{~Hz}\right)$, 120.4, 117.0, $111.2\left(\mathrm{~d}, J_{\mathrm{C}-\mathrm{F}}=26.1 \mathrm{~Hz}\right), 96.3\left(\mathrm{~d}, J_{\mathrm{C}-\mathrm{F}}=25.7 \mathrm{~Hz}\right)$. HRMS (ESI): Exact mass calculated for $\mathrm{C}_{19} \mathrm{H}_{15} \mathrm{FN}_{3} \mathrm{O}_{2} \mathrm{~S}^{+}[\mathrm{M}+\mathrm{H}], 368.0869$. Found 368.0857. IC $\mathrm{I}_{50}: 0.31 \mu \mathrm{M}[0.30 \pm 0.058, \mathrm{n}=3 ; 0.31 \pm 0.051 \mu \mathrm{M}]$ MEK7 IC $50: 0.84 \mu \mathrm{M}[0.40 \pm 0.11, \mathrm{n}=3 ; 0.61 \pm 0.13, \mathrm{n}=3 ; 1.5 \pm 0.30, \mathrm{n}=3]$ 


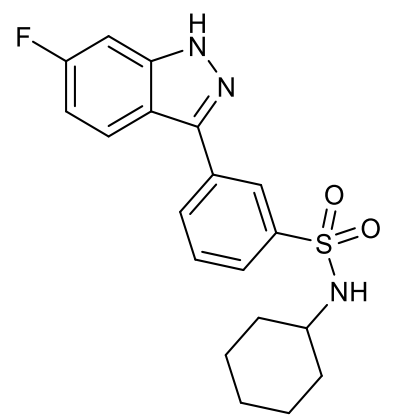

$\boldsymbol{N}$-cyclohexyl-3-(6-fluoro-1H-indazol-3-yl)benzenesulfonamide (14b). General Procedure E was used to afford 14b (350 mg, 85\%) as a pale yellow solid. Analytical data: ${ }^{1} \mathrm{H}$ NMR (500 MHz, DMSO-d6) $\delta 13.51(\mathrm{~s}$, $1 \mathrm{H}), 8.40(\mathrm{t}, J=1.8 \mathrm{~Hz}, 1 \mathrm{H}), 8.23(\mathrm{dt}, J=7.8,1.4 \mathrm{~Hz}, 1 \mathrm{H}), 8.13(\mathrm{dd}, J=9.0,5.1 \mathrm{~Hz}, 1 \mathrm{H}), 7.87-7.78(\mathrm{~m}, 2 \mathrm{H})$, $7.73(\mathrm{t}, J=7.8 \mathrm{~Hz}, 1 \mathrm{H}), 7.42(\mathrm{dd}, J=9.4,2.3 \mathrm{~Hz}, 1 \mathrm{H}), 7.16(\mathrm{td}, J=9.2,2.3 \mathrm{~Hz}, 1 \mathrm{H}), 3.05-2.92(\mathrm{~m}, 1 \mathrm{H}), 1.58$ $(\mathrm{h}, J=5.1 \mathrm{~Hz}, 4 \mathrm{H}), 1.43(\mathrm{~d}, J=12.4 \mathrm{~Hz}, 1 \mathrm{H}), 1.13(\mathrm{td}, J=9.9,8.6,5.5 \mathrm{~Hz}, 4 \mathrm{H}), 1.04(\mathrm{t}, J=10.9 \mathrm{~Hz}, 1 \mathrm{H}) .{ }^{13} \mathrm{C}$ NMR (126 MHz, DMSO-d6) $\delta 161.3\left(\mathrm{~d}, J_{\mathrm{C}-\mathrm{F}}=242.5 \mathrm{~Hz}\right), 143.0,142.0\left(\mathrm{~d}, J_{\mathrm{C}-\mathrm{F}}=12.8 \mathrm{~Hz}\right), 134.1,130.1,130.0$, 126.5, 124.0, $122.3\left(\mathrm{~d}, J_{\mathrm{C}-\mathrm{F}}=11.1 \mathrm{~Hz}\right), 117.1,111.1\left(\mathrm{~d}, J_{\mathrm{C}-\mathrm{F}}=26.1 \mathrm{~Hz}\right), 96.3\left(\mathrm{~d}, J_{\mathrm{C}-\mathrm{F}}=25.9 \mathrm{~Hz}\right), 52.2,33.2$, 24.8, 24.3. HRMS (ESI): Exact mass calculated for $\mathrm{C}_{19} \mathrm{H}_{21} \mathrm{FN}_{3} \mathrm{O}_{2} \mathrm{~S}^{+}[\mathrm{M}+\mathrm{H}]$, 374.1338. Found 374.1342. IC $\mathrm{I}_{50}$ : $0.86 \mu \mathrm{M}[0.84 \pm 0.20, \mathrm{n}=3 ; 0.87 \pm 0.30, \mathrm{n}=3]$

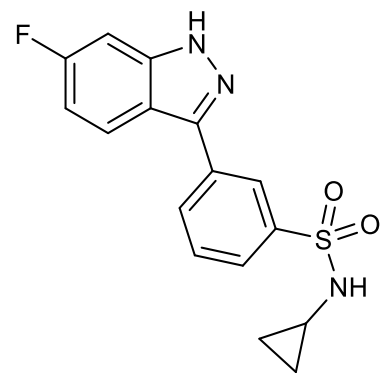

$\boldsymbol{N}$-cyclopropyl-3-(6-fluoro-1 $\boldsymbol{H}$-indazol-3-yl)benzenesulfonamide (14c). General Procedure E was used to afford 14c (158 mg, 49\%) as a pale yellow solid. Analytical data: ${ }^{1} \mathrm{H}$ NMR (500 MHz, DMSO- $\left.d_{6}\right) \delta 13.51(\mathrm{~s}$, $1 \mathrm{H}), 8.40(\mathrm{~s}, 1 \mathrm{H}), 8.27(\mathrm{~d}, J=7.9,1.3 \mathrm{~Hz}, 1 \mathrm{H}), 8.12(\mathrm{dd}, J=9.0,5.1 \mathrm{~Hz}, 1 \mathrm{H}), 8.06(\mathrm{~d}, J=2.7 \mathrm{~Hz}, 1 \mathrm{H}), 7.87-$ $7.82(\mathrm{~m}, 1 \mathrm{H}), 7.77(\mathrm{t}, J=7.8 \mathrm{~Hz}, 1 \mathrm{H}), 7.43(\mathrm{dd}, J=9.5,2.3 \mathrm{~Hz}, 1 \mathrm{H}), 7.16(\mathrm{td}, J=9.1,2.2 \mathrm{~Hz}, 1 \mathrm{H}), 2.16(\mathrm{tq}, J=$ $6.8,3.3 \mathrm{~Hz}, 1 \mathrm{H}), 0.50(\mathrm{dt}, J=6.8,3.3 \mathrm{~Hz}, 2 \mathrm{H}), 0.42$ (q, $J=3.7 \mathrm{~Hz}, 2 \mathrm{H}) .{ }^{13} \mathrm{C}$ NMR $\left(126 \mathrm{MHz}, \mathrm{DMSO}-d_{6}\right) \delta$ $161.3\left(\mathrm{~d}, J_{\mathrm{C}-\mathrm{F}}=242.5 \mathrm{~Hz}\right), 141.9,141.5\left(\mathrm{~d}, J_{\mathrm{C}-\mathrm{F}}=128.6 \mathrm{~Hz}\right), 134.1,130.4,130.0,126.1,124.5,122.3\left(\mathrm{~d}, J_{\mathrm{C}-\mathrm{F}}=\right.$ $11.0 \mathrm{~Hz}), 117.08,111.2\left(\mathrm{~d}, J_{\mathrm{C}-\mathrm{F}}=26.1 \mathrm{~Hz}\right), 96.3\left(\mathrm{~d}, J_{\mathrm{C}-\mathrm{F}}=25.9 \mathrm{~Hz}\right), 24.2,5.1$. HRMS (ESI): Exact mass calculated for $\mathrm{C}_{16} \mathrm{H}_{15} \mathrm{FN}_{3} \mathrm{O}_{2} \mathrm{~S}^{+}[\mathrm{M}+\mathrm{H}], 332.0869$. Found 332.0863. $\mathrm{IC}_{50}: 0.38 \mu \mathrm{M}[0.32 \pm 0.31, \mathrm{n}=3 ; 0.44 \pm$ $0.065, \mathrm{n}=3]$ 


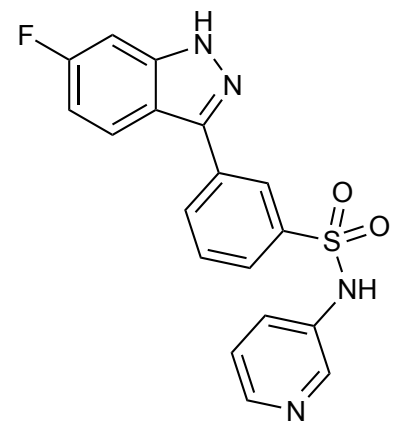

3-(6-fluoro-1 $\boldsymbol{H}$-indazol-3-yl)- $\boldsymbol{N}$-(pyridin-3-yl)benzenesulfonamide (14d). General Procedure E was used to afford 14d (196 mg, 38\%) as a white solid. Analytical data: ${ }^{1} \mathrm{H}$ NMR (500 MHz, DMSO-d $\left.d\right) \quad 13.52(\mathrm{~s}, 1 \mathrm{H})$, $10.68(\mathrm{bs}, 1 \mathrm{H}), 8.35-8.30(\mathrm{~m}, 2 \mathrm{H}), 8.27(\mathrm{dd}, J=4.7,1.5 \mathrm{~Hz}, 1 \mathrm{H}), 8.24(\mathrm{dt}, J=7.8,1.4 \mathrm{~Hz}, 1 \mathrm{H}), 7.96(\mathrm{dd}, J=$ 9.0, $5.0 \mathrm{~Hz}, 1 \mathrm{H}), 7.78(\mathrm{dt}, J=8.0,1.4 \mathrm{~Hz}, 1 \mathrm{H}), 7.71(\mathrm{t}, J=7.8 \mathrm{~Hz}, 1 \mathrm{H}), 7.56(\mathrm{ddd}, J=8.3,2.7,1.5 \mathrm{~Hz}, 1 \mathrm{H})$, $7.42(\mathrm{dd}, J=9.4,2.3 \mathrm{~Hz}, 1 \mathrm{H}), 7.31(\mathrm{dd}, J=8.3,4.7 \mathrm{~Hz}, 1 \mathrm{H}), 7.14(\mathrm{td}, J=9.1,2.3 \mathrm{~Hz}, 1 \mathrm{H}) .{ }^{13} \mathrm{C} \mathrm{NMR}(126$ $\mathrm{MHz}, \mathrm{DMSO}) \delta 161.3\left(\mathrm{~d}, J_{\mathrm{C}-\mathrm{F}}=242.6 \mathrm{~Hz}\right), 145.6,142.0,142.0,141.9,141.6,139.8,134.4,134.3,131.0,130.3$, $127.7,125.9,124.2\left(\mathrm{~d}, J_{\mathrm{C}-\mathrm{F}}=14.0 \mathrm{~Hz}\right), 122.1\left(\mathrm{~d}, J_{\mathrm{C}-\mathrm{F}}=11.1 \mathrm{~Hz}\right), 117.0,111.2\left(\mathrm{~d}, J_{\mathrm{C}-\mathrm{F}}=26.1 \mathrm{~Hz}\right), 96.3\left(\mathrm{~d}, J_{\mathrm{C}-\mathrm{F}}\right.$ $=26.0 \mathrm{~Hz})$. HRMS (ESI): Exact mass calculated for $\mathrm{C}_{18} \mathrm{H}_{13} \mathrm{FN}_{4} \mathrm{O}_{2} \mathrm{~S}^{+}[\mathrm{M}+\mathrm{H}], 369.0821$. Found 369.0821. IC $\mathrm{I}_{50}$ : $0.45 \mu \mathrm{M}[0.43 \pm 0.089, \mathrm{n}=3 ; 0.46 \pm 0.10, \mathrm{n}=3]$

\section{Tabulated Data of Compounds 15a-o}

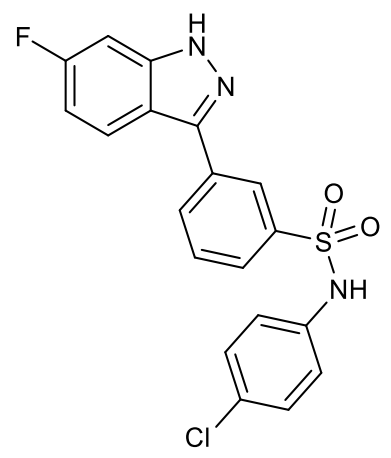

$\boldsymbol{N}$-(4-chlorophenyl)-3-(6-fluoro-1H-indazol-3-yl)benzenesulfonamide (15a). General Procedure E was used to afford 15a (390 mg, 64\%) as an off-white solid. Analytical data: ${ }^{1} \mathrm{H}$ NMR (500 MHz, DMSO- $\left.d_{6}\right) \delta 13.52(\mathrm{~s}$, $1 \mathrm{H}), 10.55$ (s, 1H), 8.29 (t, $J=1.8 \mathrm{~Hz}, 1 \mathrm{H}), 8.22$ (dt, $J=7.8,1.4 \mathrm{~Hz}, 1 \mathrm{H}), 7.91(\mathrm{dd}, J=9.0,5.1 \mathrm{~Hz}, 1 \mathrm{H}), 7.77$ (ddd, $J=7.9,1.9,1.2 \mathrm{~Hz}, 1 \mathrm{H}), 7.70(\mathrm{t}, J=7.8 \mathrm{~Hz}, 1 \mathrm{H}), 7.42(\mathrm{dd}, J=9.4,2.2 \mathrm{~Hz}, 1 \mathrm{H}), 7.35-7.29(\mathrm{~m}, 2 \mathrm{H}), 7.19$ $-7.09(\mathrm{~m}, 3 \mathrm{H}) .{ }^{13} \mathrm{C}$ NMR $\left(126 \mathrm{MHz}, \mathrm{DMSO}-d_{6}\right) \delta 161.3\left(\mathrm{~d}, J_{\mathrm{C}-\mathrm{F}}=242.5 \mathrm{~Hz}\right), 141.9\left(\mathrm{~d}, J_{\mathrm{C}-\mathrm{F}}=12.8 \mathrm{~Hz}\right), 141.7$, $139.9,136.7,134.2,130.9,130.2,129.3,128.4,125.9,124.2,122.0\left(\mathrm{~d}, J_{\mathrm{C}-\mathrm{F}}=11.1 \mathrm{~Hz}\right), 117.0,111.2\left(\mathrm{~d}, J_{\mathrm{C}-\mathrm{F}}=\right.$ $26.1 \mathrm{~Hz}), 96.3\left(\mathrm{~d}, J_{\mathrm{C}-\mathrm{F}}=25.8 \mathrm{~Hz}\right.$ ). HRMS (ESI): Calculated for $\mathrm{C}_{19} \mathrm{H}_{13} \mathrm{ClFN}_{3} \mathrm{O}_{2} \mathrm{~S}^{+}[\mathrm{M}+\mathrm{H}]$, 402.0474. Found 402.0481. $\mathrm{IC}_{50}: 1.4 \mu \mathrm{M}[1.0 \pm 0.58, \mathrm{n}=3,1.8 \pm 0.79, \mathrm{n}=3]$ 


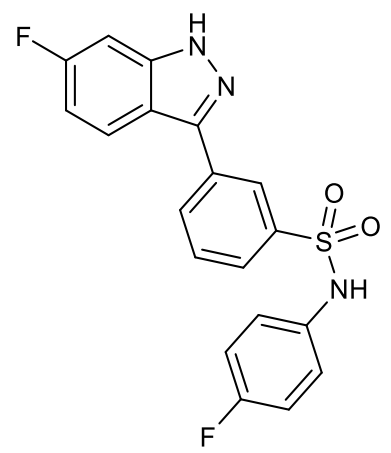

3-(6-fluoro-1 $\boldsymbol{H}$-indazol-3-yl)- $\boldsymbol{N}$-(4-fluorophenyl)benzenesulfonamide (15b). General Procedure E was used to afford 15b (160 mg, 38\%) as an off-white solid. Analytical data: ${ }^{1} \mathrm{H}$ NMR (500 MHz, DMSO- $\left.d_{6}\right) \delta 13.51(\mathrm{~s}$, $1 \mathrm{H}), 10.35(\mathrm{~s}, 1 \mathrm{H}), 8.26(\mathrm{t}, J=1.8 \mathrm{~Hz}, 1 \mathrm{H}), 8.21(\mathrm{dt}, J=7.5,1.5 \mathrm{~Hz}, 1 \mathrm{H}), 7.92(\mathrm{dd}, J=9.0,5.1 \mathrm{~Hz}, 1 \mathrm{H}), 7.75-$ $7.66(\mathrm{~m}, 2 \mathrm{H}), 7.41(\mathrm{dd}, J=9.5,2.3 \mathrm{~Hz}, 1 \mathrm{H}), 7.16-7.07(\mathrm{~m}, 5 \mathrm{H}) .{ }^{13} \mathrm{C}$ NMR $\left(126 \mathrm{MHz}, \mathrm{DMSO}-d_{6}\right) \delta 161.2(\mathrm{~d}$, $\left.J_{\mathrm{C}-\mathrm{F}}=261.0 \mathrm{~Hz}\right), 159.3\left(\mathrm{~d}, J_{\mathrm{C}-\mathrm{F}}=259.8 \mathrm{~Hz}\right), 141.9\left(\mathrm{~d}, J_{\mathrm{C}-\mathrm{F}}=12.9 \mathrm{~Hz}\right), 141.7,139.8,134.1,133.8,133.8,130.8$, $130.1,125.9,124.3,123.1\left(\mathrm{~d}, J_{\mathrm{C}-\mathrm{F}}=8.4 \mathrm{~Hz}\right), 122.1\left(\mathrm{~d}, J_{\mathrm{C}-\mathrm{F}}=11.0 \mathrm{~Hz}\right), 117.0,116.0\left(\mathrm{~d}, J_{\mathrm{C}-\mathrm{F}}=22.6 \mathrm{~Hz}\right), 111.12$ $\left(\mathrm{d}, J_{\mathrm{C}-\mathrm{F}}=26.1 \mathrm{~Hz}\right), 96.31\left(\mathrm{~d}, J_{\mathrm{C}-\mathrm{F}}=25.9 \mathrm{~Hz}\right)$. HRMS (ESI): Calculated for $\mathrm{C}_{19} \mathrm{H}_{14} \mathrm{~F}_{2} \mathrm{~N}_{3} \mathrm{O}_{2} \mathrm{~S}^{+}[\mathrm{M}+\mathrm{H}], 386.0775$, Found 386.0768. $\mathrm{IC}_{50}: 0.88 \mu \mathrm{M}[0.85 \pm 0.078, \mathrm{n}=3 ; 0.91 \pm 0.11, \mathrm{n}=3]$

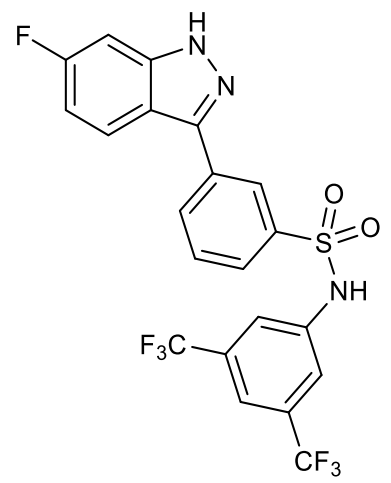

$\boldsymbol{N}$-(3,5-bis(trifluoromethyl)phenyl)-3-(6-fluoro-1 $H$-indazol-3-yl)benzenesulfonamide (15c). General Procedure E was used to afford 15c $(68 \mathrm{mg}, 54 \%)$ as a white solid. Analytical data: ${ }^{1} \mathrm{H}$ NMR $(500 \mathrm{MHz}$, DMSO-d $d_{6} \delta 13.55(\mathrm{~s}, 1 \mathrm{H}), 11.32(\mathrm{~s}, 1 \mathrm{H}), 8.36(\mathrm{t}, J=1.8 \mathrm{~Hz}, 1 \mathrm{H}), 8.27(\mathrm{dt}, J=7.8,1.4 \mathrm{~Hz}, 1 \mathrm{H}), 7.95(\mathrm{dd}, J=$ 9.0, $5.0 \mathrm{~Hz}, 1 \mathrm{H}), 7.84(\mathrm{ddd}, J=7.9,1.9,1.1 \mathrm{~Hz}, 1 \mathrm{H}), 7.80-7.70(\mathrm{~m}, 4 \mathrm{H}), 7.42(\mathrm{dd}, J=9.4,2.2 \mathrm{~Hz}, 1 \mathrm{H}), 7.12$ $(\mathrm{td}, J=9.1,2.3 \mathrm{~Hz}, 1 \mathrm{H}) .{ }^{13} \mathrm{C}$ NMR $\left(126 \mathrm{MHz}, \mathrm{DMSO}-d_{6}\right) \delta 161.3\left(\mathrm{~d}, J_{\mathrm{C}-\mathrm{F}}=242.8 \mathrm{~Hz}\right), 141.9\left(\mathrm{~d}, J_{\mathrm{C}-\mathrm{F}}=12.9\right.$ $\mathrm{Hz}), 141.4,140.1,139.4,134.5,131.4,131.3\left(\mathrm{q}, J_{\mathrm{C}-\mathrm{F}}=33.0 \mathrm{~Hz}\right), 130.51,125.80,124.1,122.8\left(\mathrm{q}, J_{\mathrm{C}-\mathrm{F}}=272.9\right.$ $\mathrm{Hz}), 119.1\left(\mathrm{~d}, J_{\mathrm{C}-\mathrm{F}}=3.2 \mathrm{~Hz}\right), 117.1\left(\mathrm{tt}, J_{\mathrm{C}-\mathrm{F}}=5.8,3.1 \mathrm{~Hz}\right), 117.0,111.2\left(\mathrm{~d}, J_{\mathrm{C}-\mathrm{F}}=26.1 \mathrm{~Hz}\right), 96.4\left(\mathrm{~d}, J_{\mathrm{C}-\mathrm{F}}=25.9\right.$ $\mathrm{Hz}$ ). HRMS (ESI): Exact mass calculated for $\mathrm{C}_{21} \mathrm{H}_{13} \mathrm{~F}_{7} \mathrm{~N}_{3} \mathrm{O}_{2} \mathrm{~S}^{+}[\mathrm{M}+\mathrm{H}]$, 504.0616. Found 504.0619. IC $\mathrm{I}_{50}: 3.3 \mu \mathrm{M}$ $[1.3 \pm 0.55, \mathrm{n}=3 ; 5.2 \pm 1.3, \mathrm{n}=3]$ 


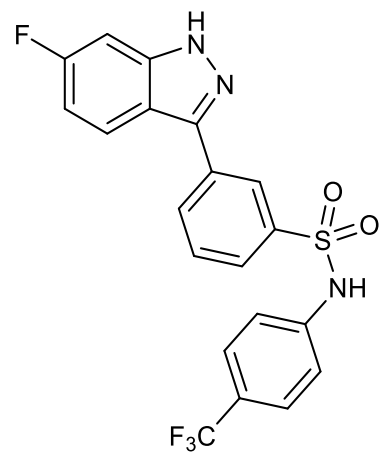

3-(6-fluoro-1 $H$-indazol-3-yl)- $N$-(4-(trifluoromethyl)phenyl)benzenesulfonamide (15d). General Procedure E was used to afford $15 d(435 \mathrm{mg}, 72 \%)$ as a yellow solid. Analytical data: ${ }^{1} \mathrm{H}$ NMR (500 MHz, DMSO- $\left.d_{6}\right) \delta$ $13.53(\mathrm{~s}, 1 \mathrm{H}), 10.99(\mathrm{~s}, 1 \mathrm{H}), 8.37$ (t, $J=1.8 \mathrm{~Hz}, 1 \mathrm{H}), 8.24(\mathrm{dt}, J=7.9,1.4 \mathrm{~Hz}, 1 \mathrm{H}), 7.96(\mathrm{dd}, J=9.0,5.1 \mathrm{~Hz}$, 1H), 7.85 (ddd, $J=7.9,2.0,1.1 \mathrm{~Hz}, 1 \mathrm{H}), 7.72$ (t, $J=7.8 \mathrm{~Hz}, 1 \mathrm{H}), 7.63$ (d, $J=8.6 \mathrm{~Hz}, 2 \mathrm{H}), 7.42$ (dd, $J=9.4,2.2$ $\mathrm{Hz}, 1 \mathrm{H}), 7.35(\mathrm{~d}, J=8.5 \mathrm{~Hz}, 2 \mathrm{H}), 7.13(\mathrm{td}, J=9.2,2.3 \mathrm{~Hz}, 1 \mathrm{H}) .{ }^{13} \mathrm{C}$ NMR $\left(126 \mathrm{MHz}\right.$, DMSO- $\left.d_{6}\right) \delta 161.8\left(\mathrm{~d}, J_{\mathrm{C}-}\right.$ $\mathrm{F}=242.6 \mathrm{~Hz}), 142.4\left(\mathrm{~d}, J_{\mathrm{C}-\mathrm{F}}=12.9 \mathrm{~Hz}\right), 142.1,140.5,134.8,131.6,130.8,127.2,127.2\left(\mathrm{q}, J_{\mathrm{C}-\mathrm{F}}=3.8 \mathrm{~Hz}\right)$, $127.1,126.3,124.65\left(\mathrm{~d}, J_{\mathrm{C}-\mathrm{F}}=271.4 \mathrm{~Hz}\right), 124.62,122.5\left(\mathrm{~d}, J_{\mathrm{C}-\mathrm{F}}=11.1 \mathrm{~Hz}\right), 119.5,117.5,111.6\left(\mathrm{~d}, J_{\mathrm{C}-\mathrm{F}}=26.1\right.$ $\mathrm{Hz}$ ), $96.8\left(\mathrm{~d}, J_{\mathrm{C}-\mathrm{F}}=25.7 \mathrm{~Hz}\right.$ ). HRMS (ESI): Mass calculated for $\mathrm{C}_{20} \mathrm{H}_{13} \mathrm{~F}_{4} \mathrm{~N}_{3} \mathrm{O}_{2} \mathrm{SNa}^{+}[\mathrm{M}+\mathrm{Na}]$, 458.0563. Found 458.0565. $\mathrm{IC}_{50}: 3.1 \mu \mathrm{M}[2.3 \pm 0.34, \mathrm{n}=3 ; 3.9 \pm 0.89, \mathrm{n}=3]$

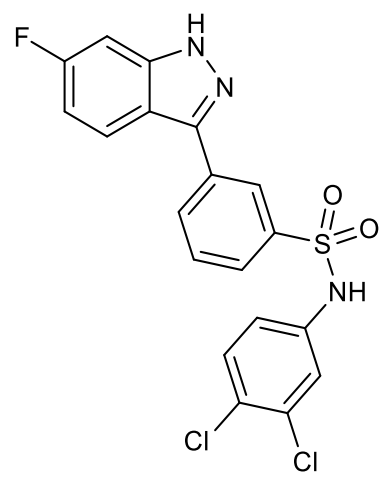

$\mathrm{N}$-(3,4-dichlorophenyl)-3-(6-fluoro-1 $\mathrm{H}$-indazol-3-yl)benzenesulfonamide (15e). General Procedure E was used to afford 15e (240 mg, 40\%) as a white solid. Analytical data: ${ }^{1} \mathrm{H}$ NMR (500 MHz, DMSO- $\left.d_{6}\right) \delta 13.54$ (s, $1 \mathrm{H}), 10.82(\mathrm{~s}, 1 \mathrm{H}), 8.32(\mathrm{t}, J=1.8 \mathrm{~Hz}, 1 \mathrm{H}), 8.25(\mathrm{dt}, J=7.7,1.4 \mathrm{~Hz}, 1 \mathrm{H}), 7.94(\mathrm{dd}, J=9.0,5.0 \mathrm{~Hz}, 1 \mathrm{H}), 7.81$ (dt, $J=7.9,1.4 \mathrm{~Hz}, 1 \mathrm{H}), 7.73$ (t, $J=7.8 \mathrm{~Hz}, 1 \mathrm{H}), 7.53(\mathrm{~d}, J=8.8 \mathrm{~Hz}, 1 \mathrm{H}), 7.42$ (dd, $J=9.4,2.3 \mathrm{~Hz}, 1 \mathrm{H}), 7.35$ (d, $J=2.5 \mathrm{~Hz}, 1 \mathrm{H}), 7.18-7.11(\mathrm{~m}, 2 \mathrm{H}) .{ }^{13} \mathrm{C}$ NMR $\left(126 \mathrm{MHz}, \mathrm{DMSO}-d_{6}\right) \delta 161.3\left(\mathrm{~d}, J_{\mathrm{C}-\mathrm{F}}=242.6 \mathrm{~Hz}\right), 141.9$ $\left(\mathrm{d}, J_{\mathrm{C}-\mathrm{F}}=12.8 \mathrm{~Hz}\right), 141.6,139.6,137.9,134.3,131.5,131.4,131.2,130.4,126.3,125.9,124.2,122.0\left(\mathrm{~d}, J_{\mathrm{C}-\mathrm{F}}=\right.$ $11.1 \mathrm{~Hz}), 121.1,119.9,117.0,111.2\left(\mathrm{~d}, J_{\mathrm{C}-\mathrm{F}}=26.1 \mathrm{~Hz}\right), 96.4\left(\mathrm{~d}, J_{\mathrm{C}-\mathrm{F}}=25.9 \mathrm{~Hz}\right)$. HRMS (ESI): Calculated for $\mathrm{C}_{19} \mathrm{H}_{12} \mathrm{Cl}_{2} \mathrm{FN}_{3} \mathrm{O}_{2} \mathrm{~S}^{+}[\mathrm{M}+\mathrm{H}], 436.0084$, Found 436.0095. IC $\mathrm{I}_{50}: 1.6 \mu \mathrm{M}[1.4 \pm 0.99, \mathrm{n}=3 ; 1.8 \pm 0.44, \mathrm{n}=3]$ 


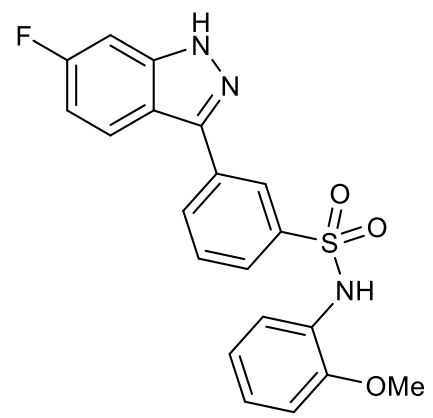

3-(6-fluoro-1H-indazol-3-yl)- $\mathrm{N}$-(2-methoxyphenyl)benzenesulfonamide (15f). General Procedure E was used to afford $\mathbf{1 5 f}(540 \mathrm{mg}, 70 \%)$ as a white solid. Analytical data: ${ }^{1} \mathrm{H}$ NMR (500 MHz, DMSO- $\left.d_{6}\right) \delta 13.53$ (s, $1 \mathrm{H}), 10.98(\mathrm{~s}, 1 \mathrm{H}), 8.37(\mathrm{t}, J=1.8 \mathrm{~Hz}, 1 \mathrm{H}), 8.23(\mathrm{dt}, J=7.9,1.4 \mathrm{~Hz}, 1 \mathrm{H}), 7.96(\mathrm{dd}, J=9.0,5.1 \mathrm{~Hz}, 1 \mathrm{H}), 7.86$ (ddt, $J=9.3,6.4,1.9 \mathrm{~Hz}, 3 \mathrm{H}), 7.72(\mathrm{t}, J=7.9 \mathrm{~Hz}, 1 \mathrm{H}), 7.41(\mathrm{dd}, J=9.4,2.3 \mathrm{~Hz}, 1 \mathrm{H}), 7.30-7.25(\mathrm{~m}, 2 \mathrm{H}), 7.12$ (td, $J=9.1,2.3 \mathrm{~Hz}, 1 \mathrm{H}), 2.45(\mathrm{~s}, 3 \mathrm{H}) .{ }^{13} \mathrm{C}$ NMR $\left(126 \mathrm{MHz}, \mathrm{DMSO}-d_{6}\right) \delta 196.5,161.3\left(\mathrm{~d}, J_{\mathrm{C}-\mathrm{F}}=242.5 \mathrm{~Hz}\right)$, $142.3,141.9\left(\mathrm{~d}, J_{\mathrm{C}-\mathrm{F}}=12.9 \mathrm{~Hz}\right), 141.6,140.1,134.3,132.1,131.1,130.3,129.9,125.9,124.2,122.1\left(\mathrm{~d}, J_{\mathrm{C}-\mathrm{F}}=\right.$ $11.1 \mathrm{~Hz}), 118.2,117.0,111.2\left(\mathrm{~d}, J_{\mathrm{C}-\mathrm{F}}=26.1 \mathrm{~Hz}\right), 96.3\left(\mathrm{~d}, J_{\mathrm{C}-\mathrm{F}}=25.8 \mathrm{~Hz}\right), 26.4$. HRMS (ESI): Calculated for $\mathrm{C}_{20} \mathrm{H}_{16} \mathrm{FN}_{3} \mathrm{O}_{3} \mathrm{~S}^{+}[\mathrm{M}+\mathrm{H}], 398.0969$. Found 398.0977. $\mathrm{IC}_{50}: 0.42 \mu \mathrm{M}[0.28 \pm 0.13, \mathrm{n}=3 ; 0.56 \pm 0.44, \mathrm{n}=3]$

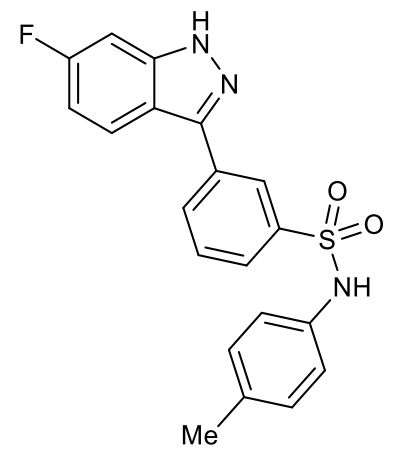

3-(6-fluoro-1 $H$-indazol-3-yl)- $N$-(p-tolyl)benzenesulfonamide (15g). General Procedure E was used to afford 15g (367 mg, 70\%) as a white solid. Analytical data: ${ }^{1} \mathrm{H}$ NMR $\left(500 \mathrm{MHz}\right.$, DMSO- $\left.d_{6}\right) \delta 8.27(\mathrm{t}, J=1.8 \mathrm{~Hz}$, $1 \mathrm{H}), 8.19(\mathrm{~d}, J=7.7 \mathrm{~Hz}, 1 \mathrm{H}), 7.90(\mathrm{dd}, J=9.0,5.0 \mathrm{~Hz}, 1 \mathrm{H}), 7.77-7.72(\mathrm{~m}, 1 \mathrm{H}), 7.68(\mathrm{t}, J=7.8 \mathrm{~Hz}, 1 \mathrm{H}), 7.41$ (dd, $J=9.4,2.3 \mathrm{~Hz}, 1 \mathrm{H}), 7.12$ (td, $J=9.1,2.3 \mathrm{~Hz}, 1 \mathrm{H}), 7.08-6.99(\mathrm{~m}, 4 \mathrm{H}), 2.17(\mathrm{~s}, 3 \mathrm{H}) .{ }^{13} \mathrm{C} \mathrm{NMR}(126 \mathrm{MHz}$, DMSO- $\left.d_{6}\right) \delta 161.3\left(\mathrm{~d}, J_{\mathrm{C}-\mathrm{F}}=242.6 \mathrm{~Hz}\right), 141.9\left(\mathrm{~d}, J_{\mathrm{C}-\mathrm{F}}=12.8 \mathrm{~Hz}\right), 141.8,140.2,135.0,134.0,133.7,130.7$, $130.0,129.7,125.9,124.3,122.1\left(\mathrm{~d}, J_{\mathrm{C}-\mathrm{F}}=11.1 \mathrm{~Hz}\right), 120.9,117.0,111.1\left(\mathrm{~d}, J_{\mathrm{C}-\mathrm{F}}=26.1 \mathrm{~Hz}\right), 96.3\left(\mathrm{~d}, J_{\mathrm{C}-\mathrm{F}}=25.8\right.$ $\mathrm{Hz}$ ), 20.3. HRMS (ESI): Calculated for $\mathrm{C}_{20} \mathrm{H}_{17} \mathrm{FN}_{3} \mathrm{O}_{2} \mathrm{~S}^{+}[\mathrm{M}+\mathrm{H}]$, 382.1026, found 382.1028. $\mathrm{IC}_{50}$ : $1.5 \mu \mathrm{M}[1.0 \pm$ $0.10, \mathrm{n}=3 ; 1.9 \pm 0.82, \mathrm{n}=3$ ] 


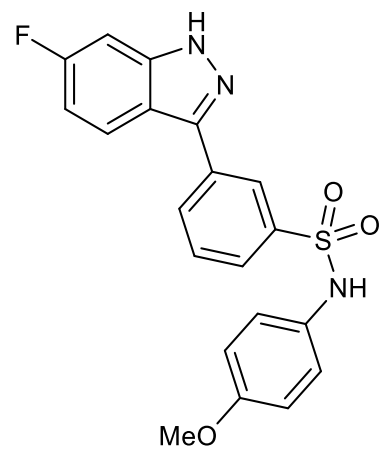

3-(6-fluoro-1 $\boldsymbol{H}$-indazol-3-yl)- $\boldsymbol{N}$-(4-methoxyphenyl)benzenesulfonamide (15h). General Procedure E was used to afford $\mathbf{1 5 h}(285 \mathrm{mg}, 61 \%)$ as a white solid. Analytical data: ${ }^{1} \mathrm{H}$ NMR $\left(500 \mathrm{MHz}, \mathrm{DMSO}-d_{6}\right) \delta 13.50(\mathrm{~s}$, $1 \mathrm{H}), 10.03(\mathrm{~s}, 1 \mathrm{H}), 8.24-8.22(\mathrm{~m}, 1 \mathrm{H}), 8.19(\mathrm{dt}, J=7.1,1.7 \mathrm{~Hz}, 1 \mathrm{H}), 7.87$ (dd, $J=9.0,5.1 \mathrm{~Hz}, 1 \mathrm{H}), 7.74-$ $7.63(\mathrm{~m}, 2 \mathrm{H}), 7.41(\mathrm{dd}, J=9.4,2.3 \mathrm{~Hz}, 1 \mathrm{H}), 7.11(\mathrm{td}, J=9.1,2.3 \mathrm{~Hz}, 1 \mathrm{H}), 7.06-6.99(\mathrm{~m}, 2 \mathrm{H}), 6.87-6.79(\mathrm{~m}$, 2H), $3.65(\mathrm{~s}, 3 \mathrm{H}) .{ }^{13} \mathrm{C}$ NMR $\left(126 \mathrm{MHz}, \mathrm{DMSO}-d_{6}\right) \delta 161.3\left(\mathrm{~d}, J_{\mathrm{C}-\mathrm{F}}=242.6 \mathrm{~Hz}\right), 160.3,156.7,142.0,141.9(\mathrm{~d}$, $\left.J_{\mathrm{C}-\mathrm{F}}=12.9 \mathrm{~Hz}\right), 140.1,134.0,130.0\left(\mathrm{~d}, J_{\mathrm{C}-\mathrm{F}}=10.6 \mathrm{~Hz}\right), 130.0,125.9,124.4,123.7,122.1\left(\mathrm{~d}, J_{\mathrm{C}-\mathrm{F}}=11.0 \mathrm{~Hz}\right)$, 117.0, 114.4, $111.0\left(\mathrm{~d}, J_{\mathrm{C}-\mathrm{F}}=26.0 \mathrm{~Hz}\right), 96.3\left(\mathrm{~d}, J_{\mathrm{C}-\mathrm{F}}=25.8 \mathrm{~Hz}\right), 55.1$. HRMS (ESI): Exact mass calculated for $\mathrm{C}_{20} \mathrm{H}_{17} \mathrm{FN}_{3} \mathrm{O}_{3} \mathrm{~S}^{+}[\mathrm{M}+\mathrm{H}], 398.0969$. Found 398.0973. $\mathrm{IC}_{50}: 0.39 \mu \mathrm{M}[0.24 \pm 0.14, \mathrm{n}=3,0.53 \pm 0.14, \mathrm{n}=3]$

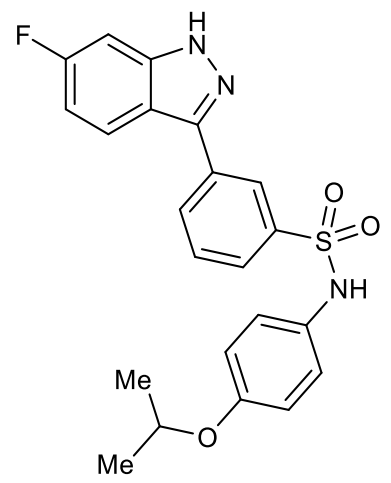

3-(6-fluoro-1 $H$-indazol-3-yl)- $\boldsymbol{N}$-(4-isopropoxyphenyl)benzenesulfonamide (15i). General Procedure E was used to afford 15i (123 mg, 60\%) as an ashy solid. Analytical data: ${ }^{1} \mathrm{H}$ NMR (500 MHz, DMSO- $\left.d_{6}\right) \delta 13.42(\mathrm{~s}$, 1H), $9.93(\mathrm{~s}, 1 \mathrm{H}), 8.24-8.06(\mathrm{~m}, 2 \mathrm{H}), 7.79(\mathrm{dd}, J=9.0,5.0 \mathrm{~Hz}, 1 \mathrm{H}), 7.67-7.58(\mathrm{~m}, 2 \mathrm{H}), 7.34(\mathrm{dd}, J=9.4,2.3$ $\mathrm{Hz}, 1 \mathrm{H}), 7.05(\mathrm{td}, J=9.3,2.3 \mathrm{~Hz}, 1 \mathrm{H}), 6.93(\mathrm{~d}, J=7.8 \mathrm{~Hz}, 2 \mathrm{H}), 6.73(\mathrm{~d}, J=8.8 \mathrm{~Hz}, 2 \mathrm{H}), 4.39$ (hept, $J=6.0 \mathrm{~Hz}$ $1 \mathrm{H}), 1.09(\mathrm{~d}, J=6.0 \mathrm{~Hz}, 6 \mathrm{H}) .{ }^{13} \mathrm{C}$ NMR $\left(126 \mathrm{MHz}, \mathrm{DMSO}-d_{6}\right) \delta 161.8\left(\mathrm{~d}, J_{\mathrm{C}-\mathrm{F}}=242.7 \mathrm{~Hz}\right), 155.4,142.4\left(\mathrm{~d}, J_{\mathrm{C}-}\right.$ $\mathrm{F}=13.1 \mathrm{~Hz}), 142.3,134.4,131.1,130.4,130.3,126.4,124.9,124.2,122.6\left(\mathrm{~d}, J_{\mathrm{C}-\mathrm{F}}=11.0 \mathrm{~Hz}\right), 117.5,116.6$, $111.6\left(\mathrm{~d}, J_{\mathrm{C}-\mathrm{F}}=26.1 \mathrm{~Hz}\right), 96.7\left(\mathrm{~d}, J_{\mathrm{C}-\mathrm{F}}=25.8 \mathrm{~Hz}\right), 69.8,39.5,22.2$. HRMS (ESI): Exact mass calculated for $\mathrm{C}_{22} \mathrm{H}_{21} \mathrm{FN}_{3} \mathrm{O}_{3} \mathrm{~S}^{+}[\mathrm{M}+\mathrm{H}], 426.1287$. Found 426.1288. IC $\mathrm{I}_{50}: 6.1 \mu \mathrm{M}[6.0 \pm 0.85, \mathrm{n}=3 ; 6.1 \pm 5.0, \mathrm{n}=3]$ MEK7 IC $50: 2.9 \mu \mathrm{M}[1.8 \pm 0.61, \mathrm{n}=3 ; 2.2 \pm 0.82, \mathrm{n}=3 ; 4.8 \pm 1.3, \mathrm{n}=3]$ 


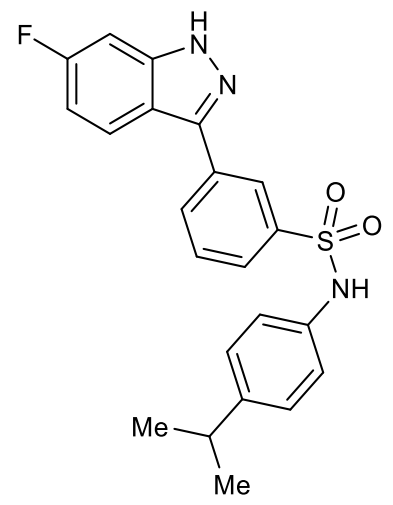

3-(6-fluoro-1H-indazol-3-yl)- $\mathrm{N}$-(4-isopropylphenyl)benzenesulfonamide (15j). General Procedure E was used to afford $15 \mathbf{j}(141 \mathrm{mg}, 58 \%)$ as an off-white solid. Analytical data: ${ }^{1} \mathrm{H}$ NMR (500 MHz, DMSO- $\left.d_{6}\right) \delta$ $13.50(\mathrm{~s}, 1 \mathrm{H}), 10.27(\mathrm{~s}, 1 \mathrm{H}), 8.29(\mathrm{t}, J=1.8 \mathrm{~Hz}, 1 \mathrm{H}), 8.20(\mathrm{dt}, J=7.8,1.4 \mathrm{~Hz}, 1 \mathrm{H}), 7.95(\mathrm{dd}, J=9.0,5.0 \mathrm{~Hz}$, 1H), 7.77 (ddd, $J=7.9,1.9,1.1 \mathrm{~Hz}, 1 \mathrm{H}), 7.68$ (t, $J=7.8 \mathrm{~Hz}, 1 \mathrm{H}), 7.41$ (dd, $J=9.4,2.2 \mathrm{~Hz}, 1 \mathrm{H}), 7.16-7.07$ (m, $3 \mathrm{H}), 7.07-7.02(\mathrm{~m}, 2 \mathrm{H}), 2.75$ (hept, $J=7.0 \mathrm{~Hz}, 1 \mathrm{H}), 1.08(\mathrm{~d}, J=6.9 \mathrm{~Hz}, 6 \mathrm{H}) .{ }^{13} \mathrm{C}$ NMR $\left(126 \mathrm{MHz}\right.$, DMSO- $\left.d_{6}\right)$ $\delta 161.3\left(\mathrm{~d}, J_{\mathrm{C}-\mathrm{F}}=242.6 \mathrm{~Hz}\right), 144.5,141.9\left(\mathrm{~d}, J_{\mathrm{C}-\mathrm{F}}=12.8 \mathrm{~Hz}\right), 141.7,140.3,135.2,134.1,130.7,130.1,127.0$, 125.9, 124.3, $111.1\left(\mathrm{~d}, J_{\mathrm{C}-\mathrm{F}}=26.1 \mathrm{~Hz}\right), 96.3\left(\mathrm{~d}, J_{\mathrm{C}-\mathrm{F}}=25.7 \mathrm{~Hz}\right), 32.7,23.7$. HRMS (ESI): Mass calculated for $\mathrm{C}_{22} \mathrm{H}_{20} \mathrm{FN}_{3} \mathrm{O}_{2} \mathrm{SNa}^{+}[\mathrm{M}+\mathrm{Na}], 432.1158$. Found 432.1159. $\mathrm{IC}_{50}: 23 \mu \mathrm{M}[10 \pm 7.1, \mathrm{n}=3 ; 36 \pm 12, \mathrm{n}=3]$

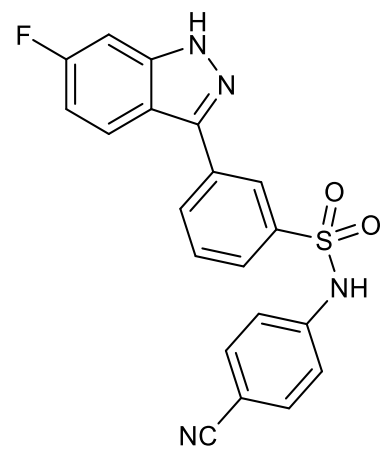

$\mathrm{N}$-(4-cyanophenyl)-3-(6-fluoro-1H-indazol-3-yl)benzenesulfonamide (15k). General Procedure E used to afford 15k (224 mg, 46\%) as an off-white solid. Analytical data: ${ }^{1} \mathrm{H}$ NMR (500 MHz, DMSO- $\left.d_{6}\right) \delta 13.53$ (s, $1 \mathrm{H}), 11.15(\mathrm{~s}, 1 \mathrm{H}), 8.36(\mathrm{t}, J=1.8 \mathrm{~Hz}, 1 \mathrm{H}), 8.24(\mathrm{dt}, J=7.9,1.3 \mathrm{~Hz}, 1 \mathrm{H}), 7.97(\mathrm{dd}, J=9.0,5.1 \mathrm{~Hz}, 1 \mathrm{H}), 7.86$ (ddd, $J=7.9,2.0,1.1 \mathrm{~Hz}, 1 \mathrm{H}), 7.76-7.67(\mathrm{~m}, 3 \mathrm{H}), 7.42(\mathrm{dd}, J=9.5,2.3 \mathrm{~Hz}, 1 \mathrm{H}), 7.29(\mathrm{~d}, J=8.5 \mathrm{~Hz}, 2 \mathrm{H})$, $7.15(\mathrm{td}, J=9.1,2.3 \mathrm{~Hz}, 1 \mathrm{H}) .{ }^{13} \mathrm{C}$ NMR $\left(126 \mathrm{MHz}, \mathrm{DMSO}-d_{6}\right) \delta 161.3\left(\mathrm{~d}, J_{\mathrm{C}-\mathrm{F}}=243.0 \mathrm{~Hz}\right), 141.9\left(\mathrm{~d}, J_{\mathrm{C}-\mathrm{F}}=\right.$ $12.7 \mathrm{~Hz}), 141.6,134.4,133.7,131.1,130.3,125.9,124.1,122.1\left(\mathrm{~d}, J_{\mathrm{C}-\mathrm{F}}=10.9 \mathrm{~Hz}\right), 118.9,117.0,111.2\left(\mathrm{~d}, J_{\mathrm{C}-\mathrm{F}}\right.$ $=26.0 \mathrm{~Hz}), 96.3\left(\mathrm{~d}, J_{\mathrm{C}-\mathrm{F}}=25.9 \mathrm{~Hz}\right)$. HRMS (ESI): Exact mass calculated for $\mathrm{C}_{20} \mathrm{H}_{13} \mathrm{FN}_{4} \mathrm{O}_{2} \mathrm{~S}^{+}[\mathrm{M}+\mathrm{H}], 393.0816$. Found 393.0822. $\mathrm{IC}_{50}: 0.47 \mu \mathrm{M}[0.21 \pm 0.023, \mathrm{n}=3 ; 0.73 \pm 0.15, \mathrm{n}=3]$ 


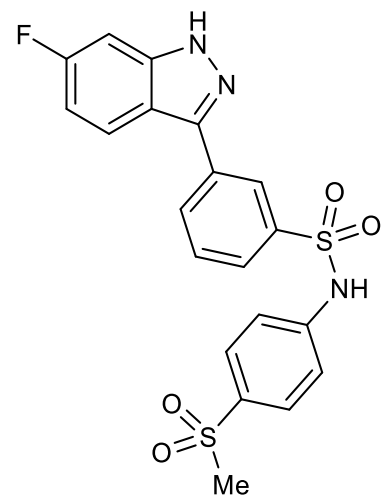

3-(6-fluoro-1H-indazol-3-yl)- $\boldsymbol{N}$-(4-(methylsulfonyl)phenyl)benzenesulfonamide (15l). General Procedure E was used to afford $15 \mathrm{l}(336 \mathrm{mg}, 55 \%)$ as a white solid. Analytical data: ${ }^{1} \mathrm{H}$ NMR (500 MHz, DMSO- $\left.d_{6}\right) \delta$ $13.54(\mathrm{~s}, 1 \mathrm{H}), 11.16(\mathrm{~s}, 1 \mathrm{H}), 8.40(\mathrm{t}, J=1.8 \mathrm{~Hz}, 1 \mathrm{H}), 8.26(\mathrm{dt}, J=8.0,1.4 \mathrm{~Hz}, 1 \mathrm{H}), 7.98(\mathrm{dd}, J=9.0,5.0 \mathrm{~Hz}$, 1H), 7.90 (ddd, $J=7.9,2.0,1.1 \mathrm{~Hz}, 1 \mathrm{H}), 7.84-7.79(\mathrm{~m}, 2 \mathrm{H}), 7.75(\mathrm{t}, J=7.8 \mathrm{~Hz}, 1 \mathrm{H}), 7.43$ (dd, $J=9.4,2.2 \mathrm{~Hz}$, $1 \mathrm{H}), 7.40-7.36(\mathrm{~m}, 2 \mathrm{H}), 7.16(\mathrm{td}, J=9.1,2.3 \mathrm{~Hz}, 1 \mathrm{H}), 3.10(\mathrm{~s}, 3 \mathrm{H}) .{ }^{13} \mathrm{C}$ NMR $\left(126 \mathrm{MHz}, \mathrm{DMSO}-d_{6}\right) \delta 161.3$ $\left(\mathrm{d}, J_{\mathrm{C}-\mathrm{F}}=242.7 \mathrm{~Hz}\right), 142.5,141.9\left(\mathrm{~d}, J_{\mathrm{C}-\mathrm{F}}=12.9 \mathrm{~Hz}\right), 141.6,140.0,135.3,134.4,131.3,130.4,128.8,125.9$, $124.2,122.6\left(\mathrm{~d}, J_{\mathrm{C}-\mathrm{F}}=11.0 \mathrm{~Hz}\right), 119.0,117.5,111.7\left(\mathrm{~d}, J_{\mathrm{C}-\mathrm{F}}=26.1 \mathrm{~Hz}\right), 96.8\left(\mathrm{~d}, J_{\mathrm{C}-\mathrm{F}}=25.9 \mathrm{~Hz}\right), 44.1$. HRMS (ESI): Exact mass calculated for $\mathrm{C}_{20} \mathrm{H}_{17} \mathrm{FN}_{3} \mathrm{O}_{4} \mathrm{~S}_{2}{ }^{+}[\mathrm{M}+\mathrm{H}], 446.0645$. Found 446.0645 IC 50 : $0.29 \mu \mathrm{M}[0.29 \pm$ $0.058, \mathrm{n}=3 ; 0.29 \pm 0.047, \mathrm{n}=3]$

MEK7 IC $50: 0.92 \mu \mathrm{M}[0.59 \pm 0.19, \mathrm{n}=3 ; 0.78 \pm 0.28, \mathrm{n}=3 ; 1.4 \pm 0.34, \mathrm{n}=3]$

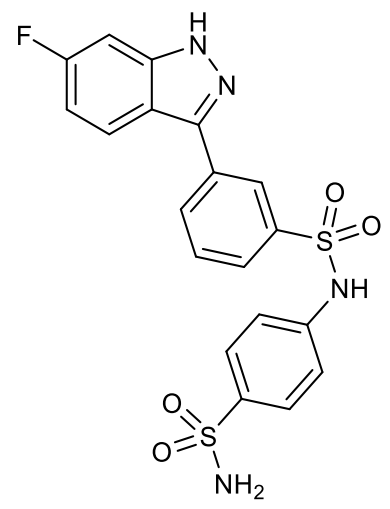

3-(6-fluoro-1 $H$-indazol-3-yl)- $\boldsymbol{N}$-(4-sulfamoylphenyl)benzenesulfonamide (15m). General Procedure E was used to afford $\mathbf{1 5 m}(287 \mathrm{mg}, 27 \%)$ as an off-white solid. Analytical data: ${ }^{1} \mathrm{H}$ NMR (500 MHz, DMSO- $\left.d_{6}\right) \delta$ $13.54(\mathrm{~s}, 1 \mathrm{H}), 10.98(\mathrm{~s}, 1 \mathrm{H}), 8.38(\mathrm{~s}, 1 \mathrm{H}), 8.23(\mathrm{dd}, J=7.8,1.7 \mathrm{~Hz}, 1 \mathrm{H}), 7.98(\mathrm{dd}, J=9.0,5.0 \mathrm{~Hz}, 1 \mathrm{H}), 7.86(\mathrm{dt}$, $J=8.0,1.3 \mathrm{~Hz}, 1 \mathrm{H}), 7.76-7.67(\mathrm{~m}, 3 \mathrm{H}), 7.42(\mathrm{dd}, J=9.5,2.3 \mathrm{~Hz}, 1 \mathrm{H}), 7.31(\mathrm{~d}, J=8.7 \mathrm{~Hz}, 2 \mathrm{H}), 7.21(\mathrm{~s}, 2 \mathrm{H})$, $7.16(\mathrm{td}, J=9.1,2.3 \mathrm{~Hz}, 1 \mathrm{H}) .{ }^{13} \mathrm{C}$ NMR $\left(126 \mathrm{MHz}, \mathrm{DMSO}-d_{6}\right) \delta 161.4\left(\mathrm{~d}, J_{\mathrm{C}-\mathrm{F}}=242.6 \mathrm{~Hz}\right), 141.9\left(\mathrm{~d}, J_{\mathrm{C}-\mathrm{F}}=\right.$ $12.9 \mathrm{~Hz}), 141.7,140.9,140.0,139.1,134.4,131.2,130.3,127.3,126.0,124.3,122.1\left(\mathrm{~d}, J_{\mathrm{C}-\mathrm{F}}=11.1 \mathrm{~Hz}\right), 118.7$, 117.0, $111.3\left(\mathrm{~d}, J_{\mathrm{C}-\mathrm{F}}=26.1 \mathrm{~Hz}\right), 96.4\left(\mathrm{~d}, J_{\mathrm{C}-\mathrm{F}}=25.8 \mathrm{~Hz}\right)$. HRMS (ESI): Mass calculated for $\mathrm{C}_{19} \mathrm{H}_{15} \mathrm{FN}_{4} \mathrm{O}_{4} \mathrm{~S}_{2} \mathrm{Na}^{+}$ $[\mathrm{M}+\mathrm{Na}], 469.0417$. Found 469.0416. $\mathrm{IC}_{50}: 0.64 \mu \mathrm{M}[0.62 \pm 0.054, \mathrm{n}=3 ; 0.65 \pm 0.071, \mathrm{n}=3]$ 


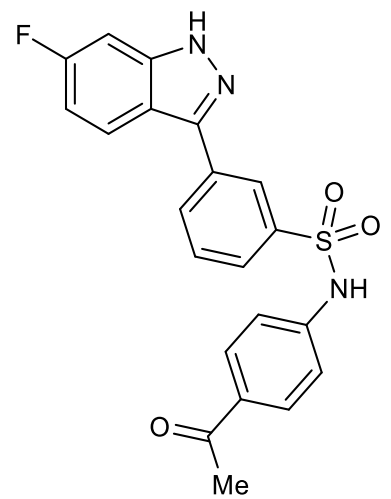

$\boldsymbol{N}$-(4-acetylphenyl)-3-(6-fluoro-1H-indazol-3-yl)benzenesulfonamide (15n). General Procedure E was used to afford $15 \mathrm{n}(678 \mathrm{mg}, 59 \%)$ as a white solid. Analytical data: ${ }^{1} \mathrm{H}$ NMR $\left(500 \mathrm{MHz}, \mathrm{DMSO}-d_{6}\right) \delta 13.53(\mathrm{~s}, 1 \mathrm{H})$, $10.98(\mathrm{~s}, 1 \mathrm{H}), 8.37(\mathrm{t}, J=1.8 \mathrm{~Hz}, 1 \mathrm{H}), 8.23(\mathrm{dt}, J=7.9,1.4 \mathrm{~Hz}, 1 \mathrm{H}), 7.96(\mathrm{dd}, J=9.0,5.1 \mathrm{~Hz}, 1 \mathrm{H}), 7.86$ (ddt, $J$ $=9.3,6.4,1.9 \mathrm{~Hz}, 3 \mathrm{H}), 7.72(\mathrm{t}, J=7.9 \mathrm{~Hz}, 1 \mathrm{H}), 7.41(\mathrm{dd}, J=9.4,2.3 \mathrm{~Hz}, 1 \mathrm{H}), 7.30-7.25(\mathrm{~m}, 2 \mathrm{H}), 7.12(\mathrm{td}, J=$ 9.1, $2.3 \mathrm{~Hz}, 1 \mathrm{H}), 2.45(\mathrm{~s}, 3 \mathrm{H}) .{ }^{13} \mathrm{C}$ NMR (126 MHz, DMSO-d $) \delta 196.5,161.3\left(\mathrm{~d}, J_{\mathrm{C}-\mathrm{F}}=242.7 \mathrm{~Hz}\right), 142.2$, $141.93\left(\mathrm{~d}, J_{\mathrm{C}-\mathrm{F}}=12.9 \mathrm{~Hz}\right), 141.6,140.0,134.2,132.2,131.1,130.3,129.9,125.9,124.2,122.1\left(\mathrm{~d}, J_{\mathrm{C}-\mathrm{F}}=11.0\right.$ $\mathrm{Hz}), 118.2,117.0,111.2\left(\mathrm{~d}, J_{\mathrm{C}-\mathrm{F}}=26.2 \mathrm{~Hz}\right), 96.3\left(\mathrm{~d}, J_{\mathrm{C}-\mathrm{F}}=25.9 \mathrm{~Hz}\right), 26.4$. HRMS (ESI): Exact mass calculated for $\mathrm{C}_{21} \mathrm{H}_{16} \mathrm{FN}_{3} \mathrm{O}_{3} \mathrm{~S}^{+}[\mathrm{M}+\mathrm{H}], 410.0969$. Found 410.0981. $\mathrm{IC}_{50}: 0.86 \mu \mathrm{M}[0.81 \pm 0.095, \mathrm{n}=3 ; 0.91 \pm 0.12, \mathrm{n}=3]$ MEK7 $\mathrm{IC}_{50}: 1.3 \mu \mathrm{M}[0.74 \pm 0.25, \mathrm{n}=3 ; 1.3 \pm 0.34, \mathrm{n}=3 ; 1.8 \pm 0.37, \mathrm{n}=3]$

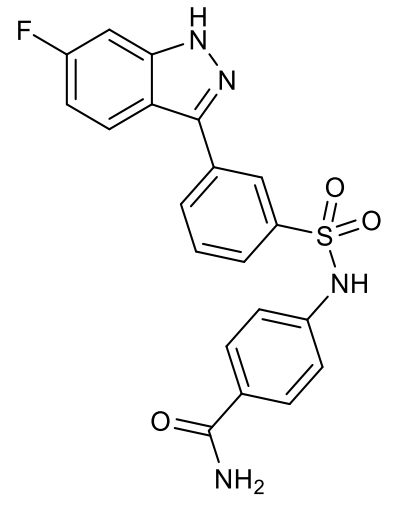

4-((3-(6-fluoro-1H-indazol-3-yl)phenyl)sulfonamido)benzamide (15o). General Procedure E was used to afford 150 (192 mg, 16\%) as a white solid. Analytical data: ${ }^{1} \mathrm{H}$ NMR (500 MHz, DMSO- $\left.d_{6}\right) \delta 13.51(\mathrm{~s}, 1 \mathrm{H})$, $10.75(\mathrm{~s}, 1 \mathrm{H}), 8.30(\mathrm{t}, J=1.8 \mathrm{~Hz}, 1 \mathrm{H}), 8.21(\mathrm{dt}, J=7.8,1.4 \mathrm{~Hz}, 1 \mathrm{H}), 7.88-7.79(\mathrm{~m}, 3 \mathrm{H}), 7.78-7.74(\mathrm{~m}, 2 \mathrm{H})$, $7.71(\mathrm{t}, J=7.8 \mathrm{~Hz}, 1 \mathrm{H}), 7.41(\mathrm{dd}, J=9.4,2.3 \mathrm{~Hz}, 1 \mathrm{H}), 7.24(\mathrm{bs}, 1 \mathrm{H}), 7.22-7.17(\mathrm{~m}, 2 \mathrm{H}), 7.12(\mathrm{td}, J=9.2,2.3$ $\mathrm{Hz}, 1 \mathrm{H}) .{ }^{13} \mathrm{C}$ NMR $\left(126 \mathrm{MHz}, \mathrm{DMSO}-d_{6}\right) \delta 167.1,161.3\left(\mathrm{~d}, J_{\mathrm{C}-\mathrm{F}}=242.5 \mathrm{~Hz}\right), 141.9\left(\mathrm{~d}, J_{\mathrm{C}-\mathrm{F}}=12.8 \mathrm{~Hz}\right), 141.7$, $140.4,140.0,134.2,131.2,130.2,129.7,128.9,125.9,124.2,122.0\left(\mathrm{~d}, J_{\mathrm{C}-\mathrm{F}}=11.1 \mathrm{~Hz}\right), 118.7,117.0,111.2(\mathrm{~d}$, $\left.J_{\mathrm{C}-\mathrm{F}}=26.1 \mathrm{~Hz}\right), 96.3\left(\mathrm{~d}, J_{\mathrm{C}-\mathrm{F}}=25.7 \mathrm{~Hz}\right)$. HRMS (ESI): Exact mass calculated for $\mathrm{C}_{20} \mathrm{H}_{15} \mathrm{FN}_{4} \mathrm{O}_{3} \mathrm{~S}^{+}[\mathrm{M}+\mathrm{H}]$, 411.0922. Found 411.0928. $\mathrm{IC}_{50}: 0.083 \mu \mathrm{M}[0.075 \pm 0.011, \mathrm{n}=3 ; 0.088 \pm 0.011, \mathrm{n}=3]$

MEK7 IC $50: 0.096 \mu \mathrm{M}[0.041 \pm 0.014, \mathrm{n}=3 ; 0.15 \pm 0.064, \mathrm{n}=3]$ 


\section{Tabulated Data for Compounds S1-5}

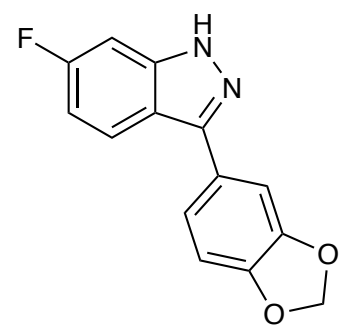

3-(benzo[d][1,3]dioxol-5-yl)-6-fluoro-1H-indazole (S1). Using General Procedure 1 with the corresponding boronic acid, S1 (218 mg, 77\%) was obtained as a brown solid. Spectra and potency match literature. ${ }^{3}$ Analytical data: ${ }^{1} \mathrm{H}$ NMR $\left(500 \mathrm{MHz}, \mathrm{DMSO}-d_{6}\right) \delta 13.19(\mathrm{~s}, 1 \mathrm{H}), 8.03(\mathrm{dd}, J=8.9,5.1 \mathrm{~Hz}, 1 \mathrm{H}), 7.56-7.41$ $(\mathrm{m}, 2 \mathrm{H}), 7.34(\mathrm{dd}, J=9.5,2.3 \mathrm{~Hz}, 1 \mathrm{H}), 7.12-6.99(\mathrm{~m}, 2 \mathrm{H}), 6.09(\mathrm{~s}, 2 \mathrm{H}) .{ }^{13} \mathrm{C}$ NMR $\left(126 \mathrm{MHz}\right.$, DMSO- $\left.d_{6}\right) \delta$ $161.2\left(\mathrm{~d}, J_{C-F}=241.8 \mathrm{~Hz}\right), 147.8,147.1,143.4,141.8\left(\mathrm{~d}, J_{C-F}=12.8 \mathrm{~Hz}\right), 127.3,122.6\left(\mathrm{~d}, J_{C-F}=11.1 \mathrm{~Hz}\right)$, 120.6, 117.1, $110.4\left(\mathrm{~d}, J_{C-F}=25.9 \mathrm{~Hz}\right), 108.7,107.0,101.2,95.8\left(\mathrm{~d}, J_{C-F}=25.7 \mathrm{~Hz}\right) . \mathrm{IC}_{50}: 0.026 \pm 0.013 \mu \mathrm{M}$, $\mathrm{n}=3$

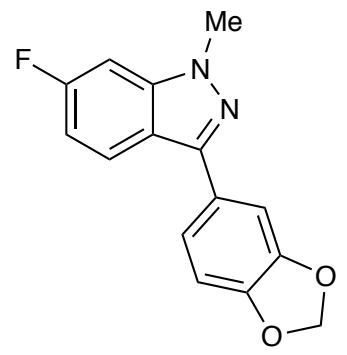

3-(benzo[ $[\boldsymbol{d}][\mathbf{1 , 3}]$ dioxol-5-yl)-6-fluoro-1-methyl-1H-indazole (S2). To a flame-dried vial was added S1 (70 $\mathrm{mg}, 0.27 \mathrm{mmol})$. It was dissolved in acetone $(0.68 \mathrm{~mL})$, and the solution reduced to $0{ }^{\circ} \mathrm{C}$, followed by addition of $\mathrm{KOH}(23 \mathrm{mg}, 0.41 \mathrm{mmol})$. After 15 minutes of stirring, MeI $(17 \mu \mathrm{L}, 0.27 \mathrm{mmol})$ was added dropwise. Reaction was monitored by UPLC. At 1 hour, more MeI was added dropwise $(34 \mu \mathrm{L}, 0.54 \mathrm{mmol})$. The reaction was washed with saturated aqueous ammonium chloride solution and concentrated. Residue was purified by flash chromatography $\left(0-30 \%\right.$ EtOAc/Hex, $\left.\mathrm{SiO}_{2}\right)$ to yield $\mathbf{S 2}(44 \mathrm{mg}, 60 \%)$ as an off-white solid. Analytical data: ${ }^{1} \mathrm{H}$ NMR $\left(500 \mathrm{MHz}, \mathrm{DMSO}-d_{6}\right) \delta 8.03(\mathrm{dd}, J=9.0,5.2 \mathrm{~Hz}, 1 \mathrm{H}), 7.56(\mathrm{dd}, J=9.8,2.2 \mathrm{~Hz}, 1 \mathrm{H}), 7.48-$ $7.39(\mathrm{~m}, 2 \mathrm{H}), 7.10-7.02(\mathrm{~m}, 2 \mathrm{H}), 6.09(\mathrm{~s}, 2 \mathrm{H}), 4.04(\mathrm{~s}, 3 \mathrm{H}) .{ }^{13} \mathrm{C}$ NMR $\left(126 \mathrm{MHz}\right.$, DMSO- $\left.d_{6}\right) \delta 161.3\left(\mathrm{~d}, J_{C-F}=\right.$ $242.2 \mathrm{~Hz}), 147.8,147.2,142.3,141.6\left(\mathrm{~d}, J_{C-F}=12.9 \mathrm{~Hz}\right), 126.8,122.8$ (d, $\left.J_{C-F}=11.1 \mathrm{~Hz}\right), 120.6,117.5,110.5$ $\left(\mathrm{d}, J_{C-F}=26.1 \mathrm{~Hz}\right), 108.7,106.9,101.2,95.7\left(\mathrm{~d}, J_{C-F}=26.5 \mathrm{~Hz}\right)$. HRMS (ESI): Exact mass calculated for $\mathrm{C}_{15} \mathrm{H}_{12} \mathrm{FN}_{2} \mathrm{O}_{2}+[\mathrm{M}+\mathrm{H}], 271.0883$. Found 271.0876. $\mathrm{IC}_{50}:>80 \mu \mathrm{M}$

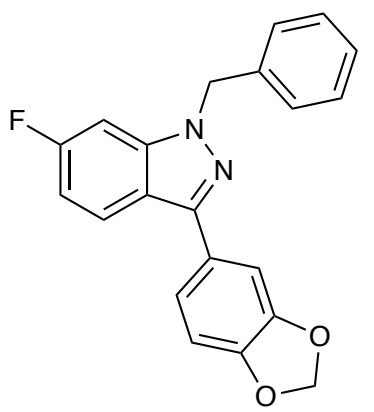

3-(benzo[d][1,3]dioxol-5-yl)-1-benzyl-6-fluoro-1 $\boldsymbol{H}$-indazole (S3). To a flame-dried vial was added $\mathbf{S 1}$ (70 $\mathrm{mg}$, $0.27 \mathrm{mmol})$. It was dissolved in acetone $(0.68 \mathrm{~mL})$. The solution was reduced to $0{ }^{\circ} \mathrm{C}$ and $\mathrm{KOH}(23 \mathrm{mg}, 0.41$ 
mmol) was added. After 15 minutes of stirring, benzyl bromide (32 $\mu \mathrm{L}, 0.27 \mathrm{mmol}$ ) was added dropwise. Reaction was monitored by UPLC. Reaction was concentrated and reconstituted in ethyl acetate. The organic layer was washed with water and brine, dried over sodium sulfate, concentrated in vacuo, and purified by flash chromatography (0-30\% EtOAc/Hex, $\left.\mathrm{SiO}_{2}\right)$ to yield $\mathbf{S 3}(73 \mathrm{mg}, 77 \%)$ as a white solid. Analytical data: ${ }^{1} \mathrm{H}$ NMR (500 MHz, DMSO-d6) $\delta 8.05(\mathrm{dd}, J=8.9,5.1 \mathrm{~Hz}, 1 \mathrm{H}), 7.67(\mathrm{dd}, J=9.8,2.3 \mathrm{~Hz}, 1 \mathrm{H}), 7.49-7.41(\mathrm{~m}$, 2H), $7.35-7.28(\mathrm{~m}, 4 \mathrm{H}), 7.26(\mathrm{tt}, J=7.2,2.2 \mathrm{~Hz}, 1 \mathrm{H}), 7.11-7.03(\mathrm{~m}, 2 \mathrm{H}), 6.09(\mathrm{~s}, 2 \mathrm{H}), 5.65(\mathrm{~s}, 2 \mathrm{H}) .{ }^{13} \mathrm{C}$ NMR $\left(126 \mathrm{MHz}, \mathrm{DMSO}-d_{6}\right) \delta 161.4\left(\mathrm{~d}, J_{C-F}=242.6 \mathrm{~Hz}\right), 147.8,147.3,143.1,141.3\left(\mathrm{~d}, J_{C-F}=12.9 \mathrm{~Hz}\right), 137.1$, $128.5,127.6,127.5,126.7,123.0\left(\mathrm{~d}, J_{C-F}=11.1 \mathrm{~Hz}\right), 120.8,117.8,110.7\left(\mathrm{~d}, J_{C-F}=26.0 \mathrm{~Hz}\right), 108.7,107.0$, 101.22, $95.9\left(\mathrm{~d}, J_{C-F}=26.6 \mathrm{~Hz}\right), 51.8$. HRMS (ESI): Exact mass calculated for $\mathrm{C}_{21} \mathrm{H}_{16} \mathrm{FN}_{2} \mathrm{O}_{2}{ }^{+}[\mathrm{M}+\mathrm{H}]$, 347.1196. Found 347.1190. $\mathrm{IC}_{50}:>80 \mu \mathrm{M}$

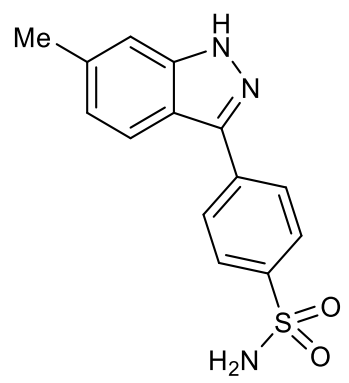

4-(6-methyl-1H-indazol-3-yl)benzenesulfonamide (S4). The procedure used to make precursor S6 was used to make the corresponding indazole starting material for S4. General Procedure $\mathrm{C}$ was then used to afford S4 (66 $\mathrm{mg}, 17 \%)$ as a pink solid. Analytical data: ${ }^{1} \mathrm{H}$ NMR $\left(500 \mathrm{MHz}, \mathrm{DMSO}-d_{6}\right) \delta 13.28(\mathrm{~s}, 1 \mathrm{H}), 8.21-8.15(\mathrm{~m}$, 2H), $8.02(\mathrm{~d}, J=8.4 \mathrm{~Hz}, 1 \mathrm{H}), 7.96-7.92(\mathrm{~m}, 2 \mathrm{H}), 7.45-7.37(\mathrm{~m}, 3 \mathrm{H}), 7.09(\mathrm{dd}, J=8.5,1.4 \mathrm{~Hz}, 1 \mathrm{H}), 2.47(\mathrm{~s}$, $3 \mathrm{H}) .{ }^{13} \mathrm{C}$ NMR (126 MHz, DMSO) $\delta 142.7,142.3,141.5,137.0,136.1,127.6,126.7,126.4,126.3,123.7,120.2$, 118.4, 110.0, 21.3. HRMS (ESI): Mass calculated for $\mathrm{C}_{14} \mathrm{H}_{13} \mathrm{~N}_{3} \mathrm{O}_{2} \mathrm{SNa}^{+}[\mathrm{M}+\mathrm{Na}], 310.0626$. Found 310.0624 . $\mathrm{IC}_{50}: 2.7 \mu \mathrm{M}[1.6 \pm 0.17, \mathrm{n}=3 ; 3.7 \pm 0.95, \mathrm{n}=3]$

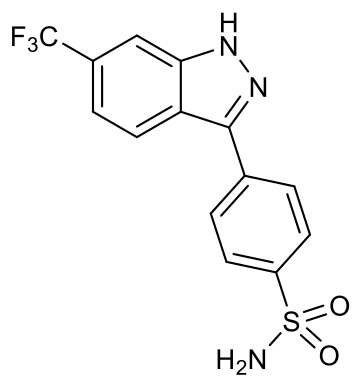

4-(6-(trifluoromethyl)-1H-indazol-3-yl)benzenesulfonamide (S5). The procedure used to make precursor S6 was used to make the corresponding indazole starting material for S5. General Procedure C was then used to afford S5 (124 mg, 23\%) as a pale orange solid. Analytical data: ${ }^{1} \mathrm{H}$ NMR (500 MHz, DMSO- $\left.d_{6}\right) \delta 13.92$ (bs, $1 \mathrm{H}), 8.38(\mathrm{~d}, J=8.6 \mathrm{~Hz}, 1 \mathrm{H}), 8.25-8.20(\mathrm{~m}, 2 \mathrm{H}), 8.02(\mathrm{~s}, 1 \mathrm{H}), 8.00-7.96(\mathrm{~m}, 2 \mathrm{H}), 7.53(\mathrm{dd}, J=8.7,1.6 \mathrm{~Hz}$, $1 \mathrm{H}), 7.44(\mathrm{~s}, 2 \mathrm{H}) .{ }^{13} \mathrm{C}$ NMR $\left(126 \mathrm{MHz}, \mathrm{DMSO}-d_{6}\right) \delta 143.4,142.4,140.5,136.0,127.1,126.9,126.8\left(\mathrm{~d}, J_{\mathrm{C}-\mathrm{F}}=\right.$ $31.5 \mathrm{~Hz}), 126.4,124.5\left(\mathrm{~d}, J_{\mathrm{C}-\mathrm{F}}=272.2 \mathrm{~Hz}\right), 122.3,121.9,117.44$ (q, $\left.J_{\mathrm{C}-\mathrm{F}}=3.0 \mathrm{~Hz}\right), 109.07-108.34(\mathrm{~m})$. HRMS (ESI): Mass calculated for $\mathrm{C}_{14} \mathrm{H}_{10} \mathrm{~F}_{3} \mathrm{~N}_{3} \mathrm{O}_{2} \mathrm{SNa}^{+}[\mathrm{M}+\mathrm{Na}], 364.0344$. Found 364.0343. IC $\mathrm{C}_{50}: 3.7 \mu \mathrm{M}$ [2.2 \pm $0.54, \mathrm{n}=3 ; 5.2 \pm 1.3, \mathrm{n}=3]$ 


\section{Selected NMR Spectra}

\section{Compounds 8a-f}

${ }^{1} \mathrm{H}$ NMR Spectrum of $8 \mathbf{a}(500 \mathrm{MHz}, \mathrm{DMSO})$

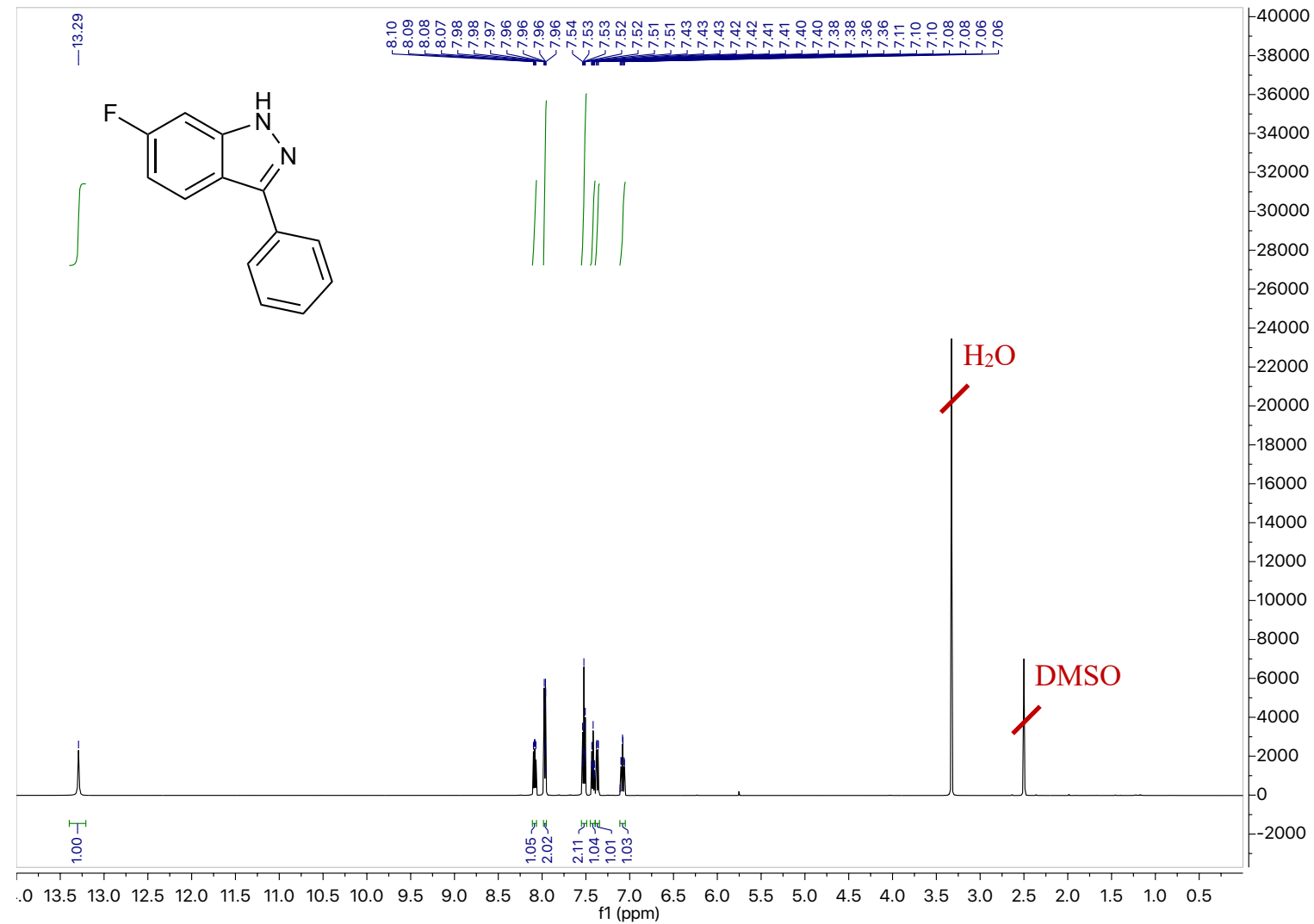

${ }^{13} \mathrm{C}$ NMR Spectrum of $8 \mathbf{a}(126 \mathrm{MHz}, \mathrm{DMSO})$

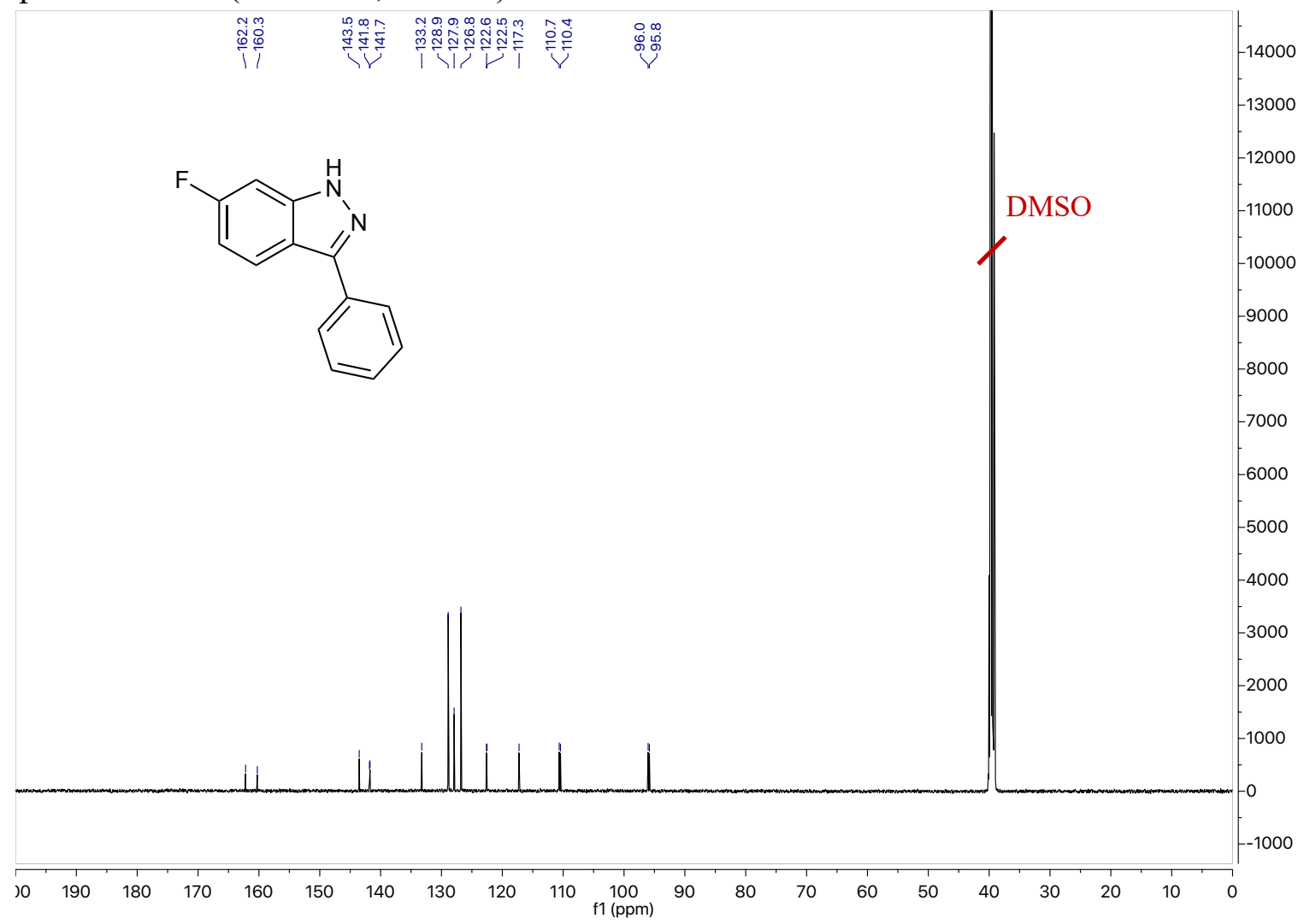


${ }^{1} \mathrm{H}$ NMR Spectrum of $\mathbf{8 b}(500 \mathrm{MHz}, \mathrm{DMSO})$

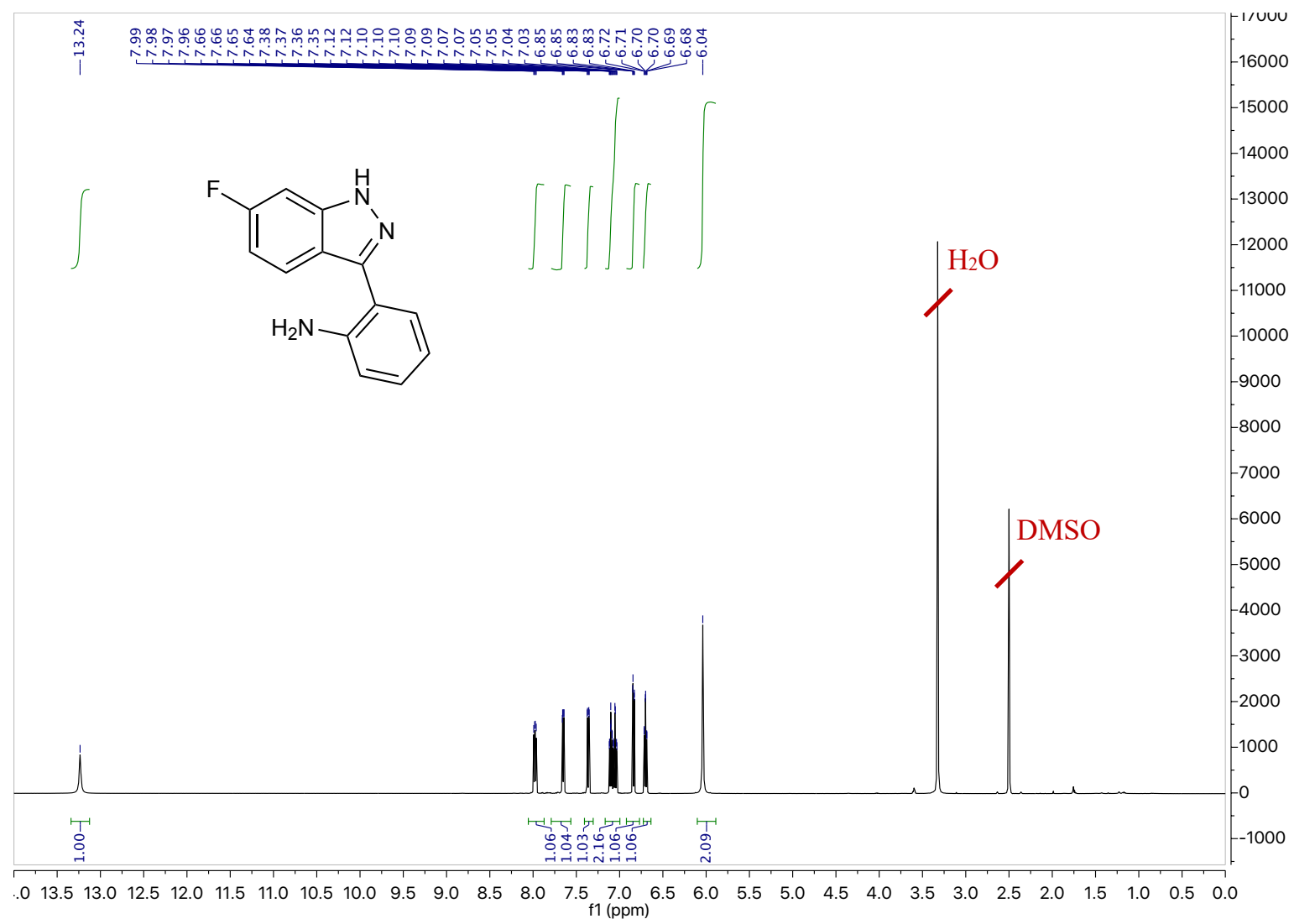

${ }^{13} \mathrm{C}$ NMR Spectrum of $\mathbf{8 b}$ (126 MHz, DMSO)

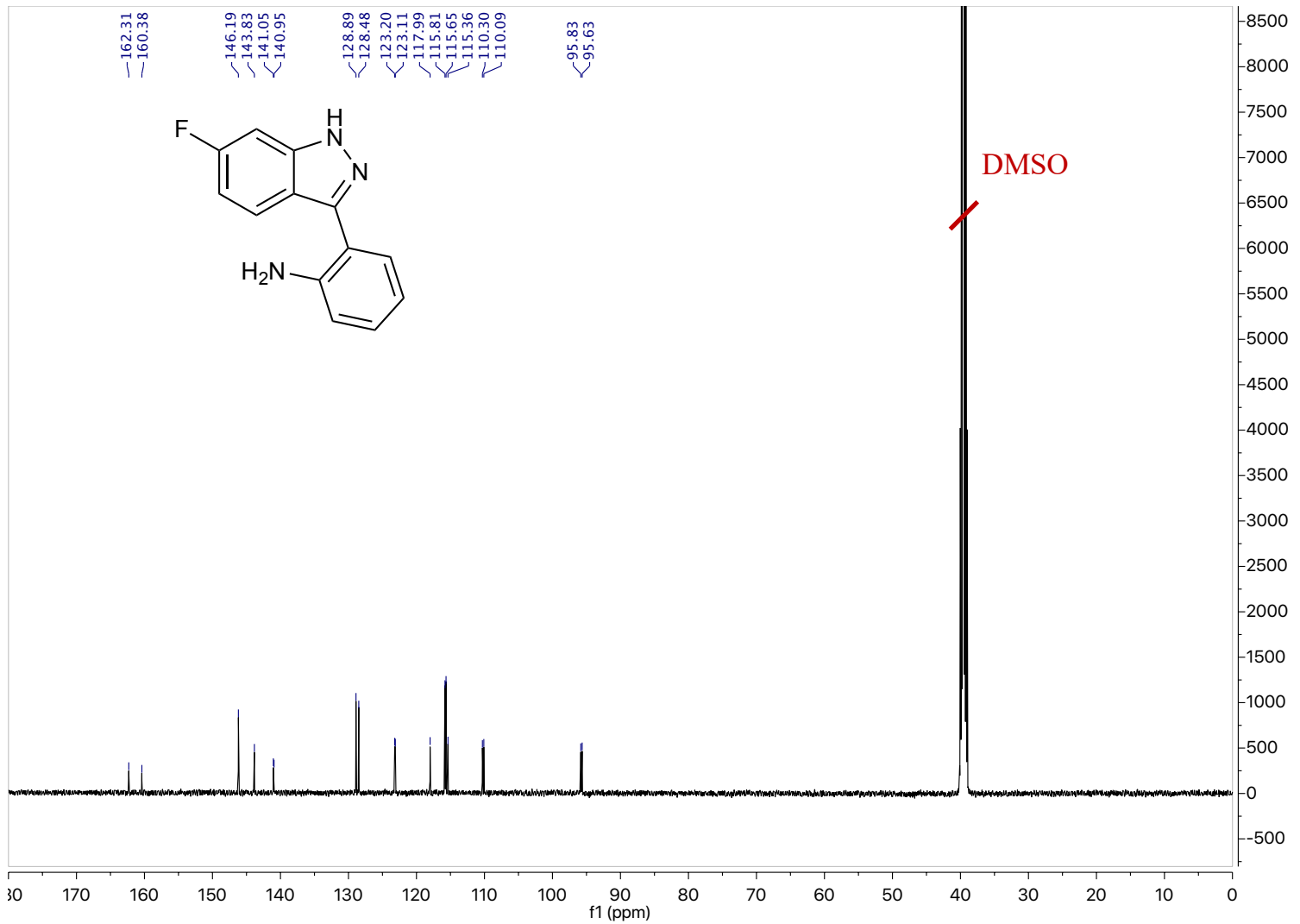


${ }^{1} \mathrm{H}$ NMR Spectrum of $\mathbf{8 c}(500 \mathrm{MHz}, \mathrm{DMSO})$

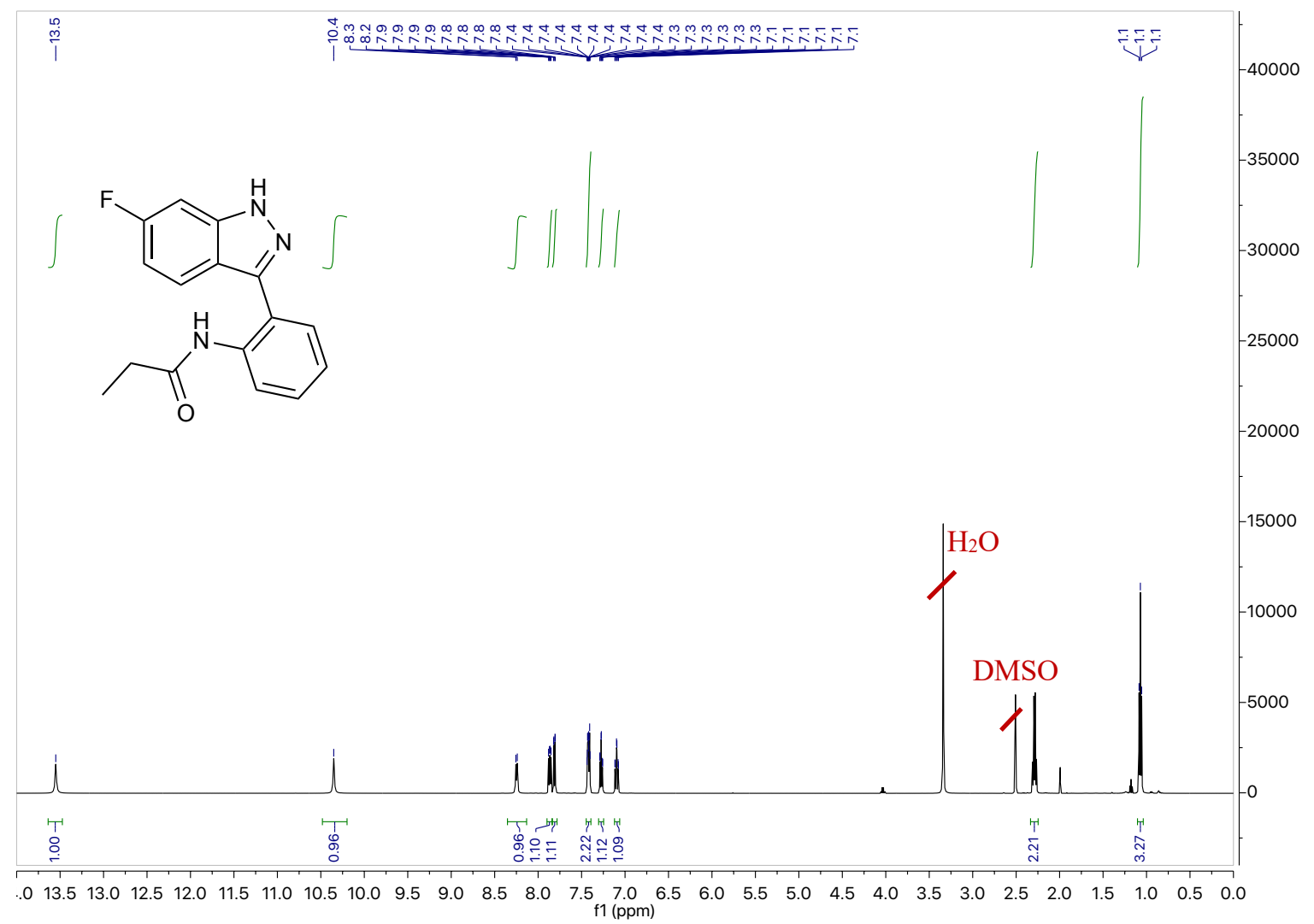

${ }^{13} \mathrm{C}$ NMR Spectrum of $\mathbf{8 c}(126 \mathrm{MHz}, \mathrm{DMSO})$

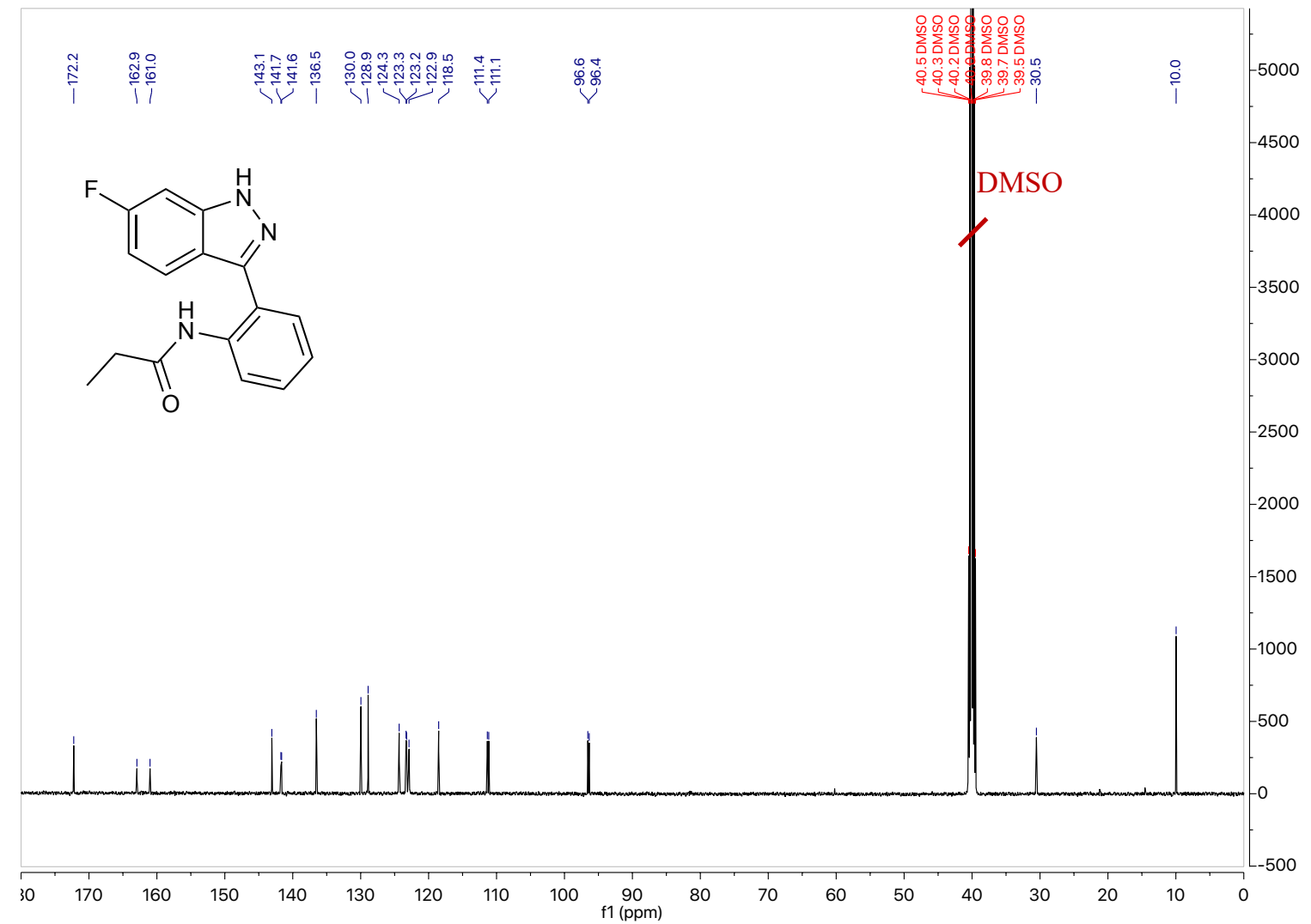


${ }^{1} \mathrm{H}$ NMR Spectrum of $8 \mathbf{d}(500 \mathrm{MHz}, \mathrm{DMSO})$

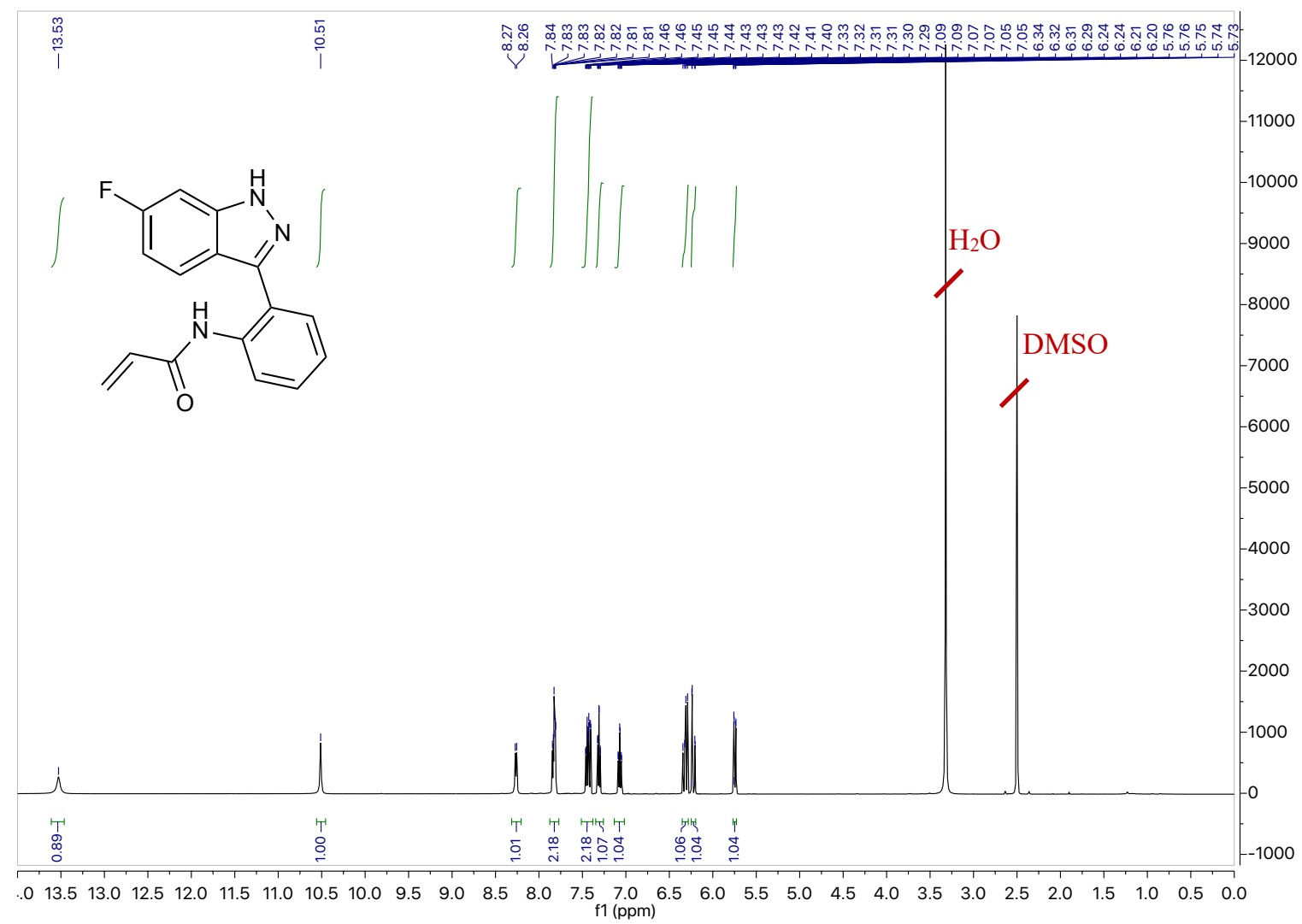

${ }^{13} \mathrm{C}$ NMR Spectrum of $8 \mathbf{d}$ (126 MHz, DMSO)

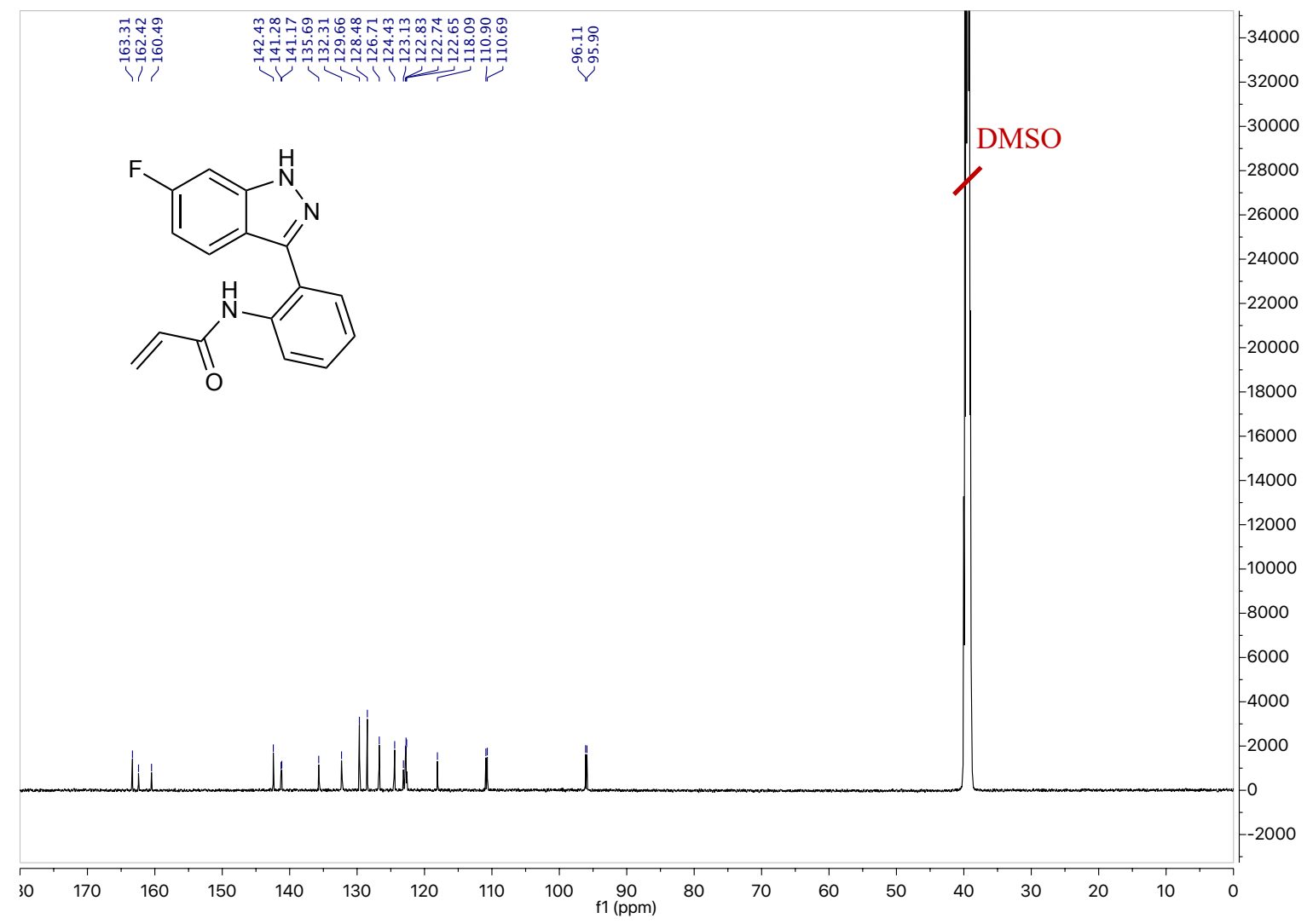


${ }^{1} \mathrm{H}$ NMR Spectrum of $8 \mathrm{e}(500 \mathrm{MHz}, \mathrm{DMSO})$

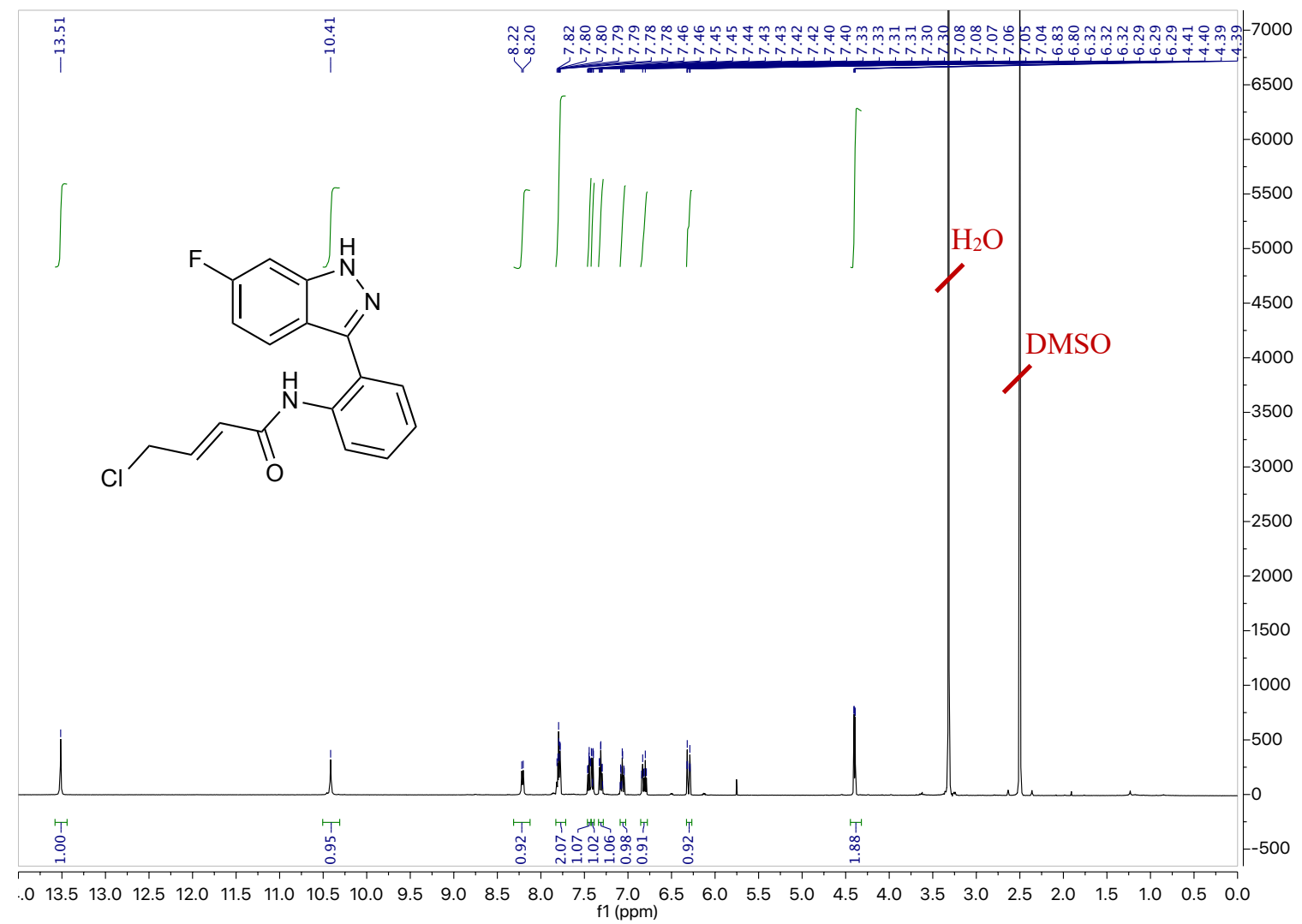

${ }^{13} \mathrm{C}$ NMR Spectrum of $8 \mathbf{e}(126 \mathrm{MHz}, \mathrm{DMSO})$

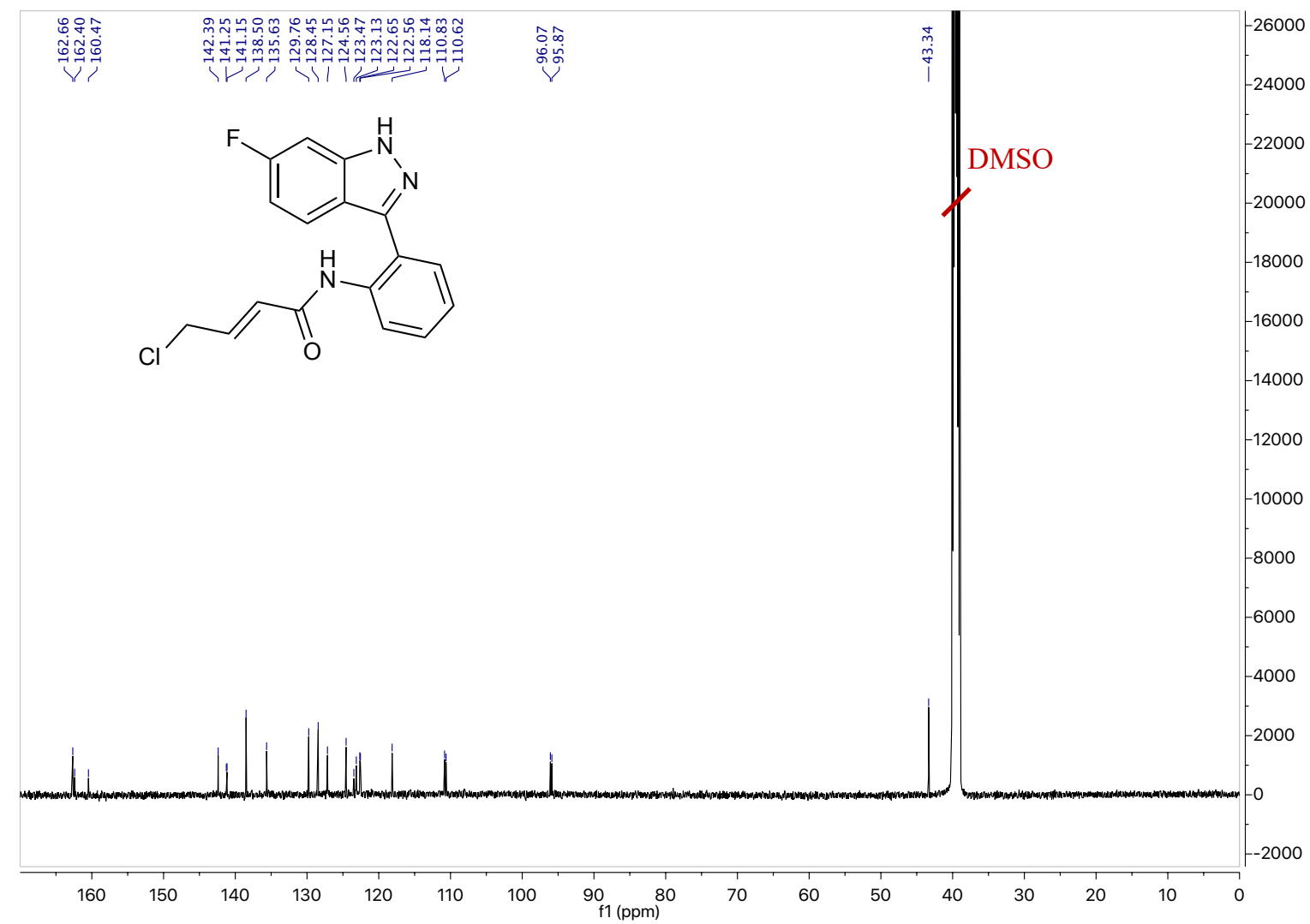


${ }^{1} \mathrm{H}$ NMR Spectrum of $8 f$ (500 MHz, DMSO)

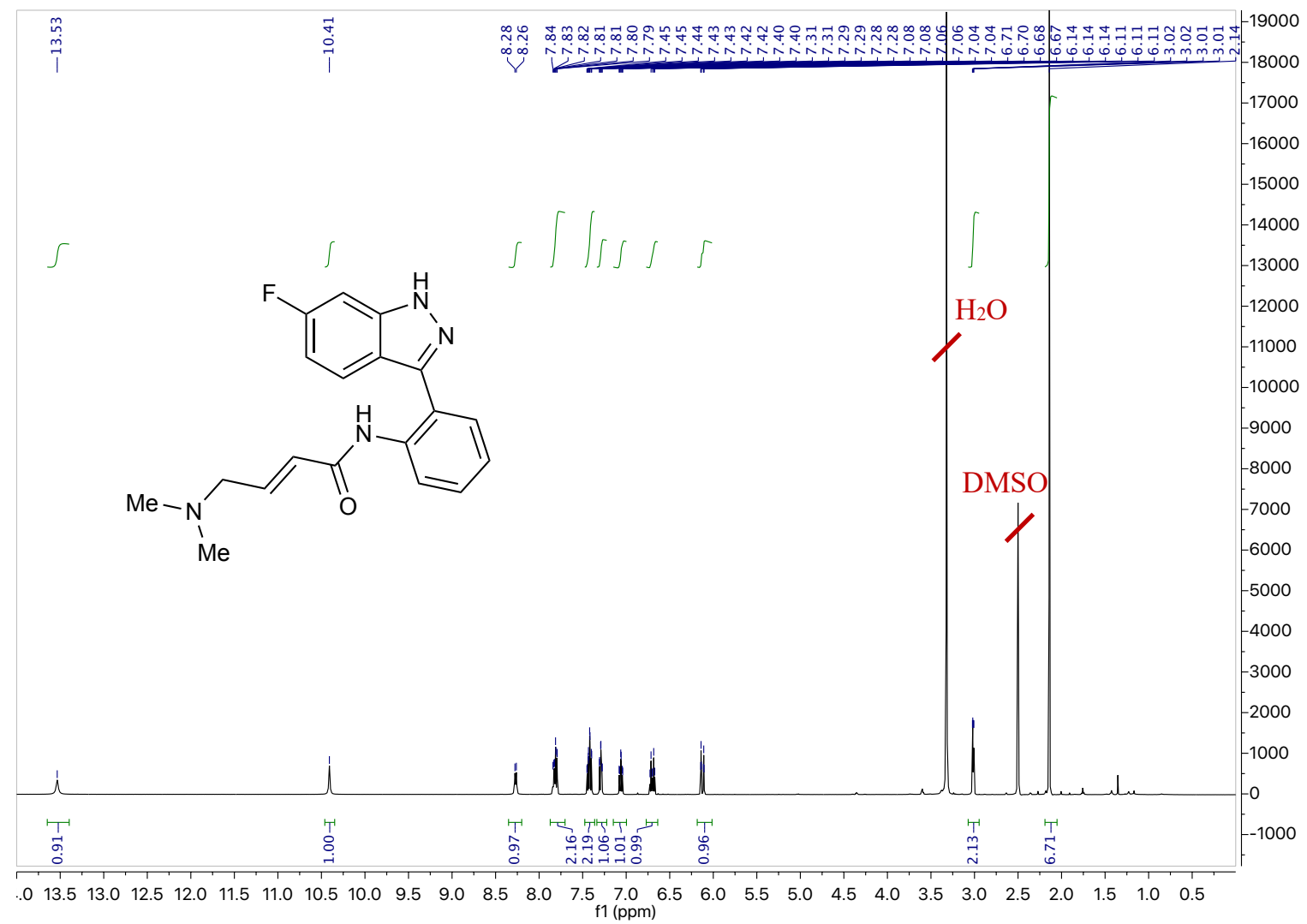

${ }^{13} \mathrm{C}$ NMR Spectrum of $\mathbf{8 f}$ (126 MHz, DMSO)

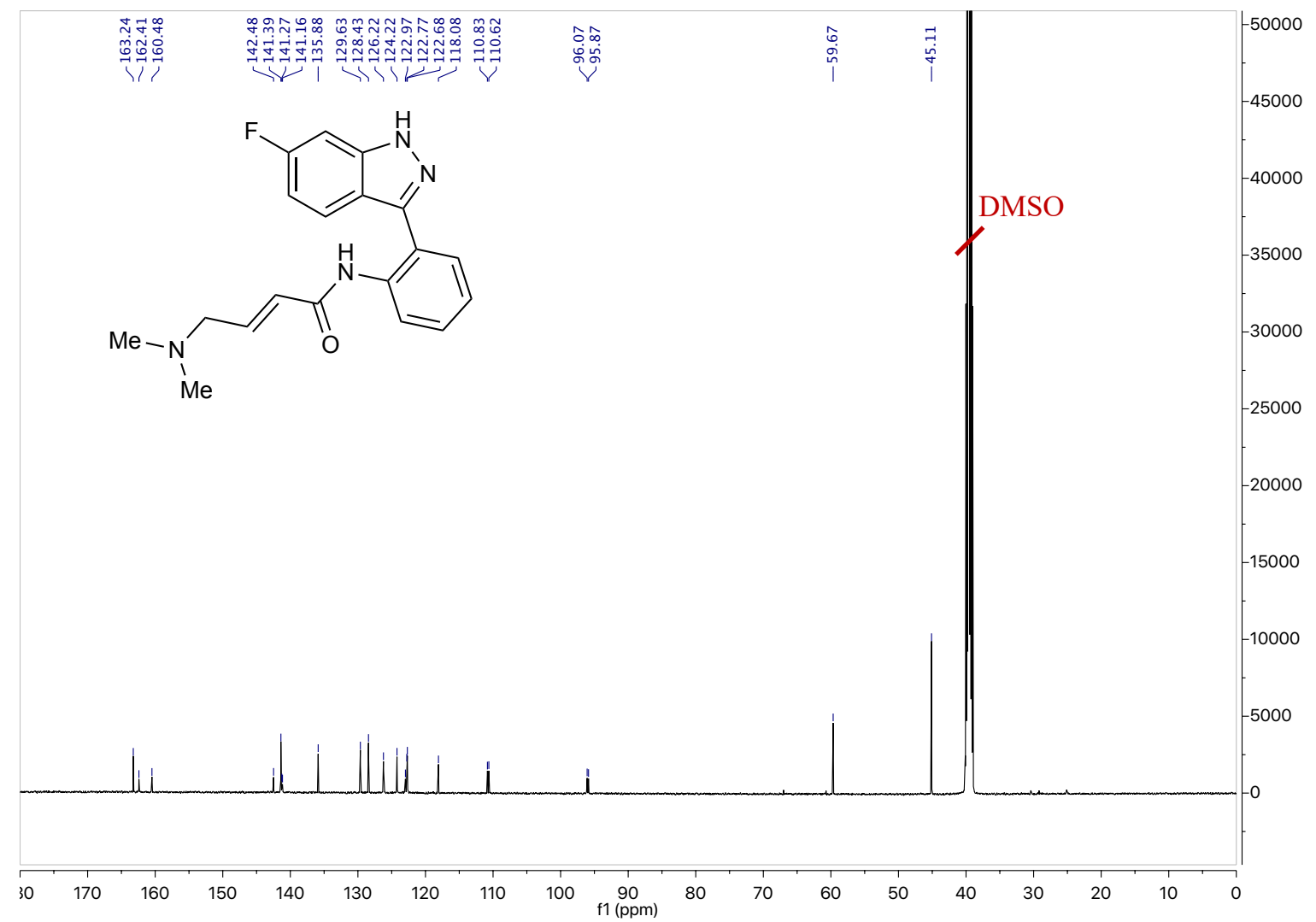




\section{Compounds 9a-d}

\section{${ }^{1} \mathrm{H}$ NMR Spectrum of 9a (500 MHz, DMSO)}

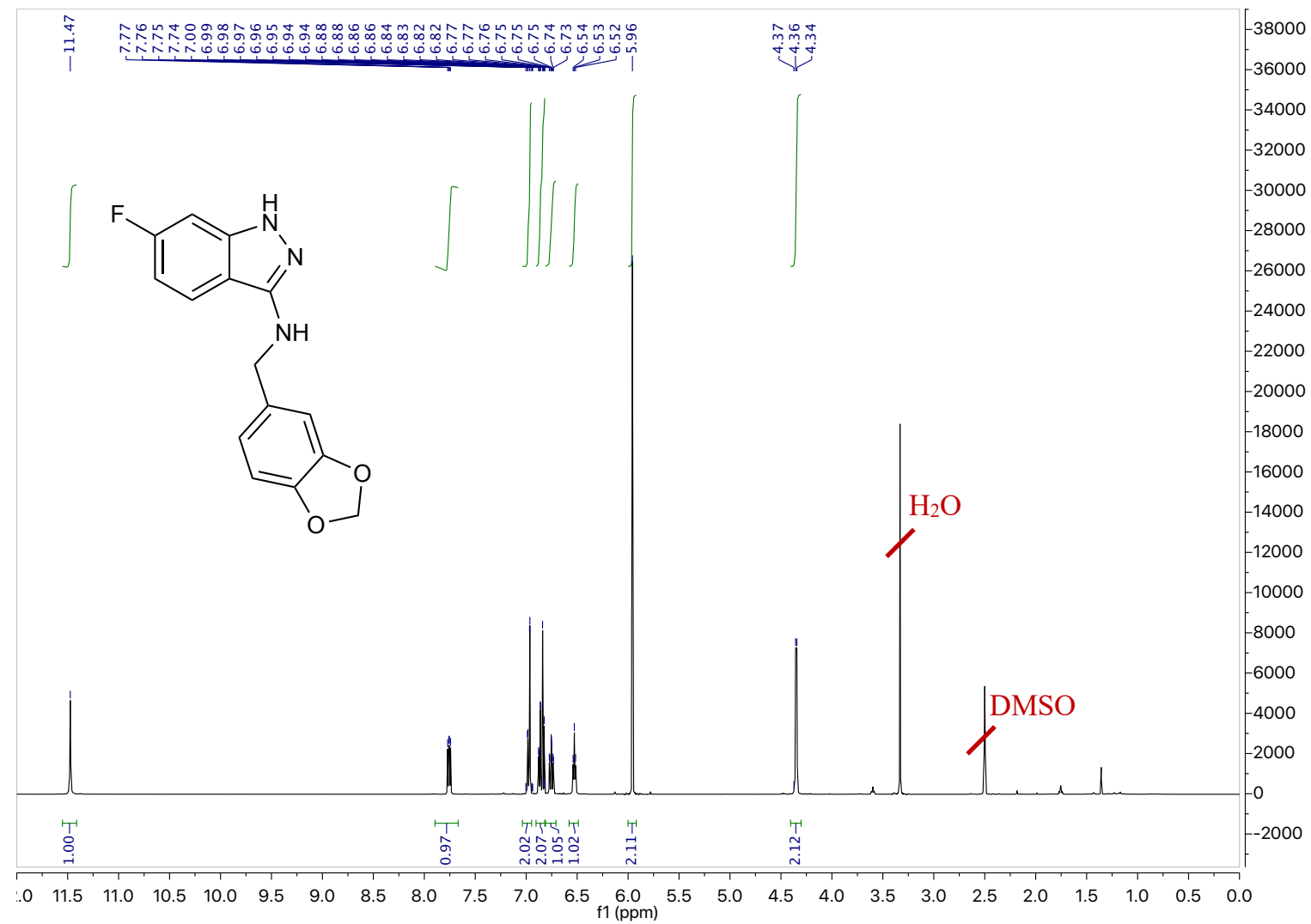

${ }^{13} \mathrm{C}$ NMR Spectrum of 9a (126 MHz, DMSO)

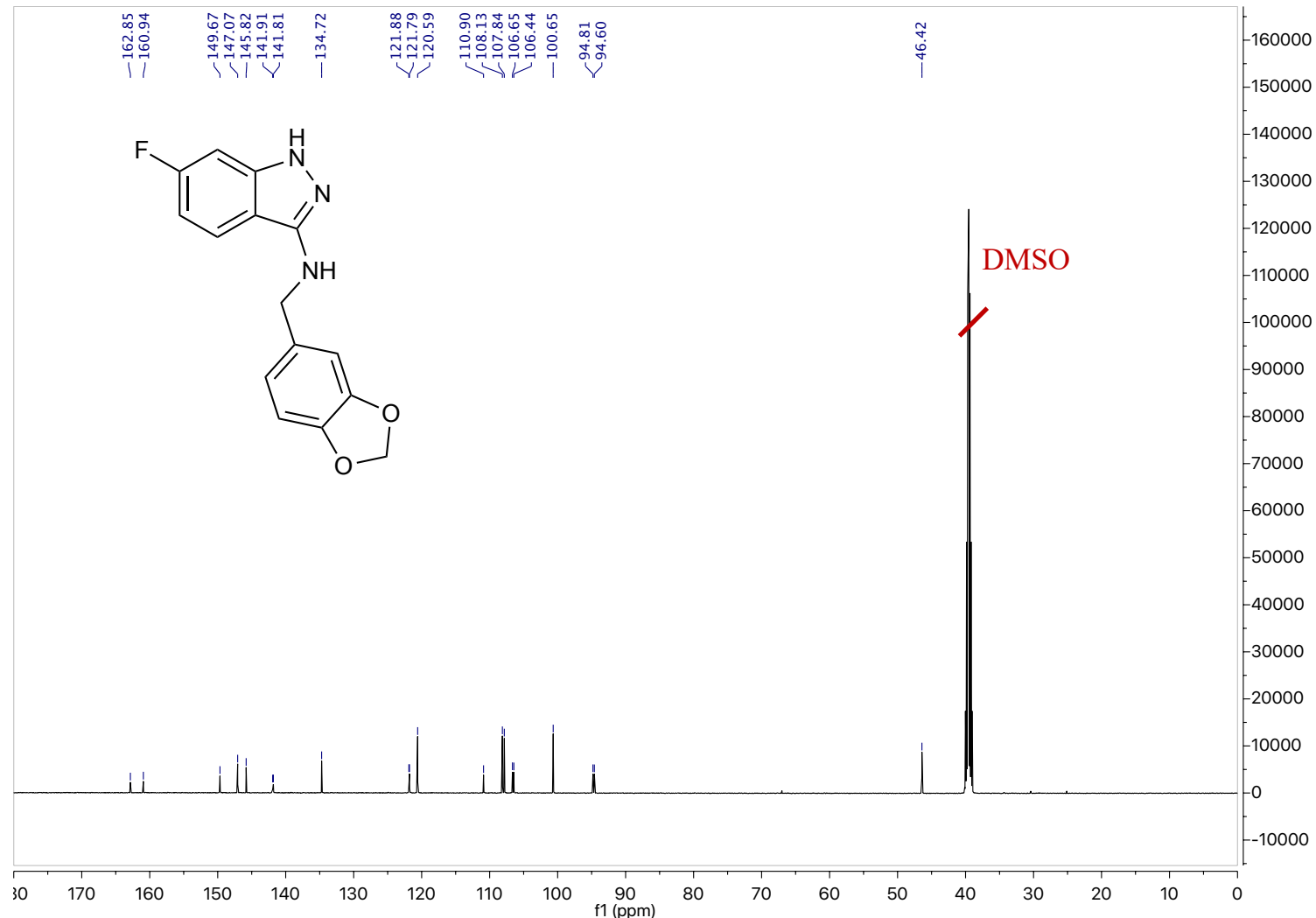


${ }^{1} \mathrm{H}$ NMR Spectrum of $\mathbf{9 b}(500 \mathrm{MHz}, \mathrm{DMSO})$

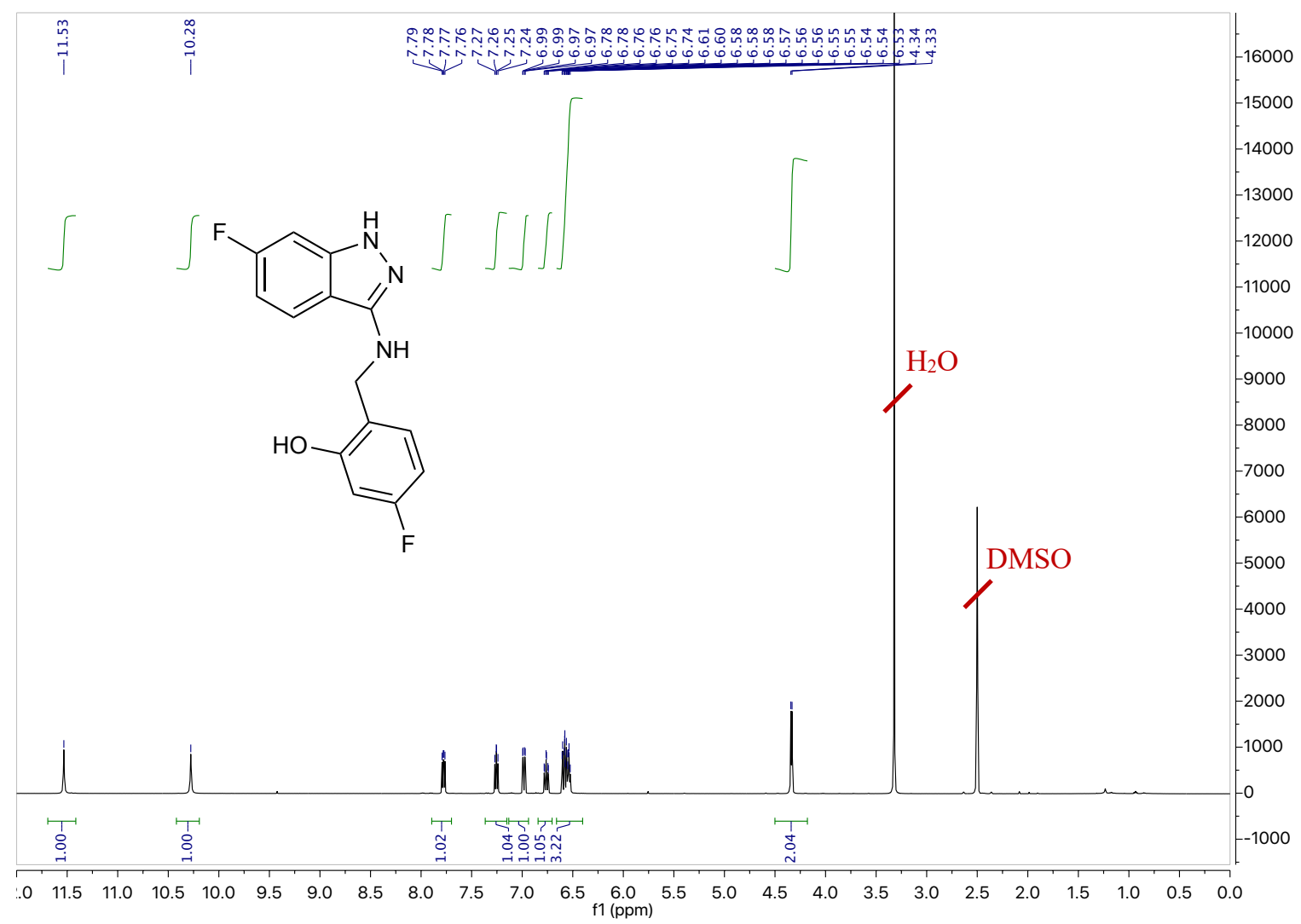

${ }^{13} \mathrm{C}$ NMR Spectrum of $9 \mathbf{b}$ (126 MHz, DMSO)

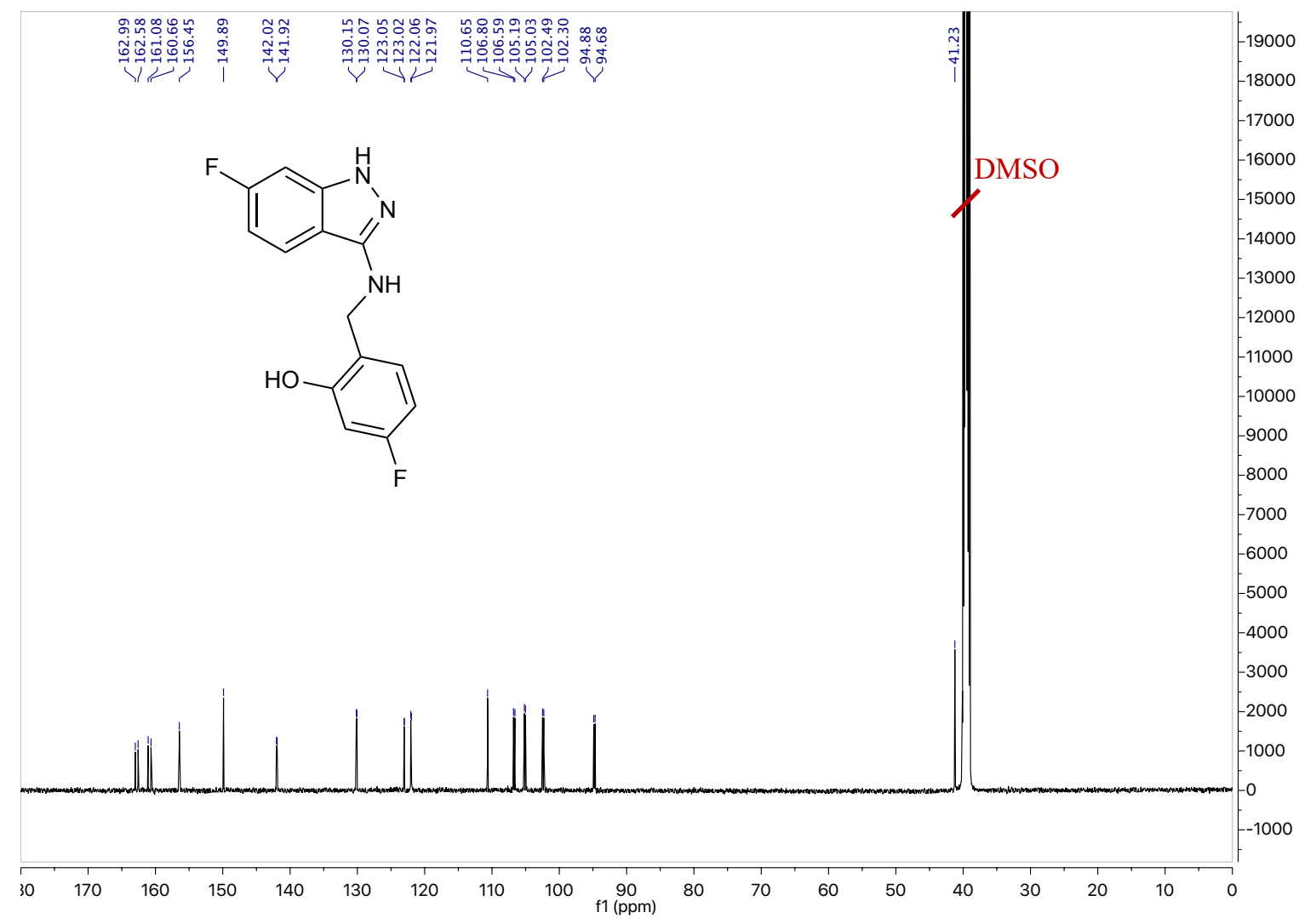


${ }^{1} \mathrm{H}$ NMR Spectrum of 9c (500 MHz, MeOD)

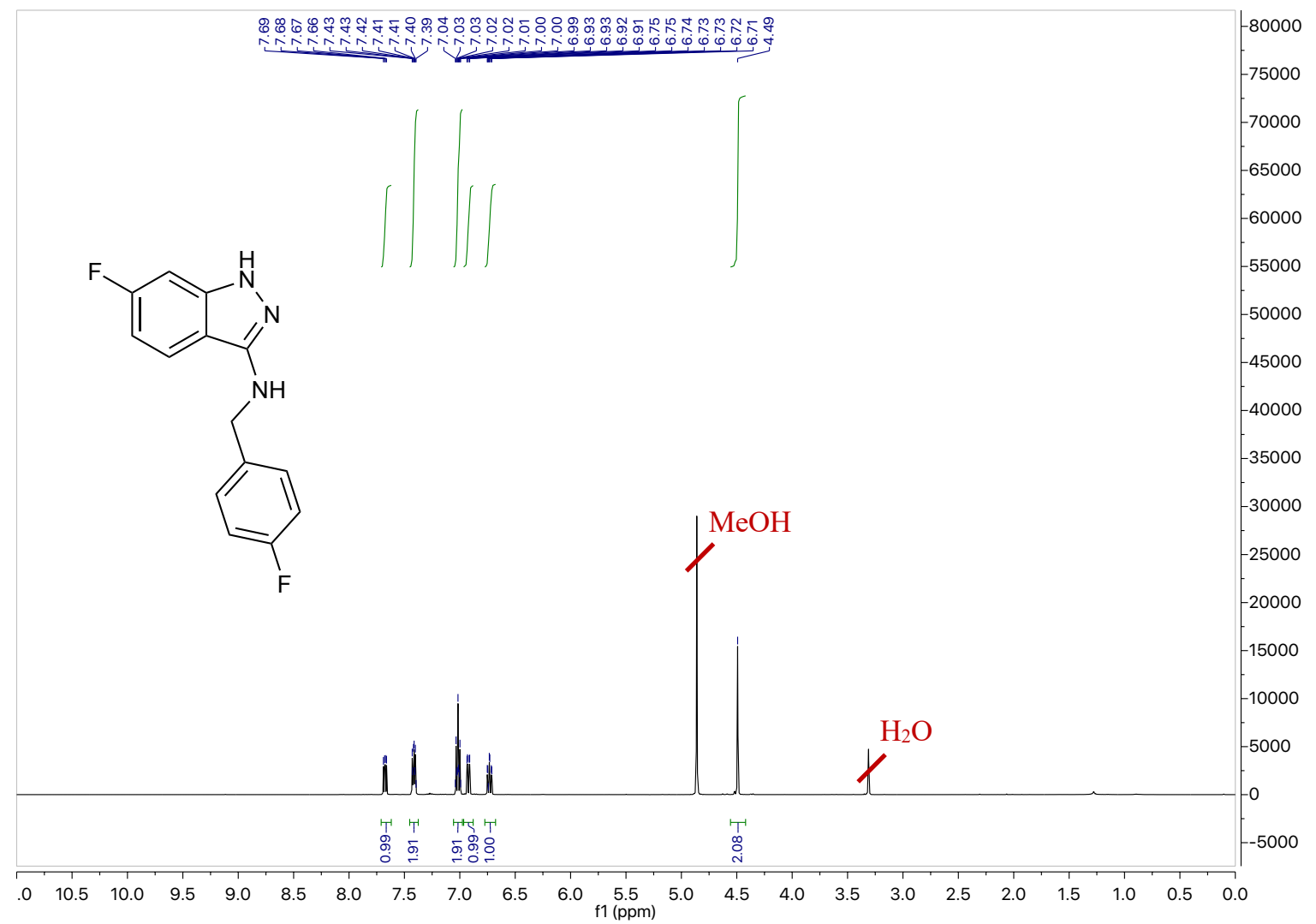

${ }^{13} \mathrm{C}$ NMR Spectrum of 9c (126 MHz, MeOD)

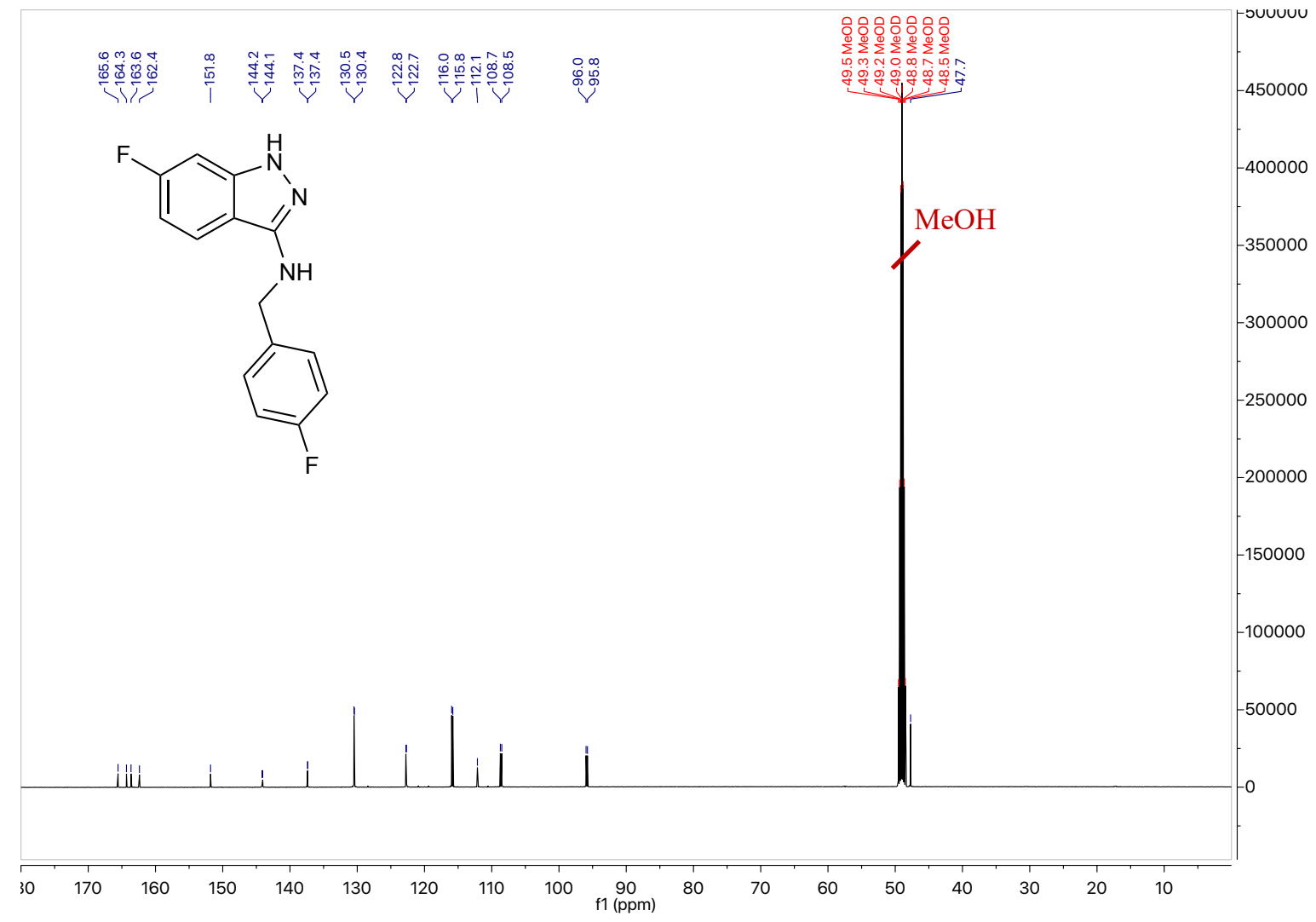


${ }^{1} \mathrm{H}$ NMR Spectrum of $\mathbf{9 d}(500 \mathrm{MHz}, \mathrm{MeOD})$

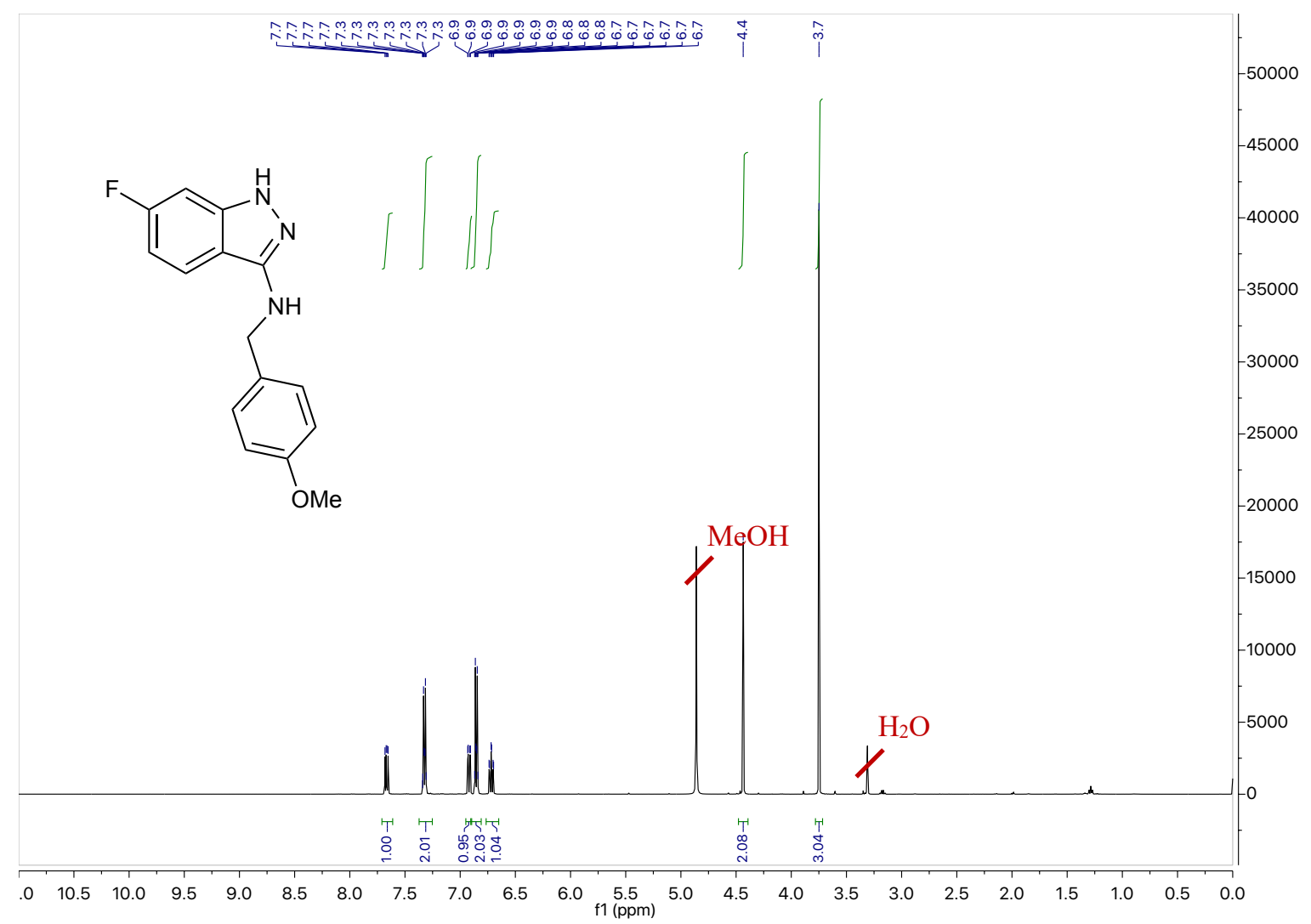

${ }^{13} \mathrm{C}$ NMR Spectrum of 9d (126 MHz, MeOD)

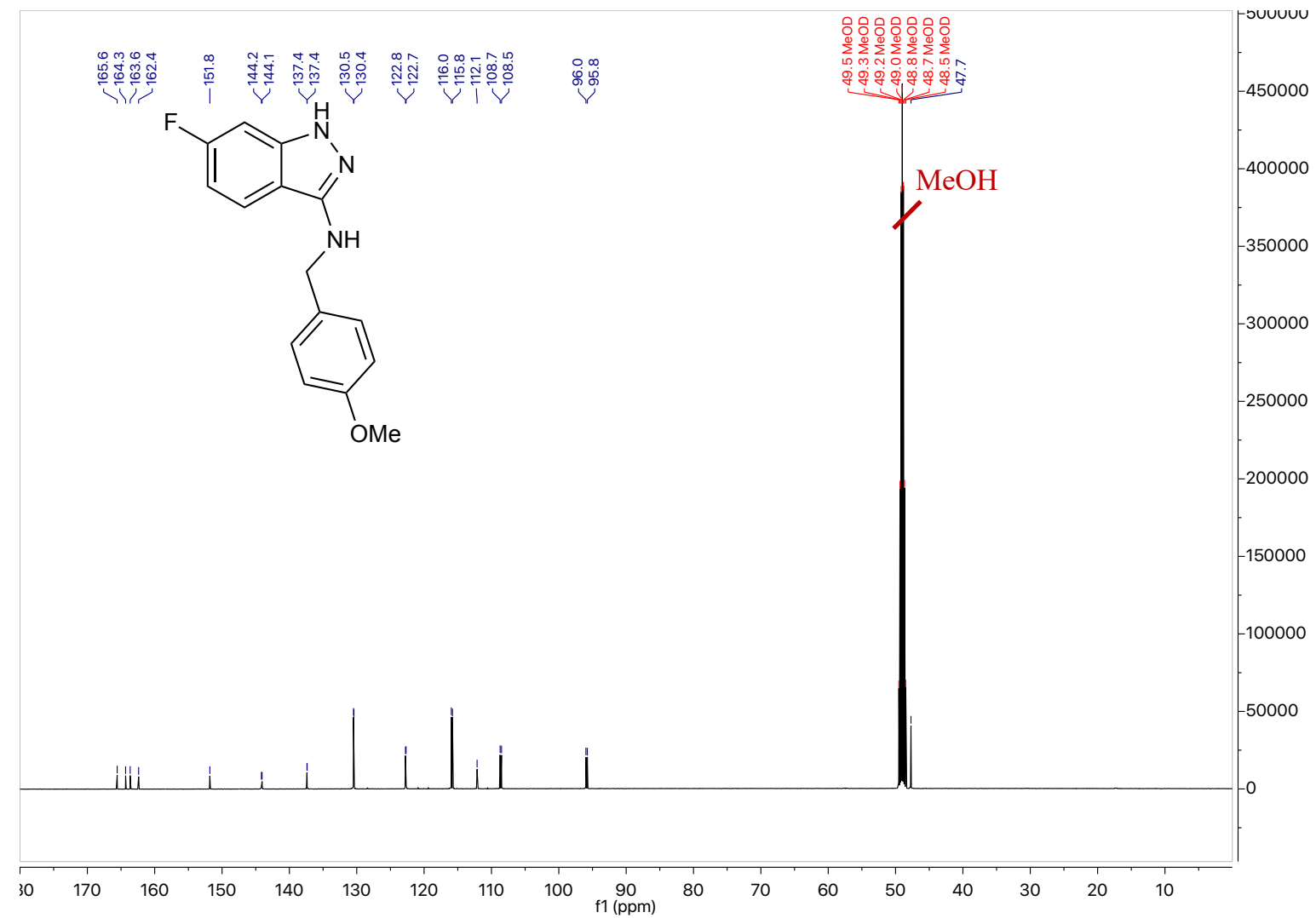




\section{Compounds 10a-e}

\section{${ }^{1} \mathrm{H}$ NMR Spectrum of 10a (500 MHz, DMSO)}

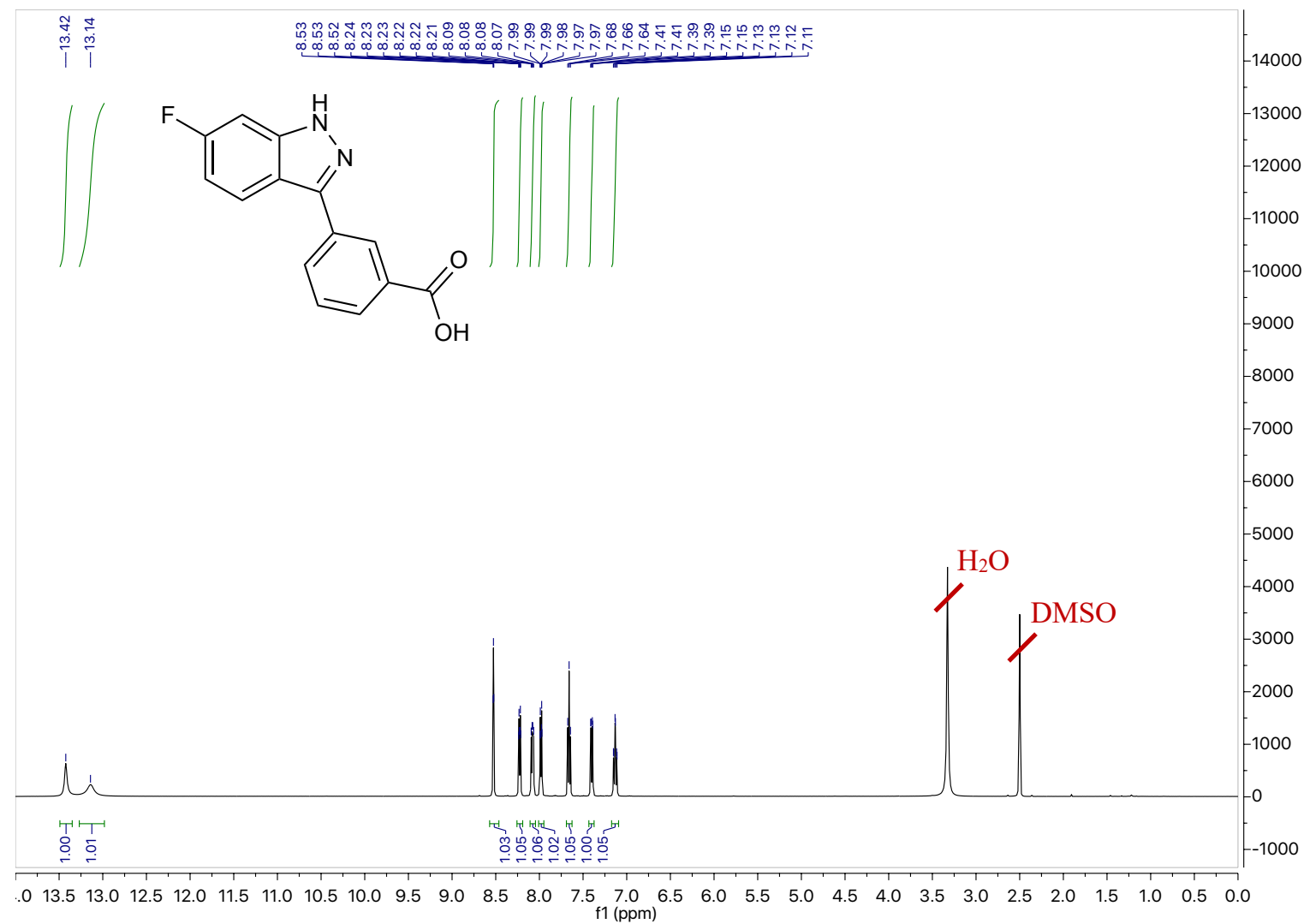

${ }^{13} \mathrm{C}$ NMR Spectrum of 10a (126 MHz, DMSO)

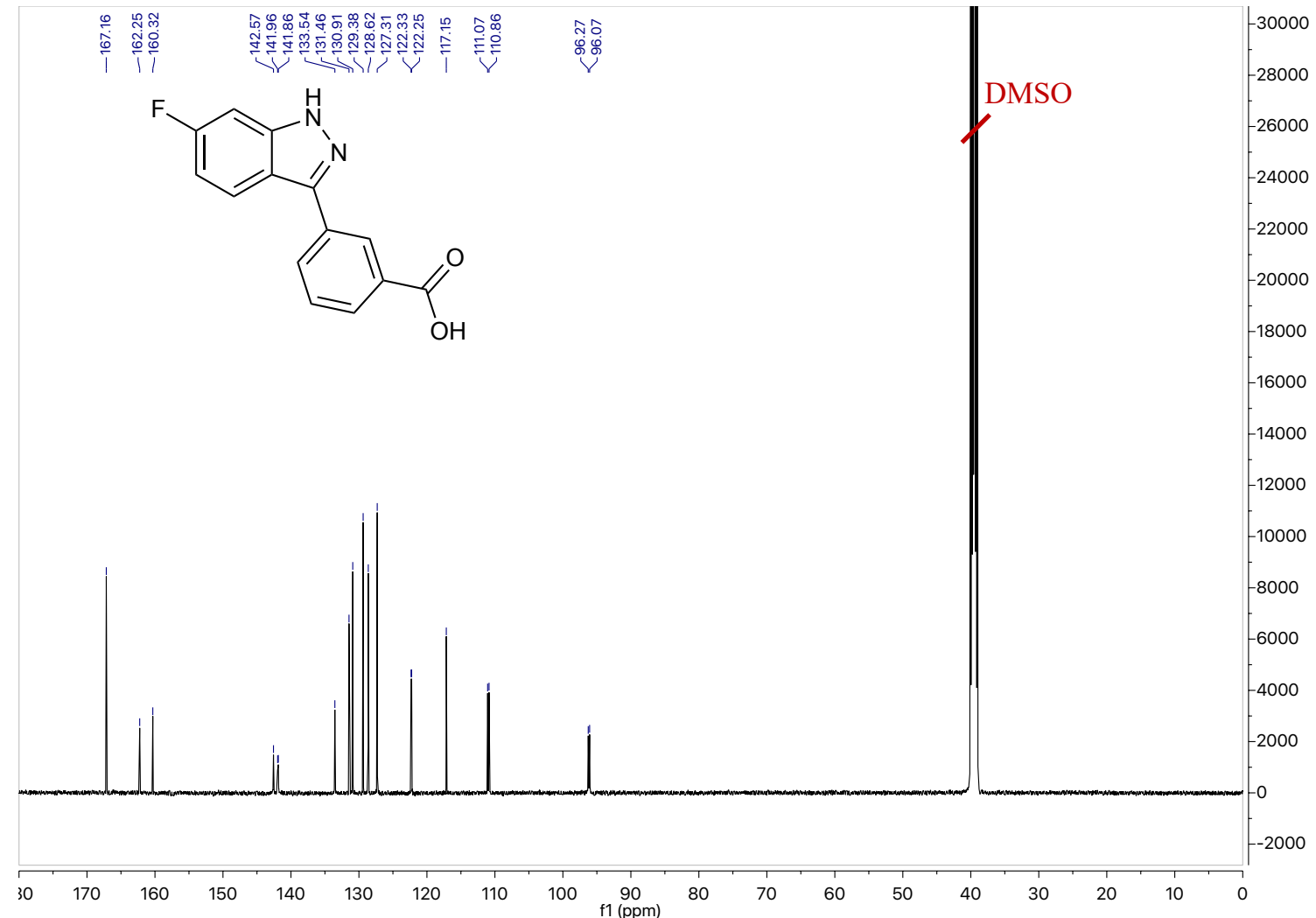


${ }^{1} \mathrm{H}$ NMR Spectrum of $\mathbf{1 0 b}(500 \mathrm{MHz}, \mathrm{MeOD})$

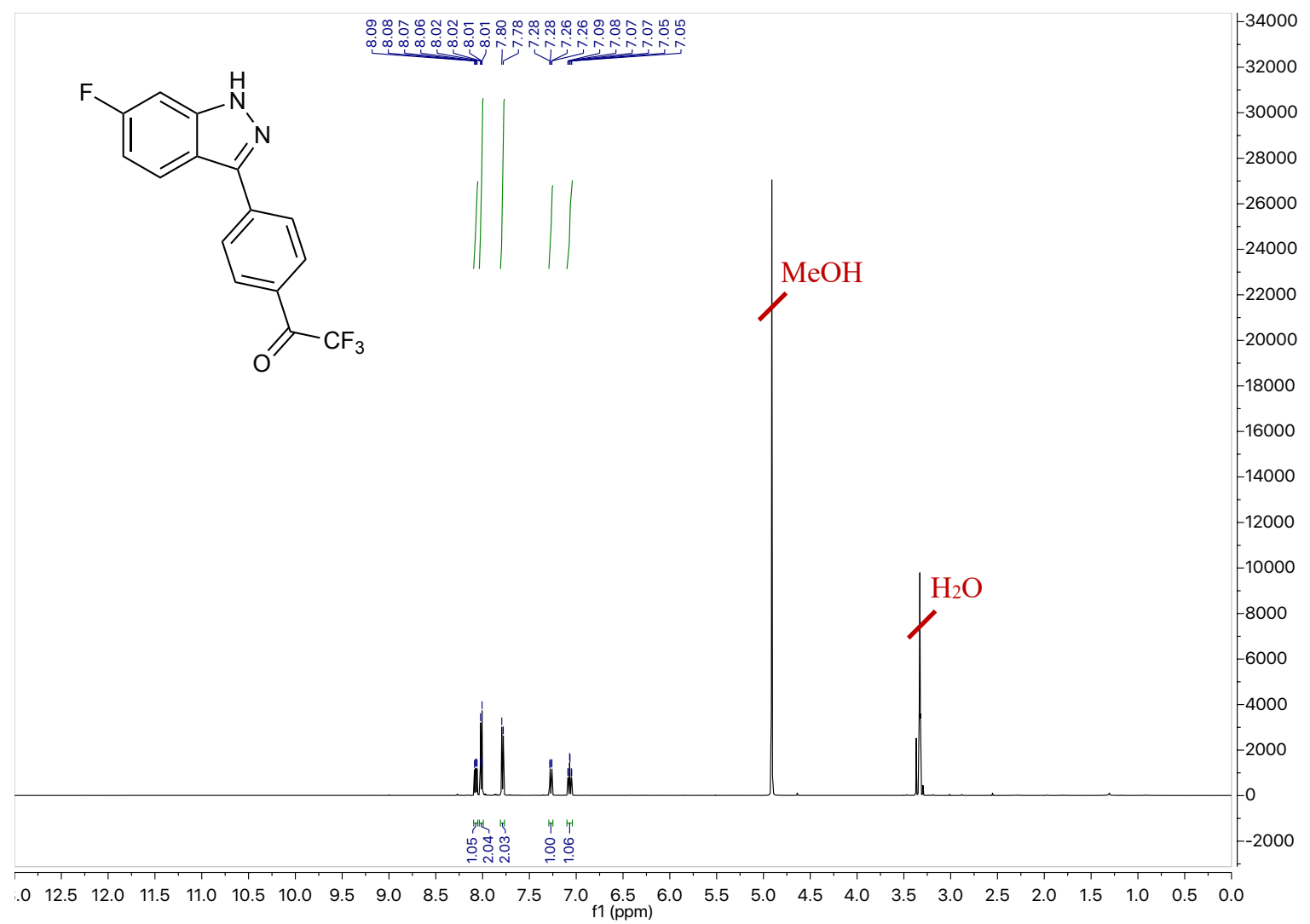

${ }^{13} \mathrm{C}$ NMR Spectrum of $\mathbf{1 0 b}(126 \mathrm{MHz}, \mathrm{MeOD})$

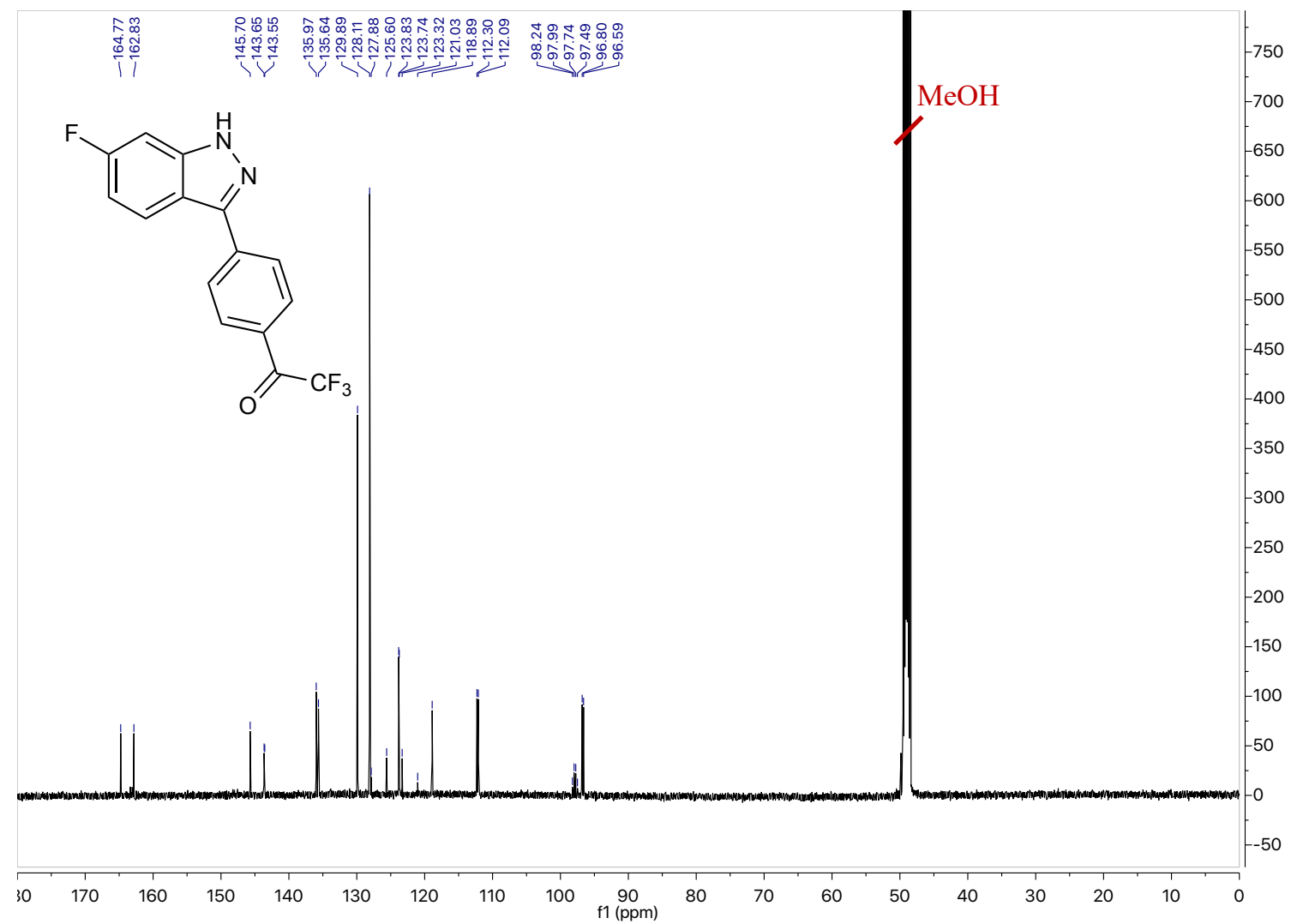


${ }^{1} \mathrm{H}$ NMR Spectrum of $\mathbf{1 0 c}(500 \mathrm{MHz}, \mathrm{DMSO})$

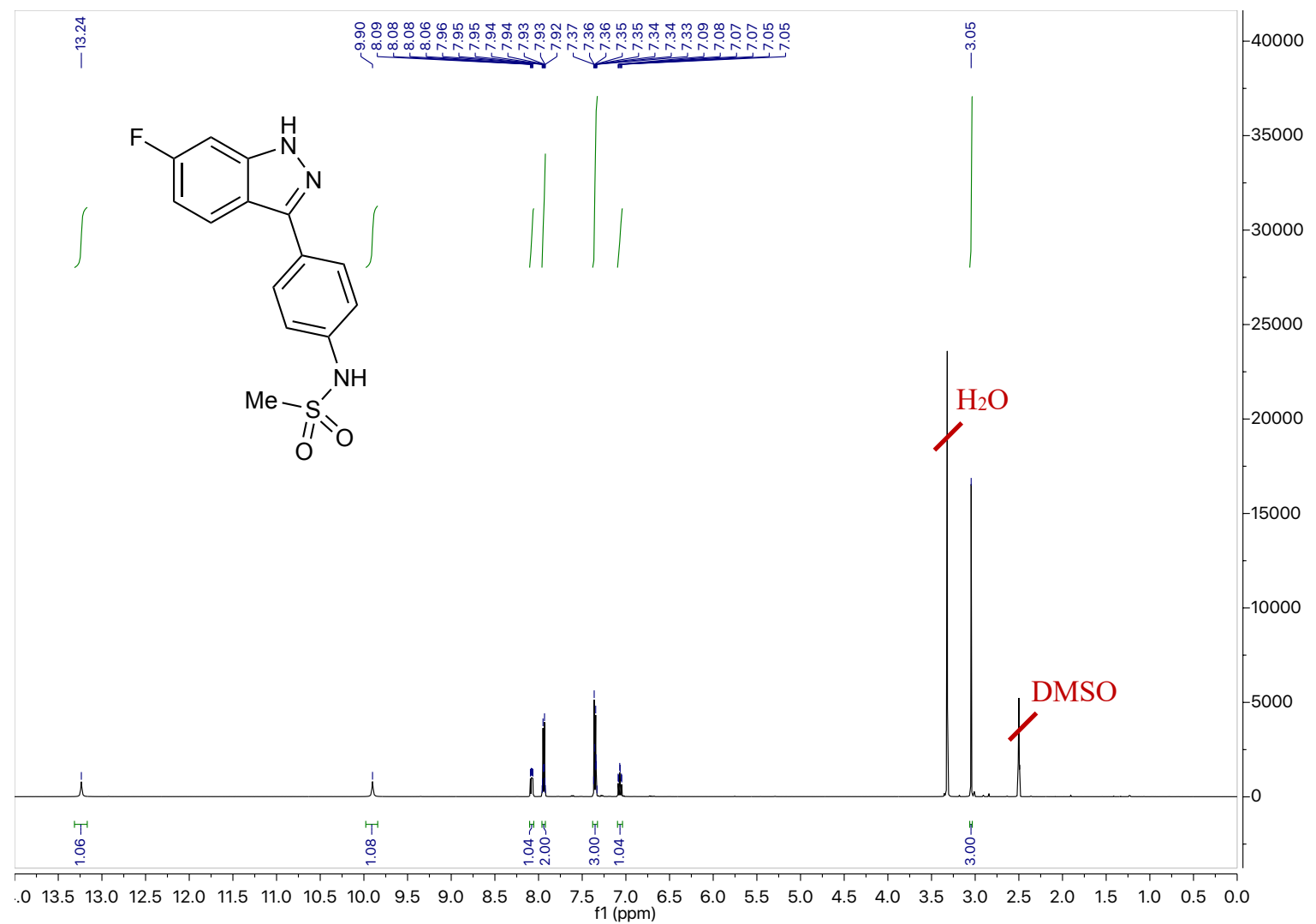

${ }^{13} \mathrm{C}$ NMR Spectrum of 10c (126 MHz, DMSO)

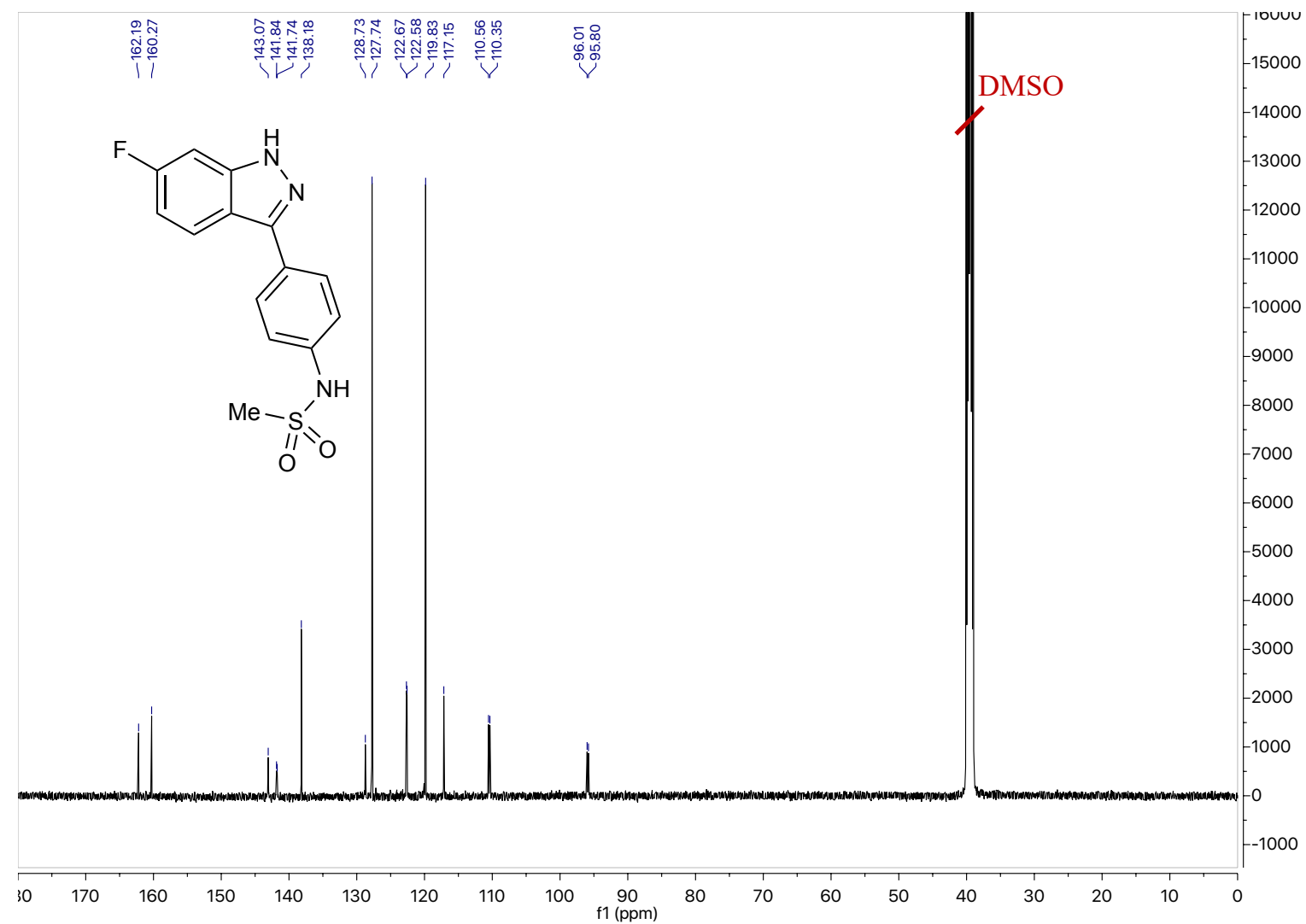


${ }^{1} \mathrm{H}$ NMR Spectrum of $\mathbf{1 0 d}(500 \mathrm{MHz}, \mathrm{DMSO})$

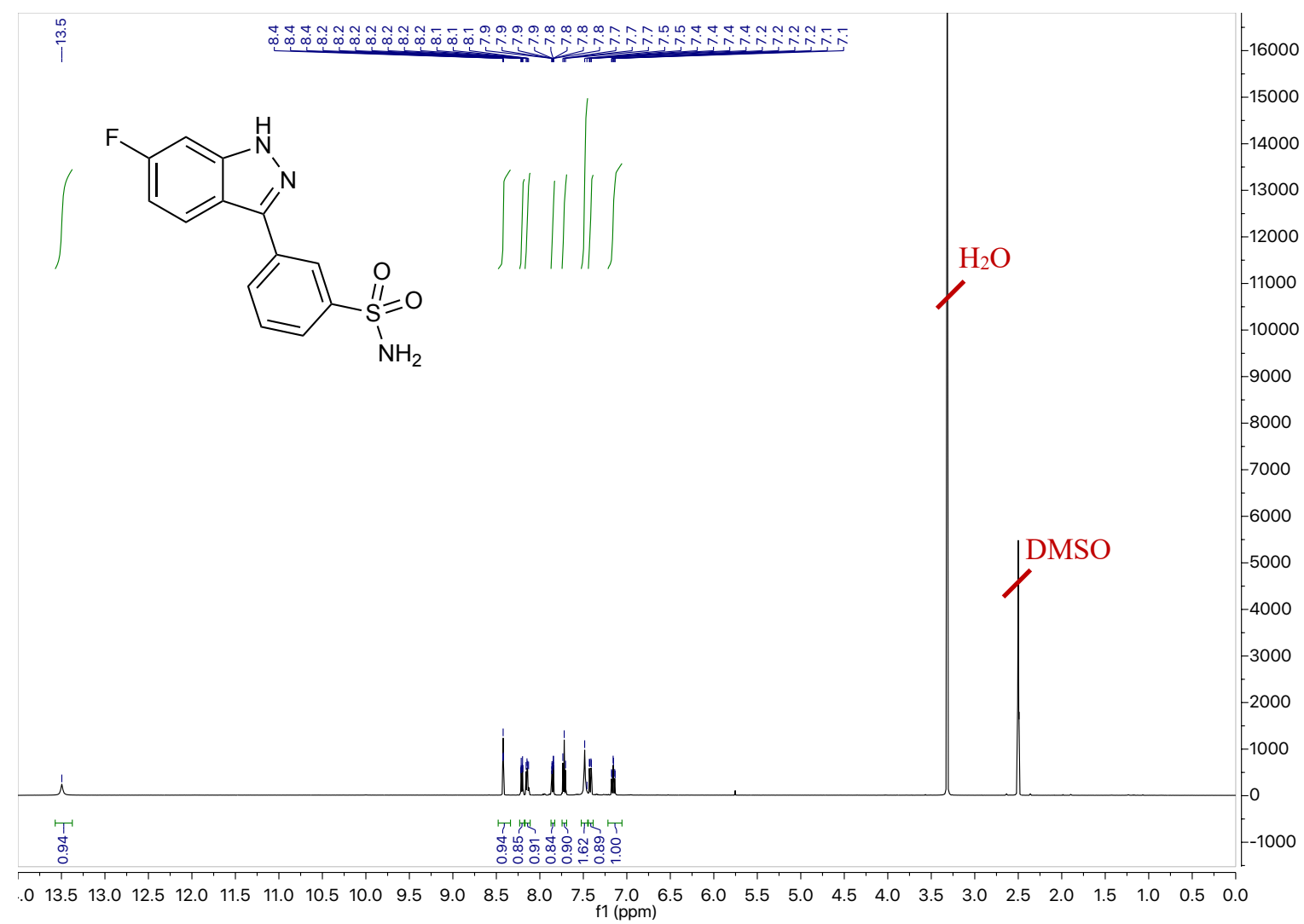

${ }^{13} \mathrm{C}$ NMR Spectrum of 10d (126 MHz, DMSO)

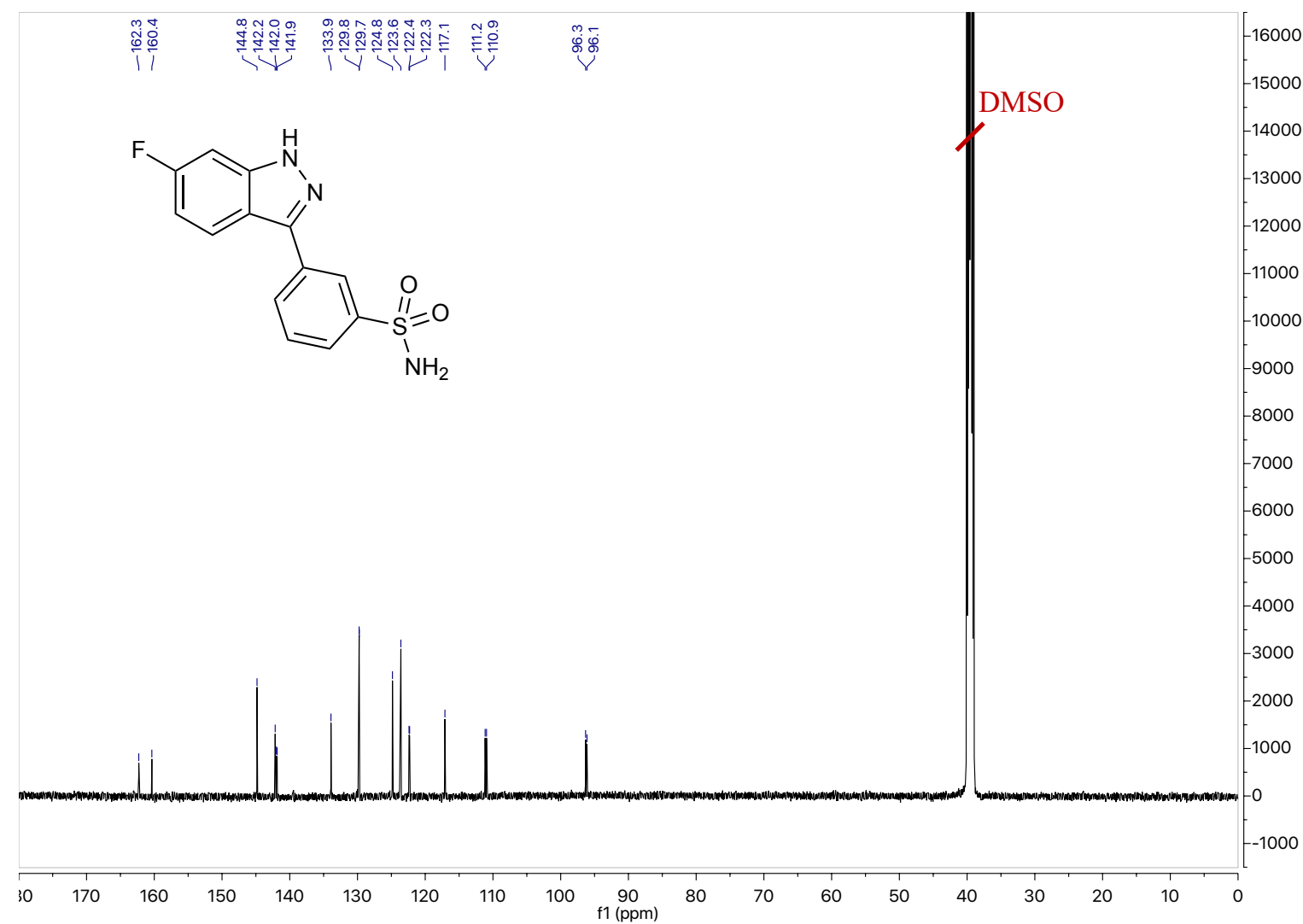


${ }^{1} \mathrm{H}$ NMR Spectrum of 10e (500 MHz, DMSO)

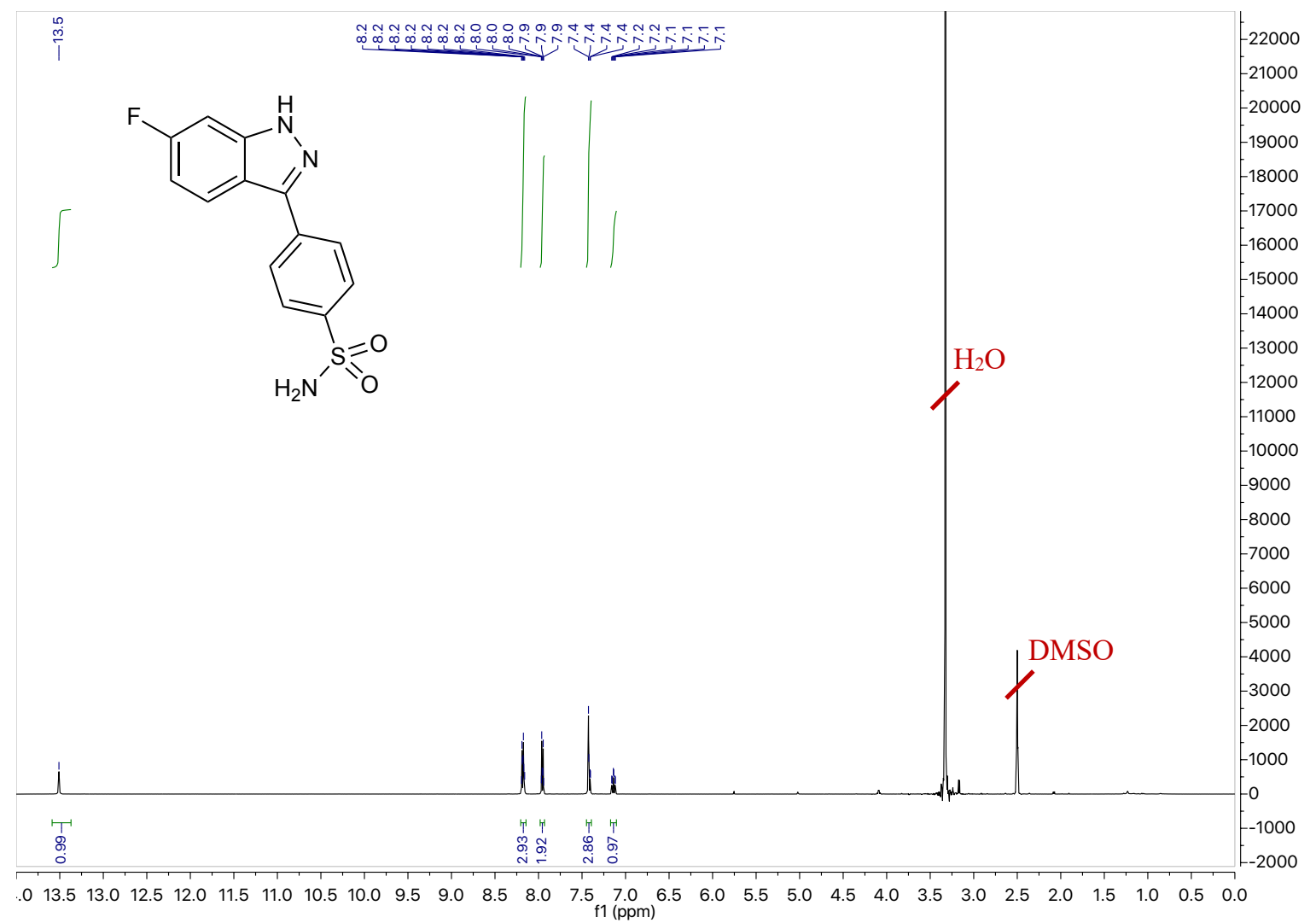

${ }^{13} \mathrm{C}$ NMR Spectrum of $\mathbf{1 0 e}(126 \mathrm{MHz}, \mathrm{DMSO})$

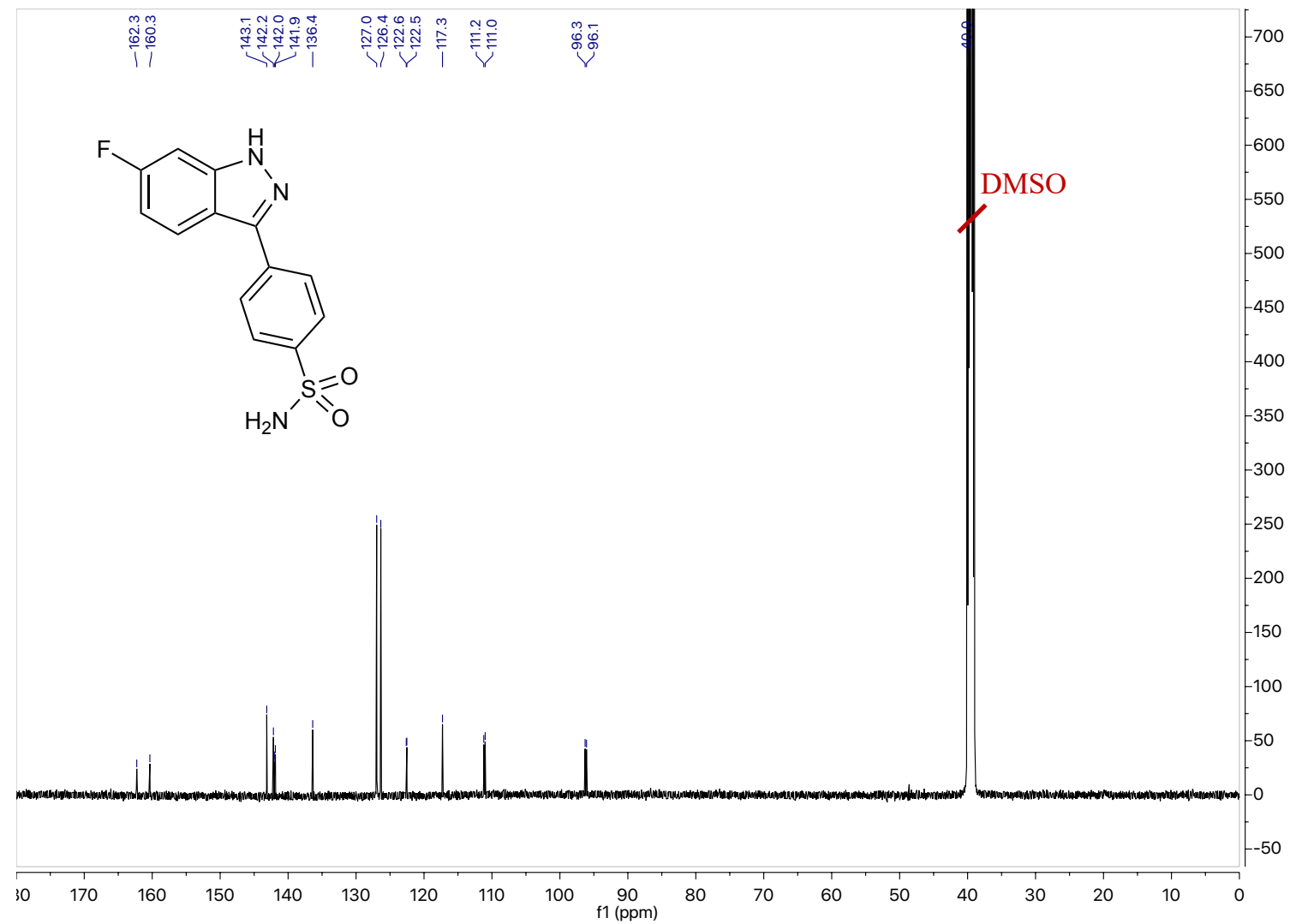




\section{Compounds 11a-d}

${ }^{1} \mathrm{H}$ NMR Spectrum of 11a (500 MHz, DMSO)

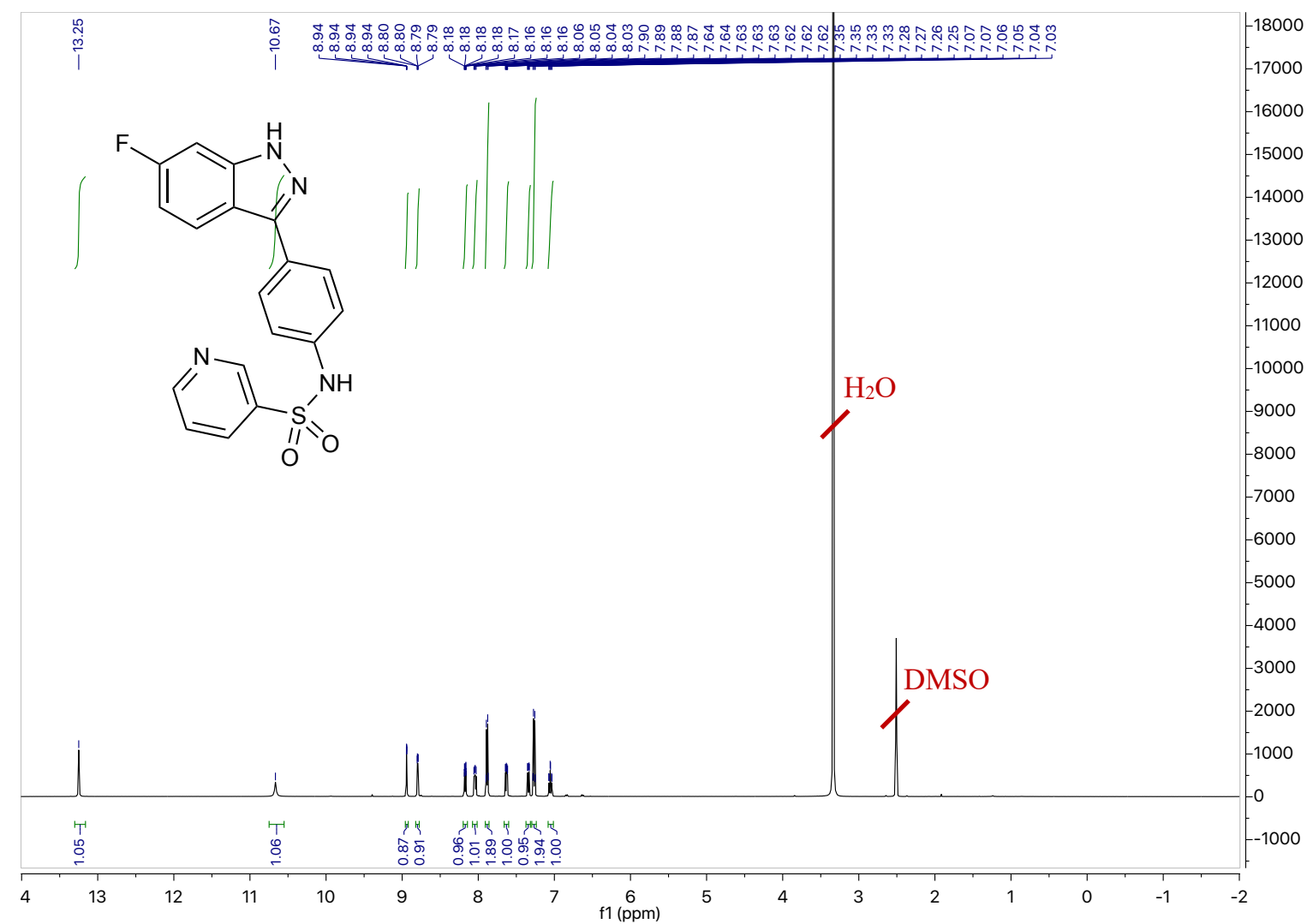

${ }^{13} \mathrm{C}$ NMR Spectrum of 11a (126 MHz, DMSO)

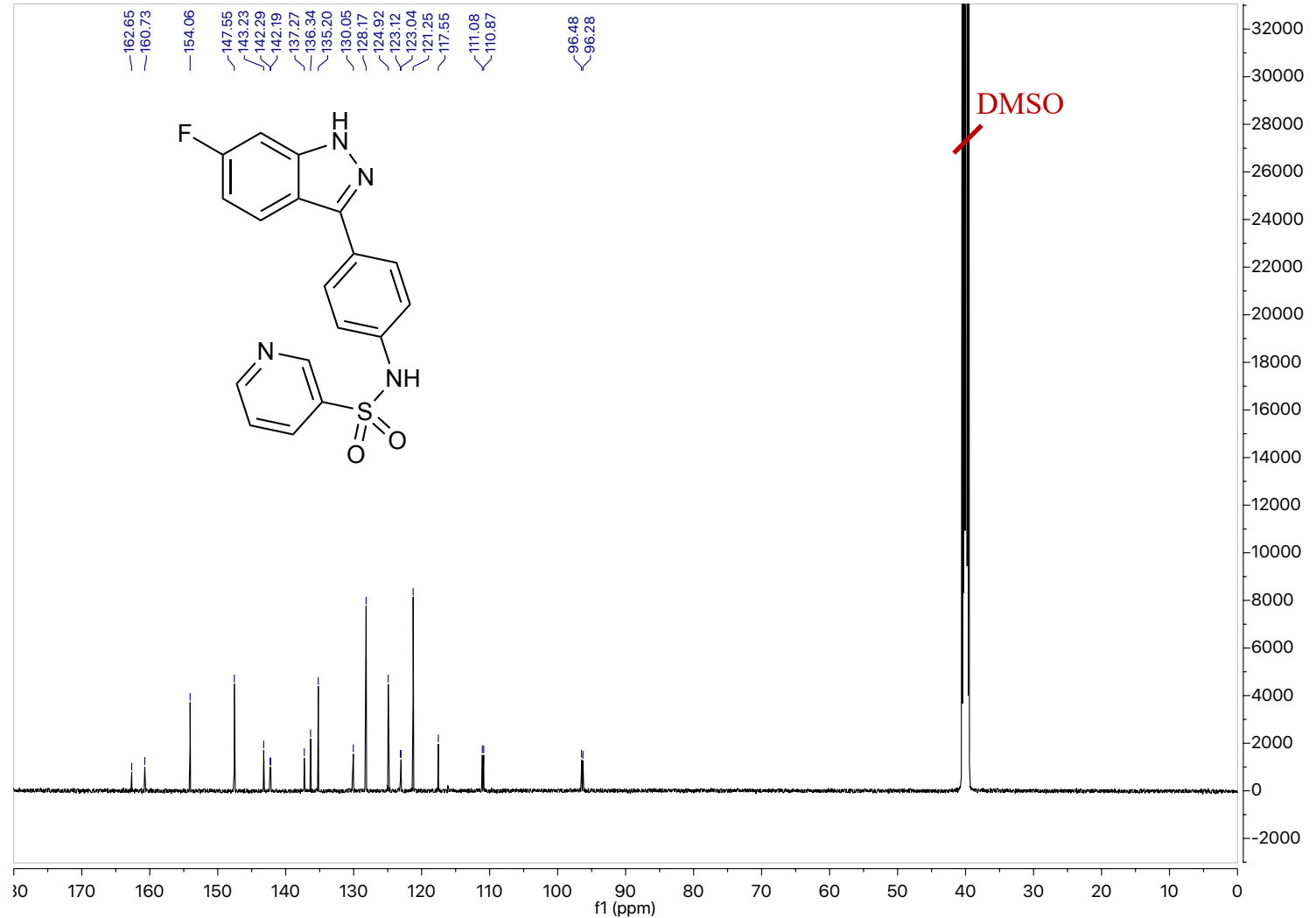


${ }^{1} \mathrm{H}$ NMR Spectrum of $\mathbf{1 1 b}(500 \mathrm{MHz}$, DMSO)

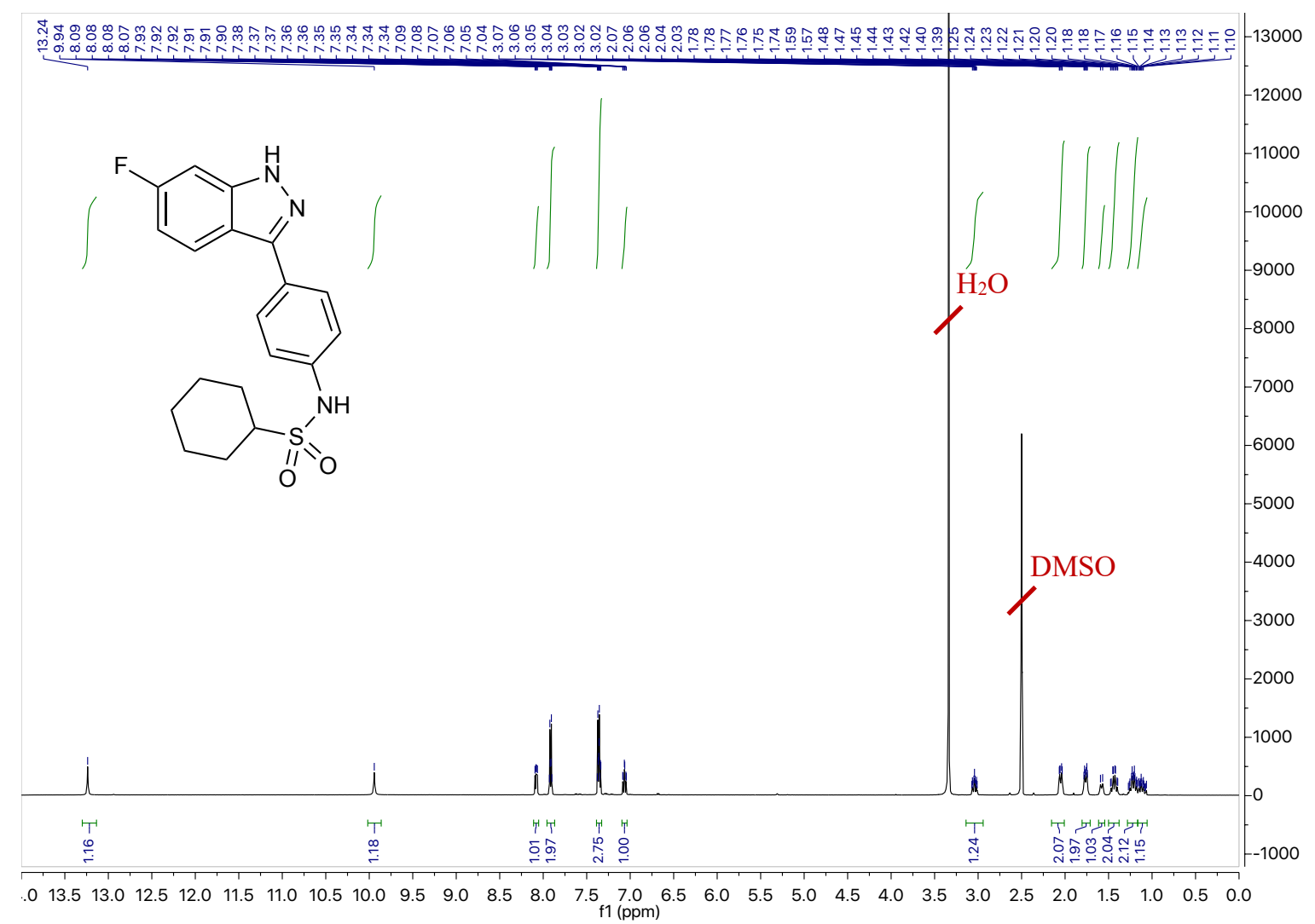

${ }^{13} \mathrm{C}$ NMR Spectrum of $\mathbf{1 1 b}$ (126 MHz, DMSO)

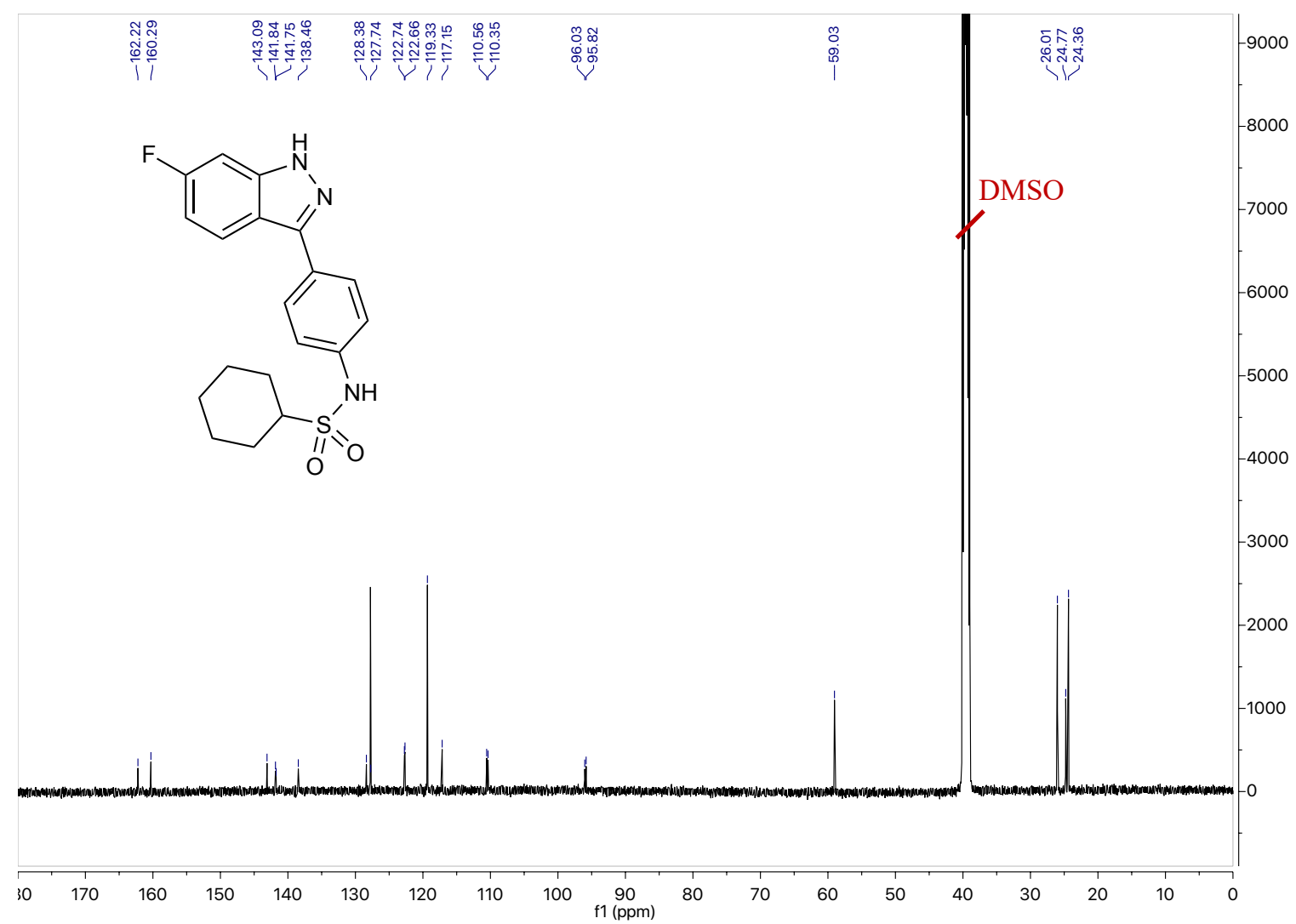


${ }^{1} \mathrm{H}$ NMR Spectrum of 11c (500 MHz, DMSO)

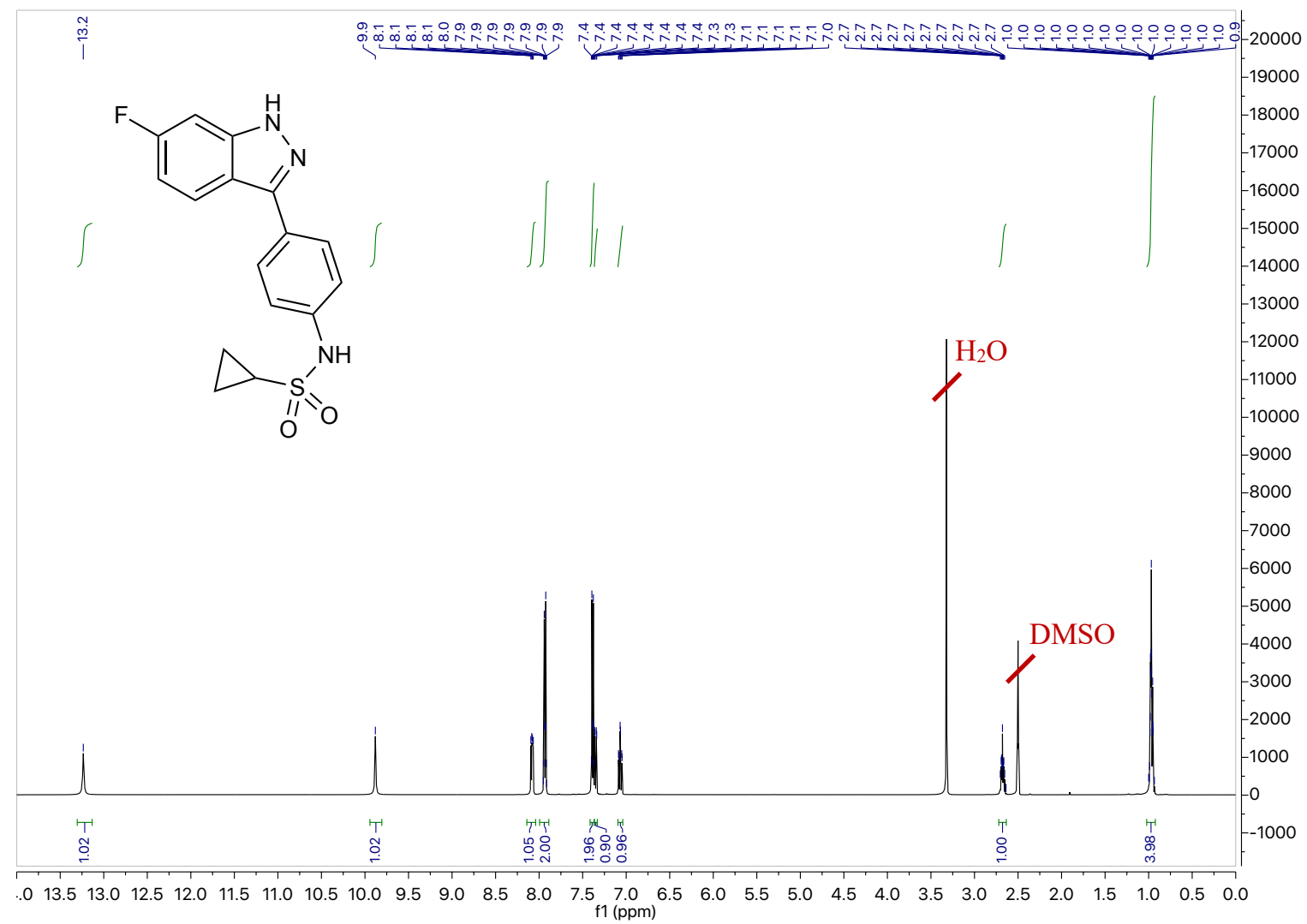

${ }^{13} \mathrm{C}$ NMR Spectrum of 11c (126 MHz, DMSO)

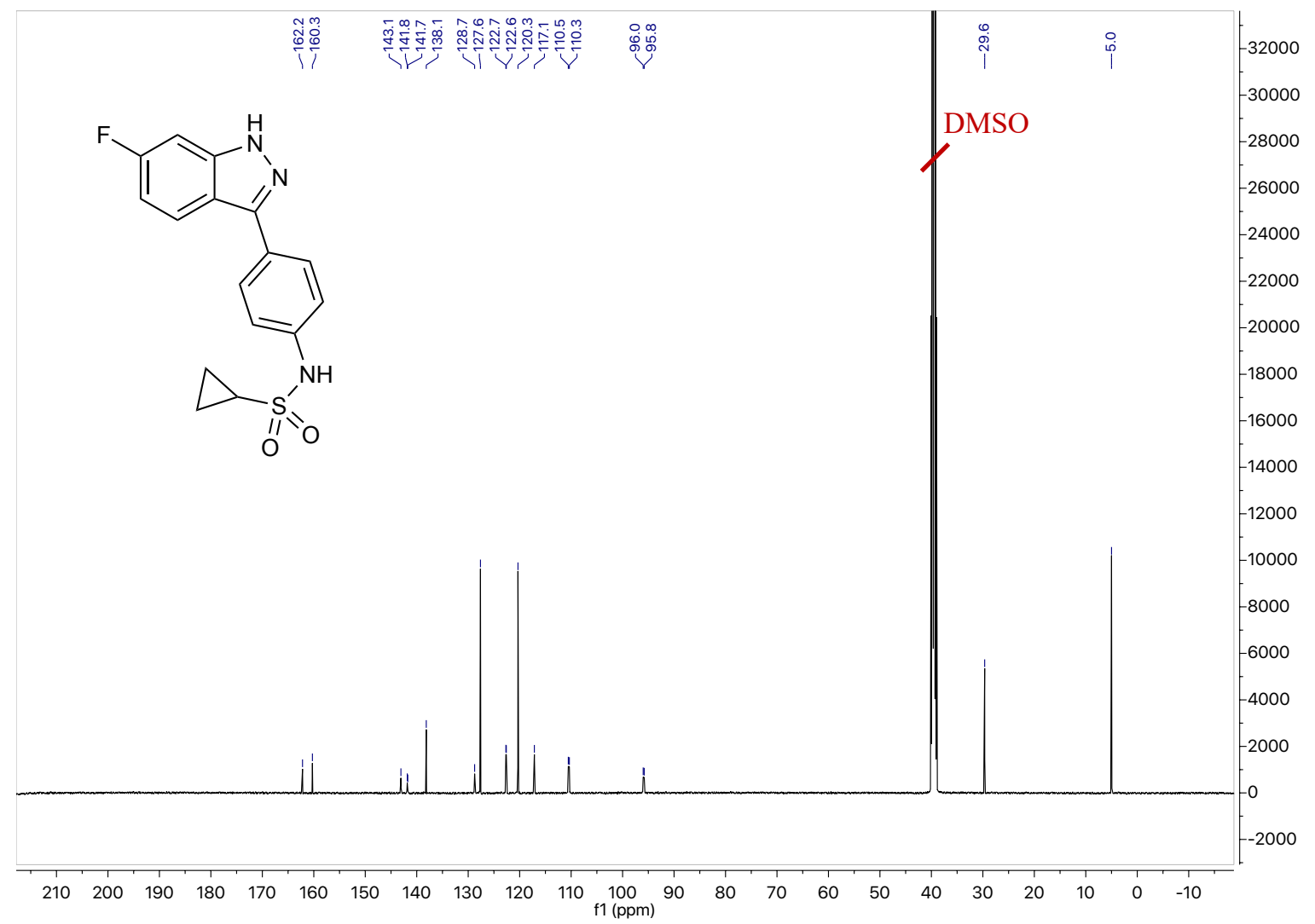




\section{Compounds 12a-c}

${ }^{1} \mathrm{H}$ NMR Spectrum of 12a (500 MHz, DMSO)

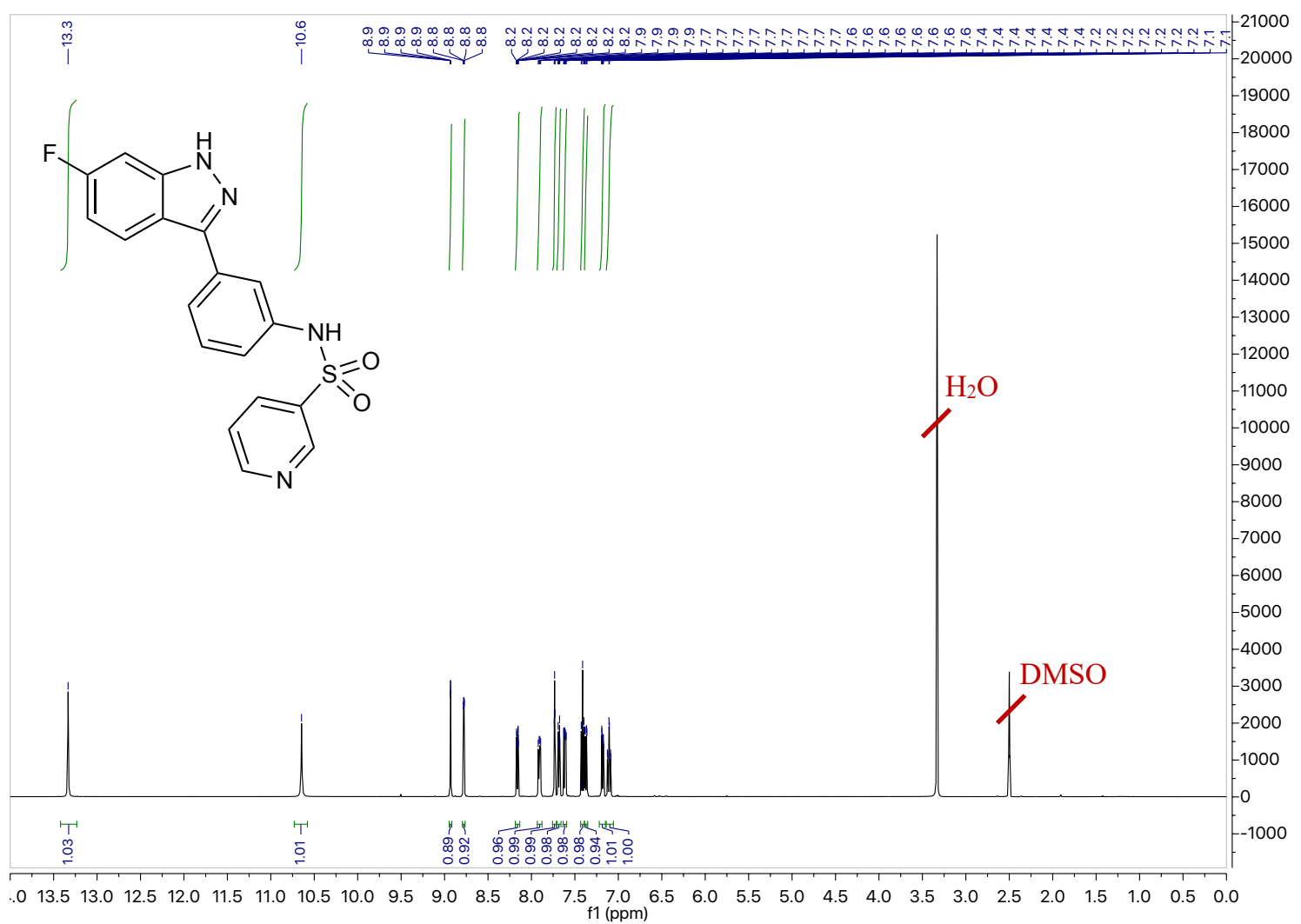

${ }^{13} \mathrm{C}$ NMR Spectrum of 12a (126 MHz, DMSO)

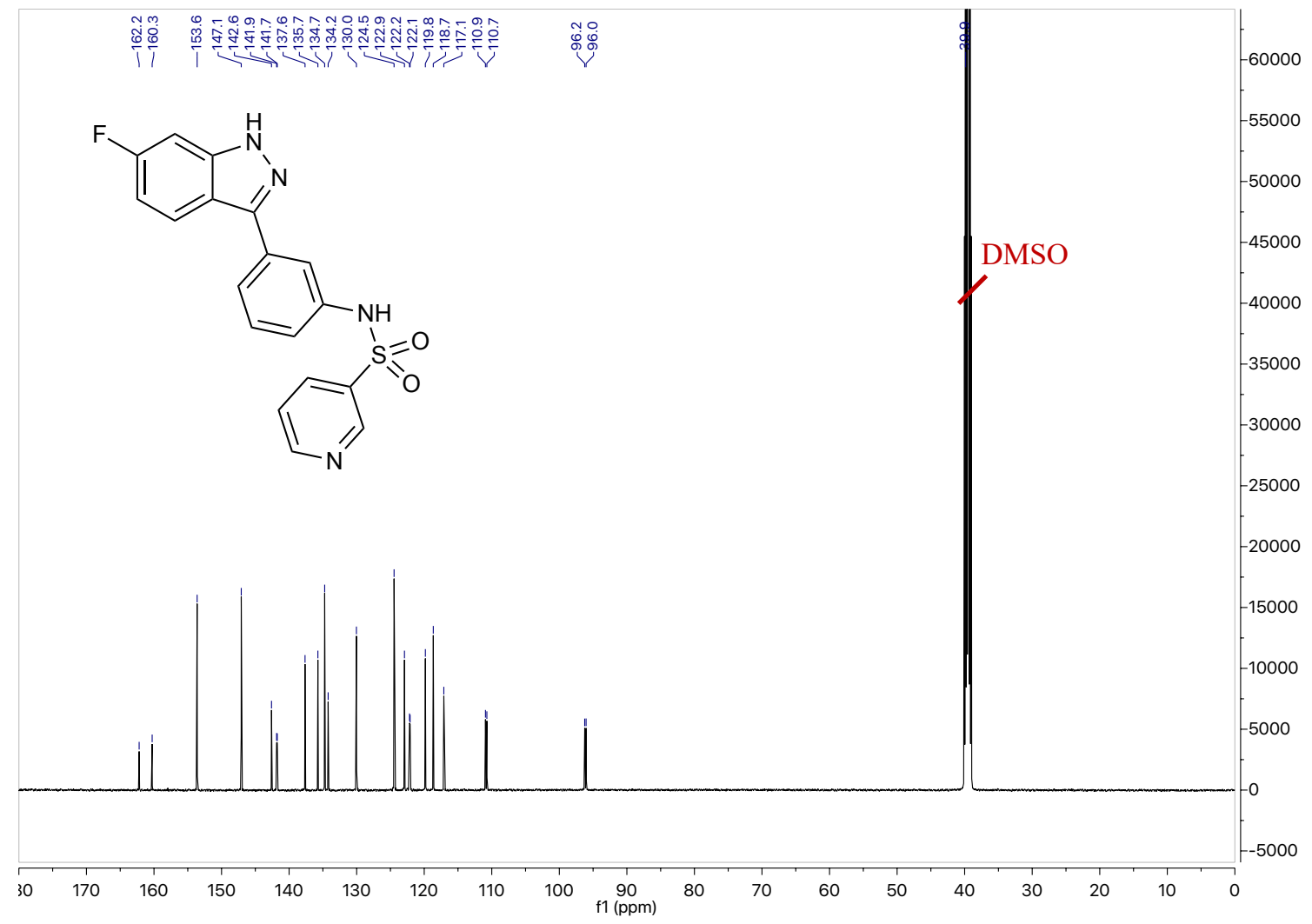


${ }^{1} \mathrm{H}$ NMR Spectrum of $\mathbf{1 2 b}(500 \mathrm{MHz}, \mathrm{DMSO})$

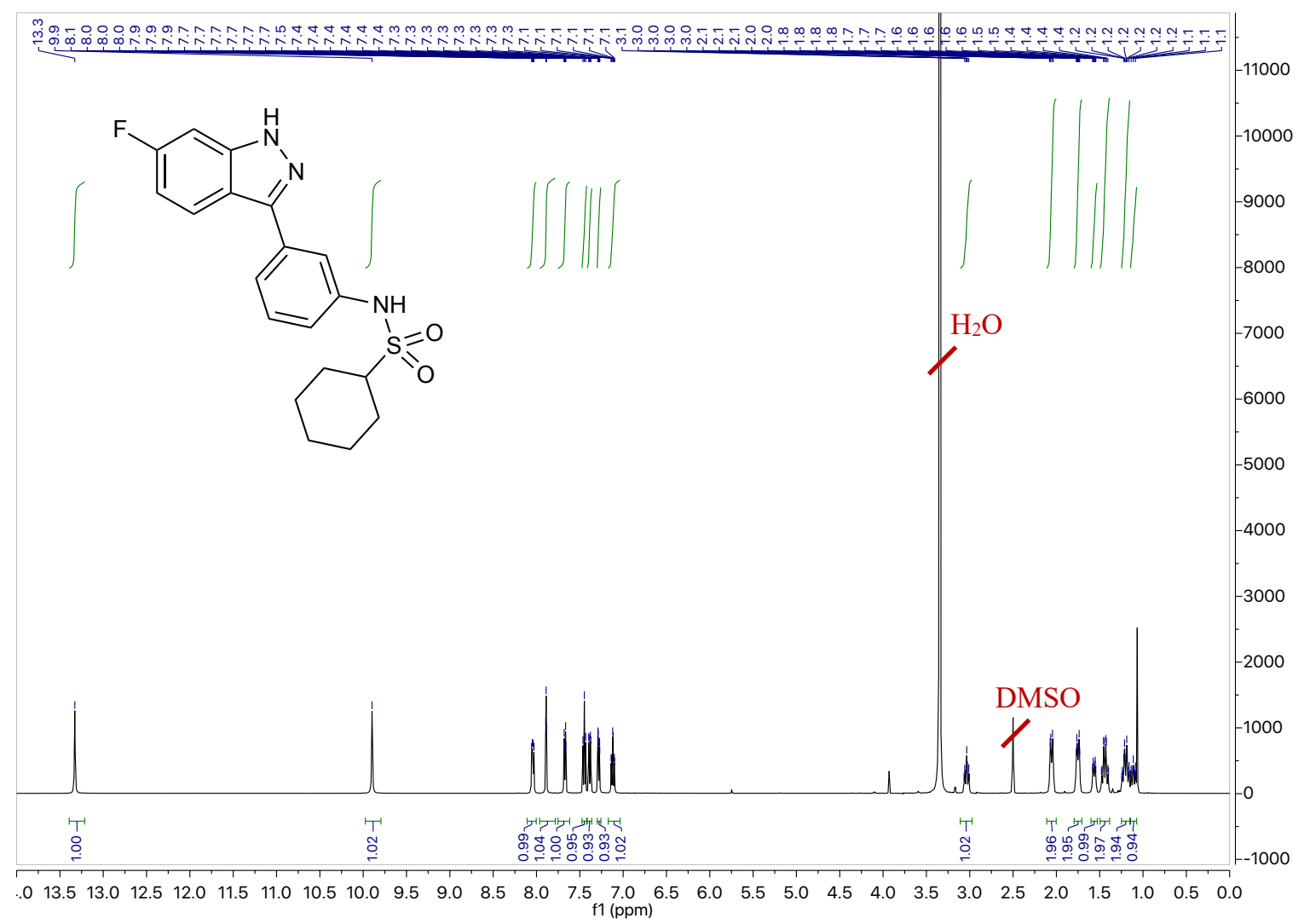

${ }^{13} \mathrm{C}$ NMR Spectrum of $\mathbf{1 2 b}$ (126 MHz, DMSO)

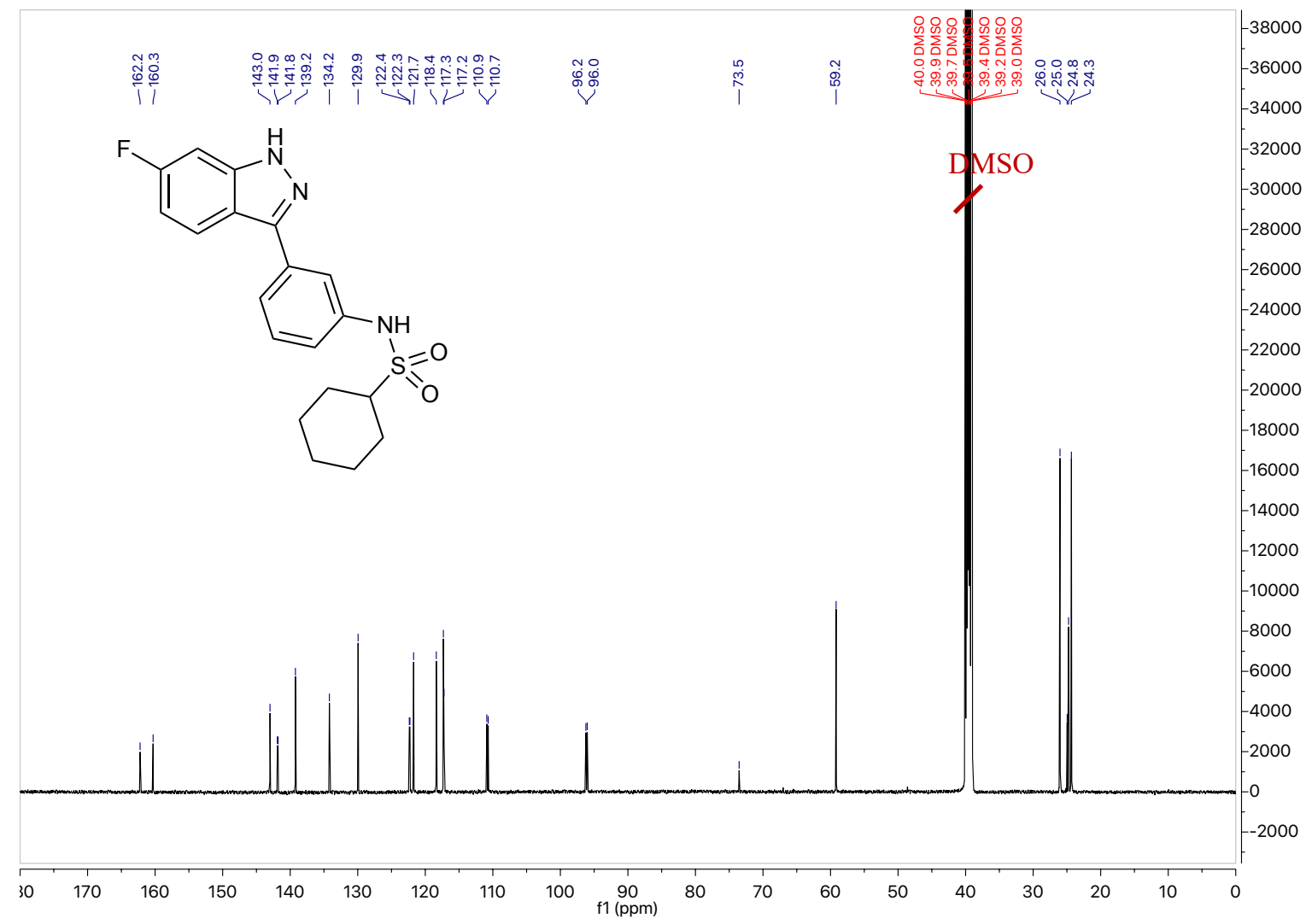


${ }^{1} \mathrm{H}$ NMR Spectrum of $\mathbf{1 2 c}(500 \mathrm{MHz}, \mathrm{DMSO})$

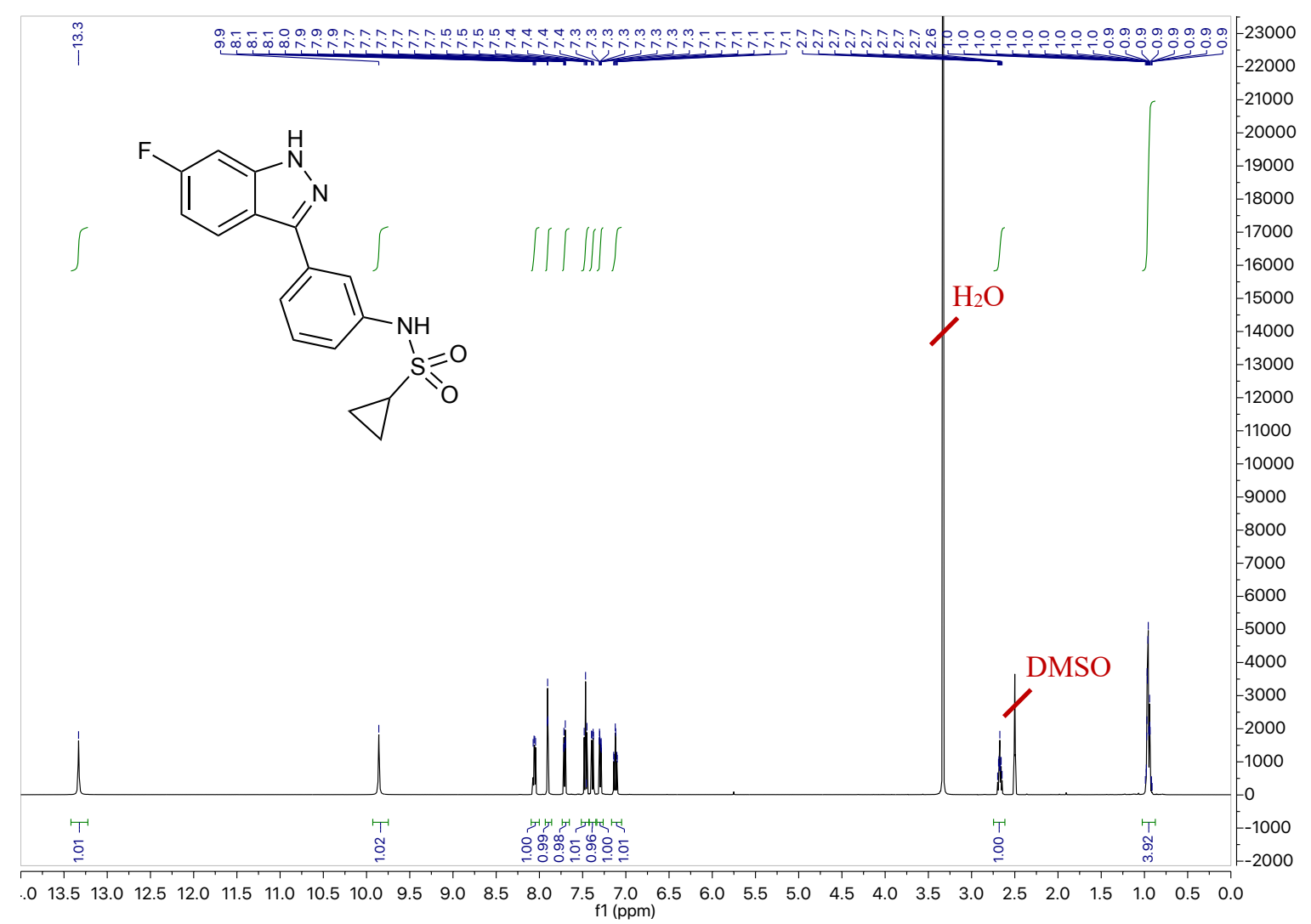

${ }^{13} \mathrm{C}$ NMR Spectrum of 12c (126 MHz, DMSO)

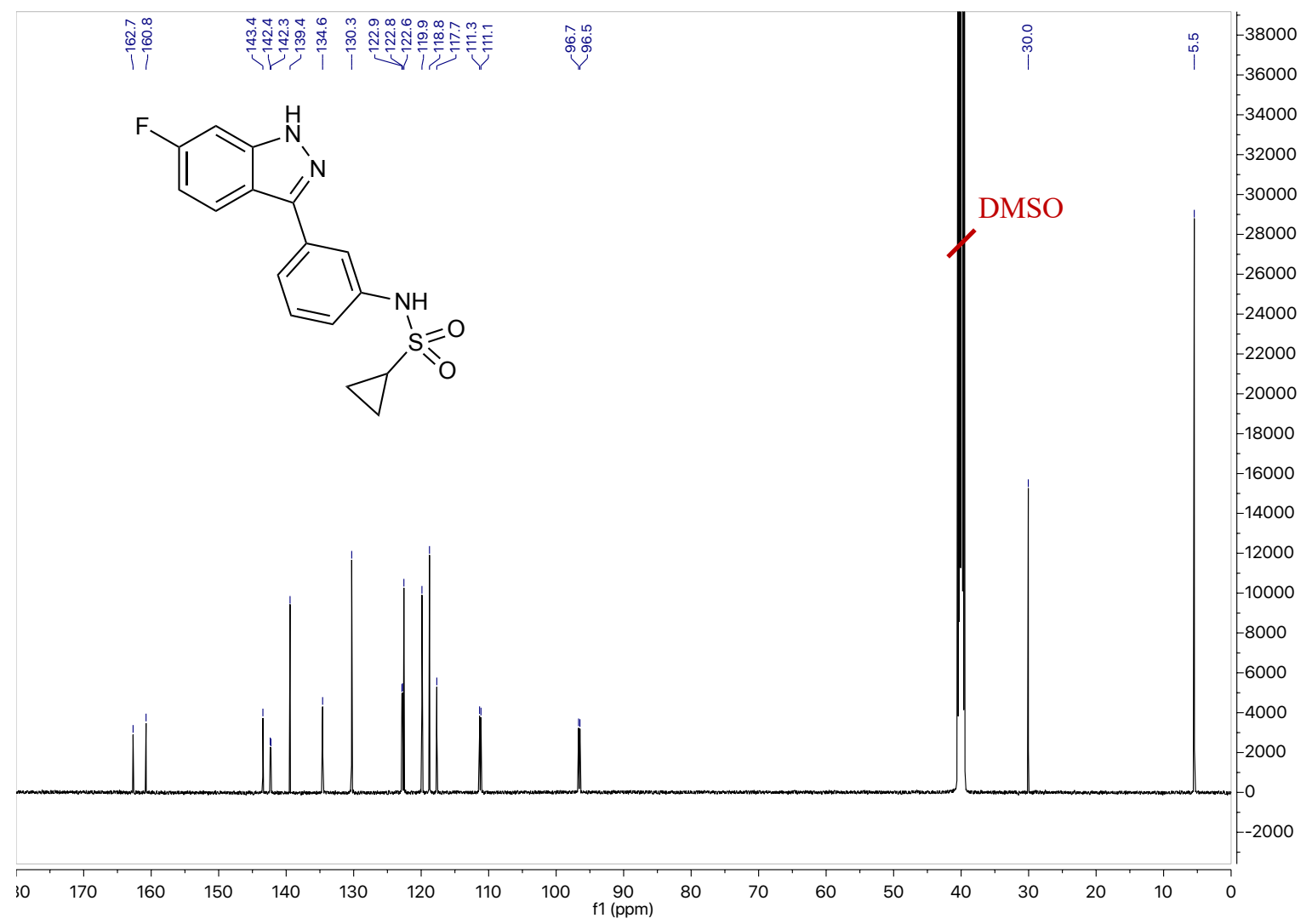




\section{Compounds 13a-c}

${ }^{1} \mathrm{H}$ NMR Spectrum of 13a (500 MHz, DMSO)

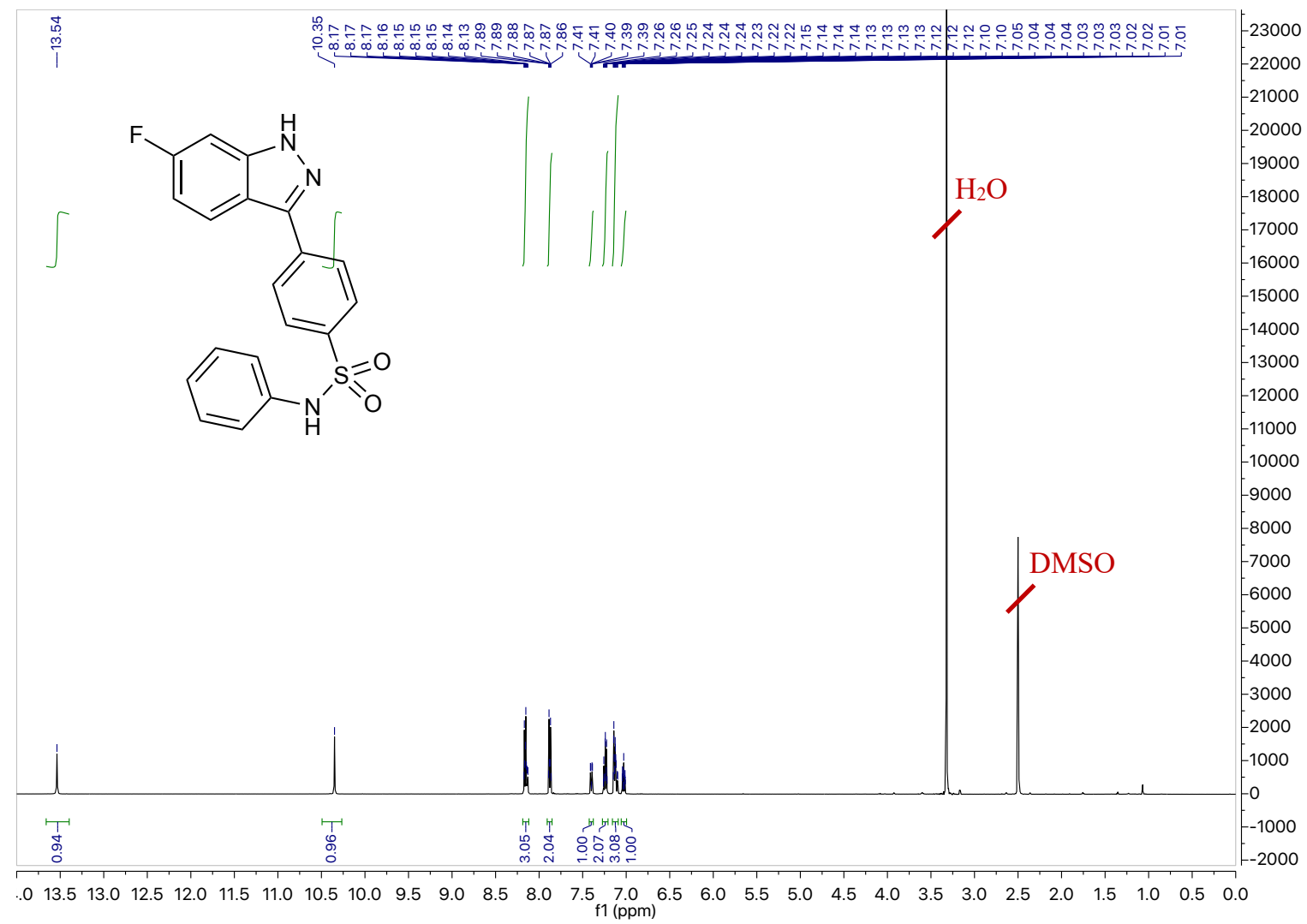

${ }^{13} \mathrm{C}$ NMR Spectrum of 13a (126 MHz, DMSO)

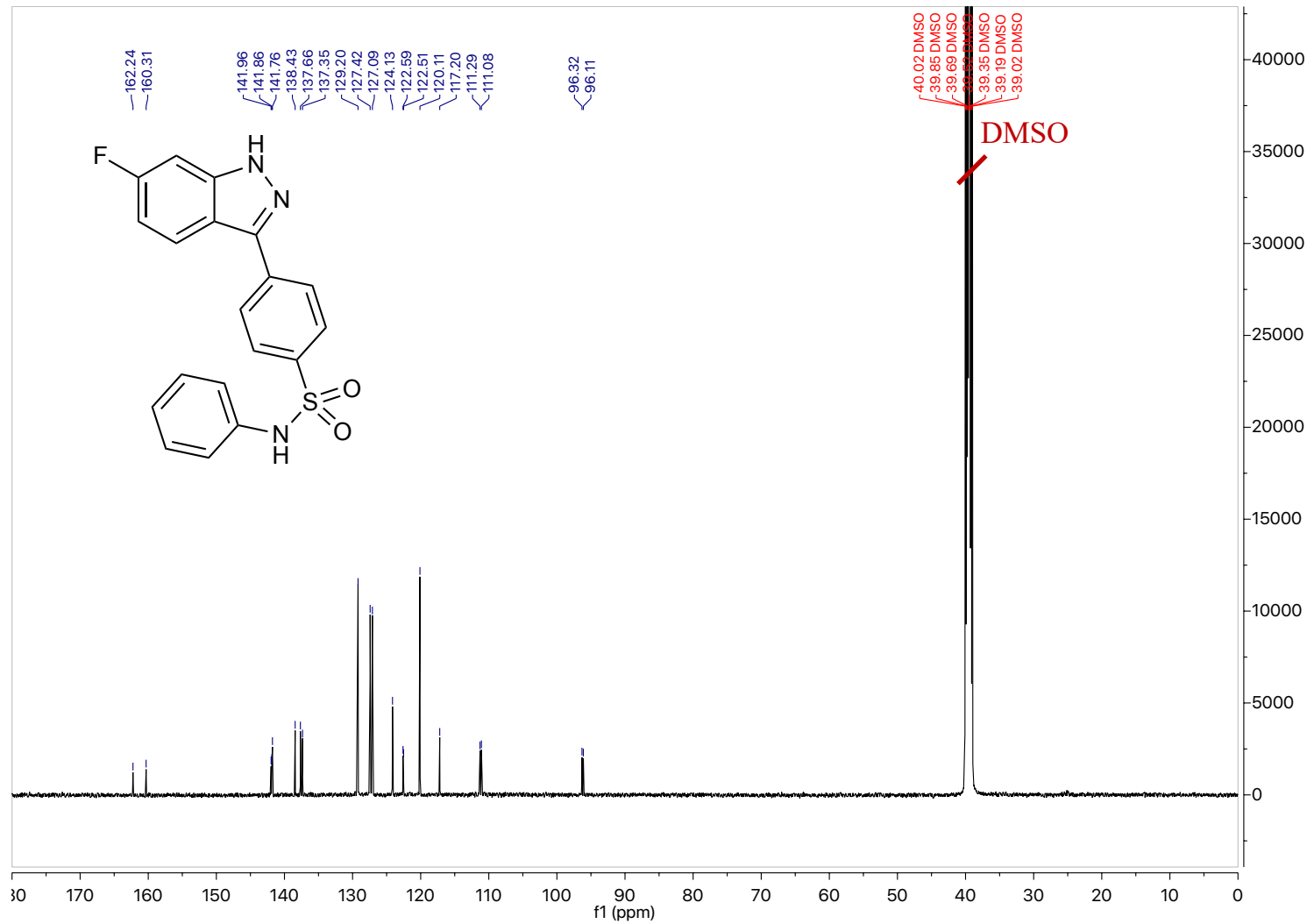


${ }^{1} \mathrm{H}$ NMR Spectrum of $\mathbf{1 3 b}(500 \mathrm{MHz}, \mathrm{DMSO})$

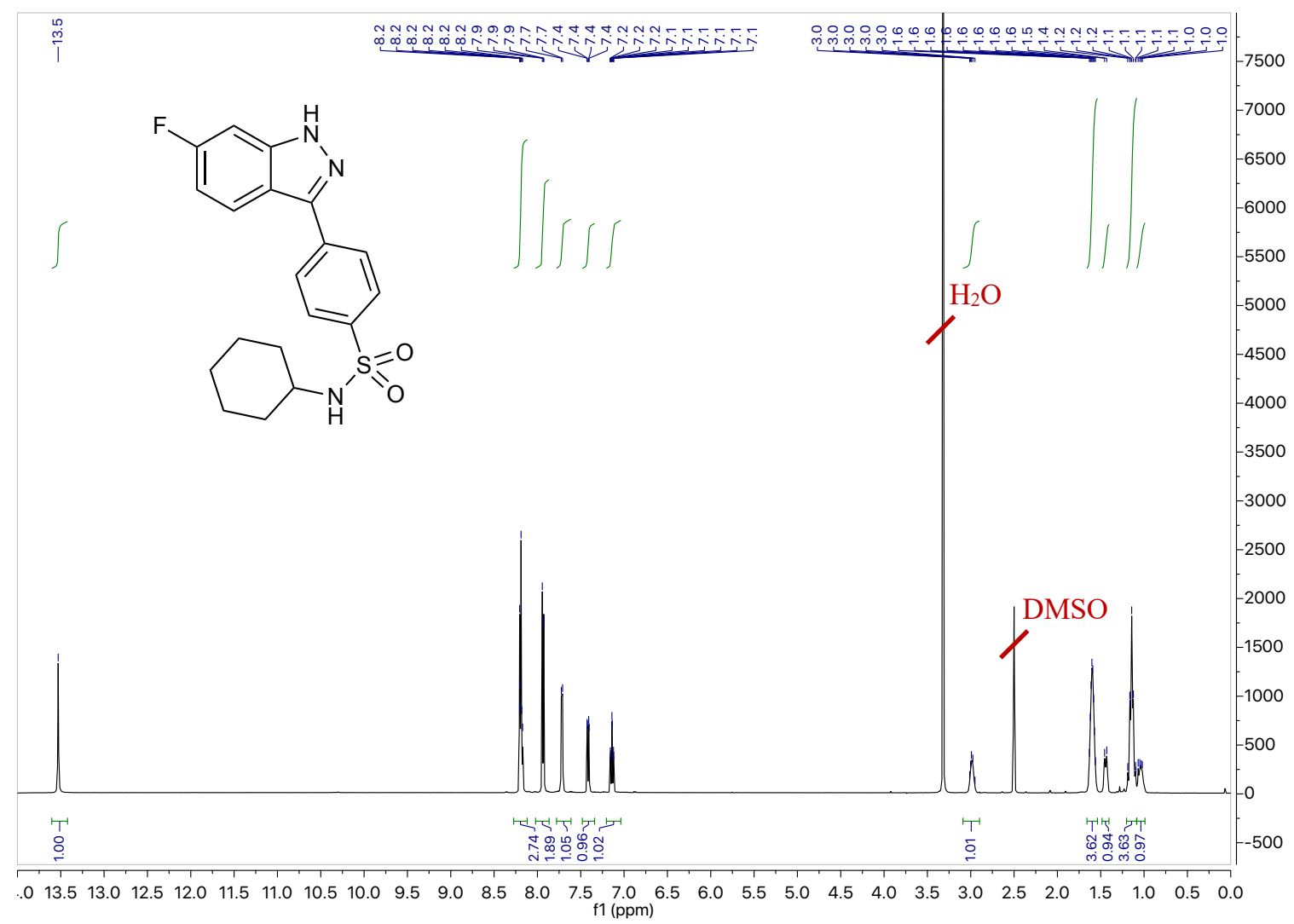

${ }^{13} \mathrm{C}$ NMR Spectrum of $\mathbf{1 3 b}$ (126 MHz, DMSO)

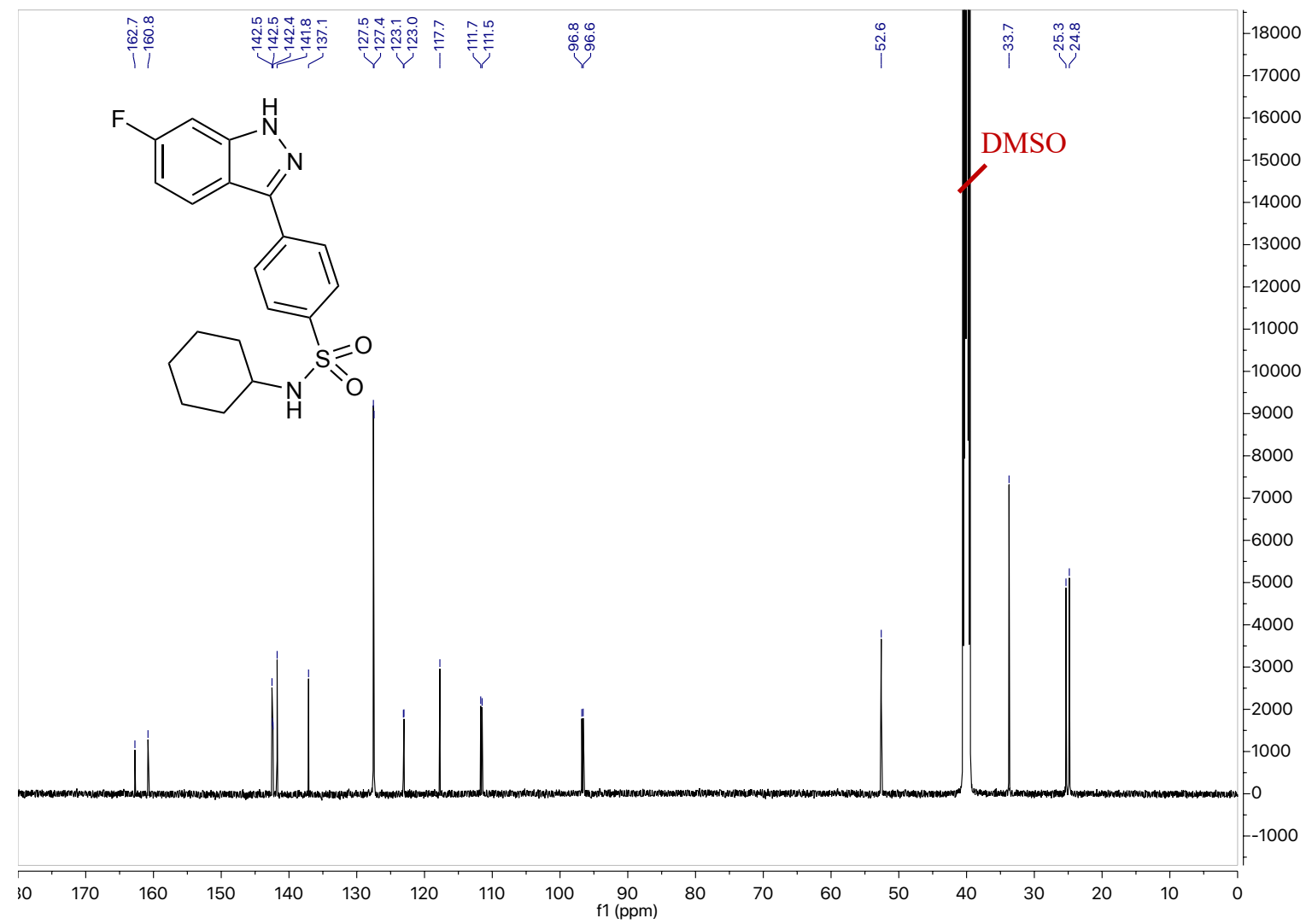


${ }^{1} \mathrm{H}$ NMR Spectrum of 13c (500 MHz, DMSO)

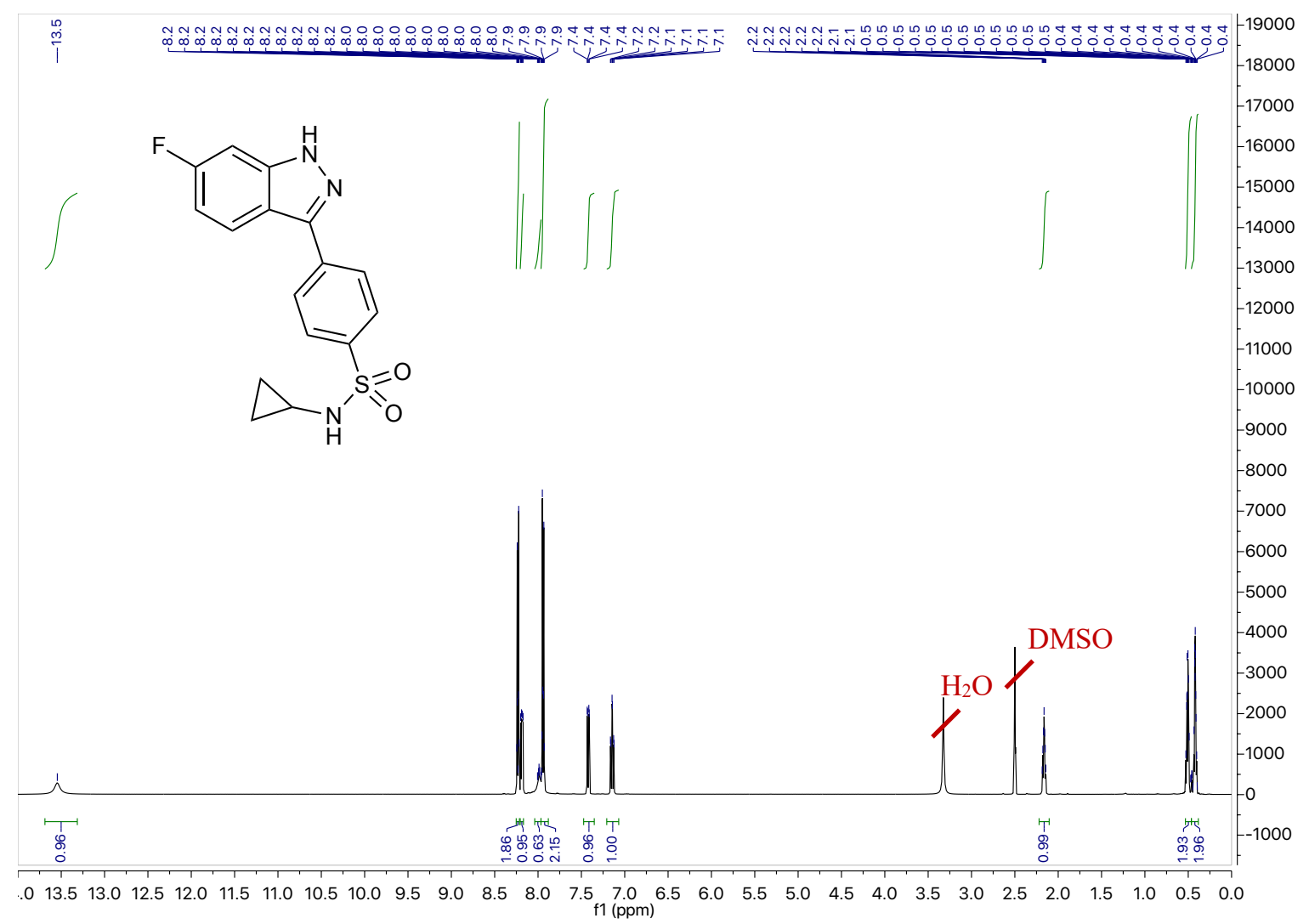

${ }^{13} \mathrm{C}$ NMR Spectrum of $13 \mathrm{c}$ (126 MHz, DMSO)

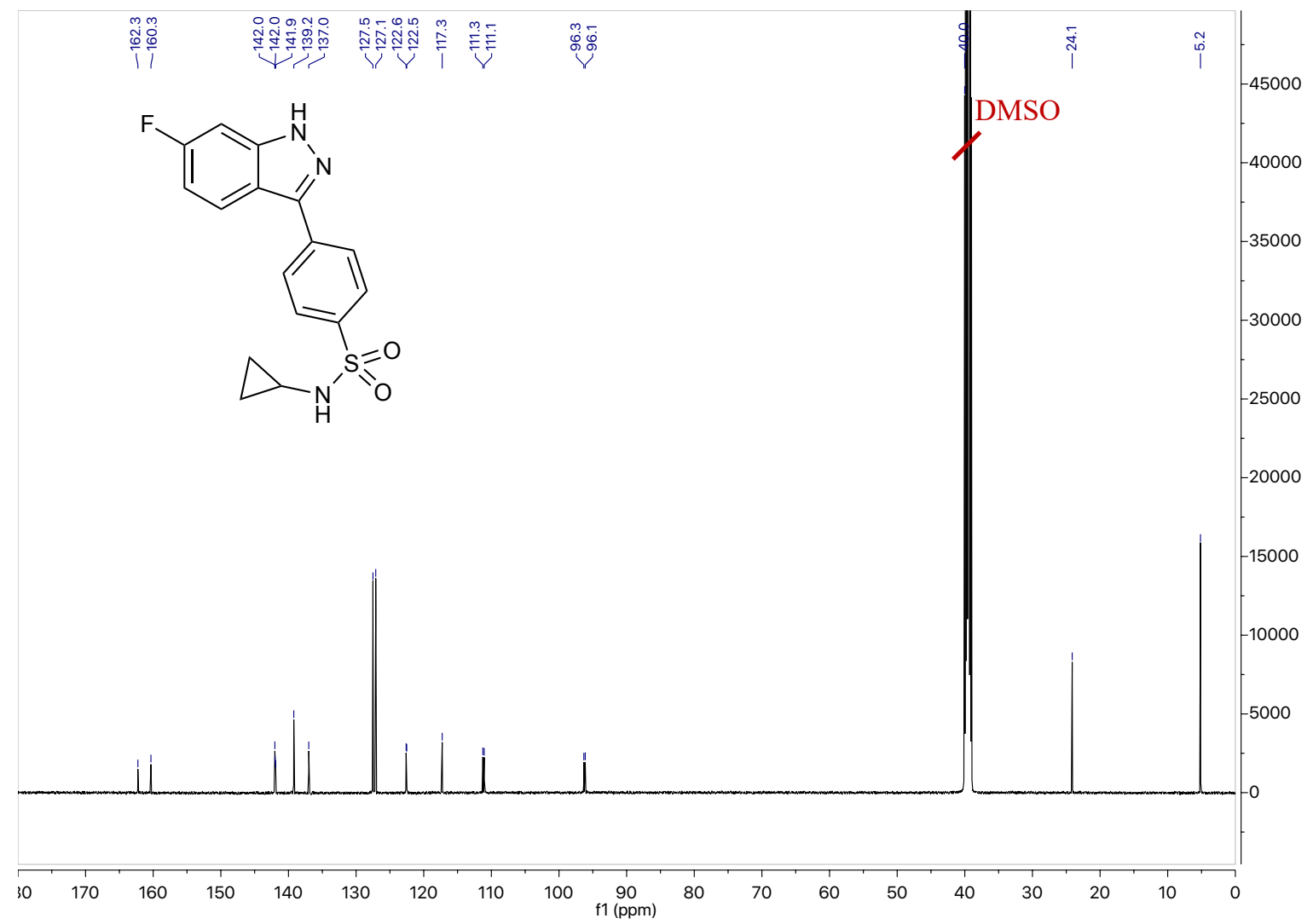




\section{Compounds 14a-d}

${ }^{1} \mathrm{H}$ NMR Spectrum of 14a (500 MHz, DMSO)

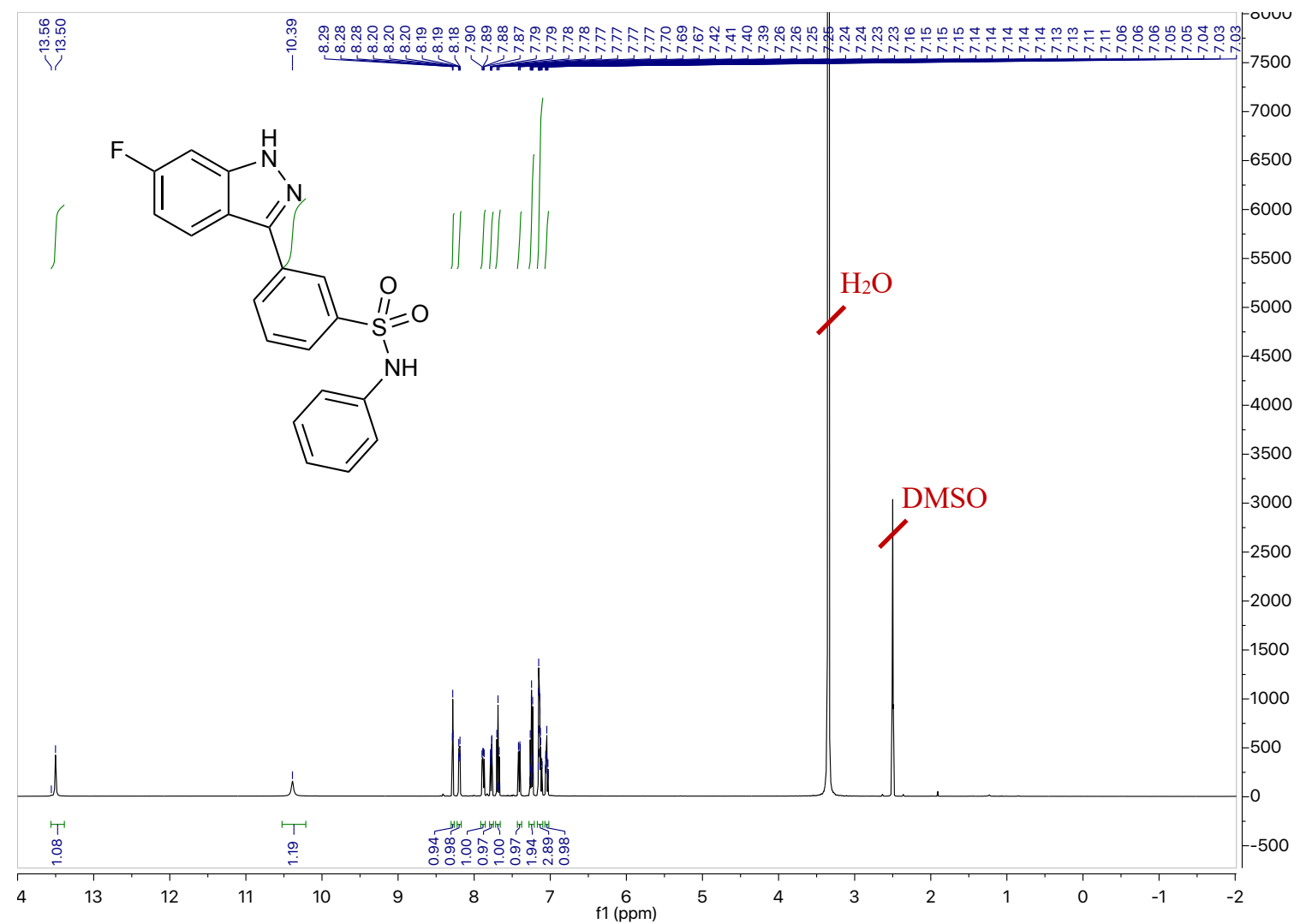

${ }^{13} \mathrm{C}$ NMR Spectrum of 14a (126 MHz, DMSO)

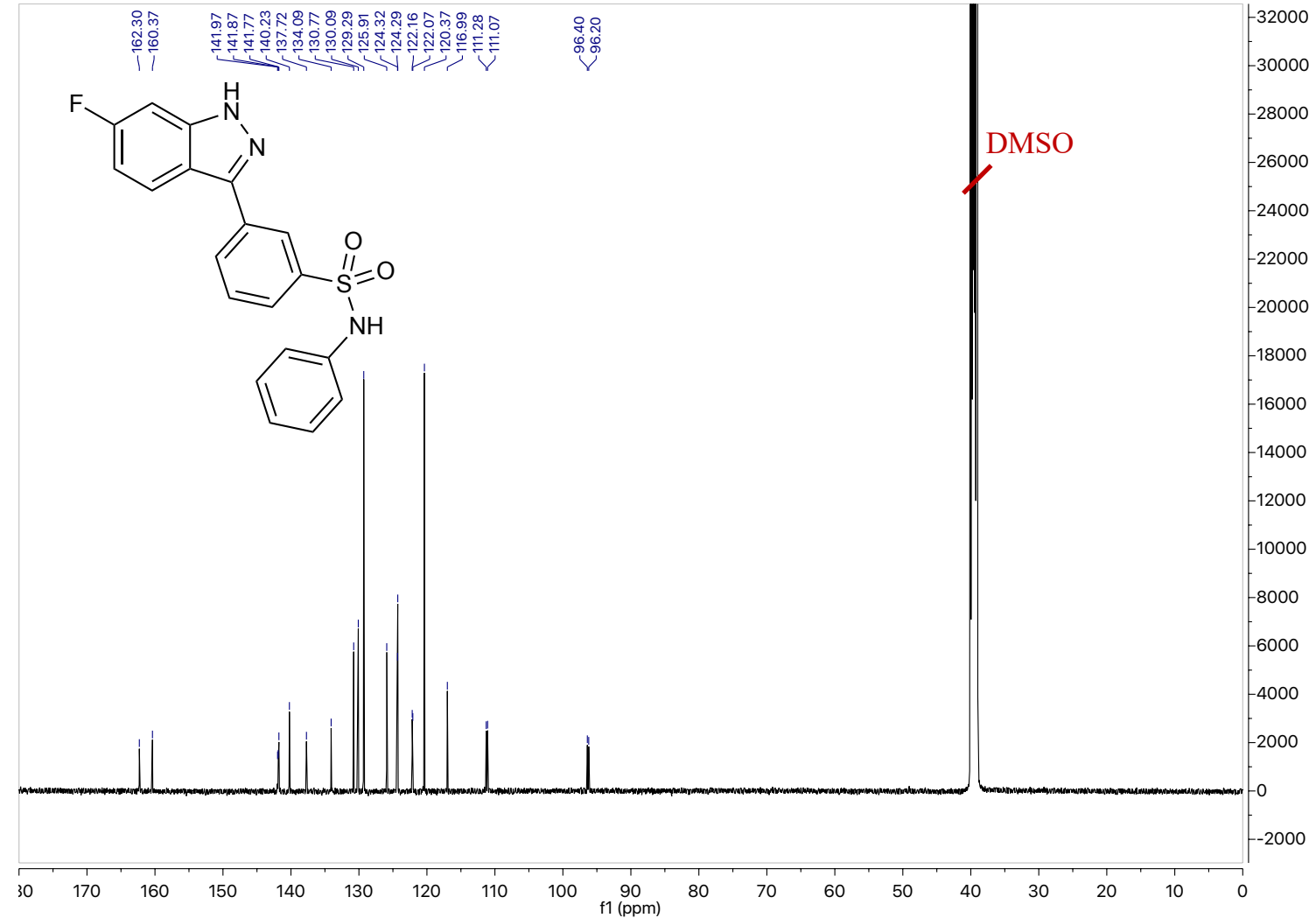


${ }^{1} \mathrm{H}$ NMR Spectrum of $\mathbf{1 4 b}(500 \mathrm{MHz}, \mathrm{DMSO})$

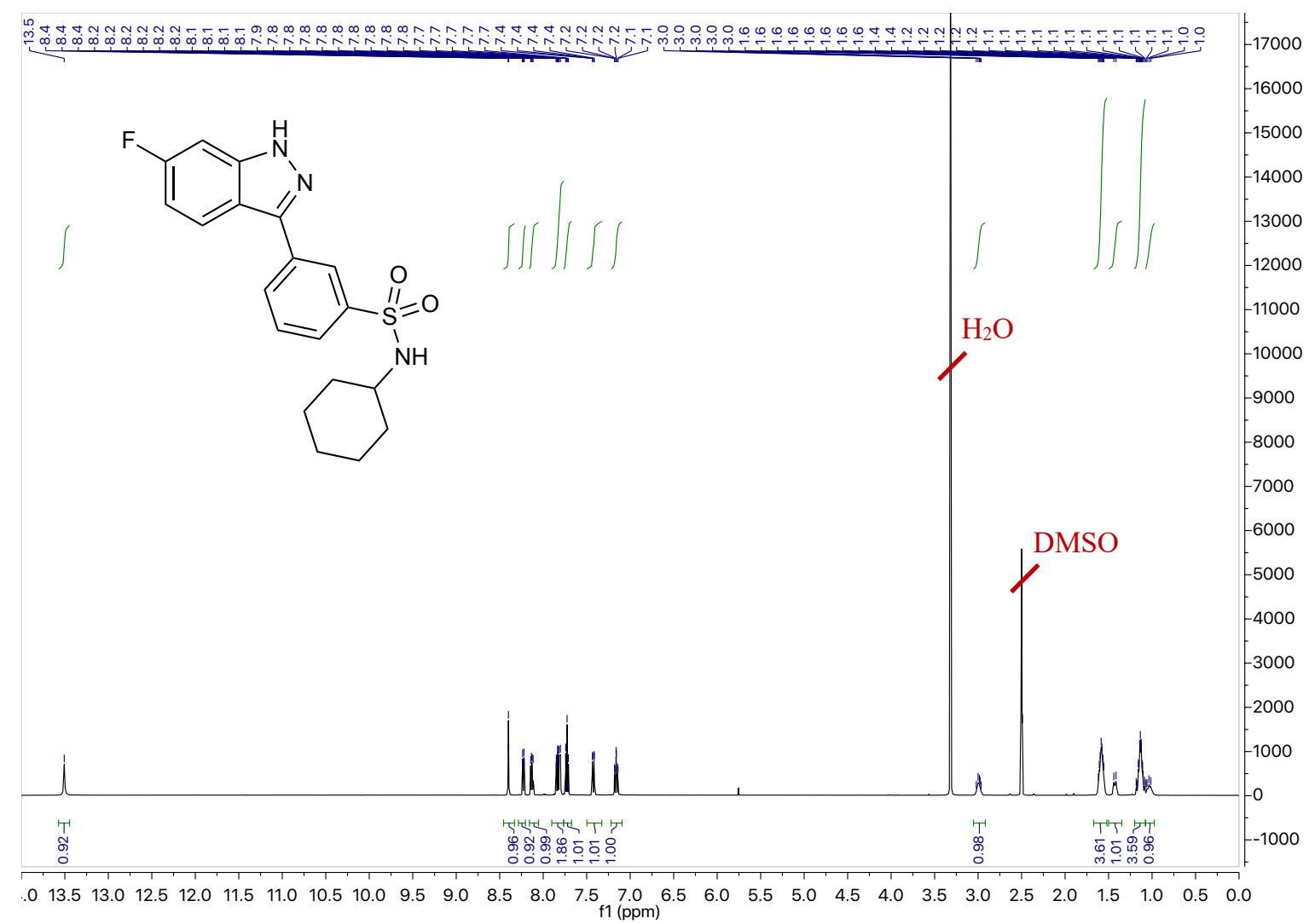

${ }^{13} \mathrm{C}$ NMR Spectrum of $\mathbf{1 4 b}$ (126 MHz, DMSO)

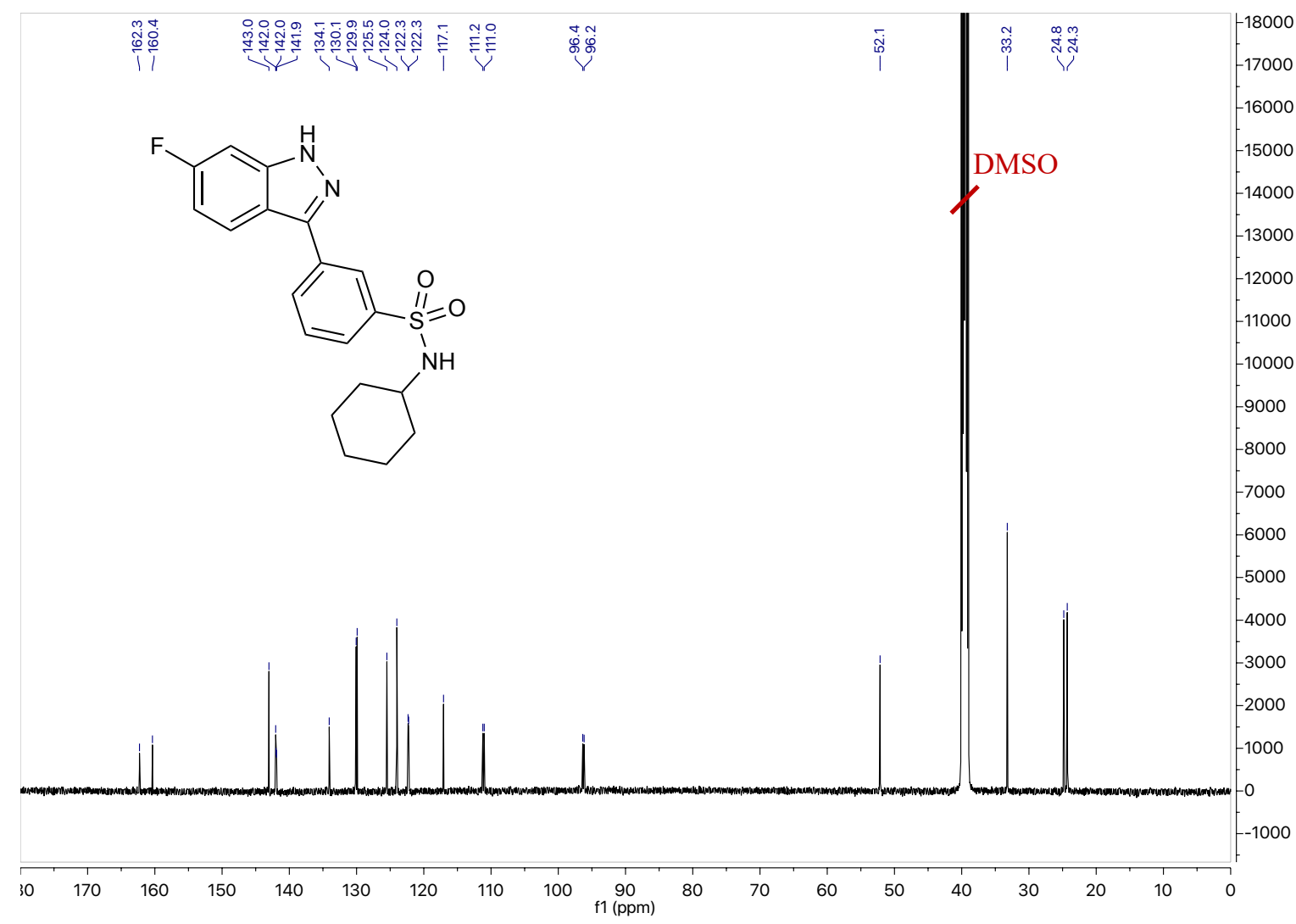


${ }^{1} \mathrm{H}$ NMR Spectrum of $\mathbf{1 4 c}(500 \mathrm{MHz}, \mathrm{DMSO})$

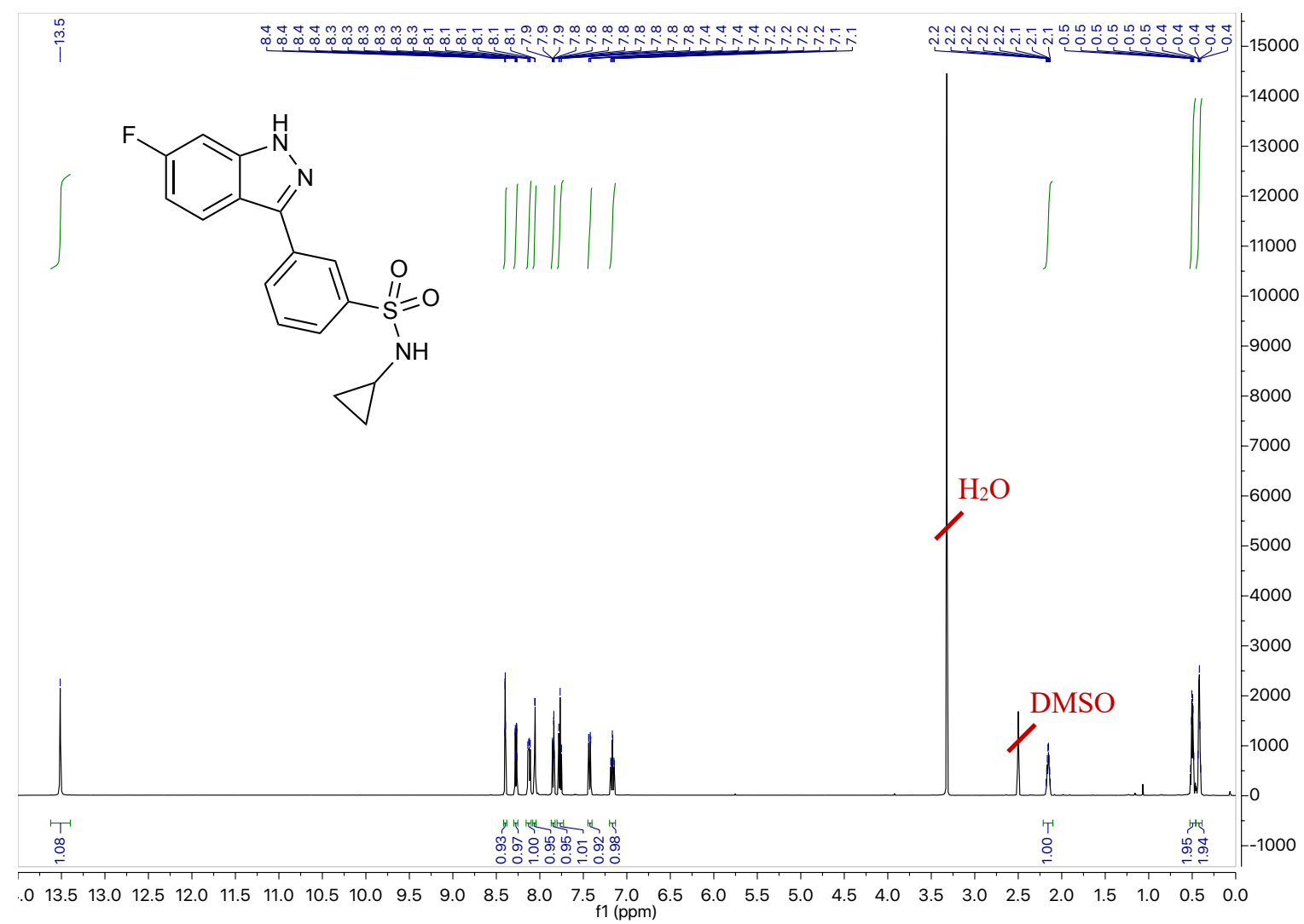

${ }^{13} \mathrm{C}$ NMR Spectrum of $\mathbf{1 4 c}(126 \mathrm{MHz}, \mathrm{DMSO})$

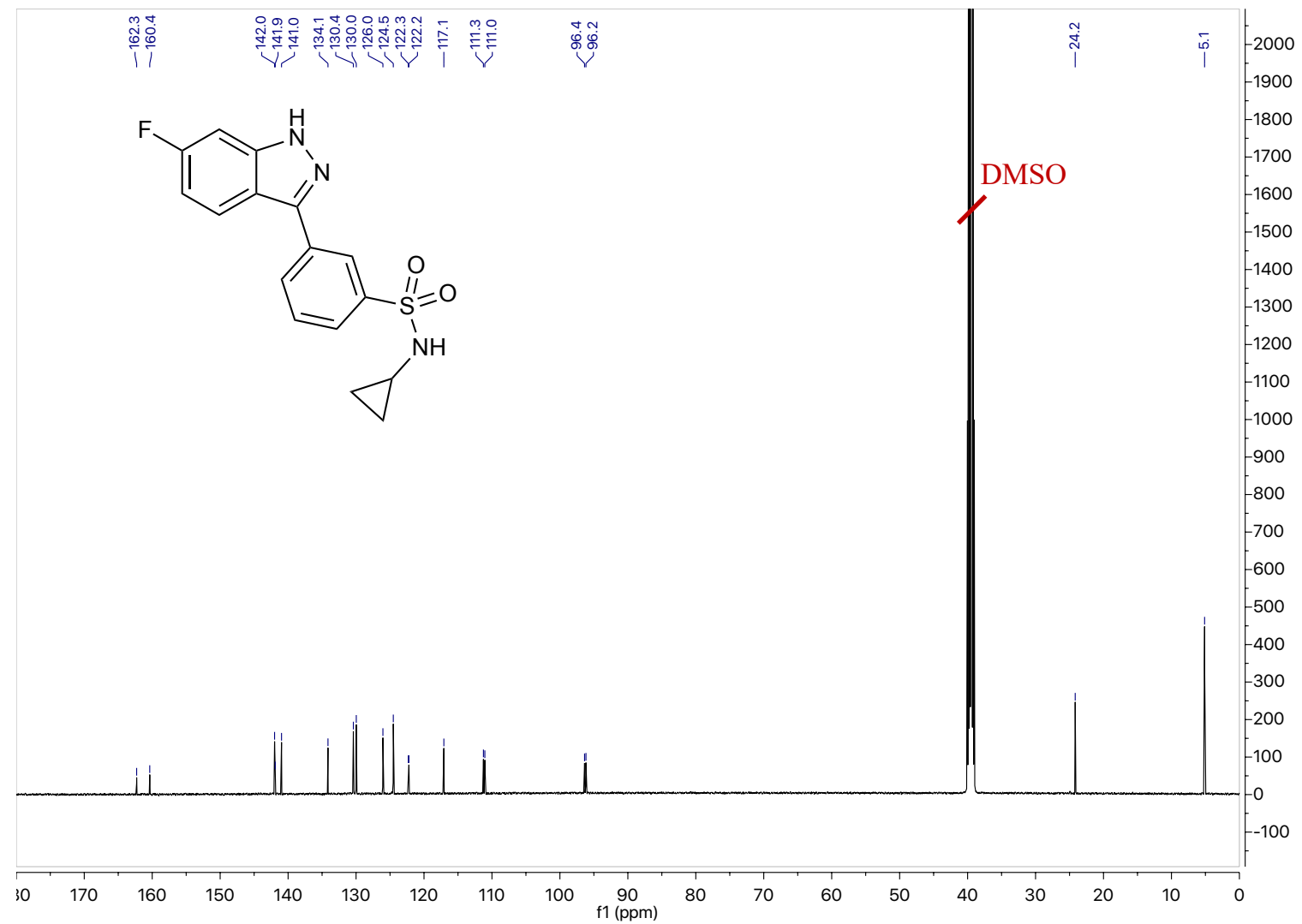


${ }^{1} \mathrm{H}$ NMR Spectrum of $\mathbf{1 4 d}(500 \mathrm{MHz}, \mathrm{DMSO})$

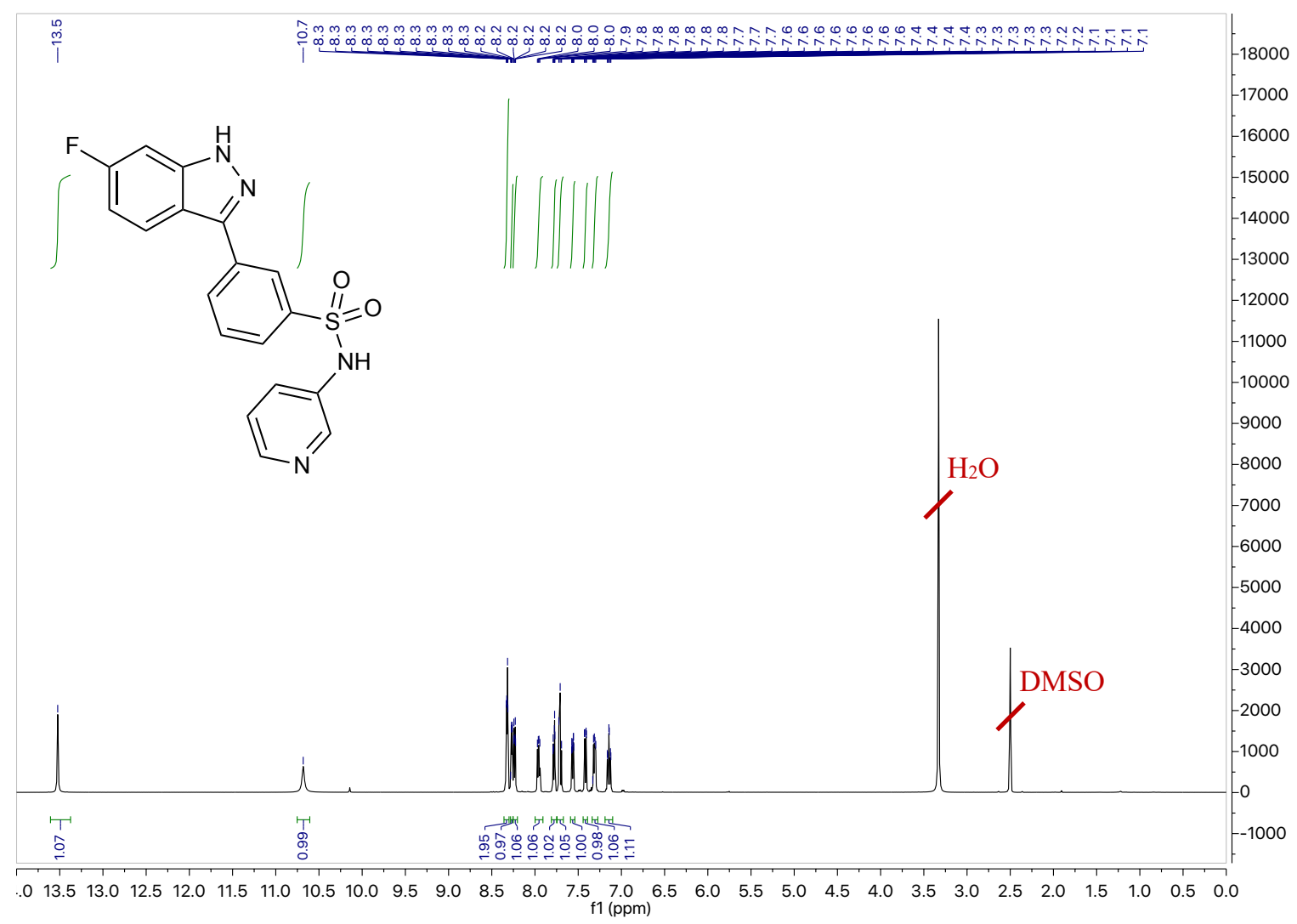

${ }^{13} \mathrm{C}$ NMR Spectrum of $\mathbf{1 4 d}$ (126 MHz, DMSO)

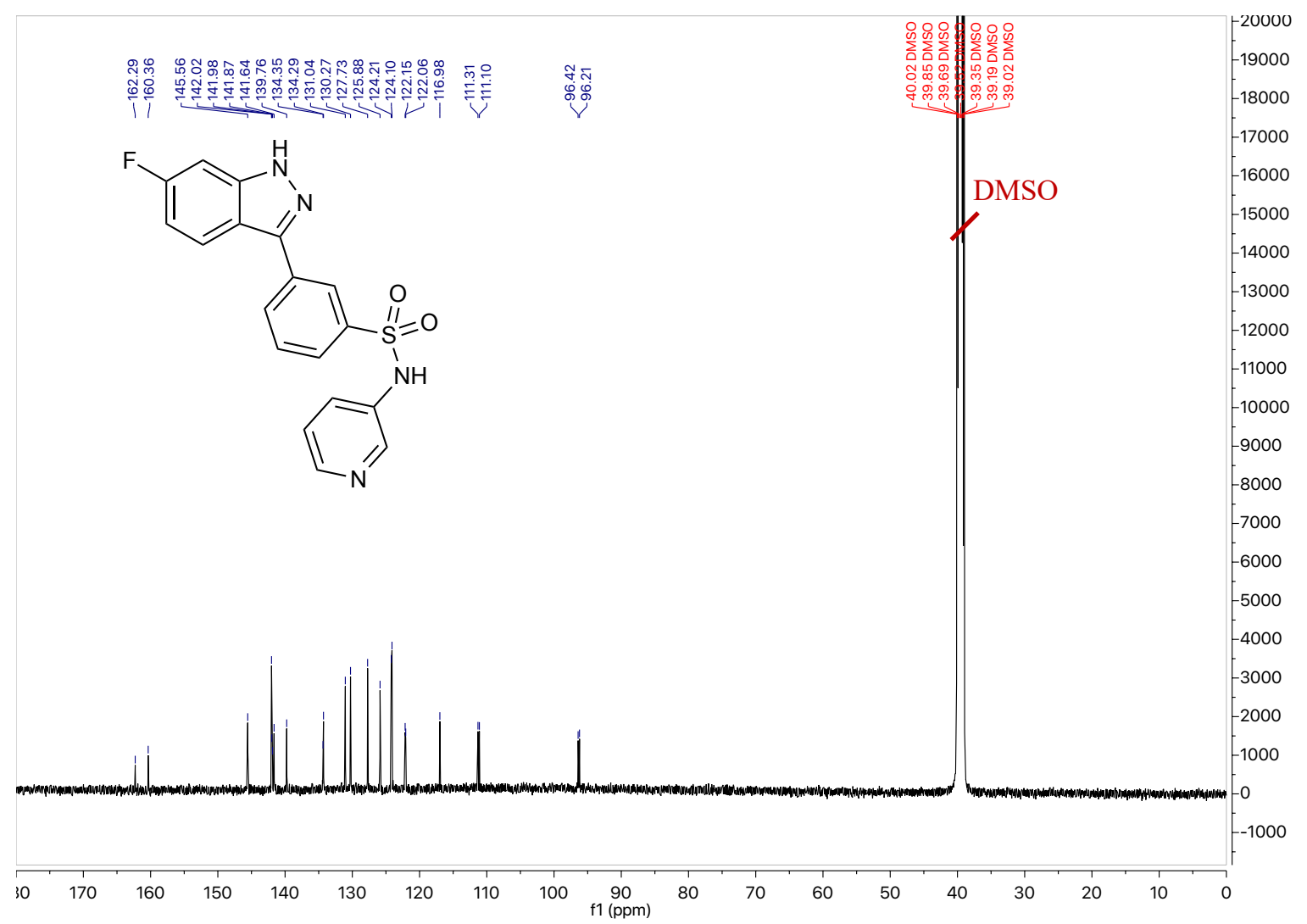




\section{Compounds 15a-o}

\section{${ }^{1} \mathrm{H}$ NMR Spectrum of 15a (500 MHz, DMSO)}

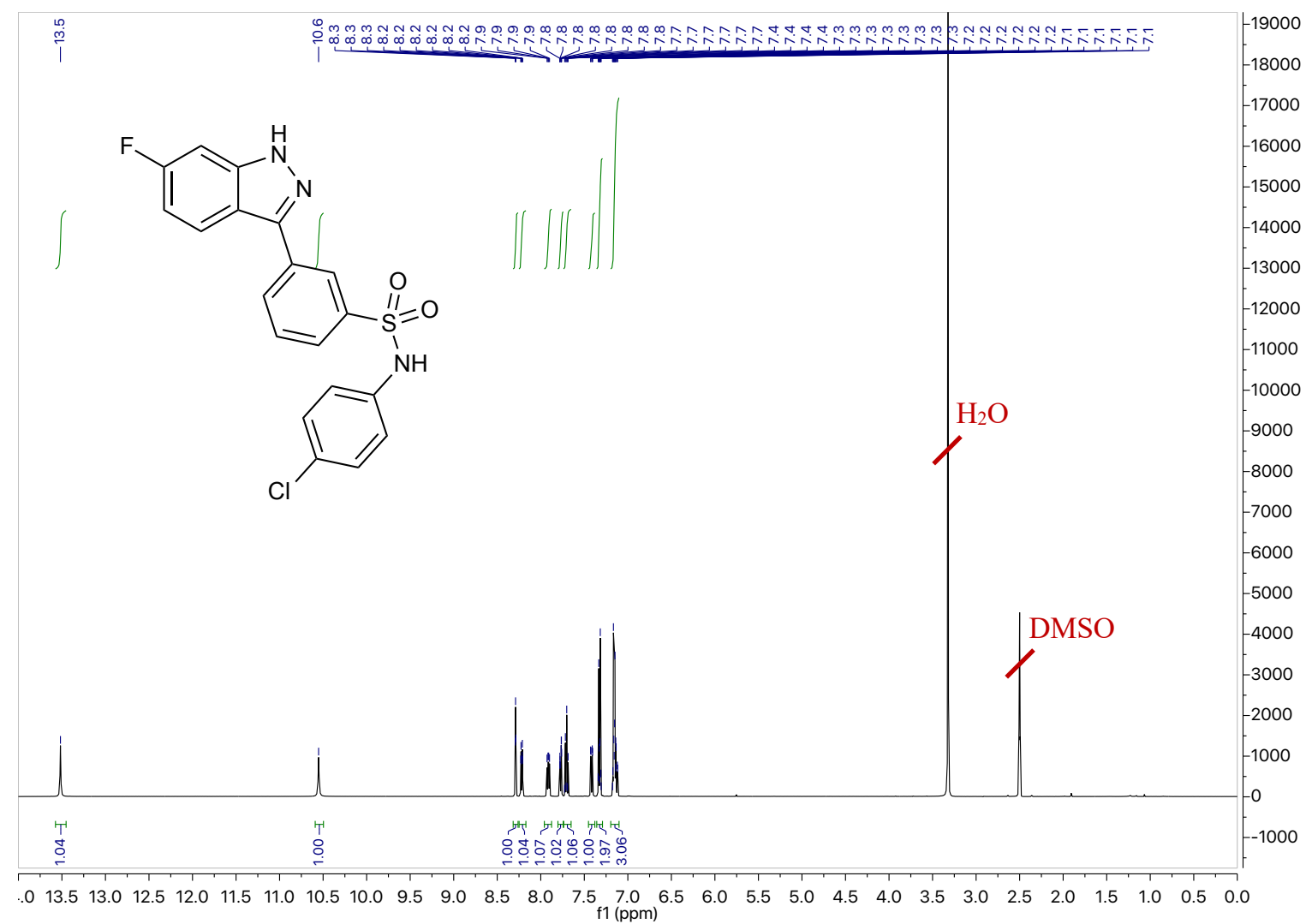

${ }^{13} \mathrm{C}$ NMR Spectrum of 15a (126 MHz, DMSO)

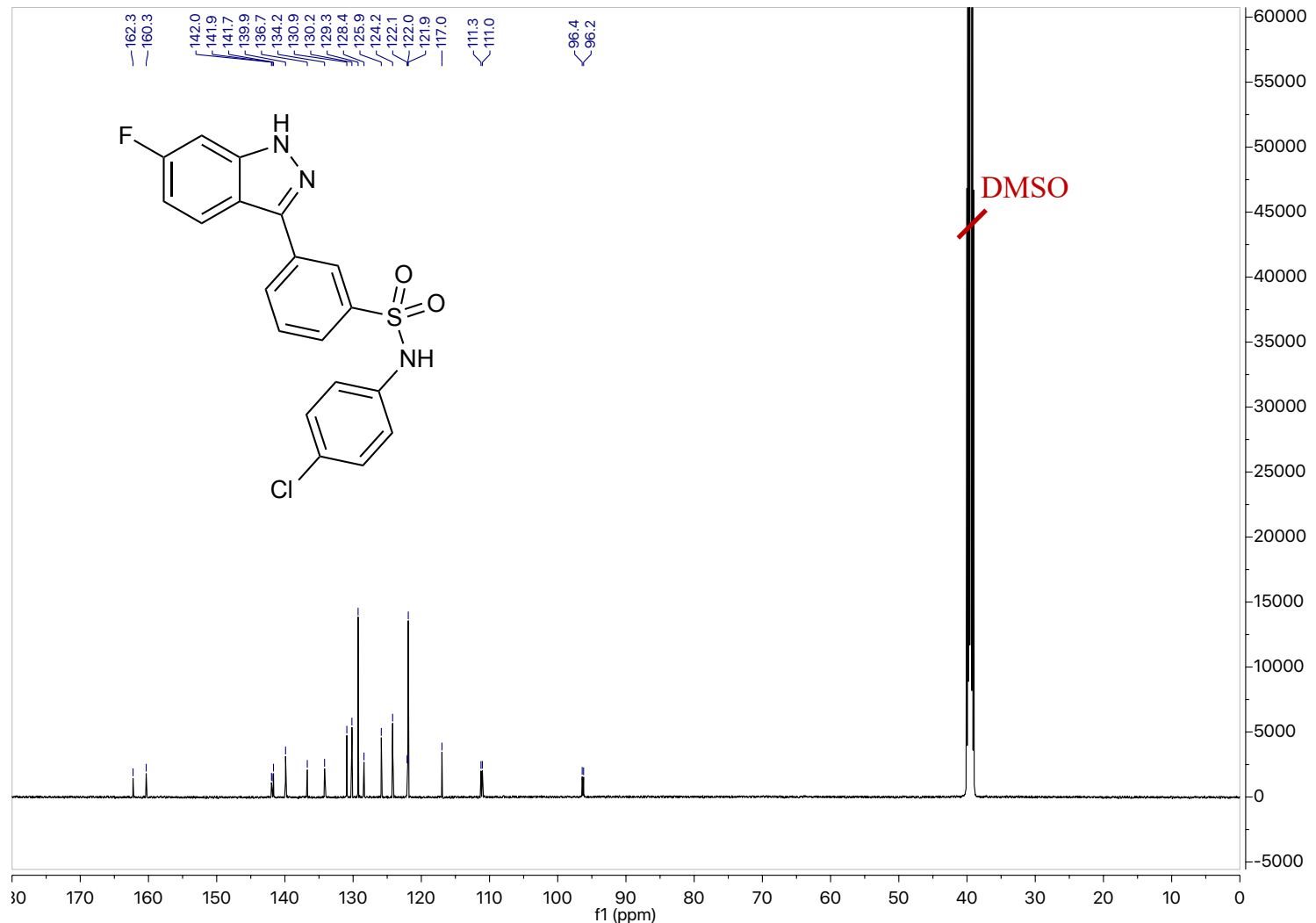


${ }^{1} \mathrm{H}$ NMR Spectrum of $\mathbf{1 5 b}$ (500 MHz, DMSO)

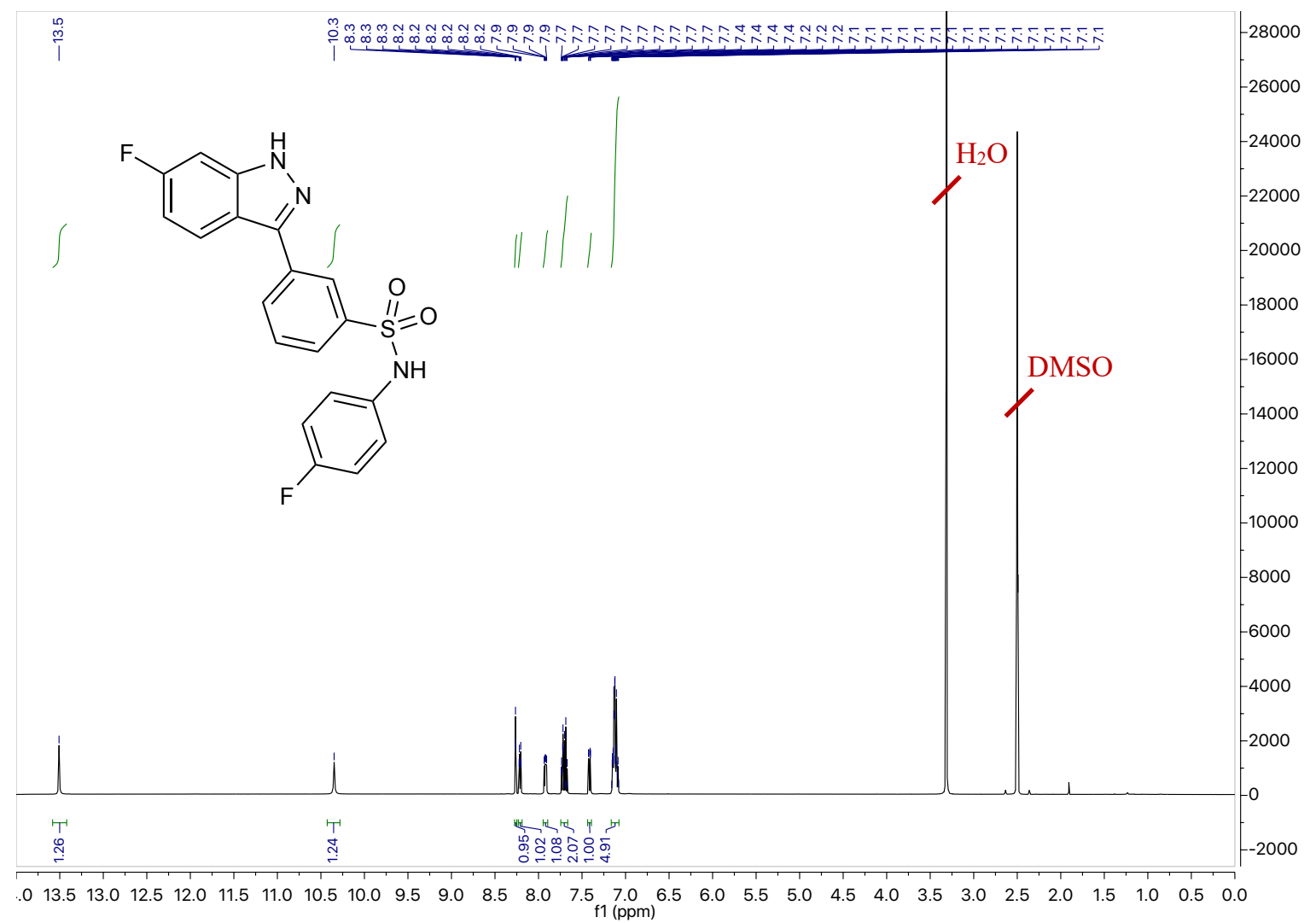

${ }^{13} \mathrm{C}$ NMR Spectrum of $\mathbf{1 5 b}$ (126 MHz, DMSO)

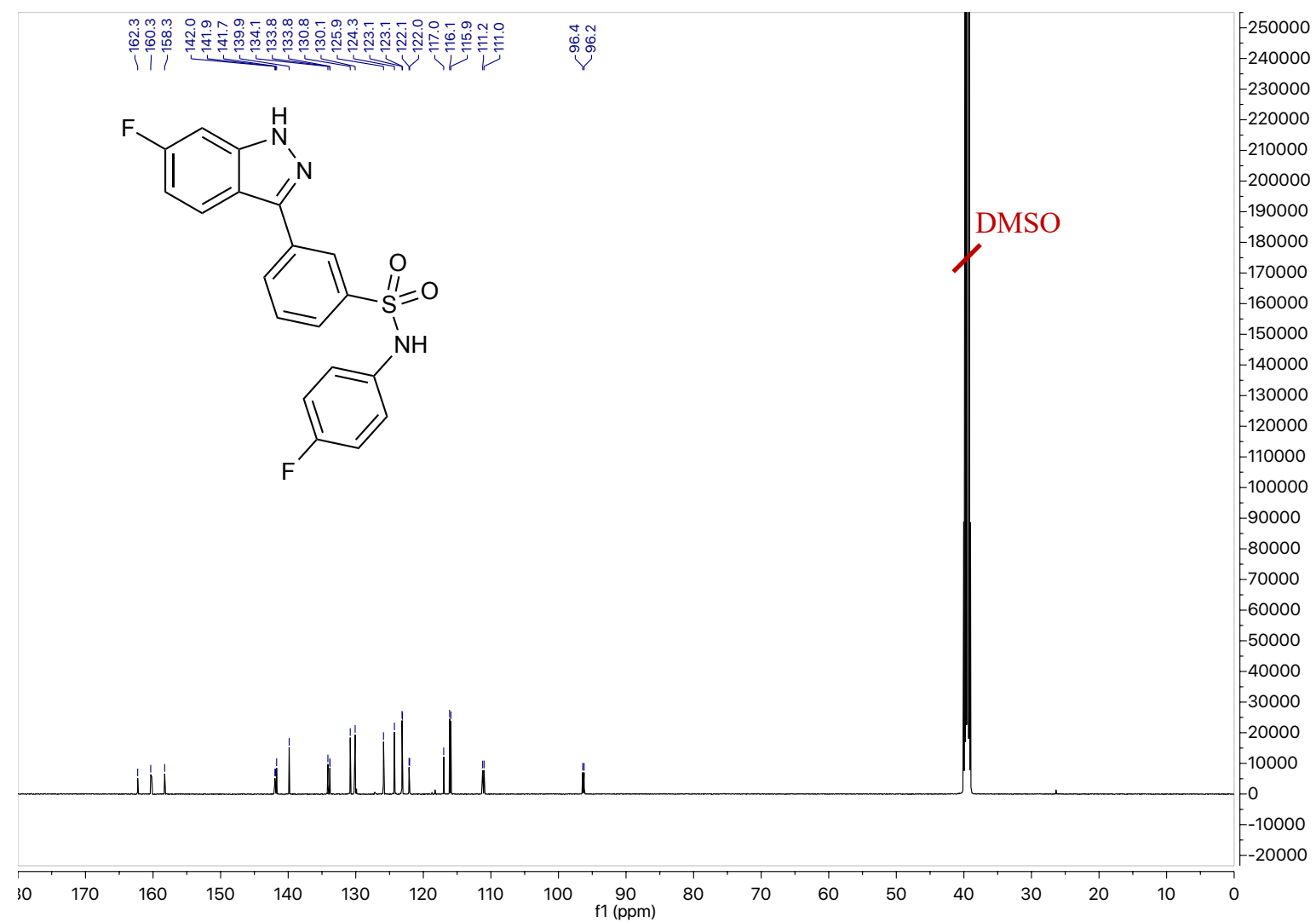


${ }^{1} \mathrm{H}$ NMR Spectrum of $\mathbf{1 5 c}(500 \mathrm{MHz}, \mathrm{DMSO})$

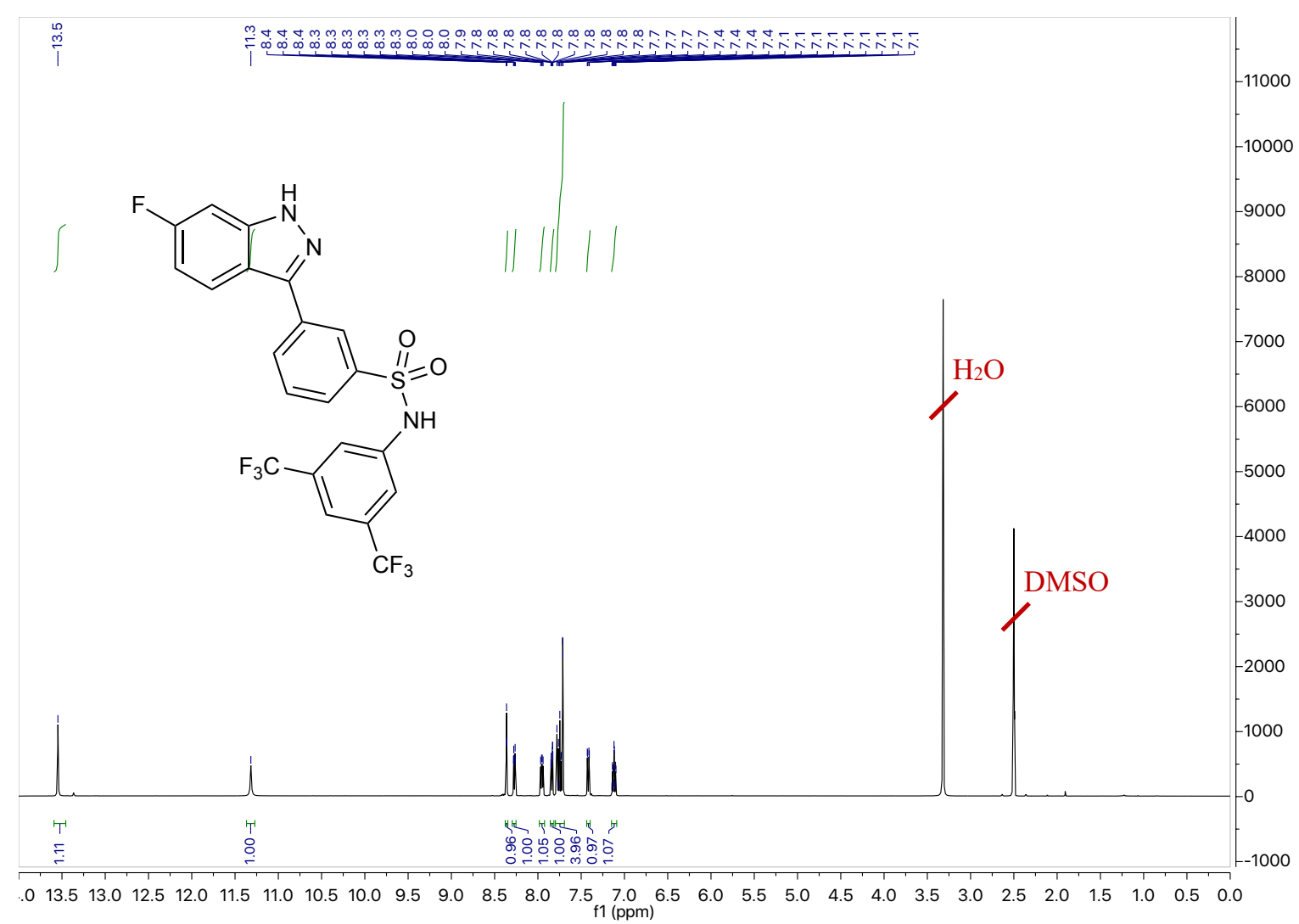

${ }^{13} \mathrm{C}$ NMR Spectrum of $15 \mathrm{c}$ (126 MHz, DMSO)

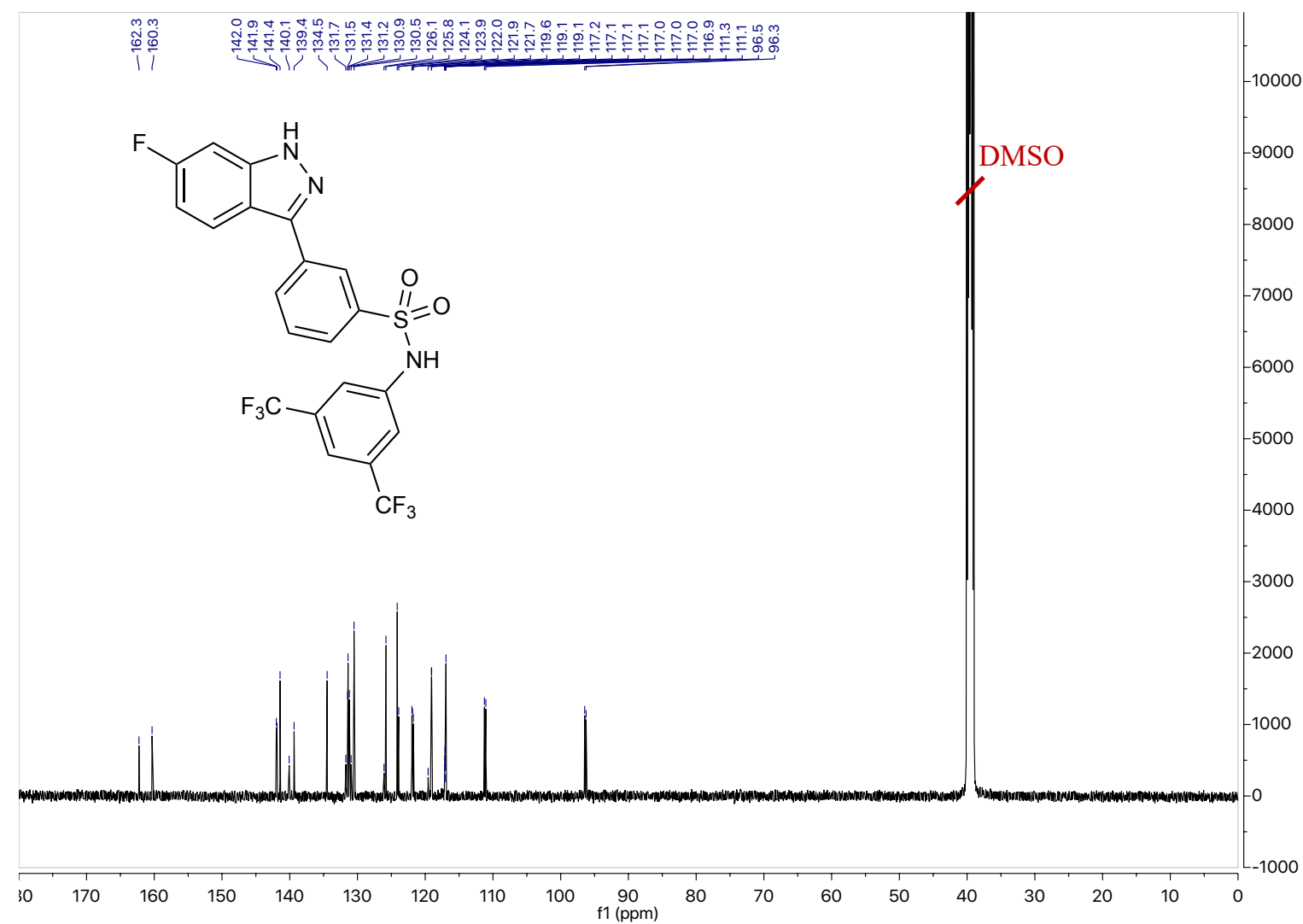


${ }^{1} \mathrm{H}$ NMR Spectrum of $\mathbf{1 5 d}(500 \mathrm{MHz}, \mathrm{DMSO})$

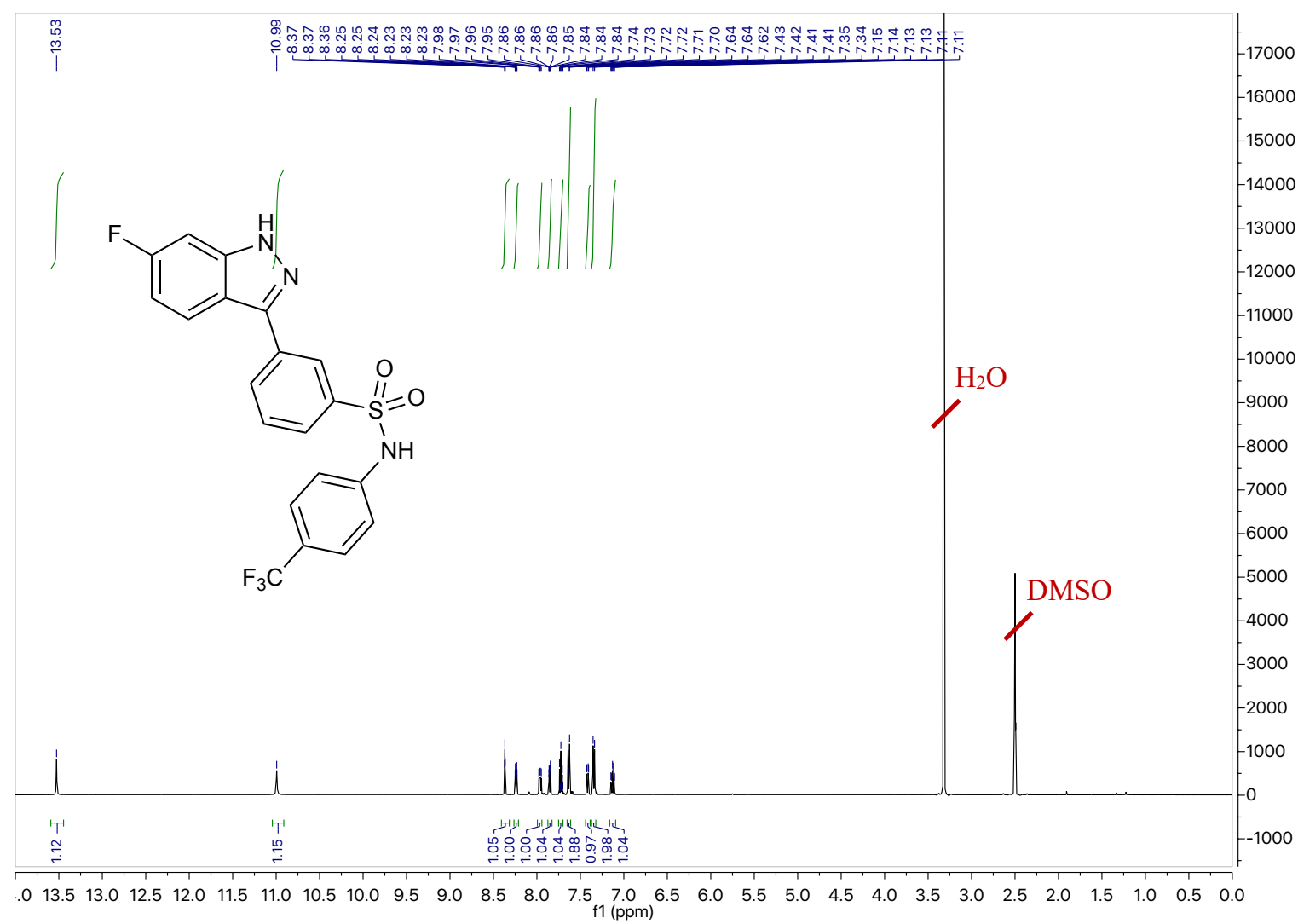

${ }^{13} \mathrm{C}$ NMR Spectrum of $\mathbf{1 5 d}(126 \mathrm{MHz}, \mathrm{DMSO})$

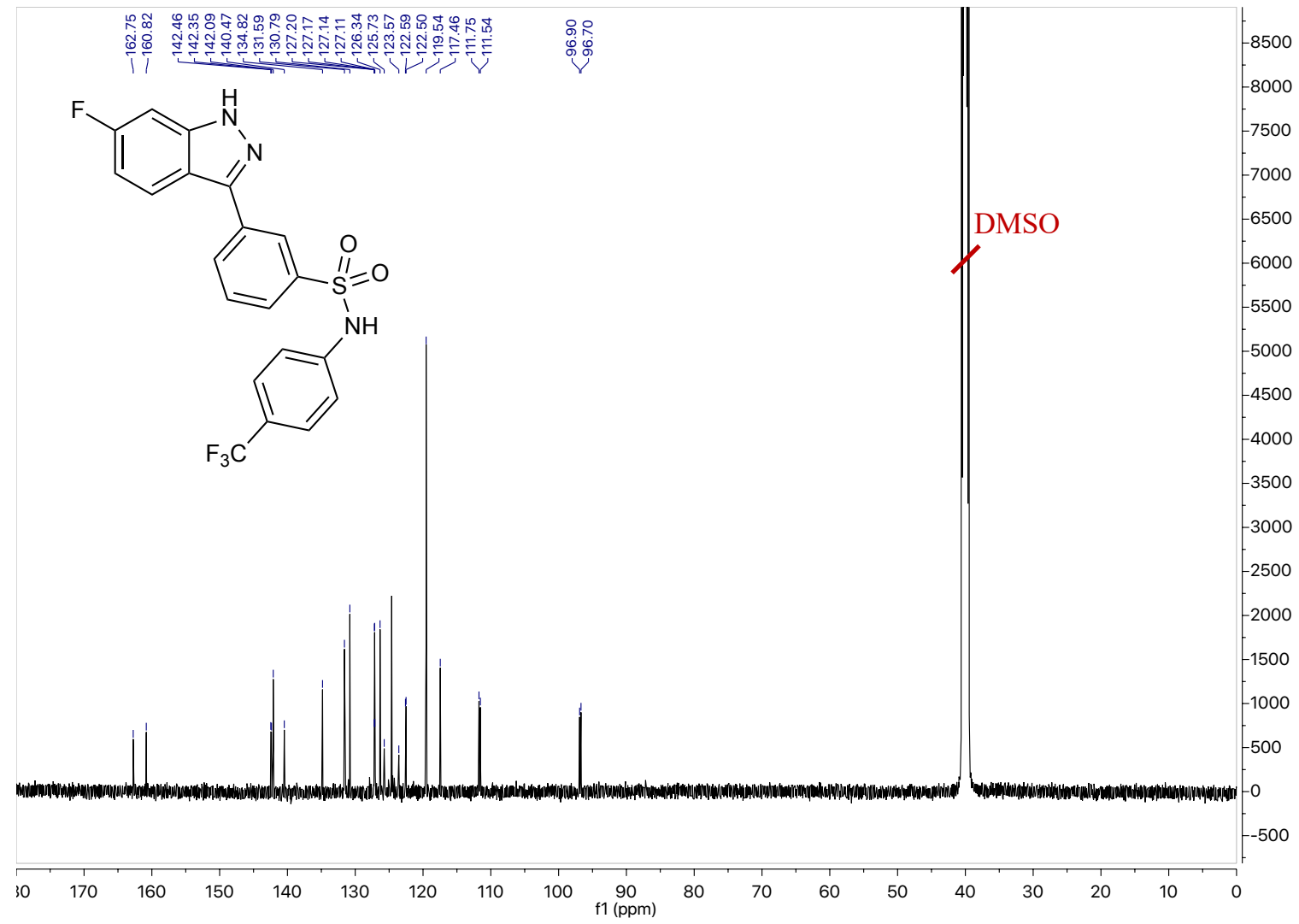


${ }^{1} \mathrm{H}$ NMR Spectrum of 15e (500 MHz, DMSO)

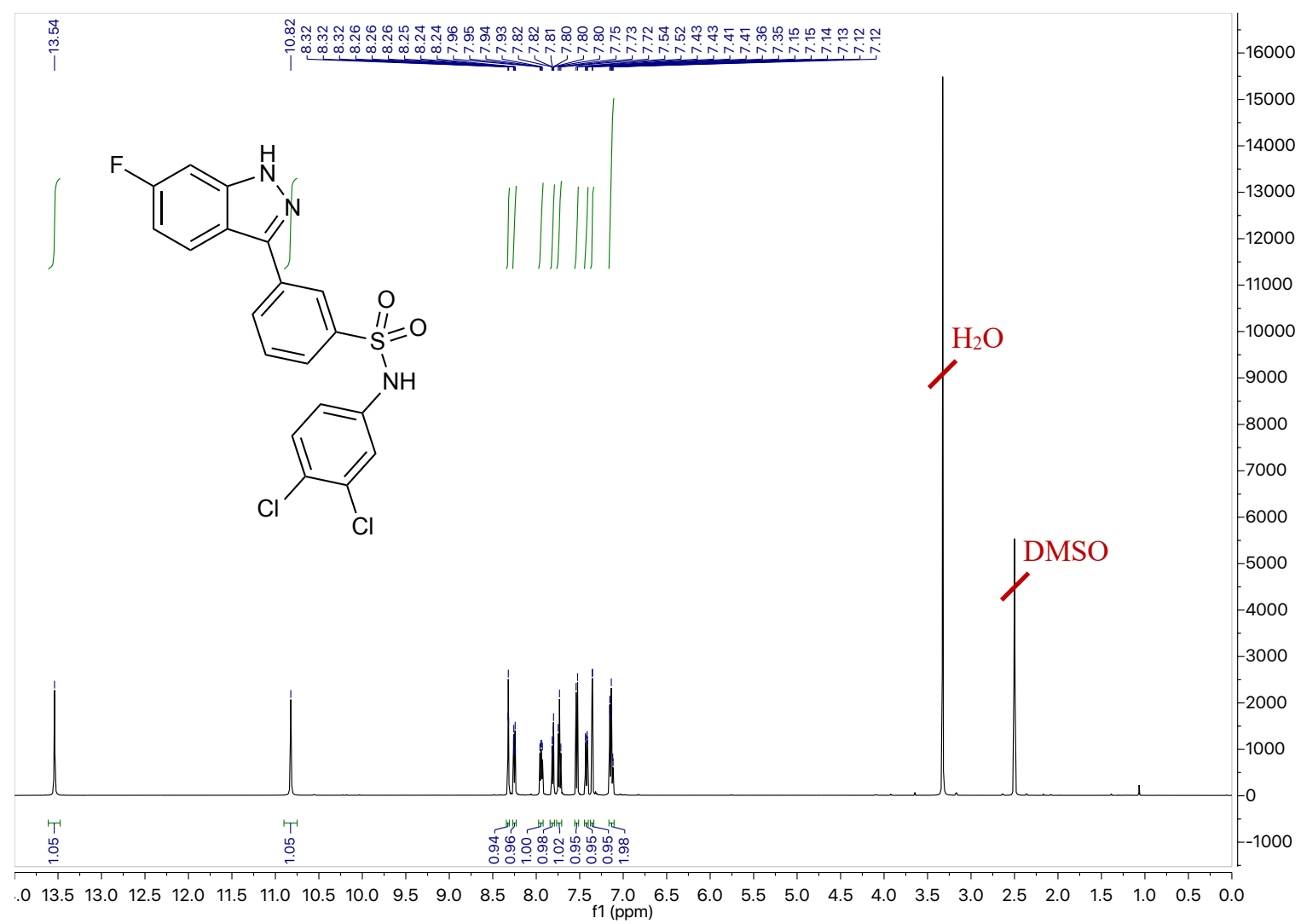

${ }^{13} \mathrm{C}$ NMR Spectrum of $15 \mathrm{e}$ (126 MHz, DMSO)

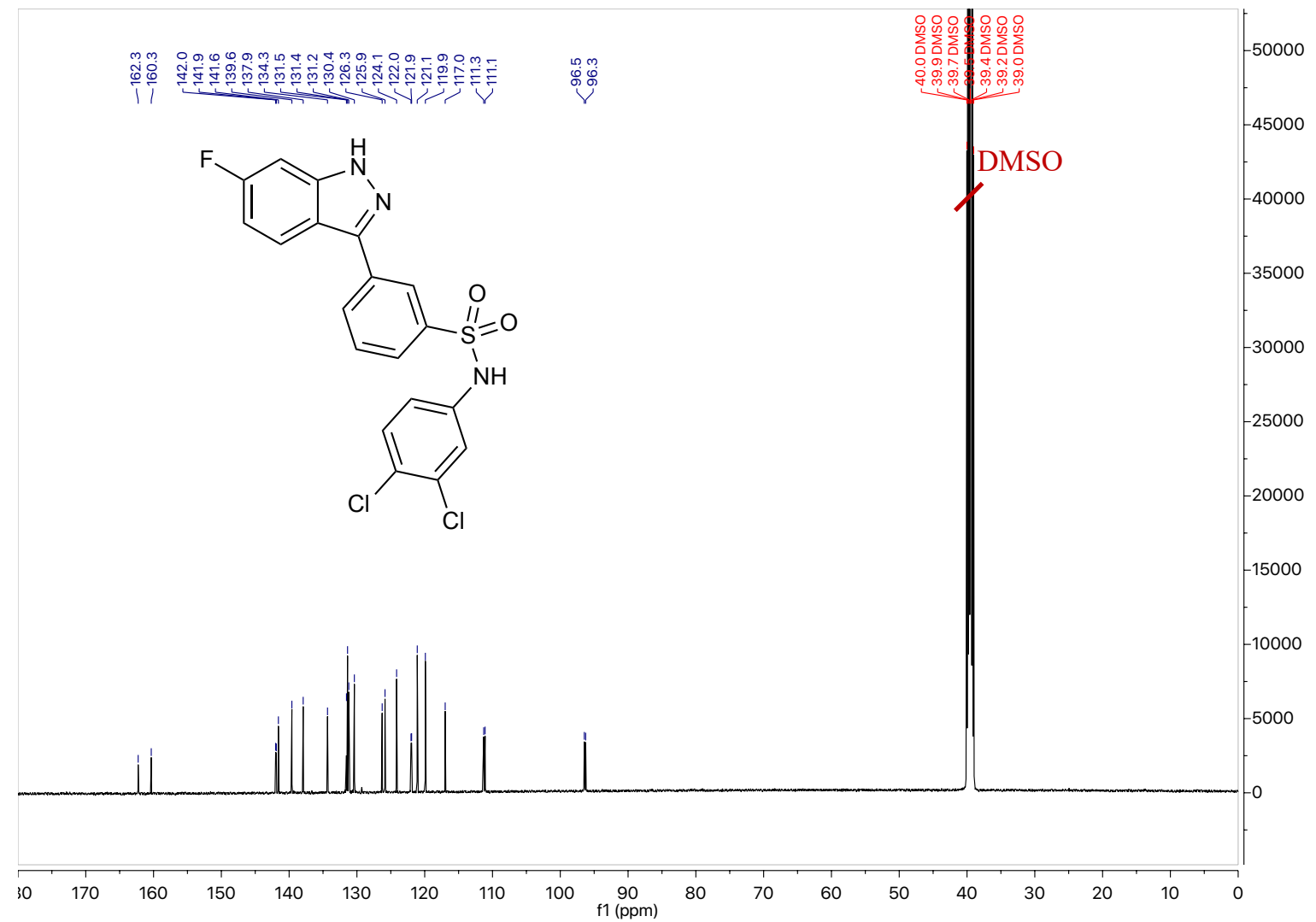


${ }^{1} \mathrm{H}$ NMR Spectrum of $\mathbf{1 5 f}(500 \mathrm{MHz}, \mathrm{DMSO})$

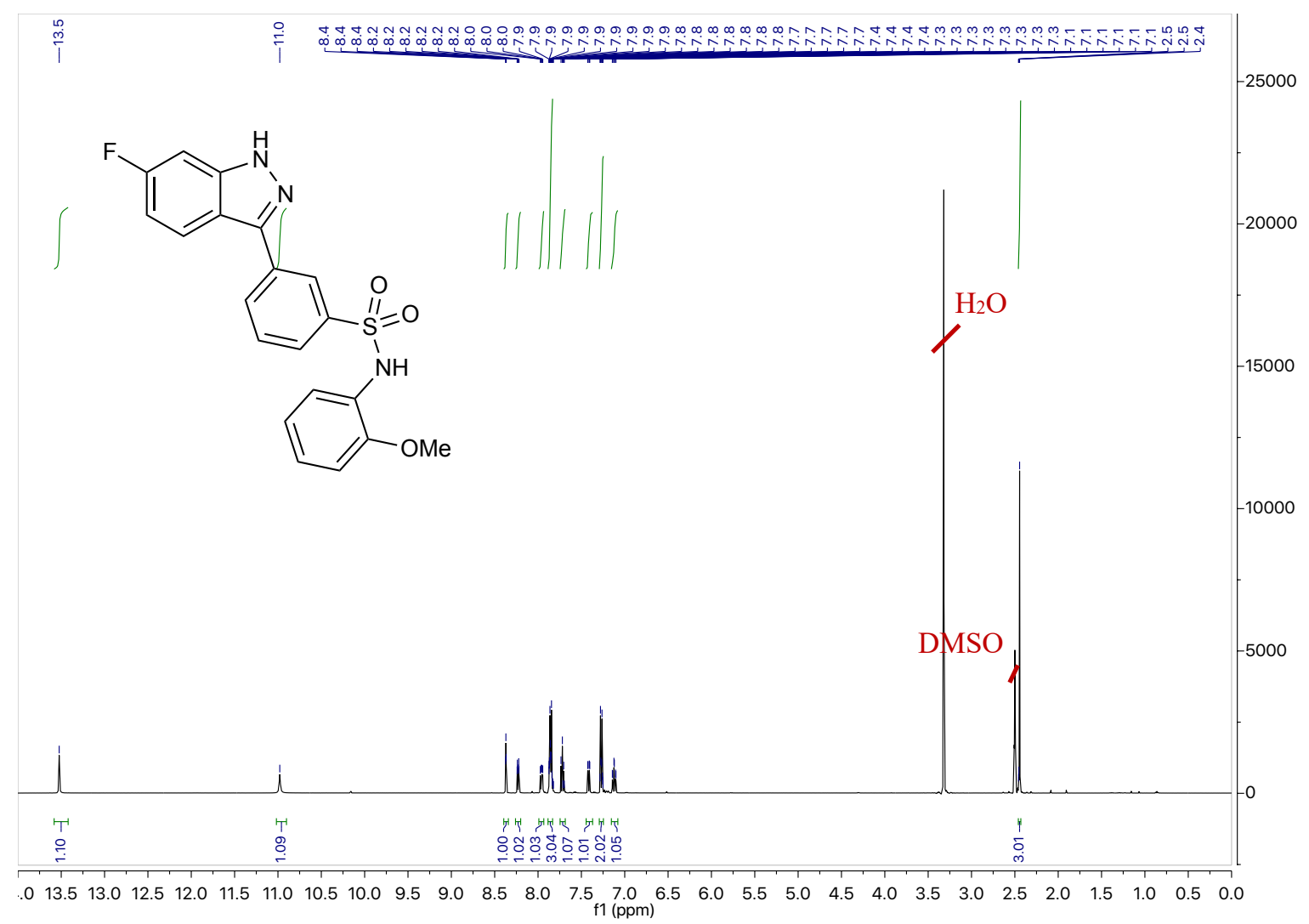

${ }^{13} \mathrm{C}$ NMR Spectrum of $\mathbf{1 5 f}(126 \mathrm{MHz}, \mathrm{DMSO})$

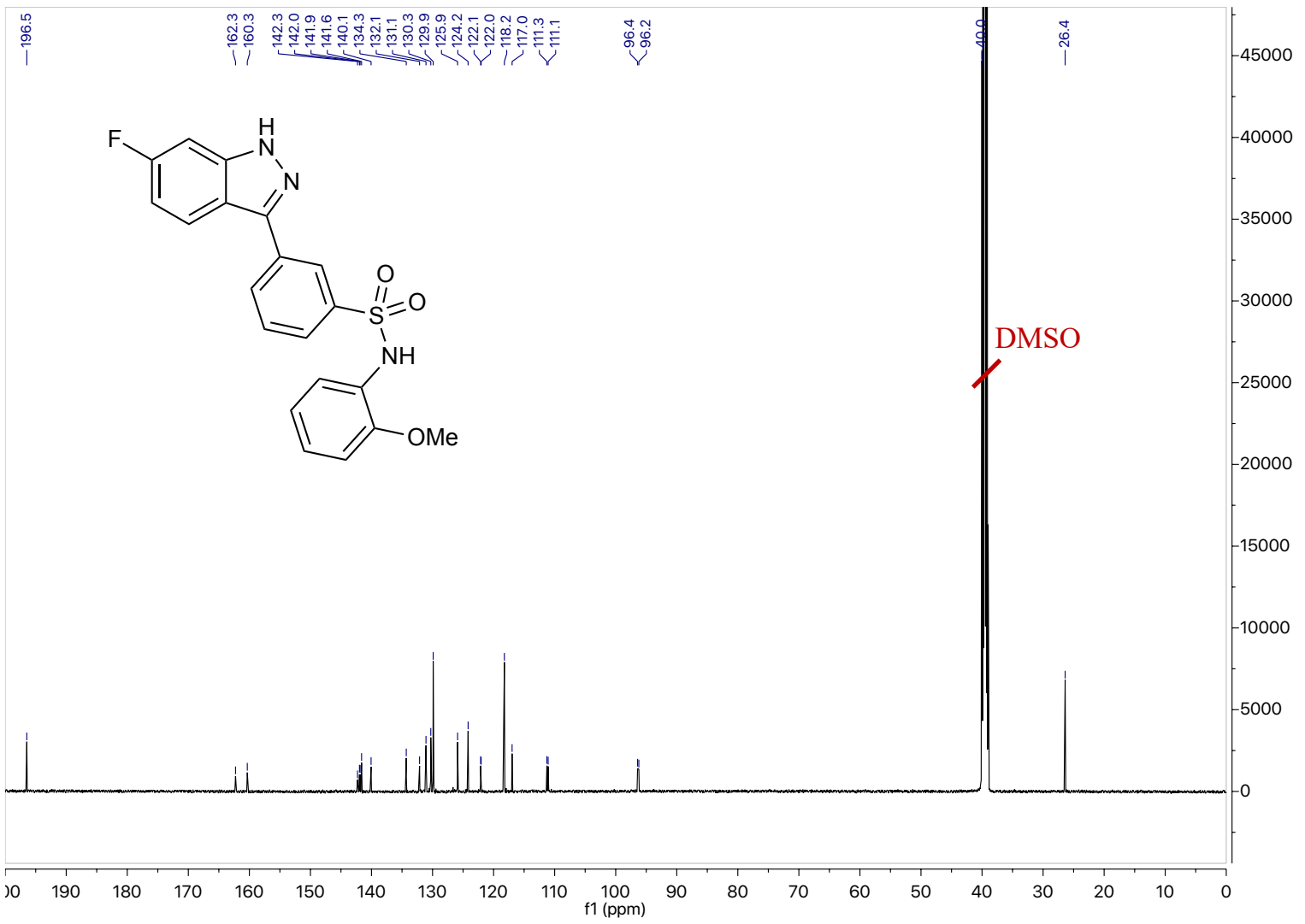


${ }^{1} \mathrm{H}$ NMR Spectrum of $\mathbf{1 5 g}$ (500 MHz, DMSO)

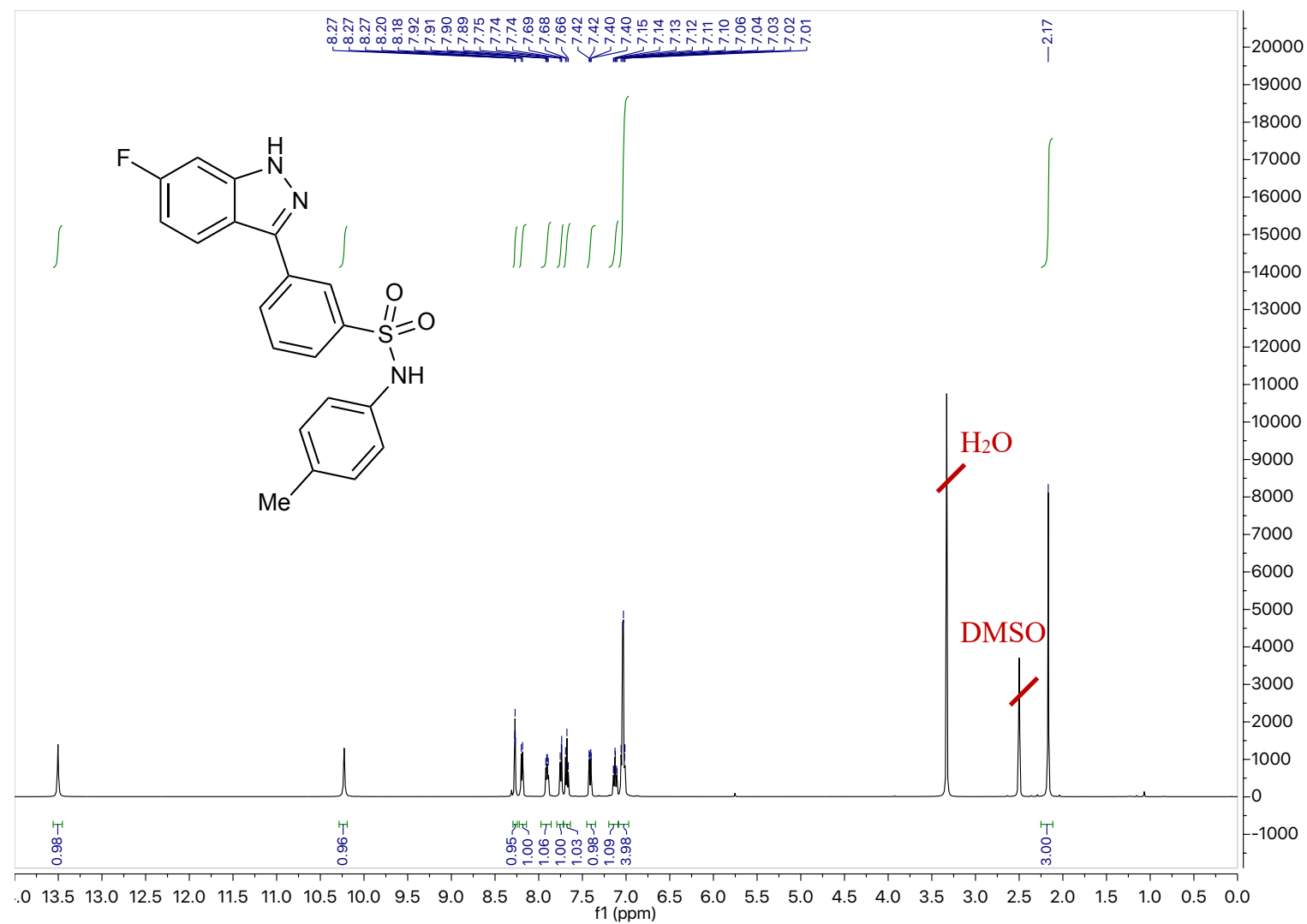

${ }^{13} \mathrm{C}$ NMR Spectrum of $\mathbf{1 5 g}$ (126 MHz, DMSO)

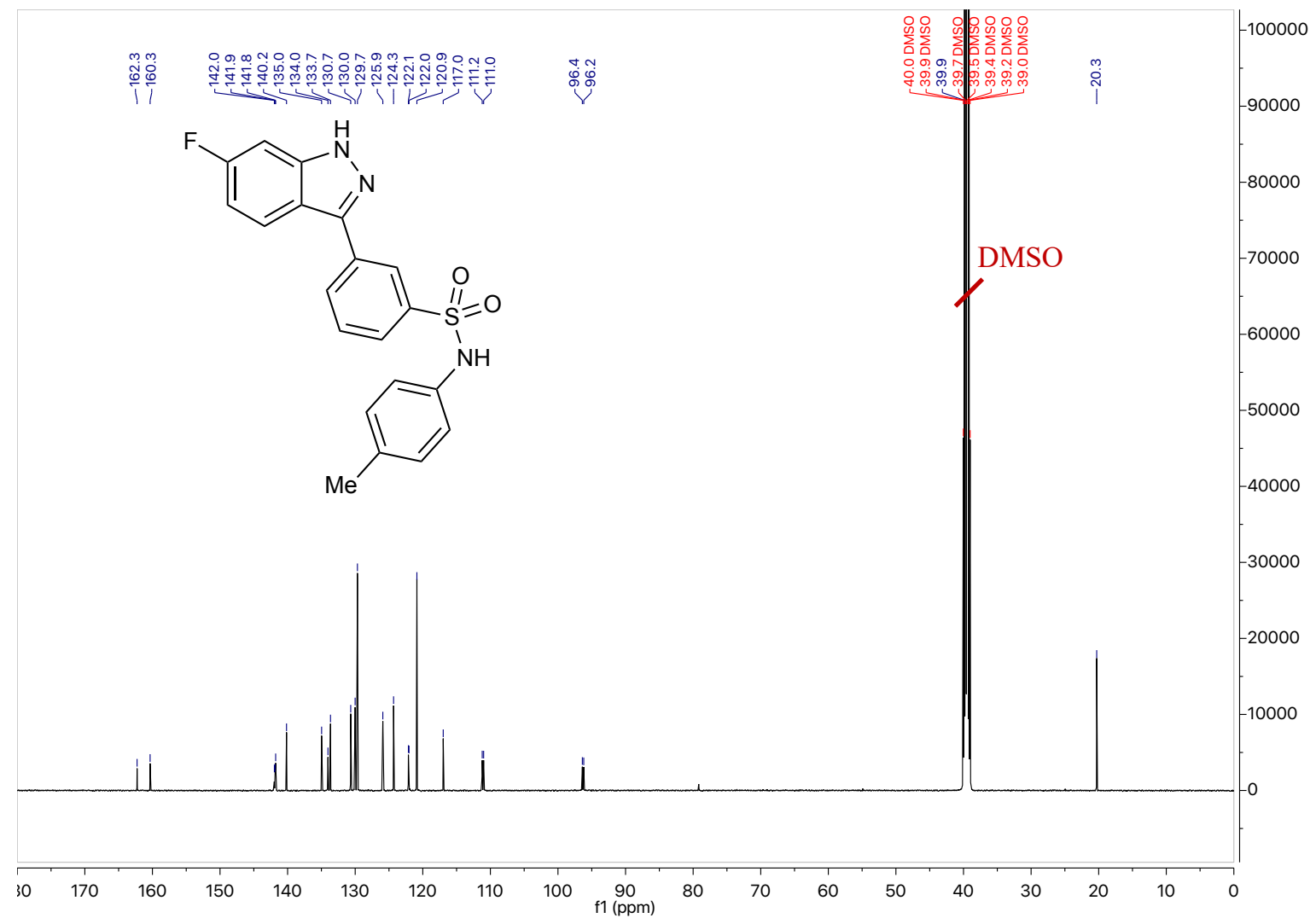


${ }^{1} \mathrm{H}$ NMR Spectrum of $\mathbf{1 5 h}(500 \mathrm{MHz}$, DMSO $)$

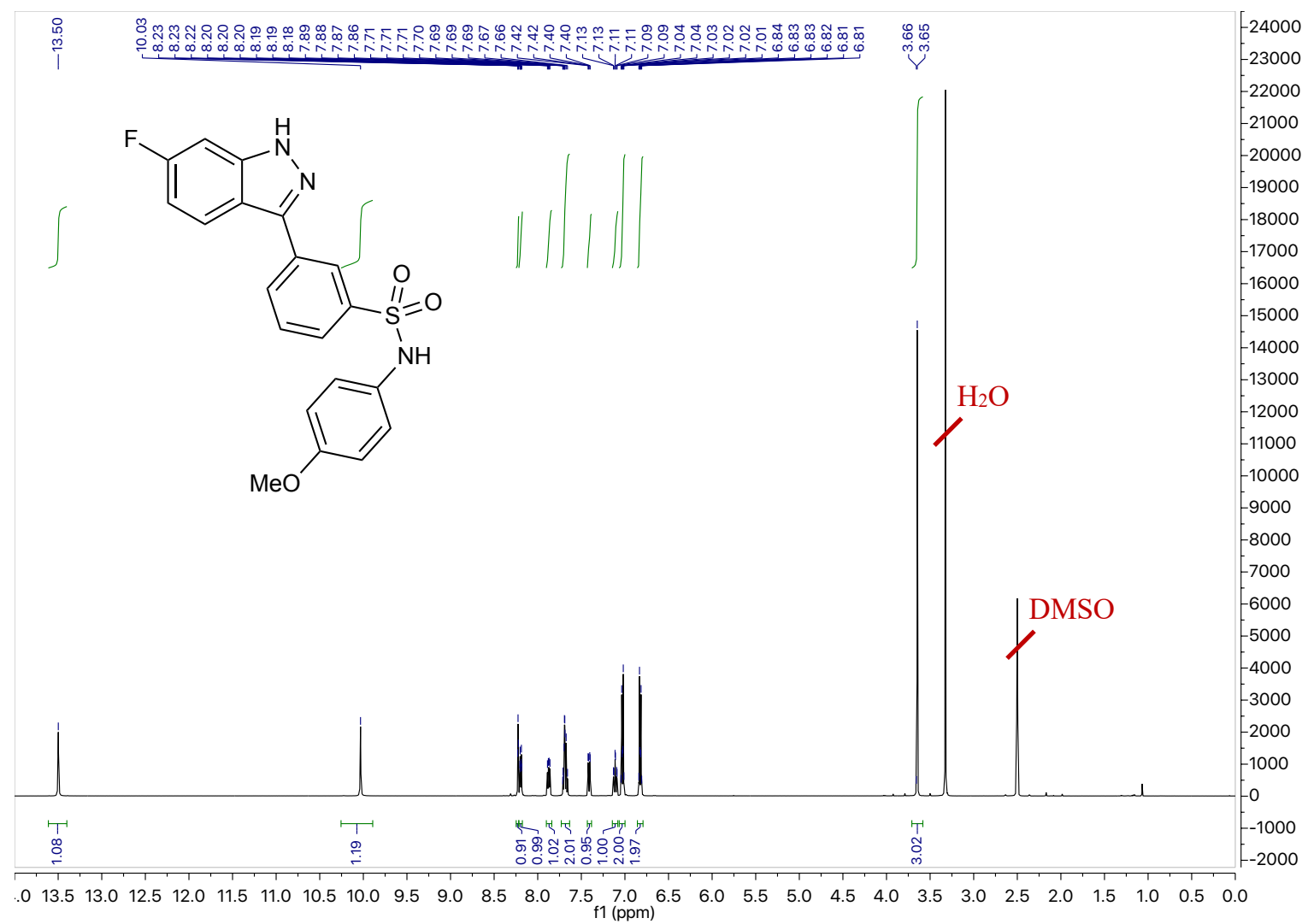

${ }^{13} \mathrm{C}$ NMR Spectrum of $\mathbf{1 5 h}$ (126 MHz, DMSO)

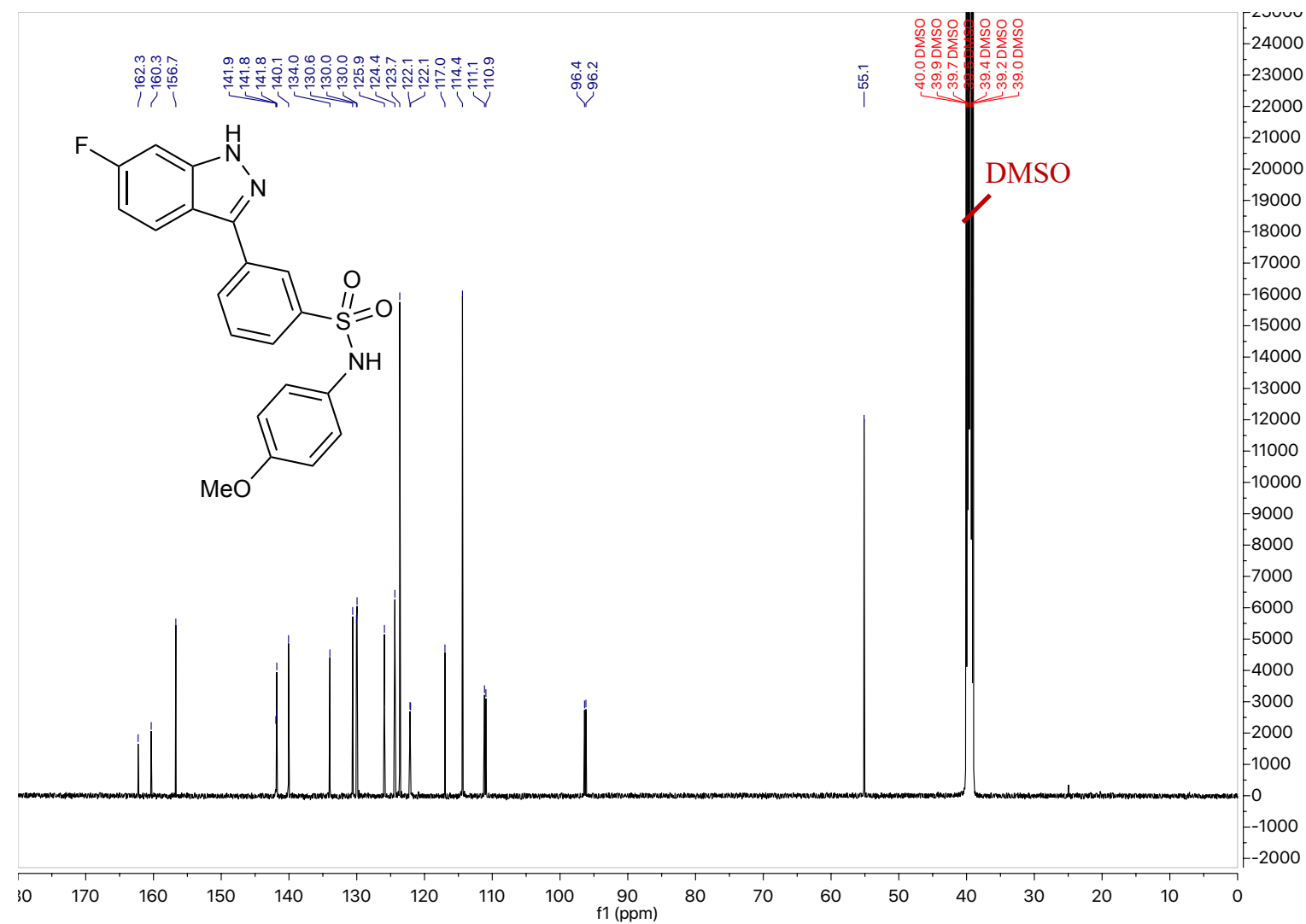


${ }^{1} \mathrm{H}$ NMR Spectrum of $\mathbf{1 5 i}$ (500 MHz, DMSO)

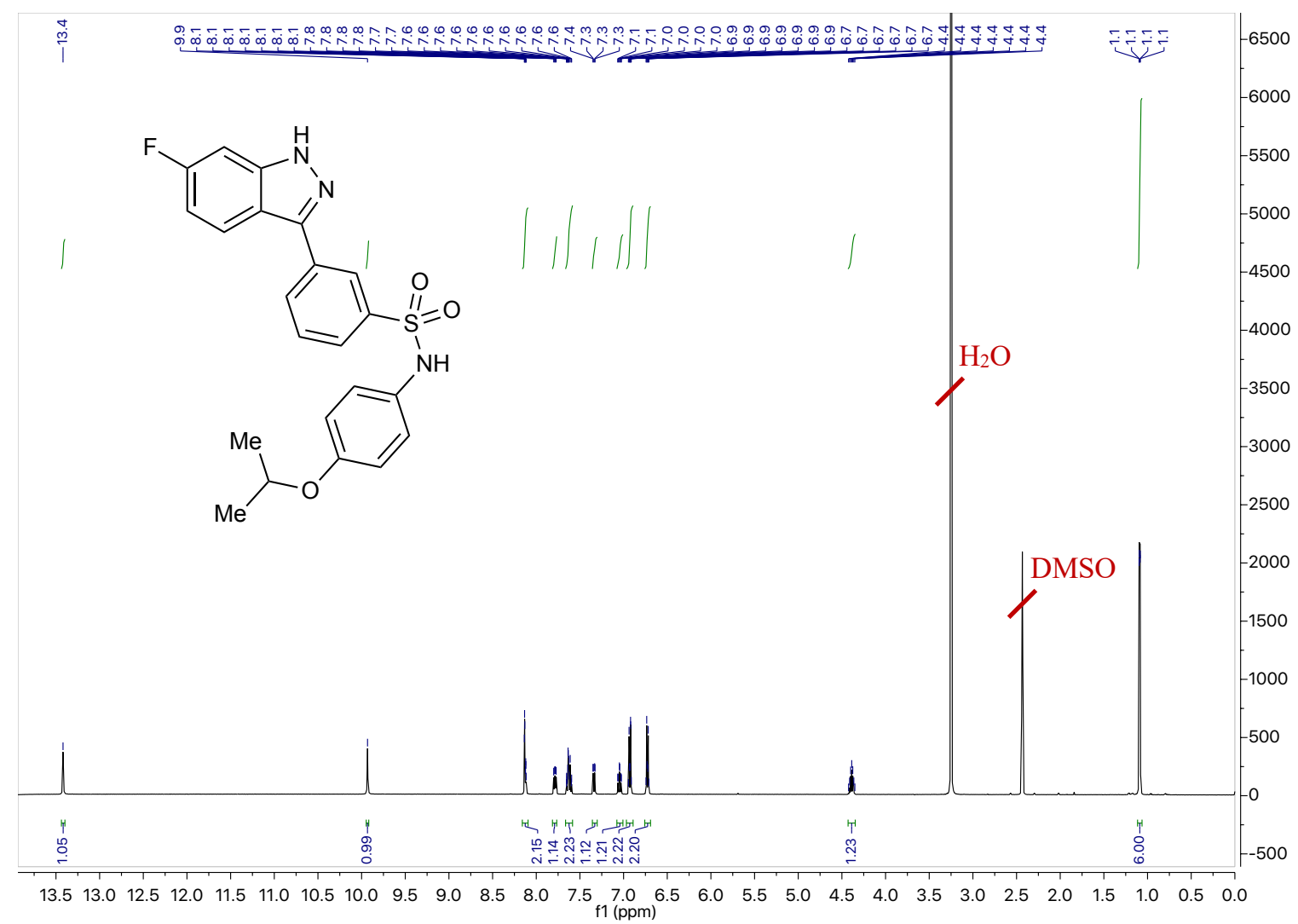

${ }^{13} \mathrm{C}$ NMR Spectrum of $\mathbf{1 5 i}$ (126 MHz, DMSO)

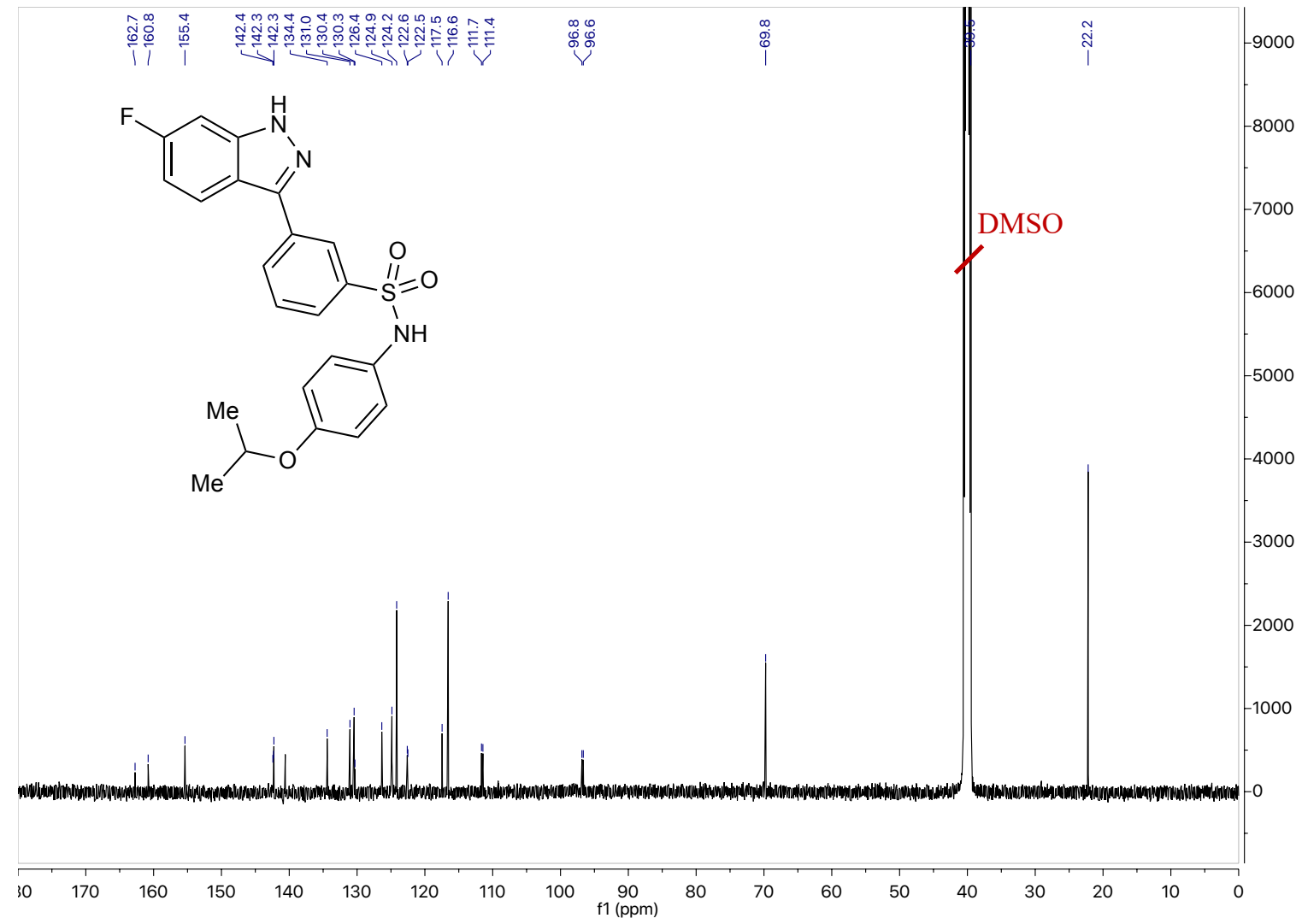


${ }^{1} \mathrm{H}$ NMR Spectrum of $\mathbf{1 5 j}$ (500 MHz, DMSO)

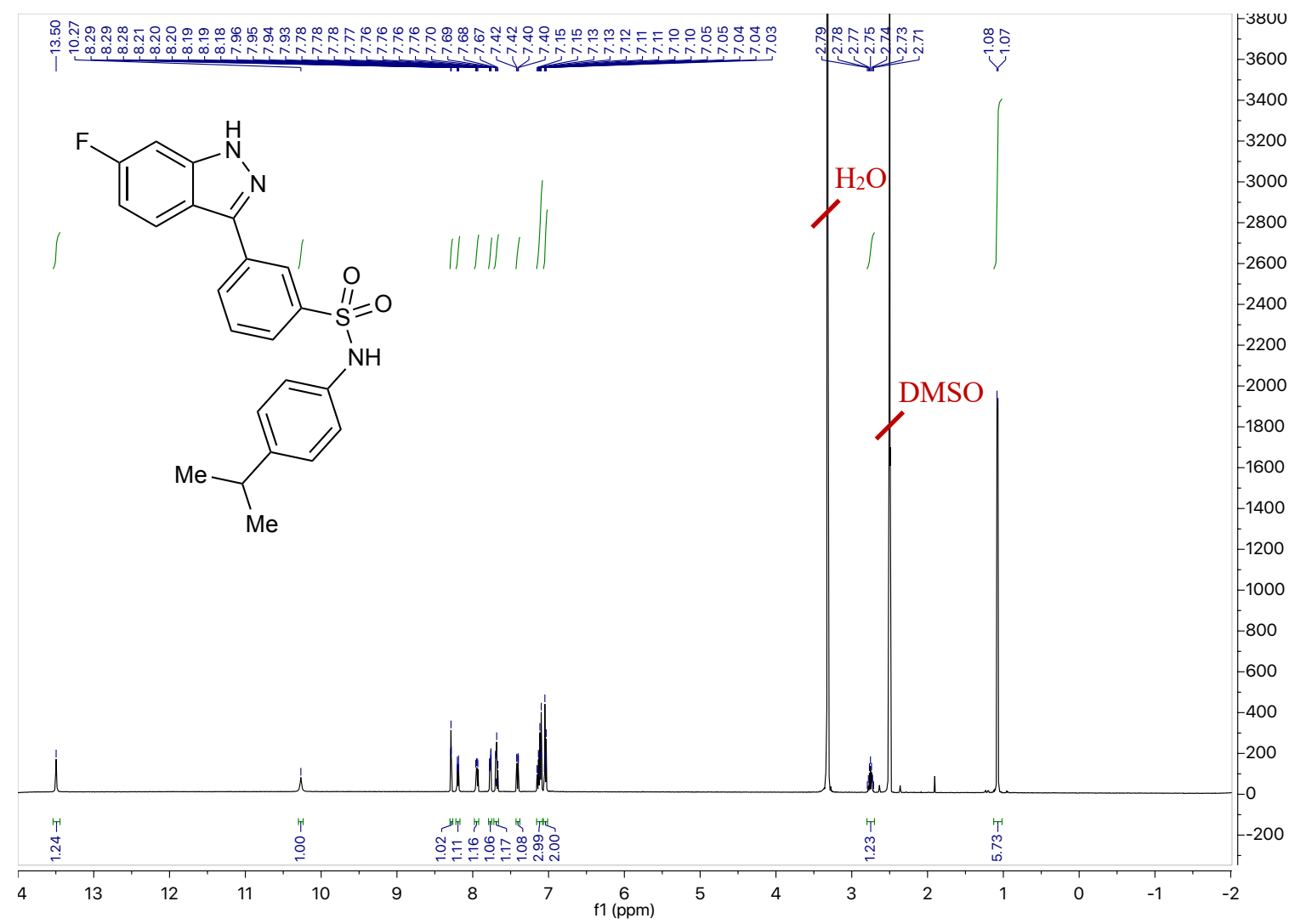

${ }^{13} \mathrm{C}$ NMR Spectrum of $\mathbf{1 5 j}$ (126 MHz, DMSO)

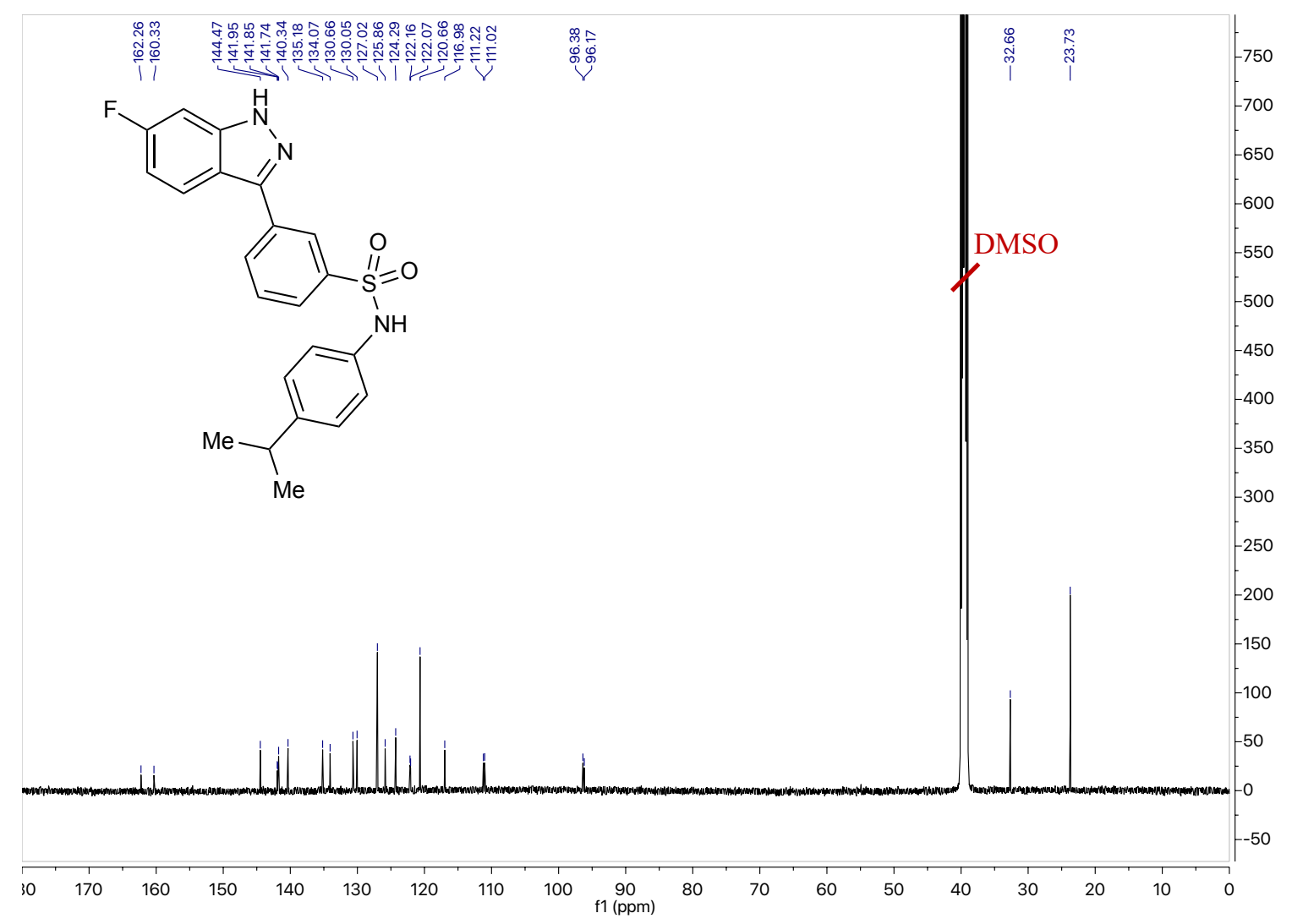


${ }^{1} \mathrm{H}$ NMR Spectrum of $\mathbf{1 5 k}(500 \mathrm{MHz}$, DMSO)

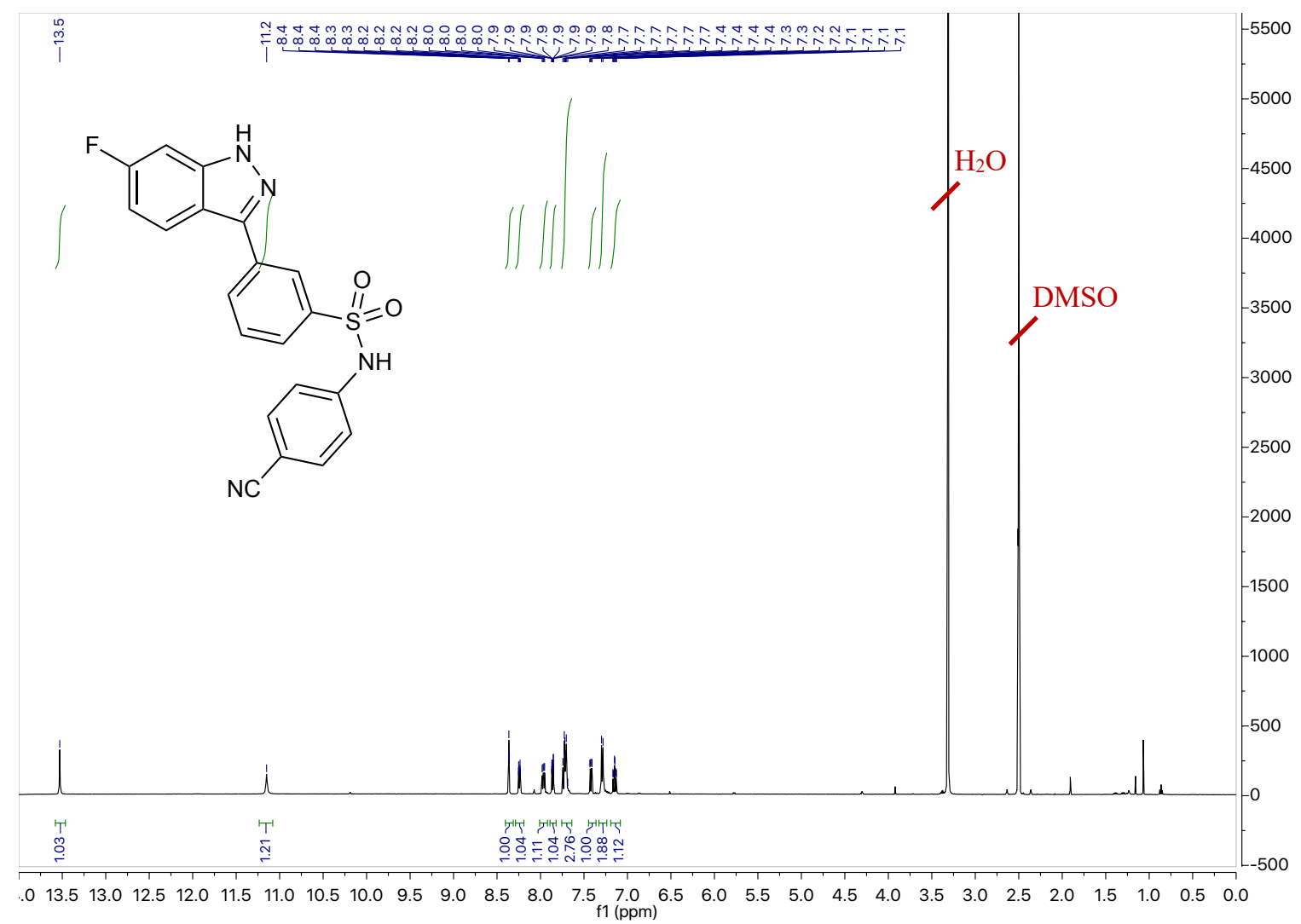

${ }^{13} \mathrm{C}$ NMR Spectrum of $\mathbf{1 5 k}$ (126 MHz, DMSO)

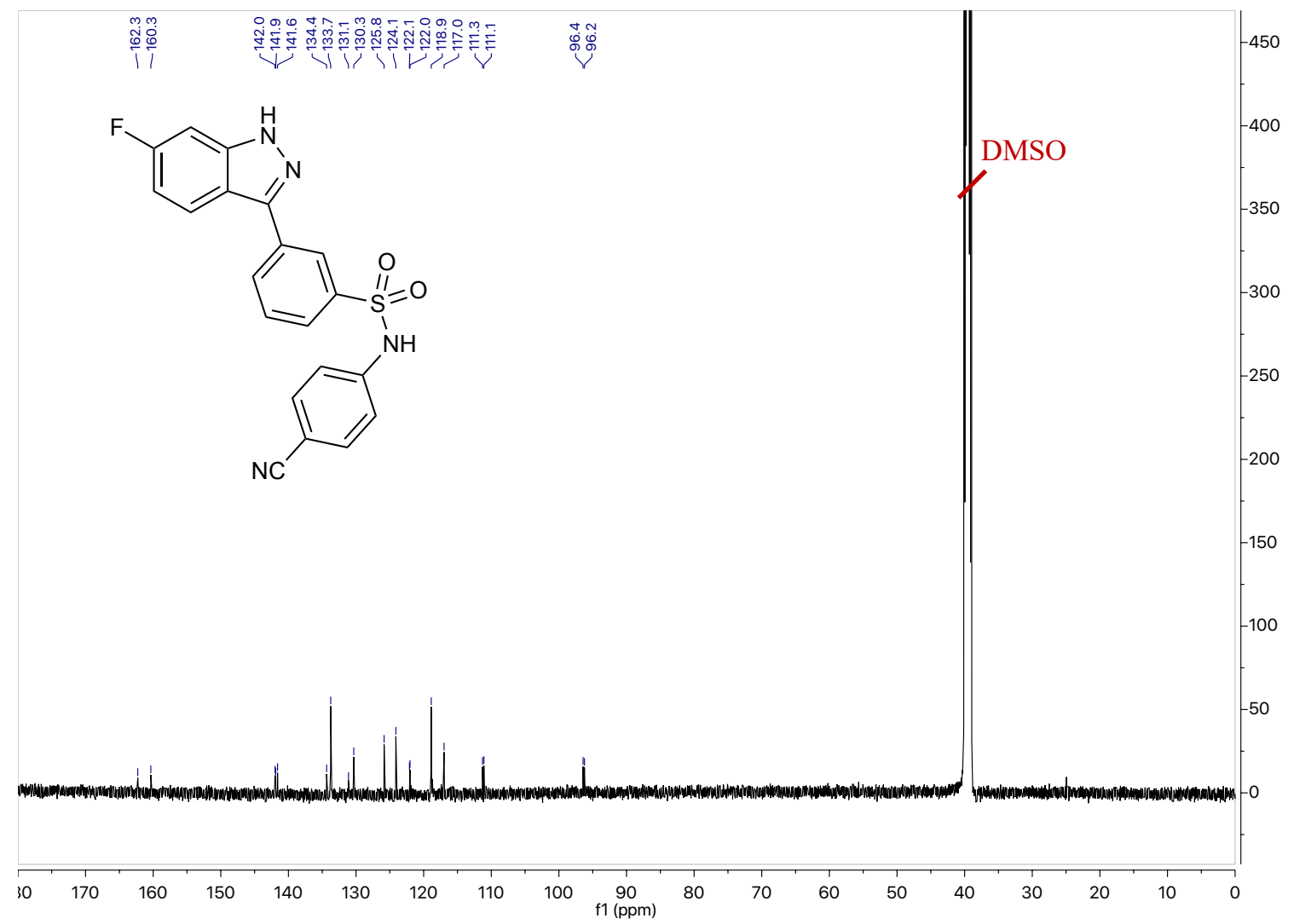


${ }^{1} \mathrm{H}$ NMR Spectrum of $\mathbf{1 5 l}(500 \mathrm{MHz}, \mathrm{DMSO})$

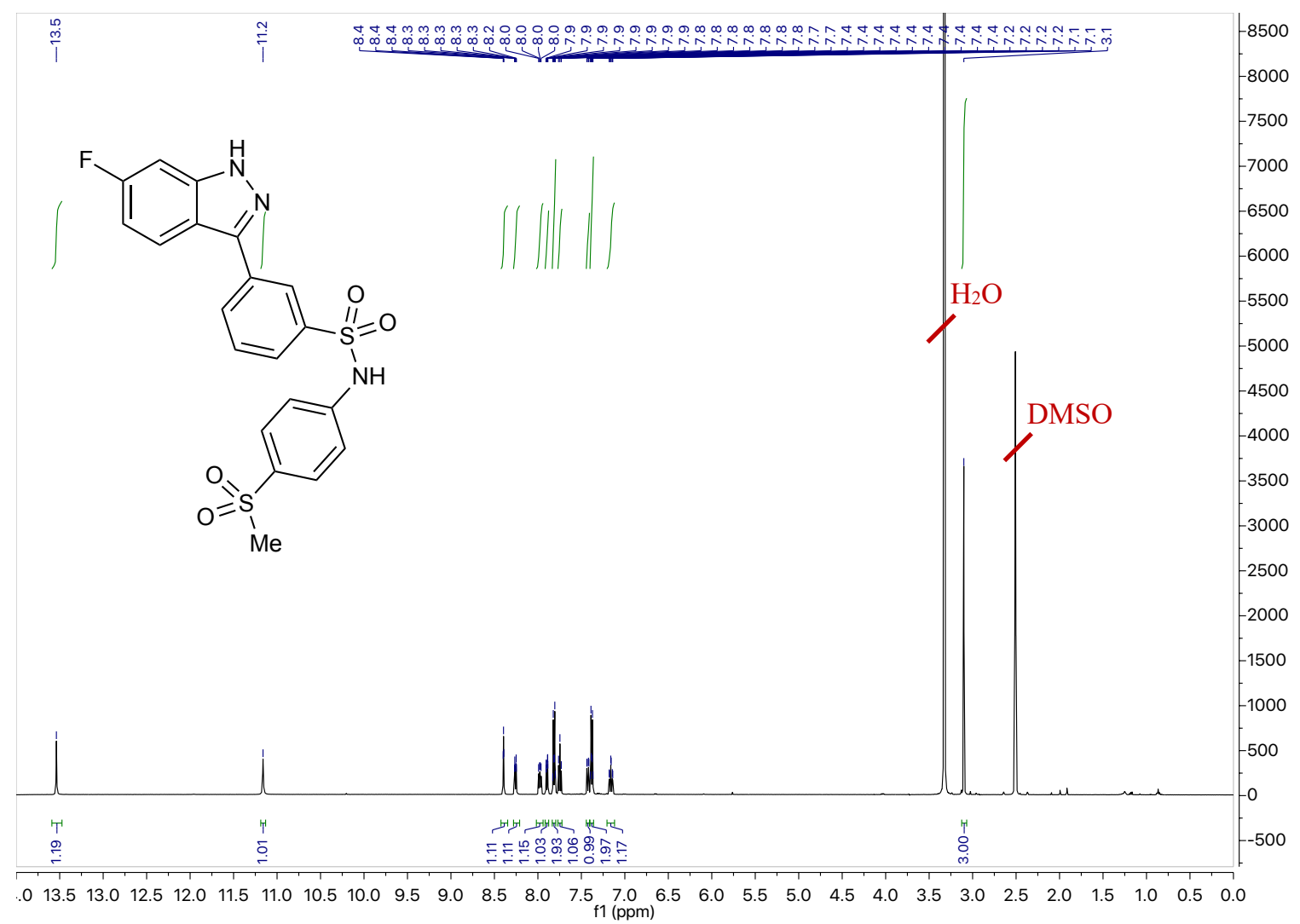

${ }^{13} \mathrm{C}$ NMR Spectrum of $\mathbf{1 5 l}$ (126 MHz, DMSO)

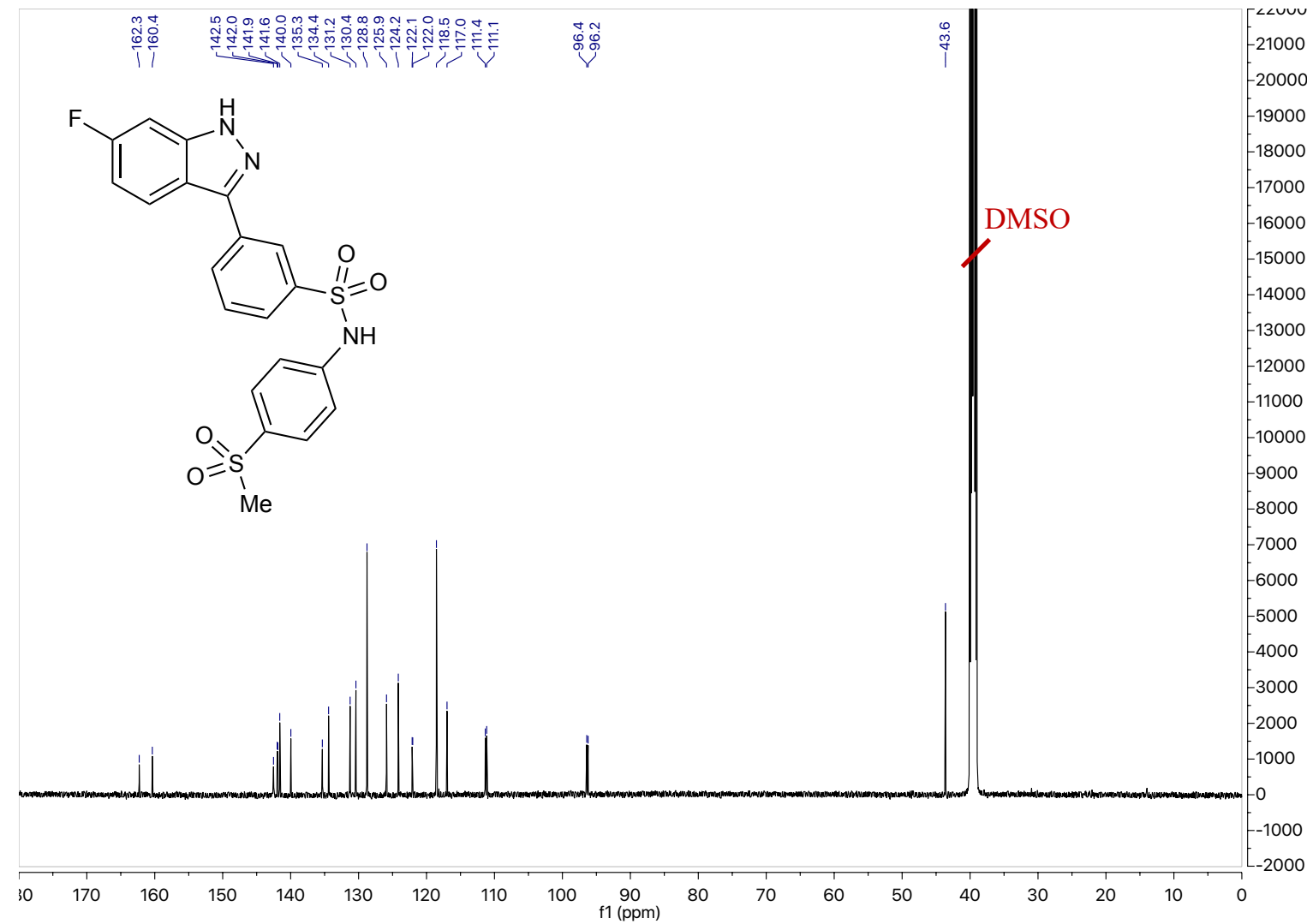


${ }^{1} \mathrm{H}$ NMR Spectrum of 15m (500 MHz, DMSO)

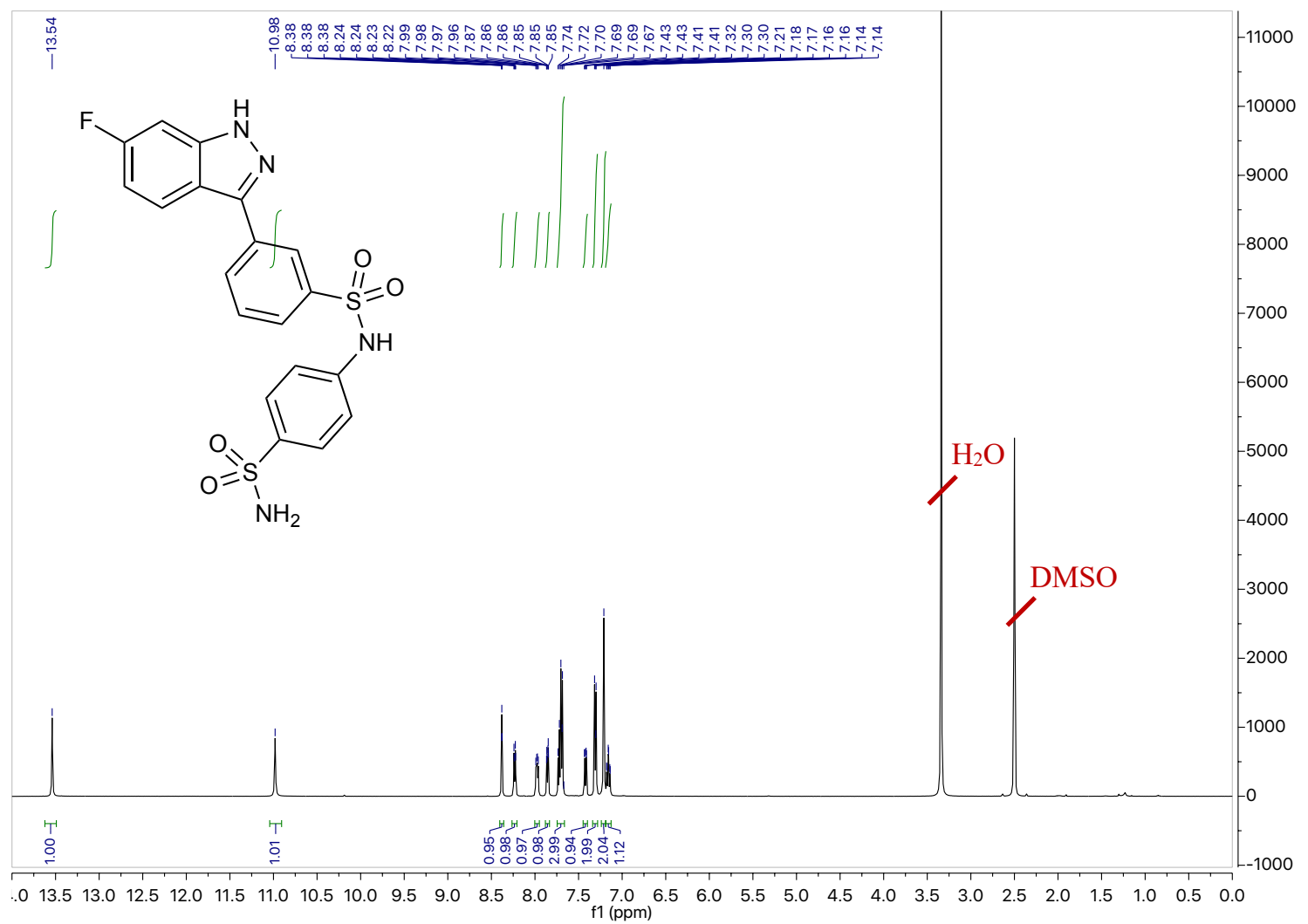

${ }^{13} \mathrm{C}$ NMR Spectrum of $\mathbf{1 5 m}(126 \mathrm{MHz}, \mathrm{DMSO})$

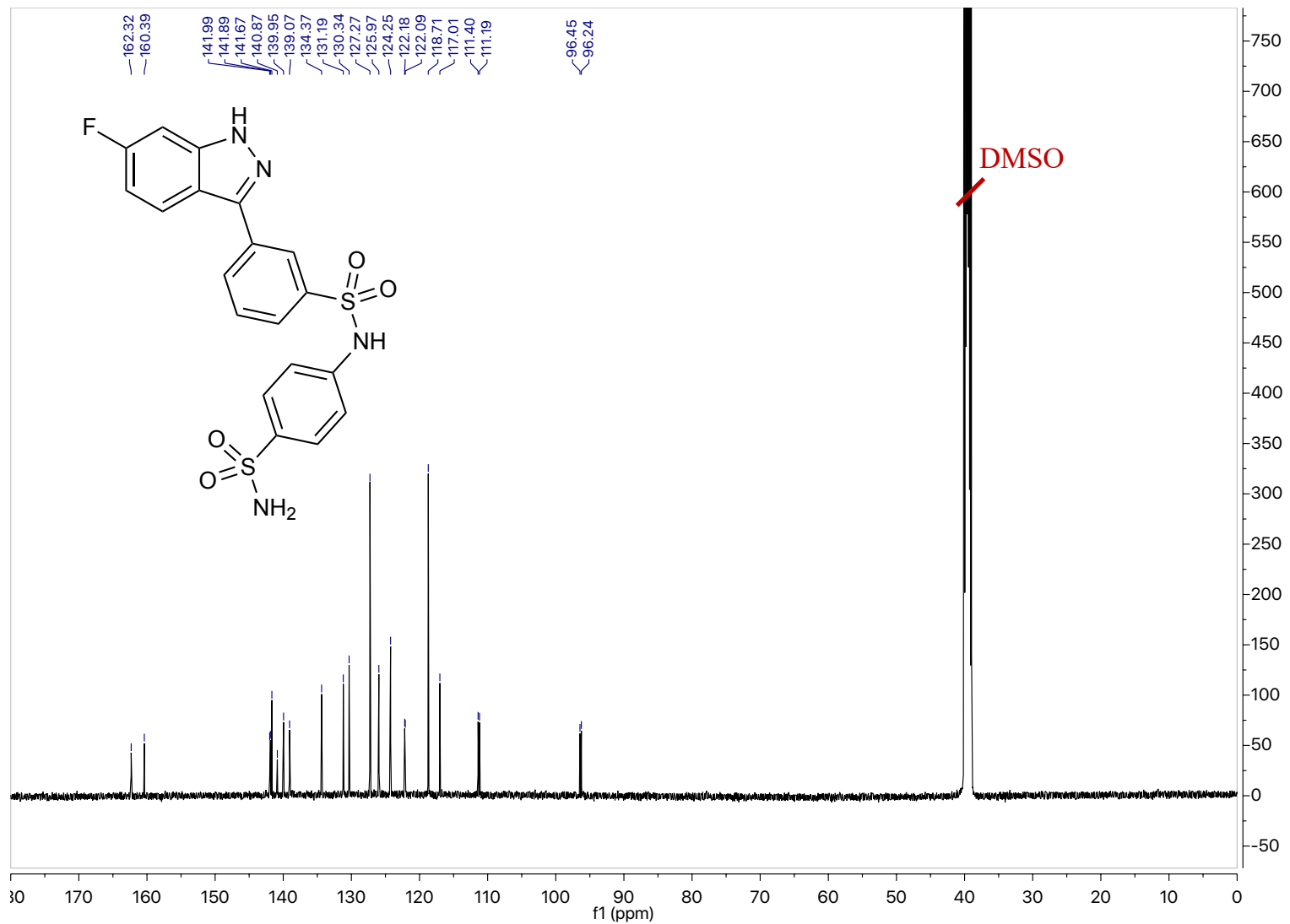


${ }^{1} \mathrm{H}$ NMR Spectrum of $\mathbf{1 5 n}(500 \mathrm{MHz}, \mathrm{DMSO})$

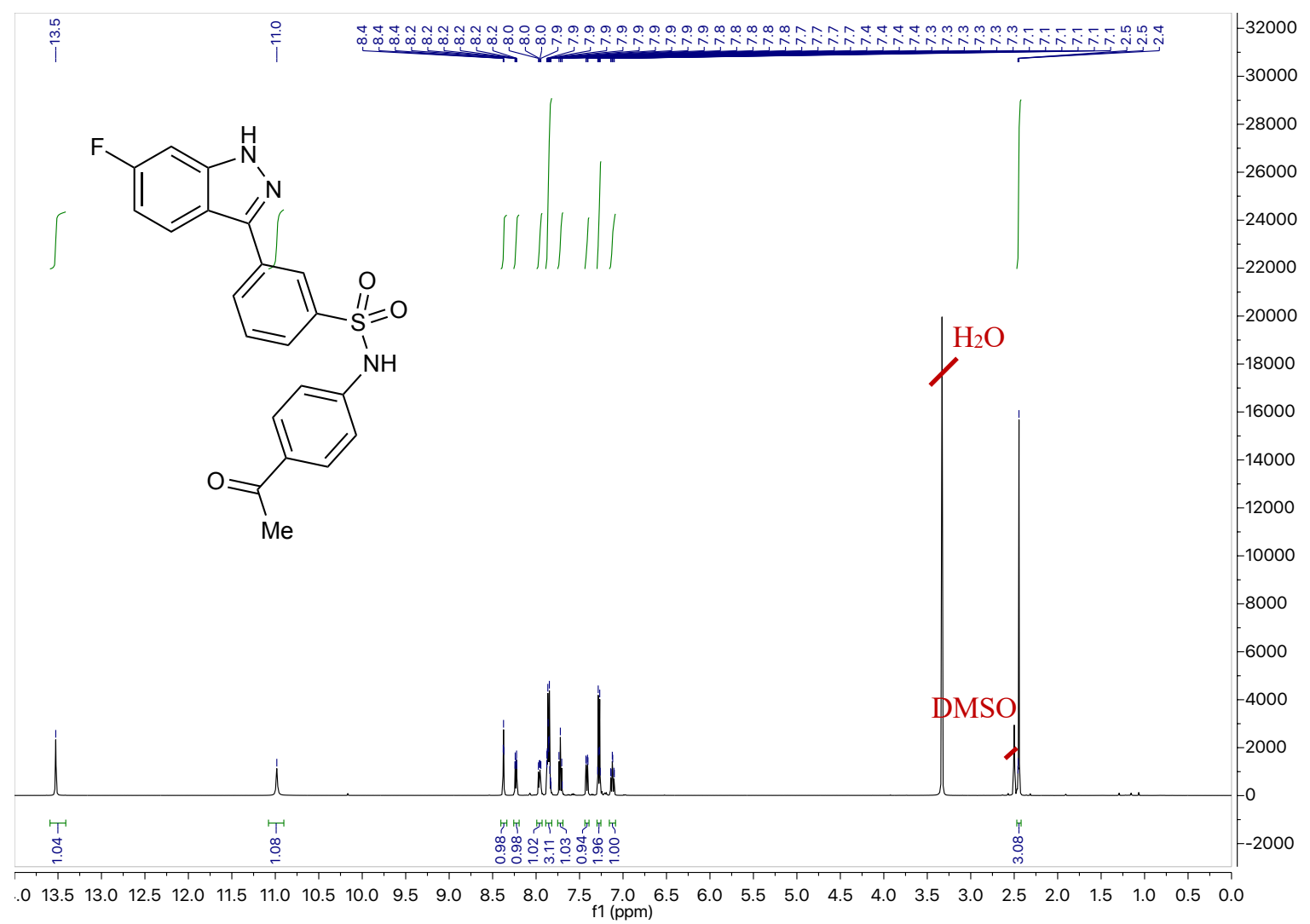

${ }^{13} \mathrm{C}$ NMR Spectrum of $\mathbf{1 5 n}$ (126 MHz, DMSO)

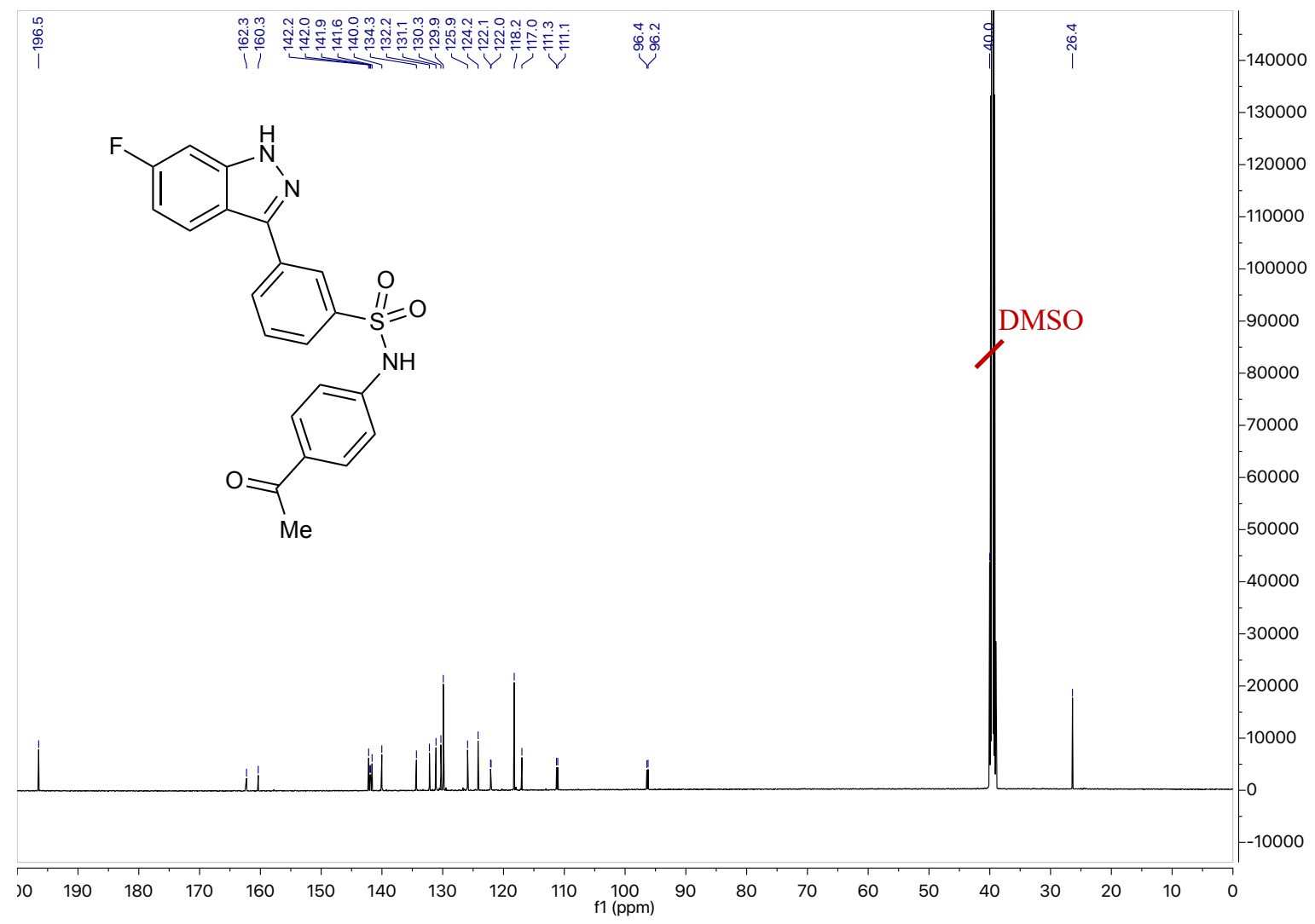


${ }^{1} \mathrm{H}$ NMR Spectrum of $\mathbf{1 5 0}$ (500 MHz, DMSO)

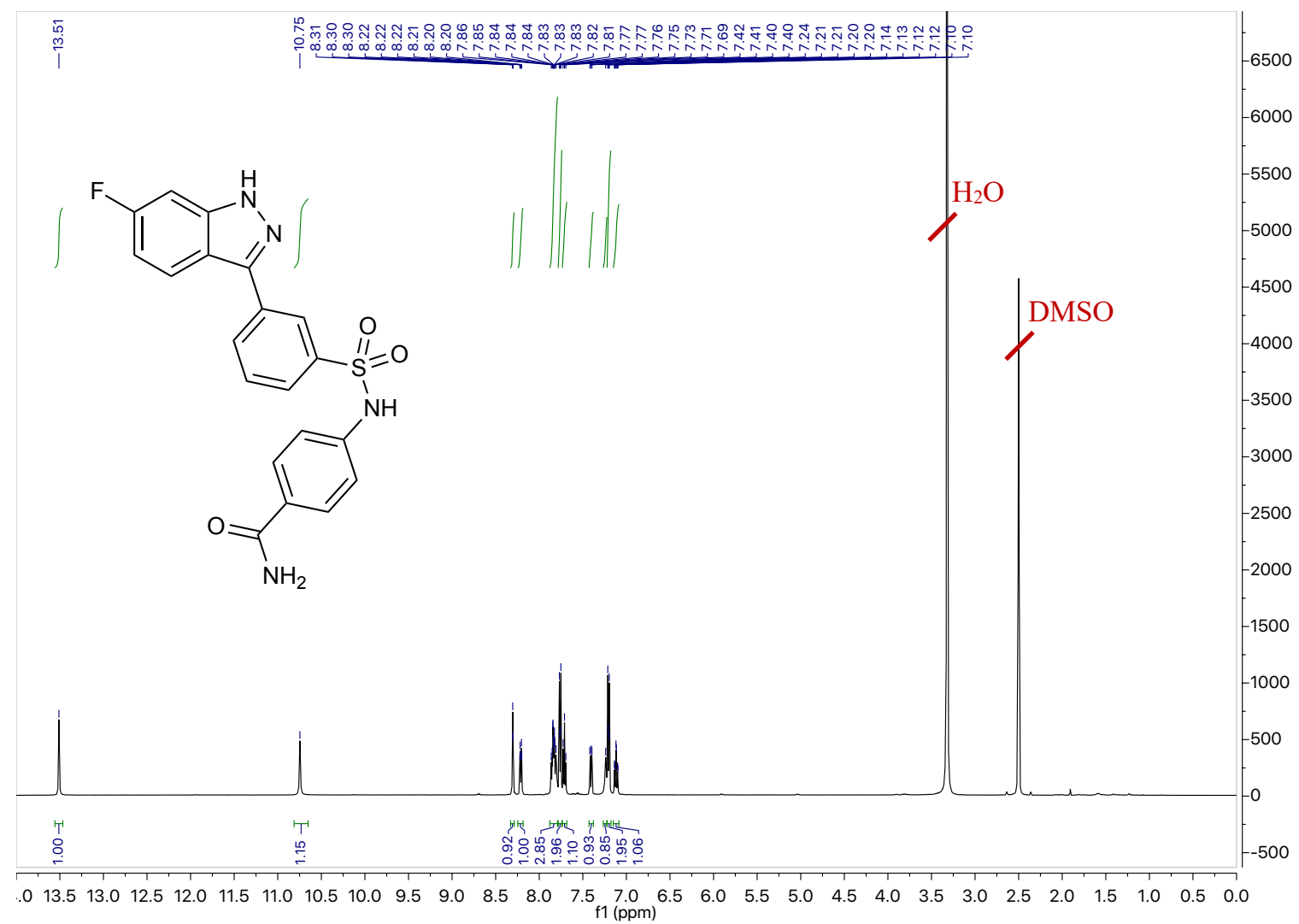

${ }^{13} \mathrm{C}$ NMR Spectrum of 150 (126 MHz, DMSO)

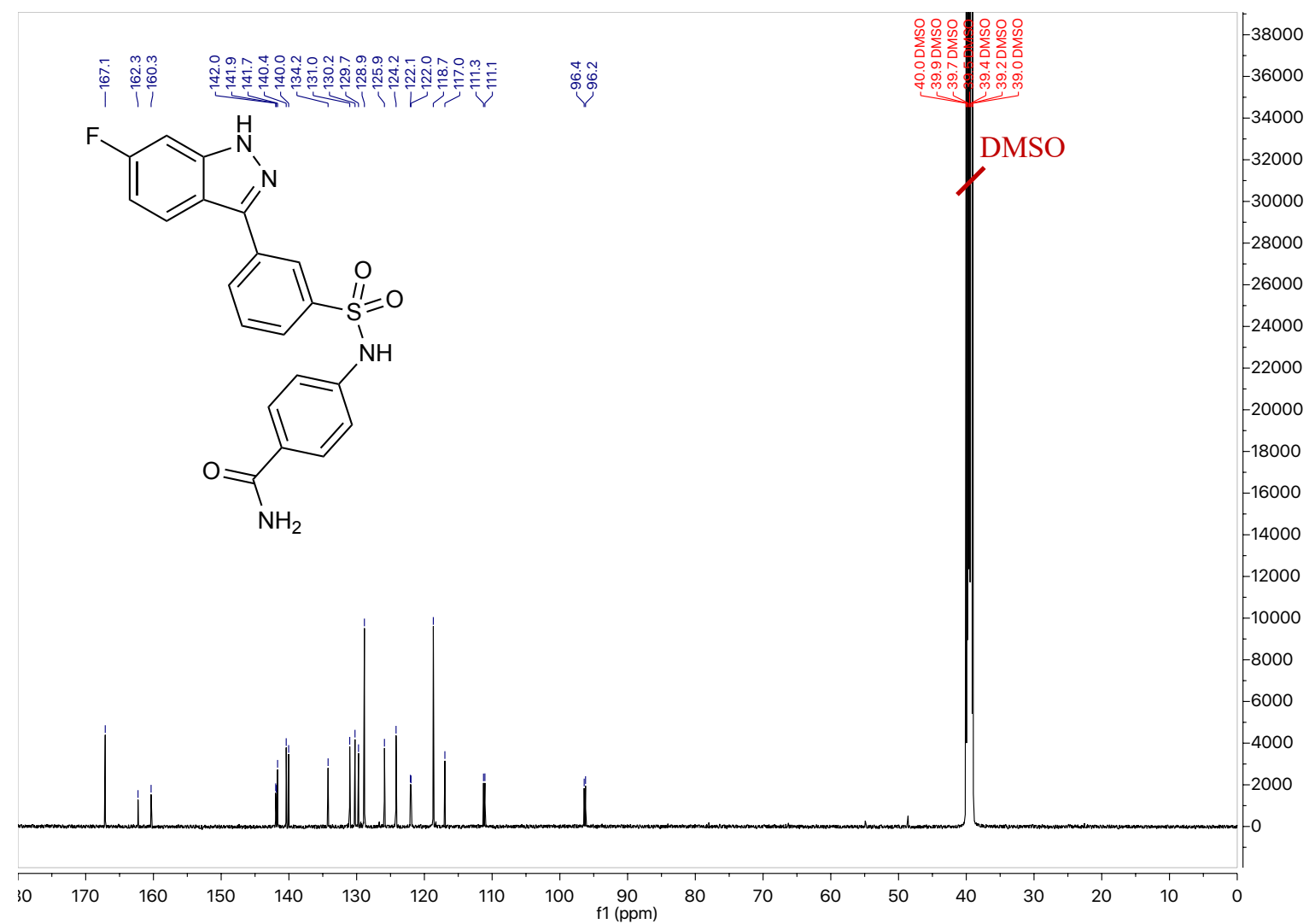




\section{Compounds S1-5}

${ }^{1} \mathrm{H}$ NMR Spectrum of SI-1 (500 MHz, DMSO)

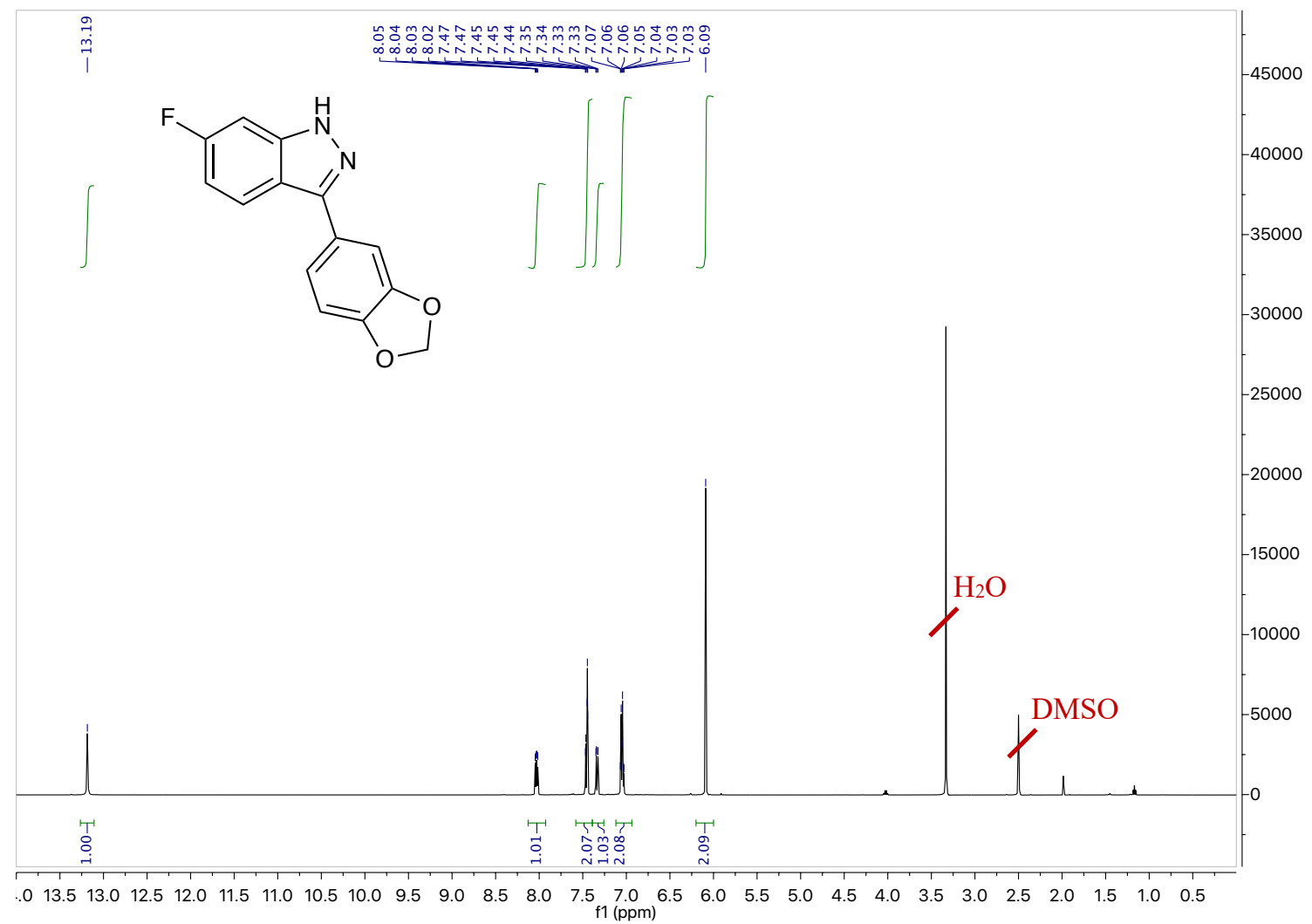

${ }^{13} \mathrm{C}$ NMR Spectrum of SI-1 (126 MHz, DMSO)

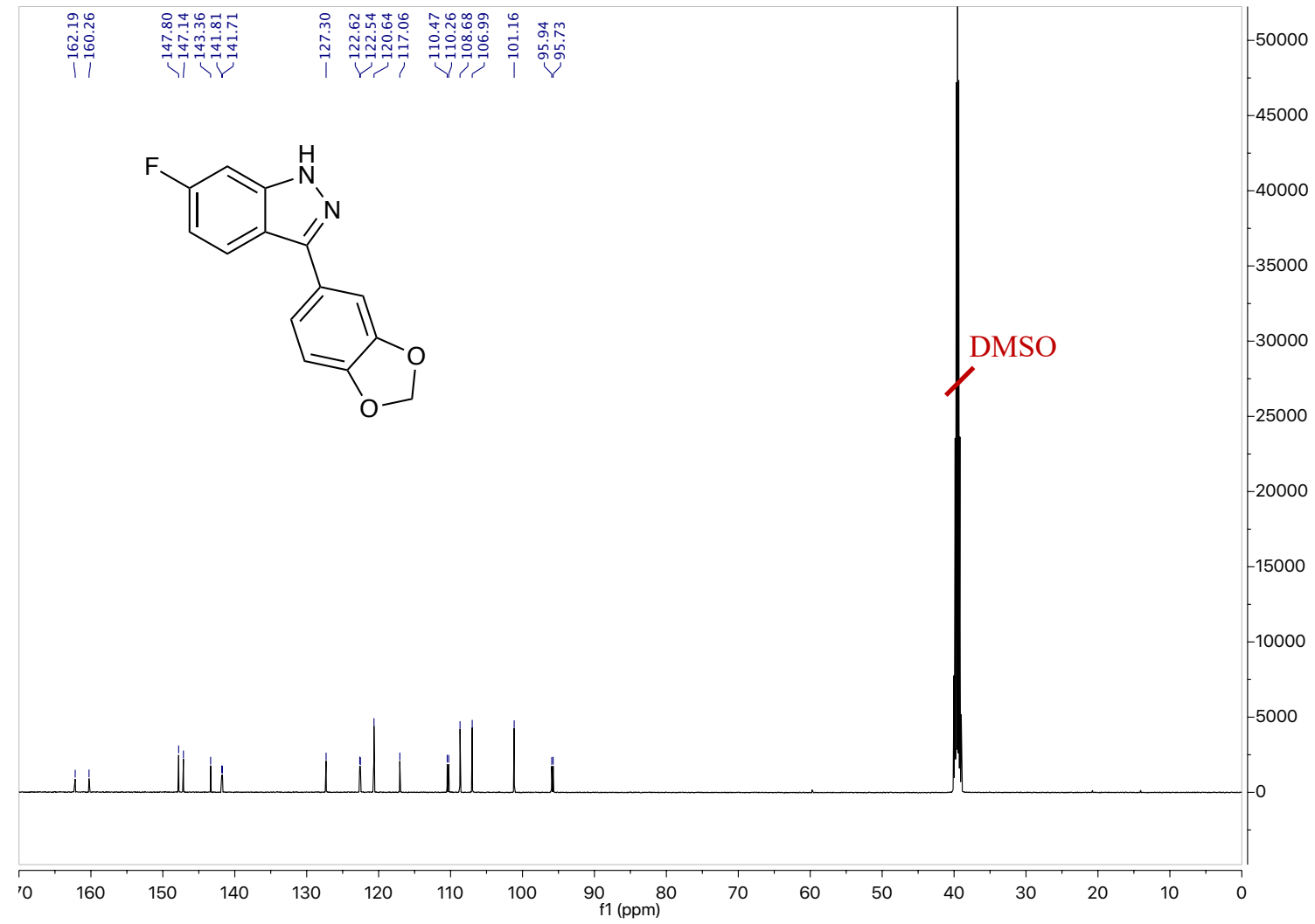


${ }^{1} \mathrm{H}$ NMR Spectrum of SI-2 (500 MHz, DMSO)

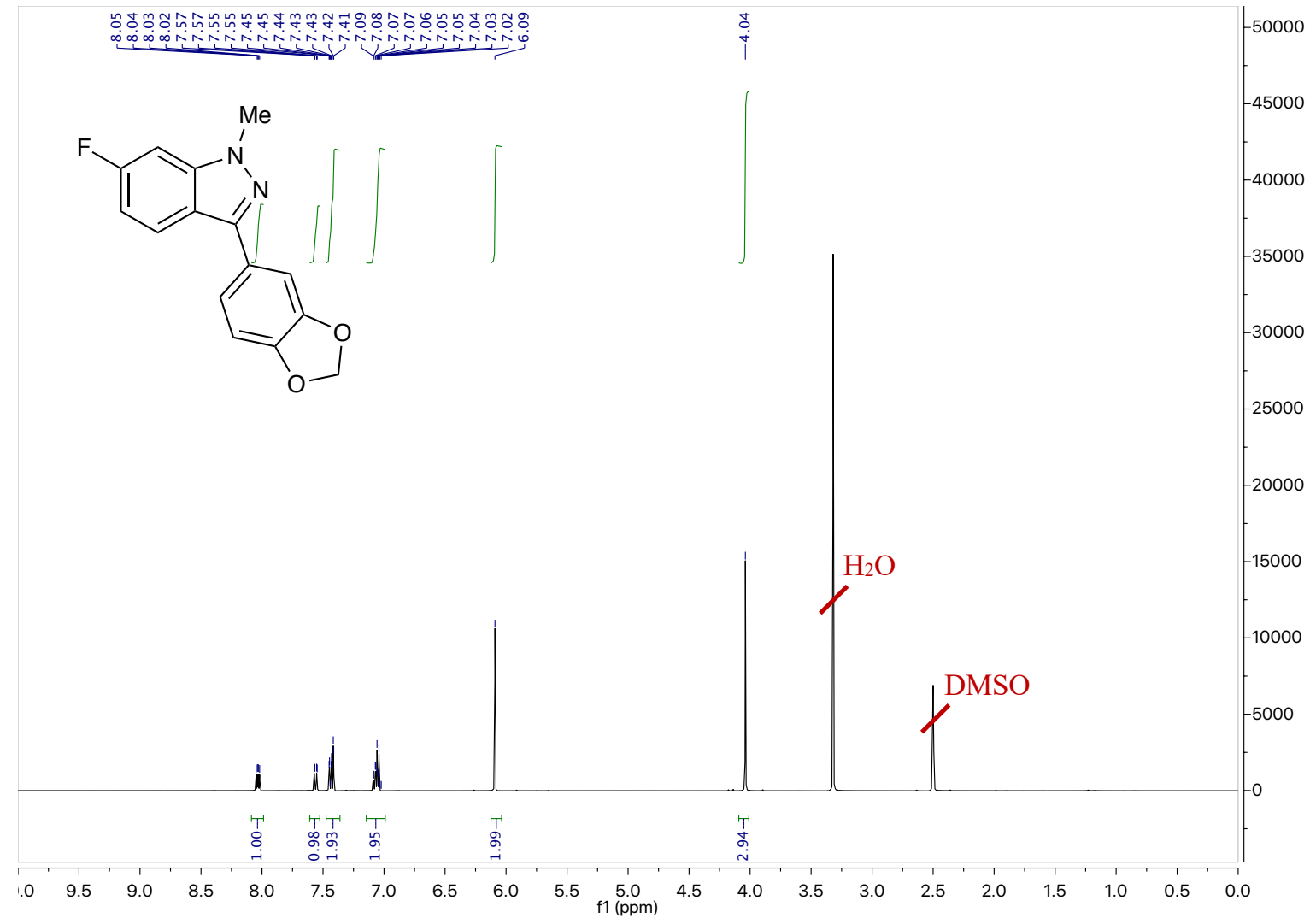

${ }^{13} \mathrm{C}$ NMR Spectrum of SI-2 (126 MHz, DMSO)

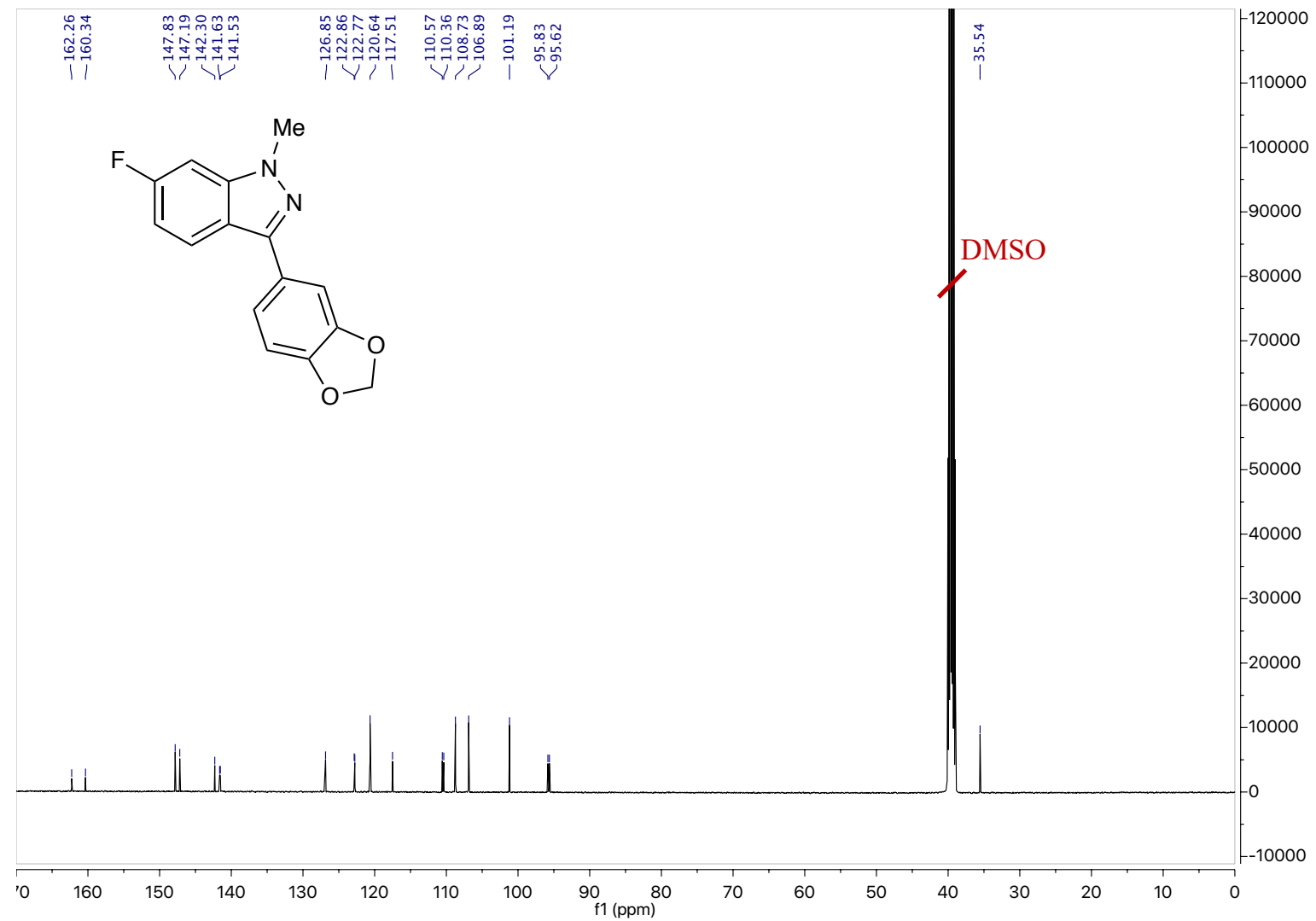


${ }^{1} \mathrm{H}$ NMR Spectrum of SI-3 (500 MHz, DMSO)

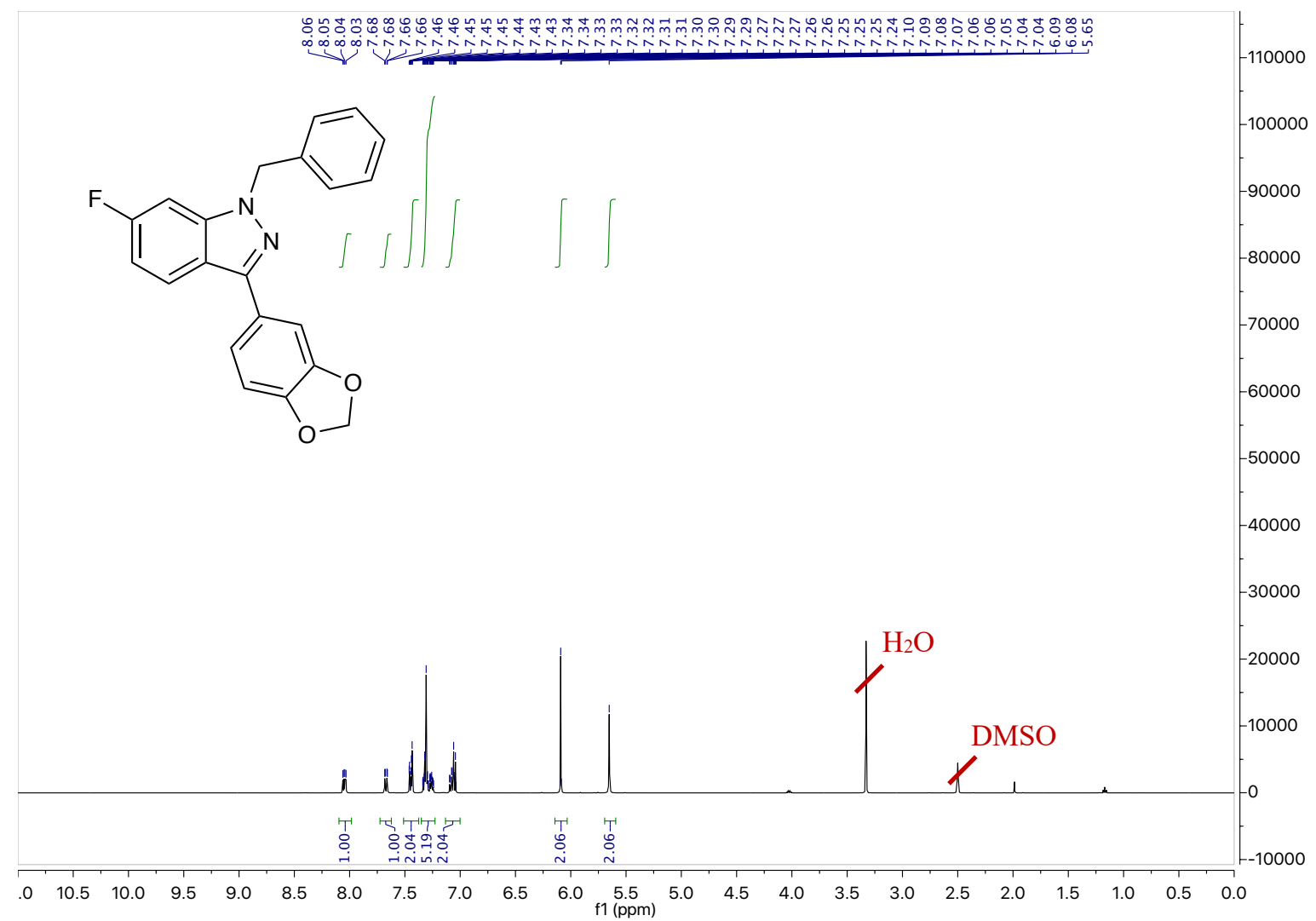

${ }^{13} \mathrm{C}$ NMR Spectrum of SI-3 (126 MHz, DMSO)

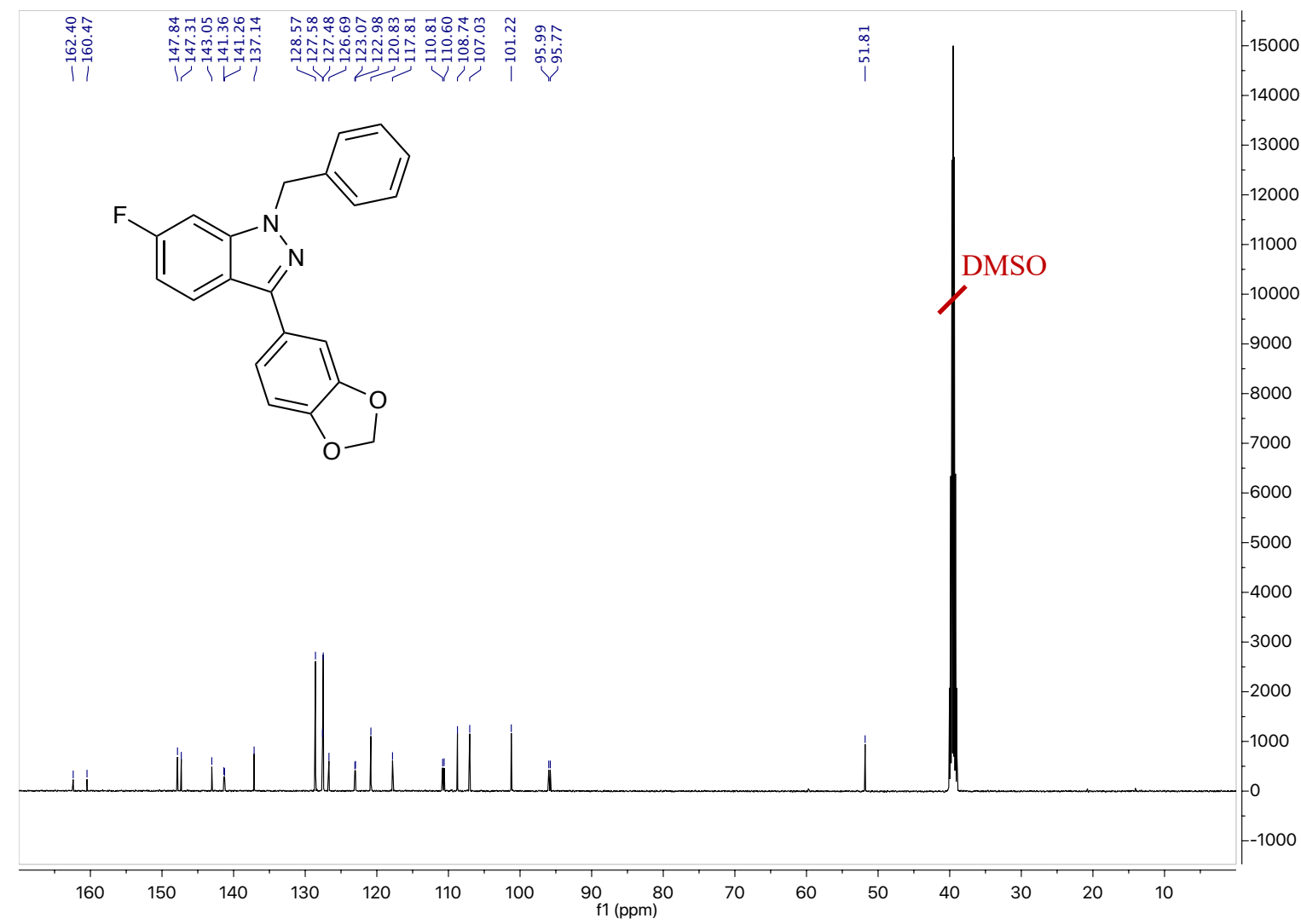


${ }^{1} \mathrm{H}$ NMR Spectrum of SI-4 (500 MHz, DMSO)

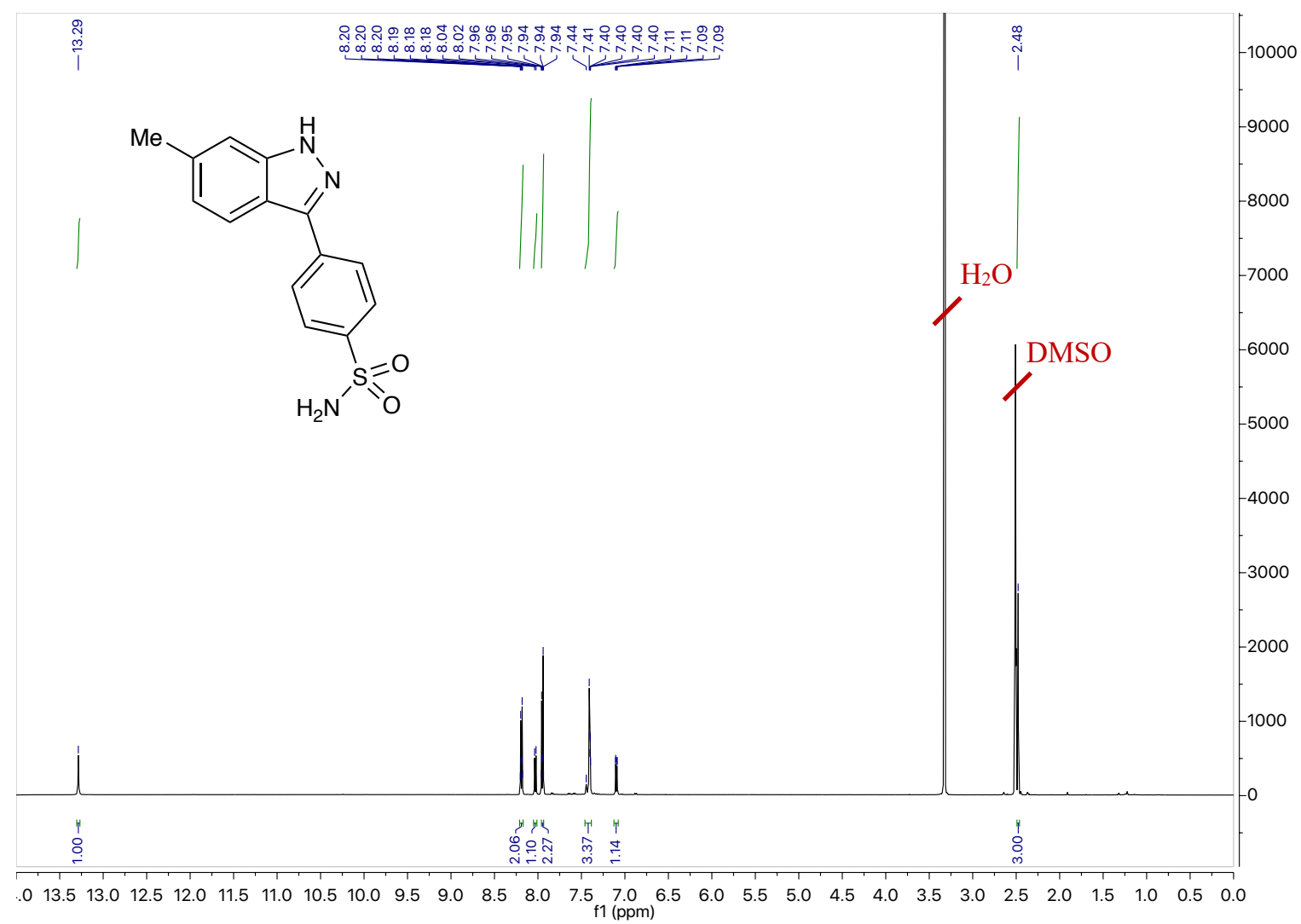

${ }^{13} \mathrm{C}$ NMR Spectrum of SI-4 (126 MHz, DMSO)

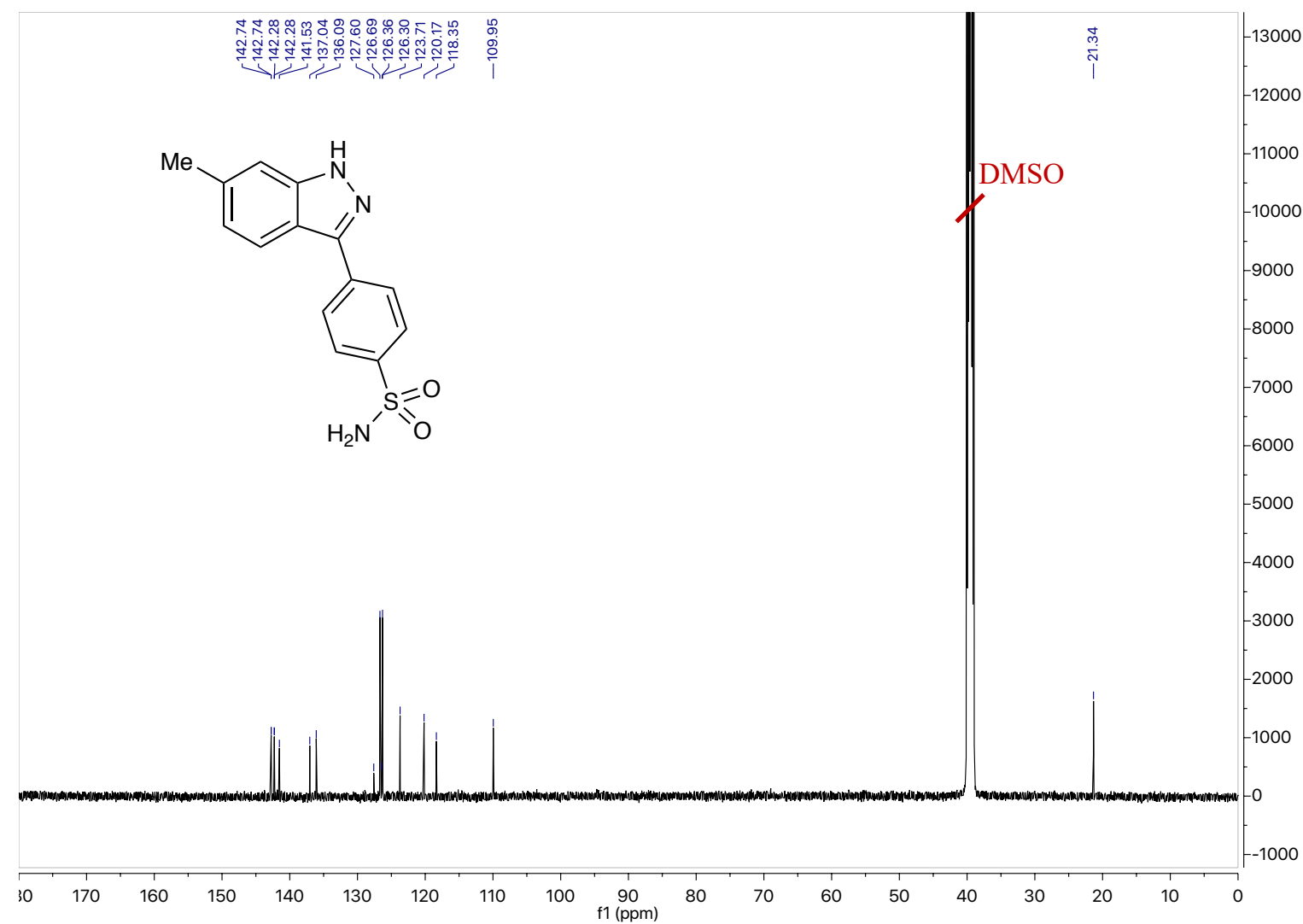


${ }^{1} \mathrm{H}$ NMR Spectrum of SI-5 (500 MHz, DMSO)

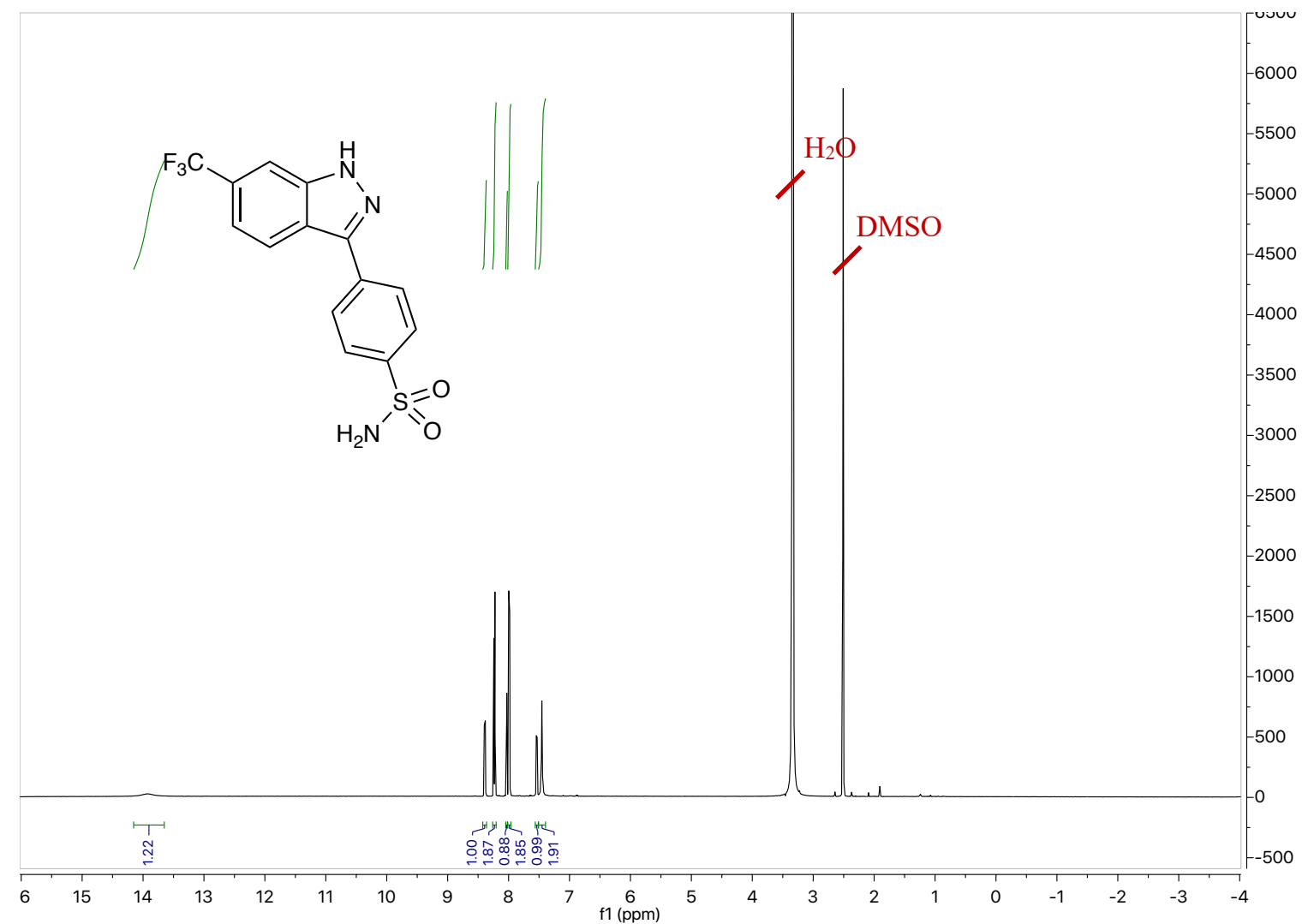

${ }^{13} \mathrm{C}$ NMR Spectrum of SI-5 (126 MHz, DMSO)

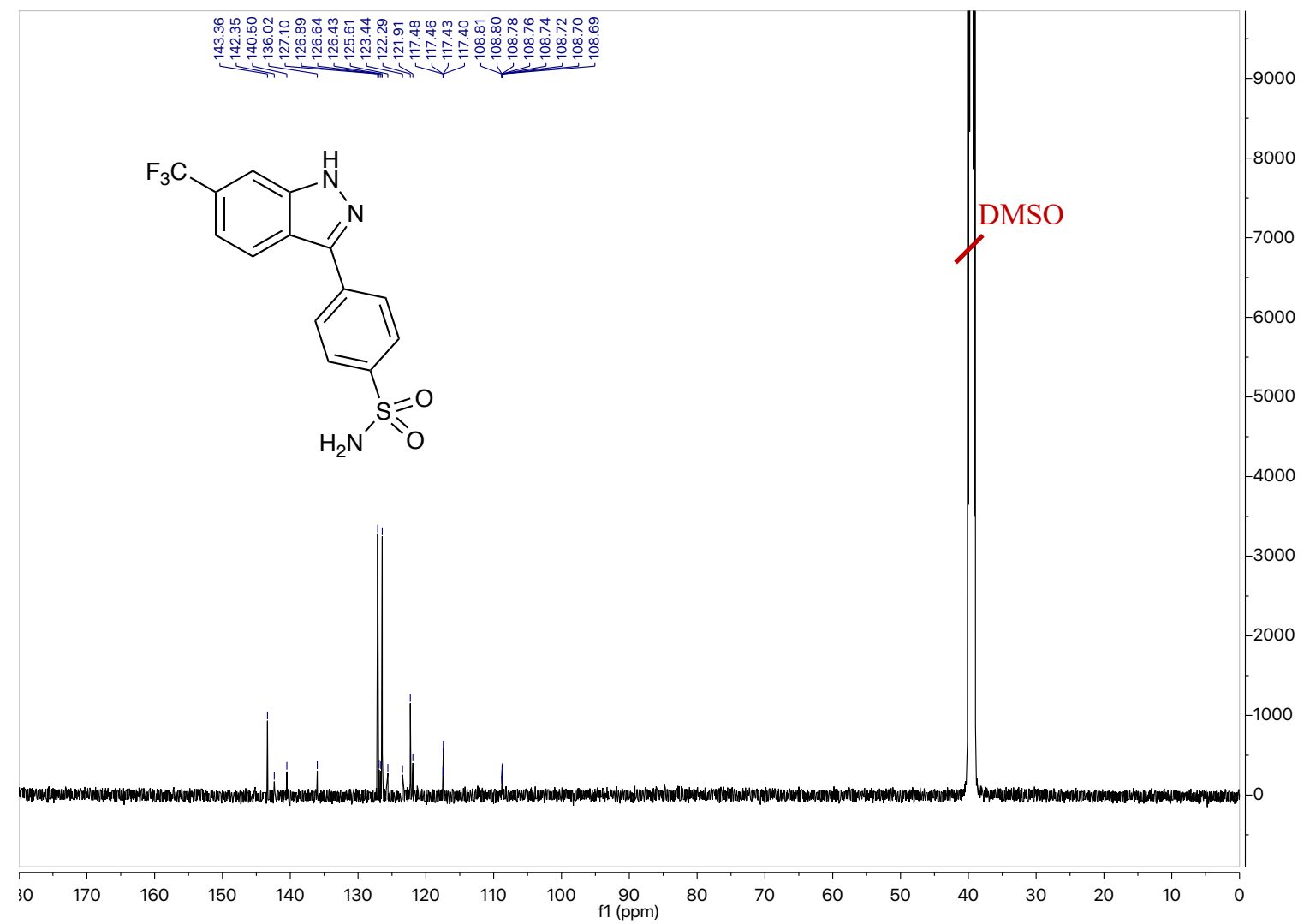




\section{References}

1. Mishra, R. K.; Deibler, K. K.; Clutter, M. R.; Vagadia, P. P.; O’Connor, M.; Schiltz, G. E.; Bergan, R.; Scheidt, K. A.; Modeling MEK4 Kinase Inhibitors through Perturbed Electrostatic Potential Charges. J. Chem. Inf. Model. 2019, 59, 4460-4466.

2. Lefebvre, V.; Cailly, T.; Fabis, F.; Rault, S.; Two-Step Synthesis of Substituted 3-Aminoindazoles from 2Bromobenzonitriles. J. Org. Chem. 2010, 75, 2730-2732.

3. Deibler, K. K.; Schiltz, G. E.; Clutter, M. R.; Mishra, R. K.; Vagadia, P. P.; O’Connor, M.; Donny George, M.; Gordon, R.; Fowler, G.; Bergan, R.; Scheidt, K.A.; Synthesis and Biological Evaluation of 3Arylindazoles as Selective MEK4 Inhibitors. ChemMedChem 2019, 14, 615-620. 